\title{
Accelerated ageing tests and long-term prediction models for durability of FRP bars in concrete
}

\author{
Yi Chen \\ West Virginia University
}

Follow this and additional works at: https://researchrepository.wvu.edu/etd

\section{Recommended Citation}

Chen, Yi, "Accelerated ageing tests and long-term prediction models for durability of FRP bars in concrete" (2007). Graduate Theses, Dissertations, and Problem Reports. 4293.

https://researchrepository.wvu.edu/etd/4293

This Dissertation is protected by copyright and/or related rights. It has been brought to you by the The Research Repository @ WVU with permission from the rights-holder(s). You are free to use this Dissertation in any way that is permitted by the copyright and related rights legislation that applies to your use. For other uses you must obtain permission from the rights-holder(s) directly, unless additional rights are indicated by a Creative Commons license in the record and/ or on the work itself. This Dissertation has been accepted for inclusion in WVU Graduate Theses, Dissertations, and Problem Reports collection by an authorized administrator of The Research Repository @ WVU.

For more information, please contact researchrepository@mail.wvu.edu. 


\title{
Accelerated Ageing Tests and Long-term Prediction Models for Durability of FRP Bars in Concrete
}

\author{
Yi Chen
}

Dissertation submitted to the College of Engineering and Mineral Resources

at West Virginia University

In Partial Fulfillment of the Requirements

For the Degree of

Doctor of Philosophy

in

Civil Engineering

Julio F. Davalos, Ph.D., Chair

Indrajit Ray, Ph.D. Co-Chair

Karl E. Barth, Ph.D.

Jacky C. Prucz, Ph.D.

Wu Zhang, Ph.D.

Department of Civil and Environmental Engineering

Morgantown, West Virginia

June, 2007

Keywords: Durability, FRP bar, Prediction Model,

Accelerated Ageing Test, Bond

Copyright $@ 2007$ Yi Chen 


\title{
ABSTRACT \\ Accelerated Ageing Tests and Long-term Prediction Models for Durability of FRP Bars in Concrete
}

\author{
Yi Chen
}

Advisors: Dr. Julio F. Davalos and Dr. Indrajit Ray

Corrosion of steel reinforcement is the major cause of deterioration of existing reinforced concrete (RC) structures, resulting in significant expenses for repair and maintenance, and leading to shorter service lives. To address the corrosion problem, fiber reinforced polymer (FRP) bars have recently emerged as a promising solution not only for the rehabilitation of existing structures but also for the construction of new and more durable RC structures. But due to their versatile applications in harsh environments and exposure to high alkalinity content of concrete, the durability performance of FRP bars and their bond with concrete are major concerns. In this dissertation the durability of both FRP bars within concrete and FRP-concrete bond interface are studied, and effective evaluation and long-term prediction performance methods are developed to provide guidelines for design applications in practice.

First, a comprehensive evaluation is conducted of simulated accelerated ageing test environments and test specimens and methods, and effective testing procedures are recommended. Then, accelerated ageing tests on durability performance of GFRP bars embedded in concrete beams, subjected to sustained load and saturated moisture under several controlled temperatures, are used to develop and propose long-term prediction models and master-curves to be used in design. The degradation mechanisms are examined by microstructure and chemical composition analyses of scanning-electron microscopy (SEM) and energy-dispersive analysis of X-rays (EDAX). Service-life prediction procedures based on Arrhenius concept are given, including analyses to verify the validity of accelerated ageing tests used to satisfy the requirement of consistent degradation mechanism induced. For the first time, predictions are given for the longterm durability performance of GFRP bars in saturated concrete subjected to sustained loading, and the predictions agree well with other short-term studies and limited field data available.

Finally, the bond behaviors of FRP bars under direct pullout test are studied for different material compositions and surface characteristics. The effects of moisture, elevated temperature, and thermal cycles on bond behaviors are investigated. The environmental effects on concrete compressive strength, FRP-bar constituent materials, and bond interface are examined. To simulate the pullout failure process, a new concept is proposed to determine the local bond-slip law for FRP bars in concrete. The predicted bond slip curves from analytical and Finite Element methods are in good agreement with the results of pullout tests. 


\section{ACKNOWLEDGEMENTS}

First, I wish to express my deep gratitude to my advisor, Dr. Julio F. Davalos, for his great commitment to my work and for his guidance, support and care both on professional and personal levels. Without his encouragement, great insight and wisdom, I would not have been able to complete this dissertation. I am indebted to Dr. Davalos for this research and educational opportunity and will forever hold him with a great deal of respect. My sincere appreciation also goes to my co-advisor, Dr. Indrajit Ray, for his generous encouragement, tremendous support and invaluable guidance through my study at West Virginia University.

Special thanks also go to the committee members: Dr. Karl E. Barth, Dr. Jacky C. Prucz, and Dr. Wu Zhang for their interests and valuable suggestions during the course of this research.

I would like to thank our laboratory technicians: Mr. David Turner, Mr. Doug Cutlip and Mr. William Comstock for their help. My appreciation also extends to my friends advised by Dr. Davalos: Chunfu Lin, Zhenhua Sun, Zhiguo Gong, An Chen, Shilpa Kodkani, Tao Hong, Weiqiao Wang, Bin Zhou, Anituddha Chatterjee, and Dayong Fan.

Finally, I also thank my parents and my family for their love and support in my life. 


\section{TABLE OF CONTENTS}

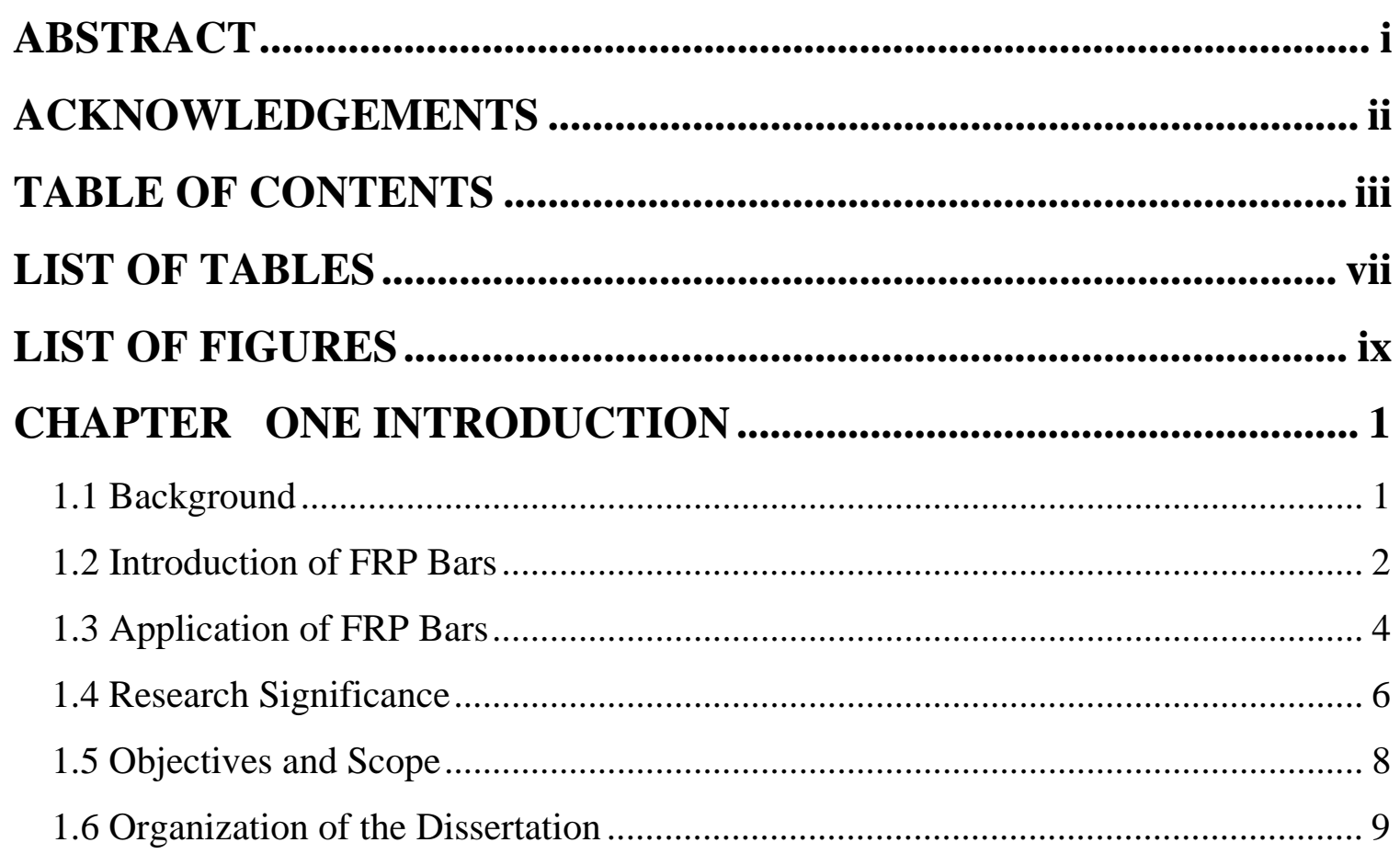

CHAPTER TWO LITERATURE REVIEW ...................................... 11

2.1 Material Aspects of FRP bars ......................................................................... 11

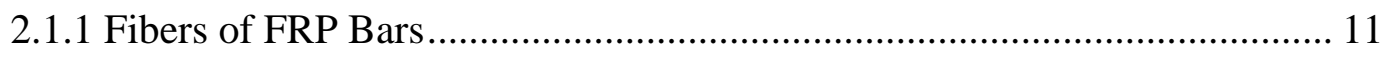

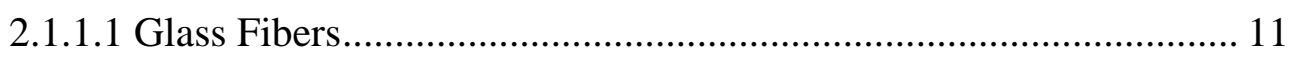

2.1.1.2 Carbon Fibers................................................................................ 12

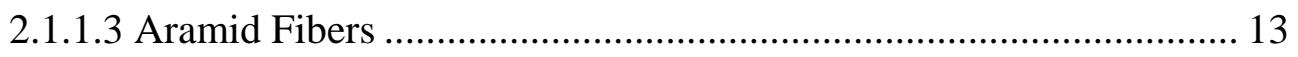

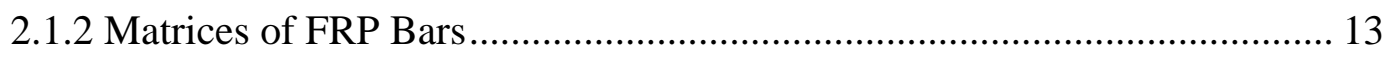

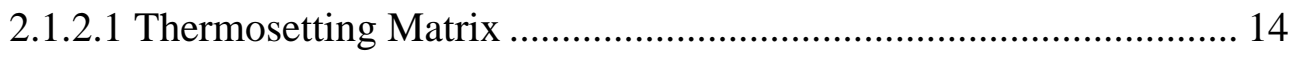

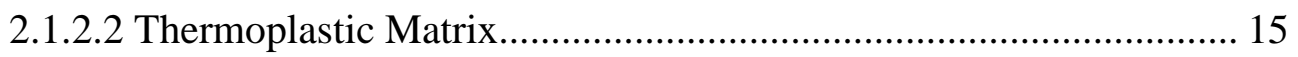

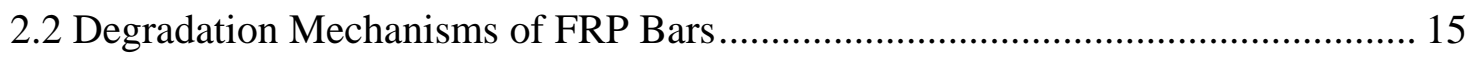

2.2.1 A General Review of Degradation of FRP Bars......................................... 16

2.2.2 Degradation of FRP Bar Matrices.............................................................. 17

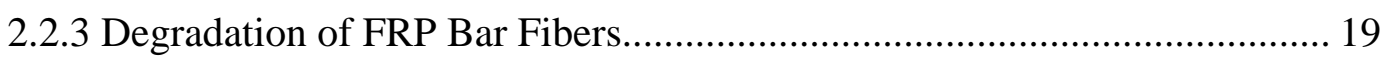

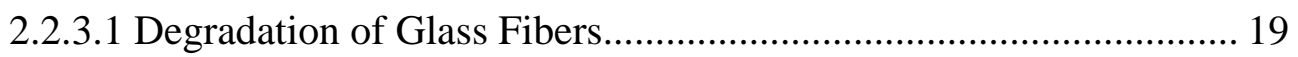

2.2.3.2 Degradation of Carbon Fibers........................................................... 21 
2.2.3.3 Degradation of Aramid Fibers ........................................................ 22

2.2.4 Degradation of Interphase Region of FRP Bars ......................................... 22

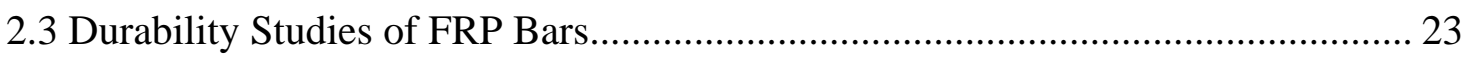

2.3.1 Environmental Effects on the Durability of FRP Bars .............................. 23

2.3.2 Material Effects on the Durability of FRP Bars........................................... 28

2.3.3 Durability of FRP Bars in Concrete ......................................................... 34

2.3.4 Creep, Relaxation and Fatigue of FRP Bars ............................................ 35

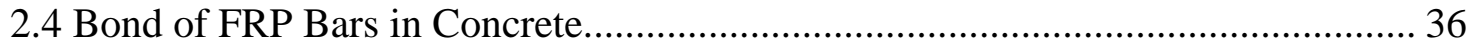

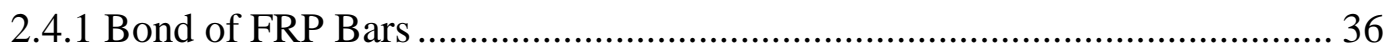

2.4.2 Durability of Bond in Concrete............................................................. 38

2.5 Accelerated Test Methods.............................................................................. 40

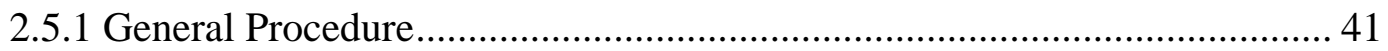

2.5.2 Arrhenius Model .................................................................................. 42

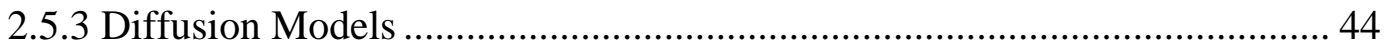

\section{CHAPTER THREE DURABILITY OF FRP BARS IN SIMULATED ENVIRONMENTS .................................................................... 47}

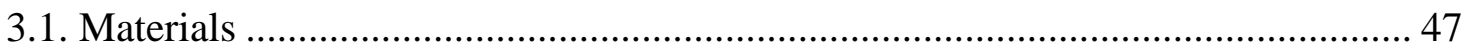

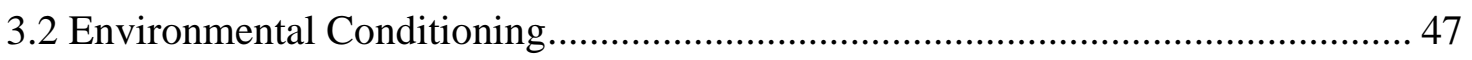

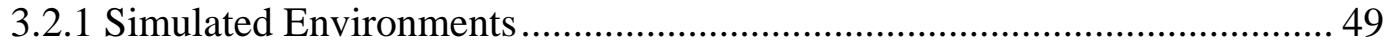

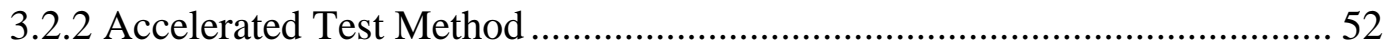

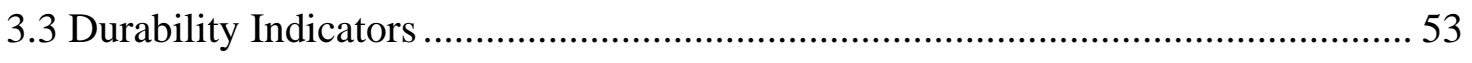

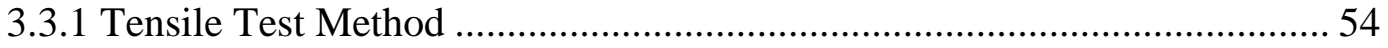

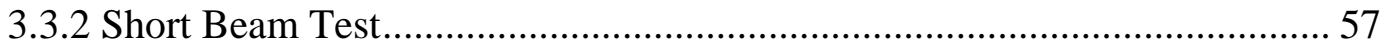

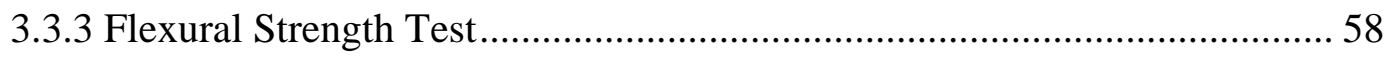

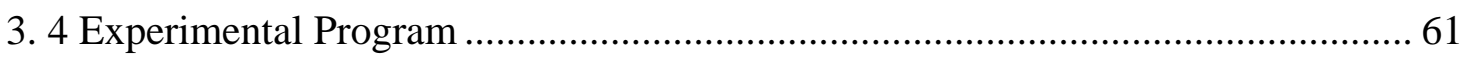

3.4.1 Testing Plan for Tensile Strength ................................................................... 61

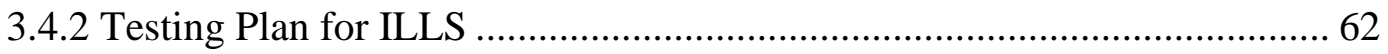

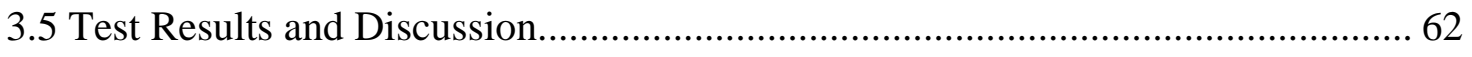

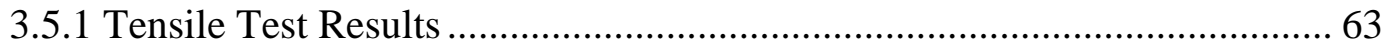

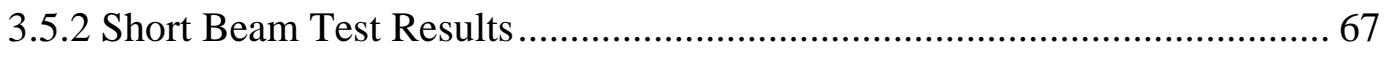




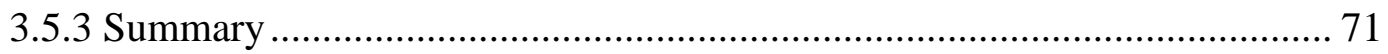

3.5.4 Tensile Test Results for Durability Predictio71n........................................ 72

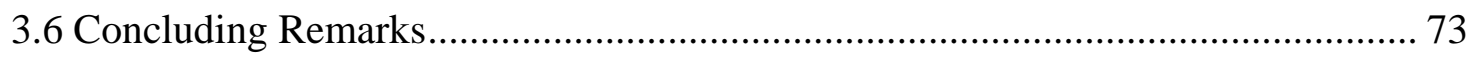

\section{CHAPTER FOUR DURABILITY OF GFRP BARS IN CONCRETE}

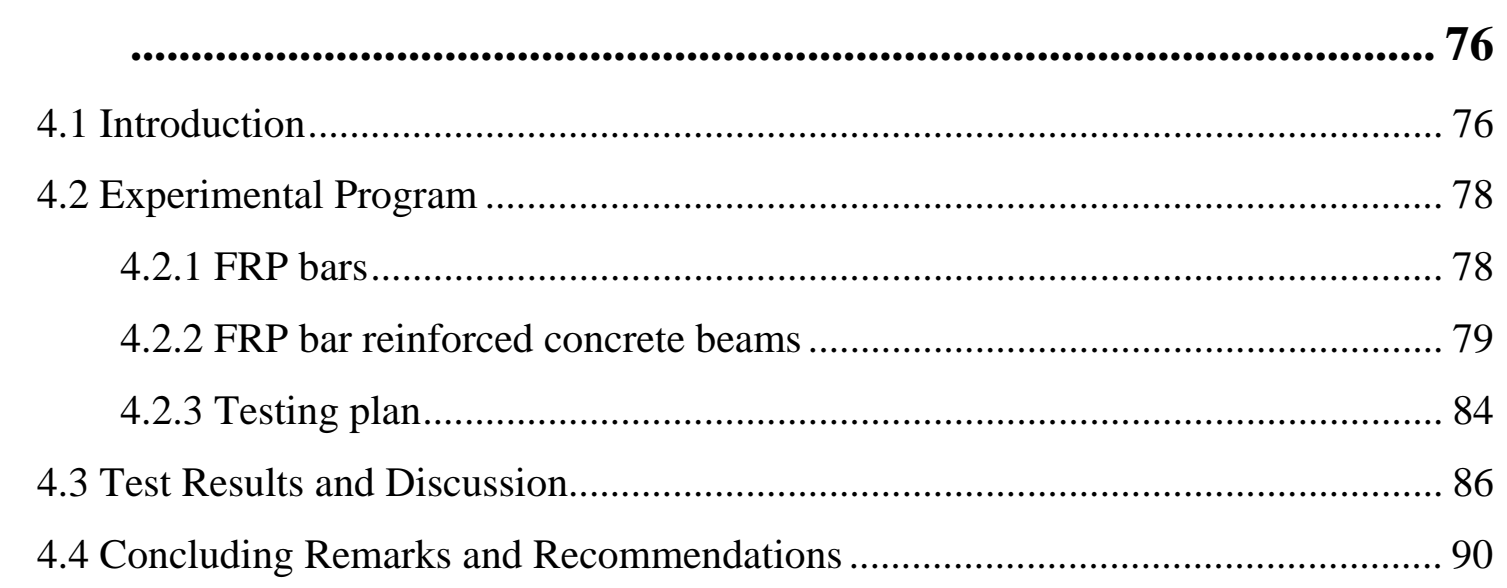

\section{CHAPTER FVIE SEM AND EDAX ANALYSIS .............................. 92}

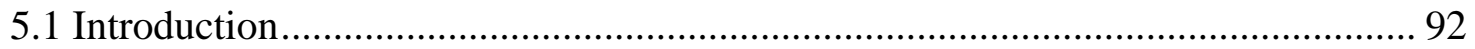

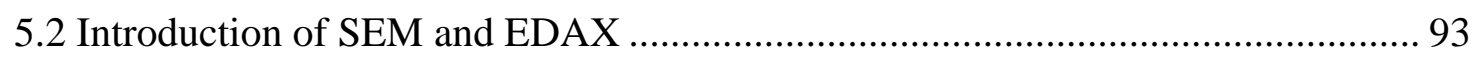

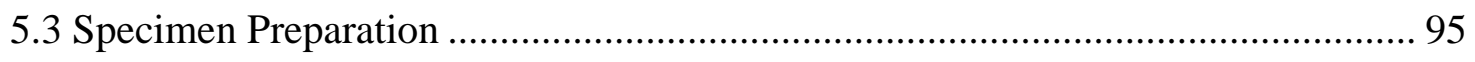

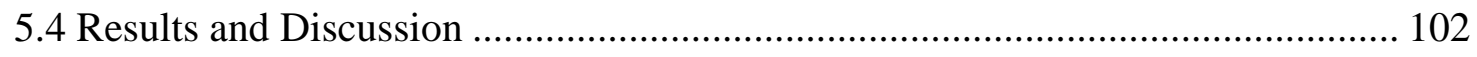

5.4.1 Unconditioned Specimens ...................................................................... 102

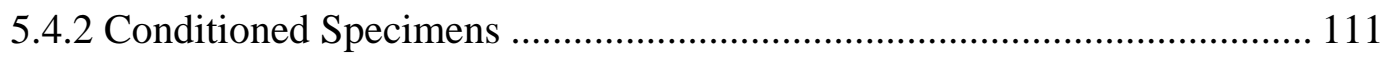

5.5 Concluding Remarks........................................................................................ 115

\section{CHAPTER SIX DURABILITY PREDICTIONS.............................. 116}

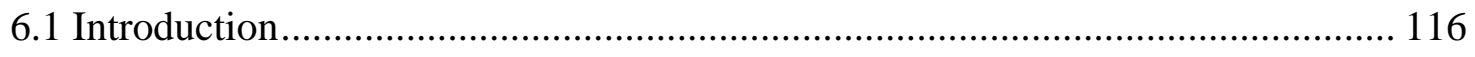

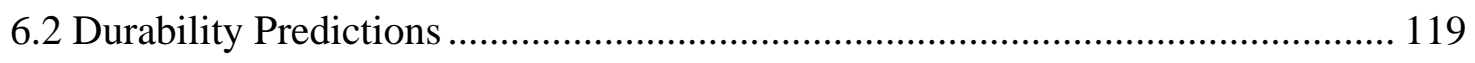

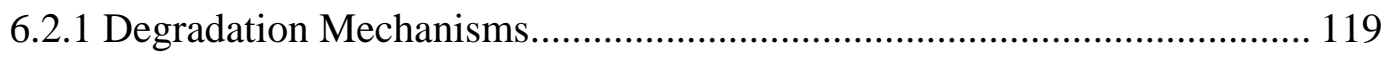

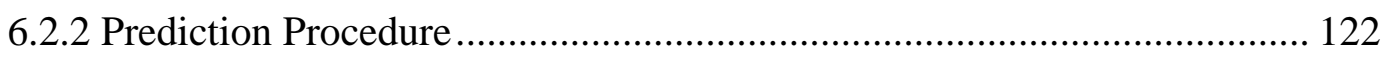

6.2.3 Durability Prediction of GFRP bars in Concrete ...................................... 130

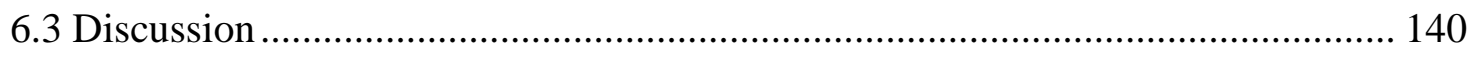




\section{CHPATER SEVEN DURABILITY OF FRP-CONCRETE BOND. 148}

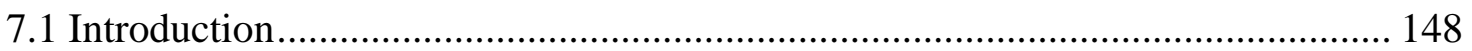

7.2 Preliminary Durability Study on the Bond of GFRP Bars................................... 149

7.2.1 Specimens ............................................................................................... 149

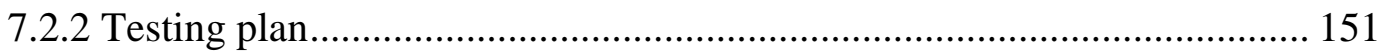

7.2.3 Test results and discussion........................................................................ 152

7.3 Further Study on the Bond of FRP Bar.......................................................... 158

7.3.1 Pullout Test Arrangement ........................................................................ 156

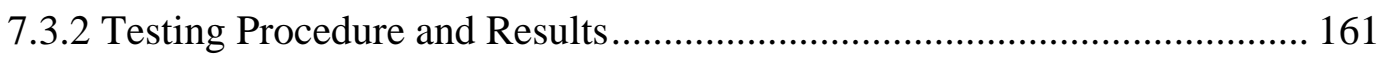

7.3.2.1 Experimental Program ............................................................................. 161

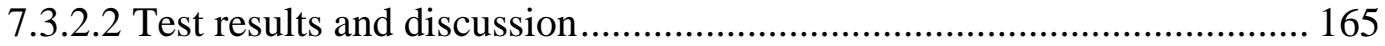

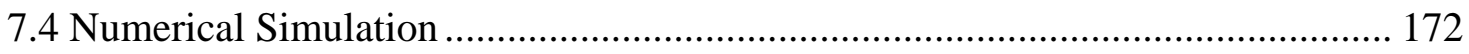

7.5 Concluding Remarks..................................................................................... 180

\section{CHAPTER EIGHT CONCLUSIONS AND RECOMMENDATIONS ..} 182

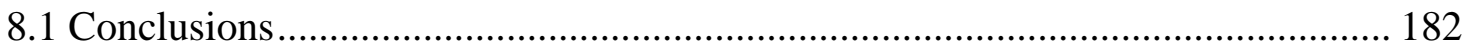

8.1.1 Durability Performance of Bare FRP bars in Simulated Environments .... 182

8.1.2 Durability Performance of GFRP bars in Concrete .................................... 184

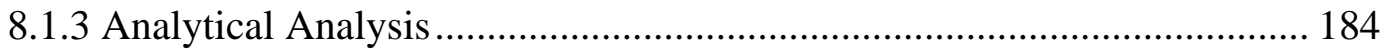

8.1.4 Durability Prediction Models................................................................. 185

8.1.5 The Bond of FRP Bar and Concrete ........................................................ 187

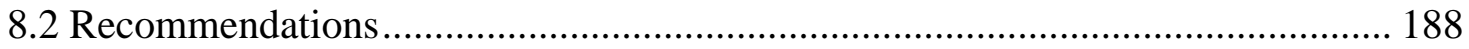

REFERENCES...........................................................191 


\section{LIST OF TABLES}

Table 1.1 Comparisons of properties of steel and FRP bars .........................................

Table 2.1 Typical properties of fibers used in fiber reinforced polymer bars ..................12

Table 2.2 Typical properties of matrices used in fiber reinforced polymer bars ..............14

Table 2.3 FRP bars under unstressed condition in alkaline environments .................32

Table 2.4 FRP bars under stressed condition in alkaline environments ..................34

Table 3.1 Material aspects of FRP bar specimens ................................48

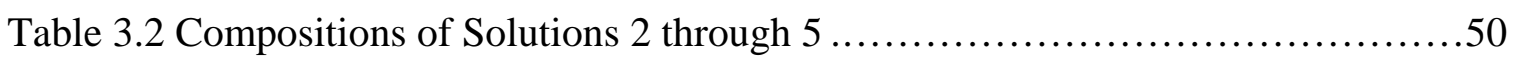

Table 3.3 GFRP1 specimens for tensile strength test .............................................61

Table 3.4 FRP specimens for tensile strength test ...................................................61

Table 3.5 Additional GFRP specimens for tensile strength test ...................................62

Table 3.6 Number of specimens for short beam test ...............................................62

Table 3.7 Environmental conditions and results from tensile test ..............................67

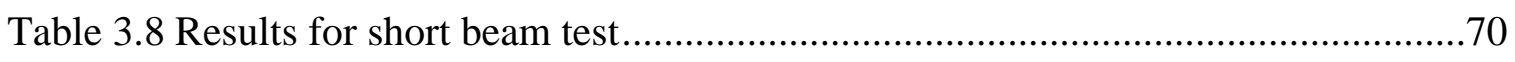

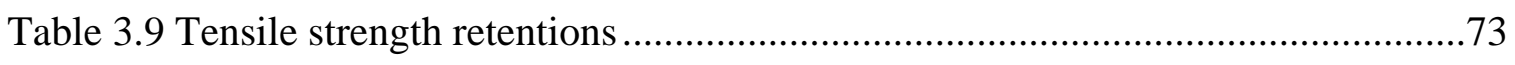

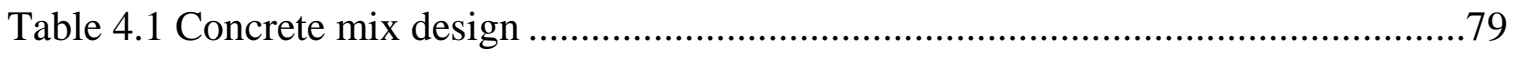

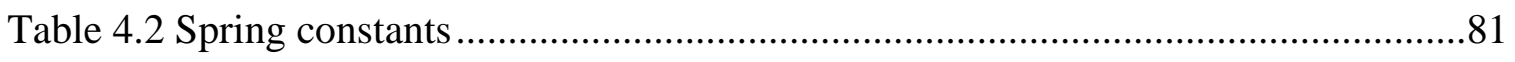

Table 4.3 GFRP3 bars specimens in temperature controlled tanks ..............................86

Table 4.4 Specimens exposed to room temperature for 150 days .................................86

Table 6.1 Coefficients of regression equations for GFRP tensile strength retention.......125

Table 6.2 Coefficients of regression equations for Arrhenius plots .............................125

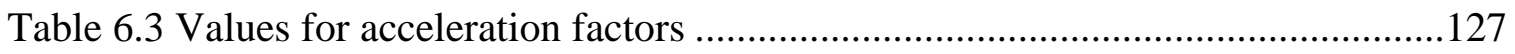

Table 6.4 Coefficients of regression equations for master curves ...............................128

Table 6.5 Coefficients of regression equations for the tensile strength retention of GFRP3

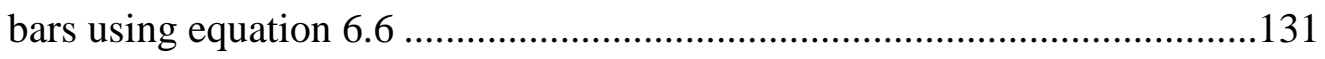

Table 6.6 Coefficients of regression equations for Arrhenius plots of GFRP3 bars using equation 6.6

Table 6.7 Values for acceleration factors (reference temperature is $20{ }^{0} \mathrm{C}$ ) of GFRP 3 bars

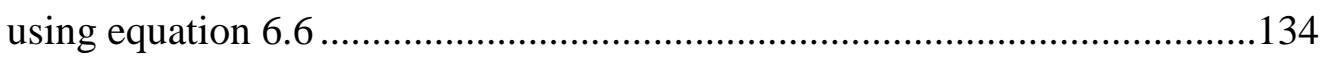


Table 6.8 Coefficients of regression equations for master curves of GFRP3 bars using equation 6.6.

Table 6.9 Coefficients of regression equations for tensile strength retention of GFRP3 bars using equation 6.8

Table 6.10 Coefficients of regression equations for Arrhenius plots of GFRP3 bars using equation 6.8

Table 6.11 Values for acceleration factors (reference temperature is 20 0C) for GFRP3 bars using equation 6.8

Table 6.12 Coefficients of regression equations for master curves using equation 6.8...140

Table 6.13 Comparison of activation energy values...................................................141

Table 6.14 Parameters for master curves of GFRP3 bars as shown in Fig. 6.17.............145

Table 7.1 Specimens for evaluation of FRP concrete interaction...................................150

Table 7.2 Concrete mix design ..............................................................................151

Table 7.3 Testing plan for the evaluation of FRP bar-concrete interaction.....................152

Table 7.4 Bond strength of GFRP1 bars in NC .........................................................153

Table 7.5 the properties of FRP bars ......................................................................162

Table 7.6 Coefficients of thermal expansion for reinforcing bars and concrete...............162

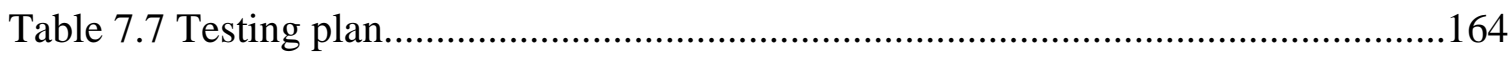

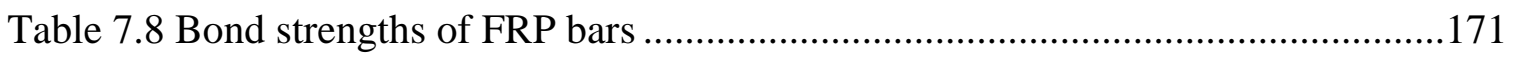

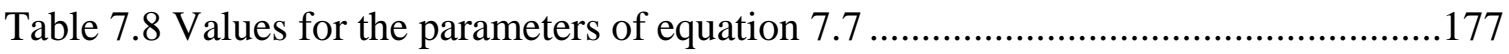

Table 7.9 Detail information for FE analysis...............................................................177 


\section{LIST OF FIGURES}

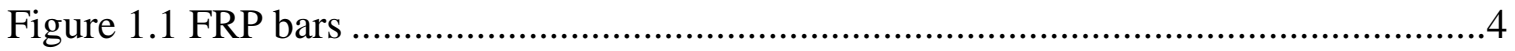

Figure 1.2 Application of FRP bars in civil engineering ................................................

Figure 2.1 Representative chemical structure (uncured) for (a) isophthalic polyester resin,

(b) vinyl ester resin, and (c) epoxy ...............................................................18

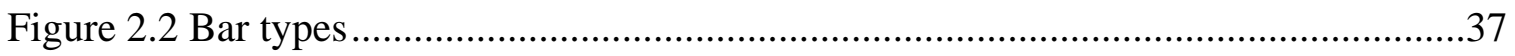

Figure 2.3 Diffusion of free ions into FRP bars.............................................................

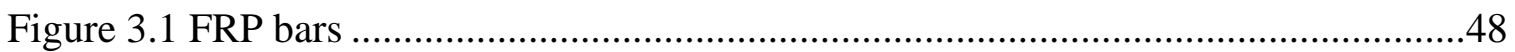

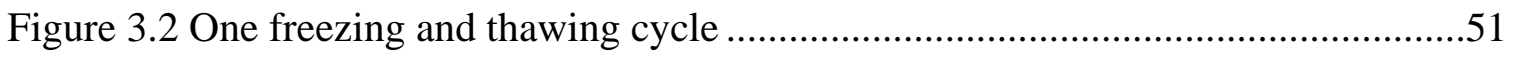

Figure 3.3 CSZ ZH-16 environmental chambers for freezing and thawing cycles ...........51

Figure 3.4 Temperature controlled tank....................................................................

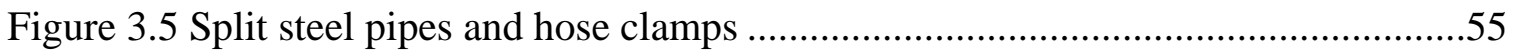

Figure 3.6 Epoxy used to bond the split steel pipes to the ends of FRP bars ....................55

Figure 3.7 FRP bars with split steel pipes clamped on both ends......................................56

Figure 3.8 Sketch illustrating the gripping of steel pipe ....................................................56

Figure 3.9 Experimental setup for tensile strength test....................................................56

Figure 3.10 Experimental setup for short beam test ......................................................58

Figure 3.11 Typical splitting failure of short beam test.................................................58

Figure 3.12 Typical shear mode failure of short beam test.............................................58

Figure 3.13 Experiment setup for flexural strength test ...................................................59

Figure 3.14 Typical flexural failure mode of GFRP1 specimens ....................................60

Figure 3.15 Typical load vs. flexural deflection of GFRP1 specimens .............................60

Figure 3.16 GFRP bars before and after exposure ........................................................63

Figure 3.17 Typical failure mode of GFRP bars.............................................................65

Figure 3.18 Typical stresses vs. strain of GFRP bars .................................................65

Figure 3.19 Typical failure mode of CFRP bars ........................................................66

Figure 3.20 Typical stresses vs. strain of CFRP bars ....................................................66

Figure 3.21 Specimens after the short beam test .........................................................68

Figure 3.22 Typical load vs. deflection of GFRP specimens in short beam test ...............69 
Figure 3.23 Typical load vs. deflection of CFRP specimens in short beam test .69

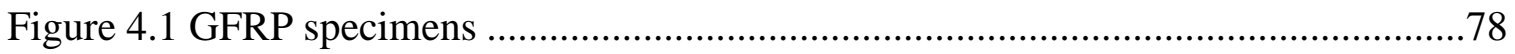

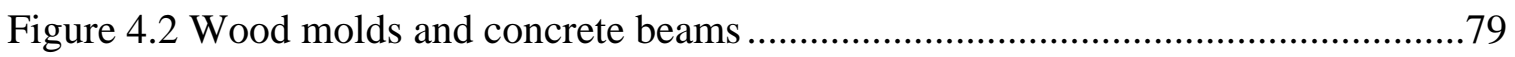

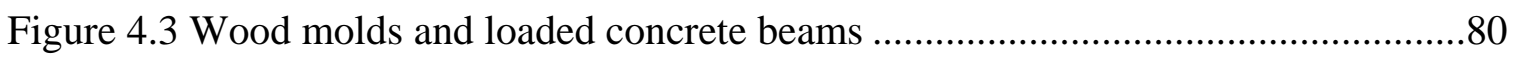

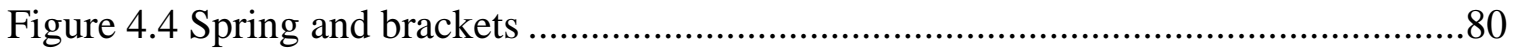

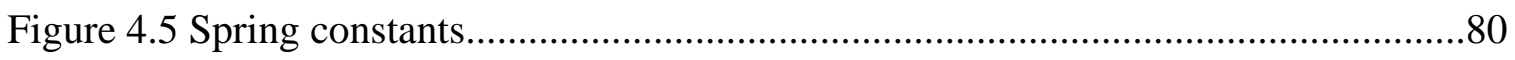

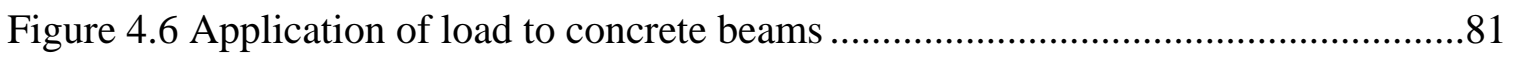

Figure 4.7 Tensile strains of bars (GFRP3) in loaded concrete beams vs. time...............83

Figure 4.8 Tensile strains of bars (GFRP4) in loaded concrete beams vs. time ...............83

Figure 4.9 Loaded concrete beams in temperature controlled tank ..............................84

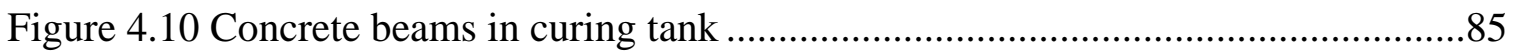

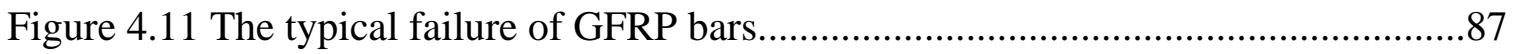

Figure 4.12 Tensile strength retention of GFRP bars in curing tank or open air of concrete

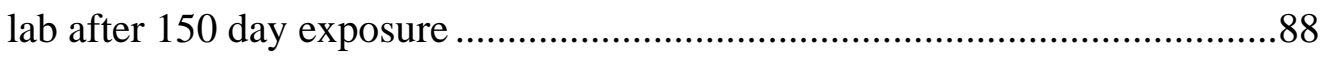

Figure 4.13 Tensile strength retention of GFRP3 bars in concrete beams under different

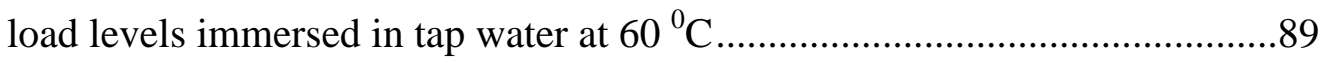

Figure 4.14 Tensile strength retention of GFRP3 bars embedded in concrete beams exposed to tap water at elevated temperature ..........................................89

Figure 5.1 Schematic diagram of a scanning electron microscope................................94

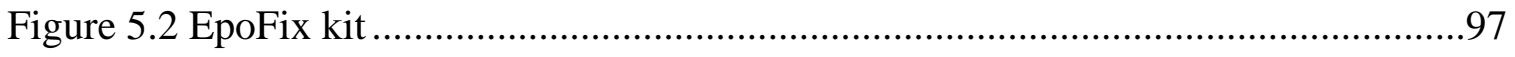

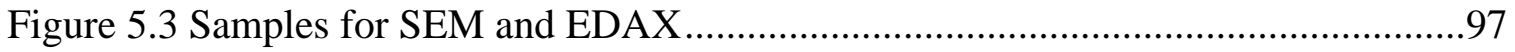

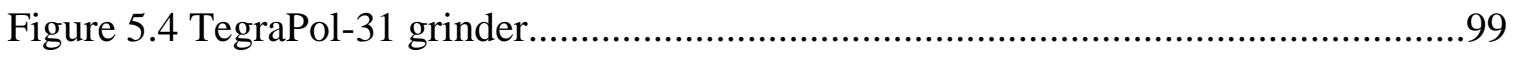

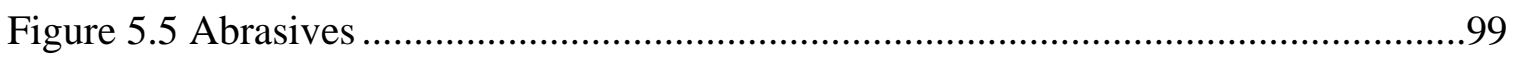

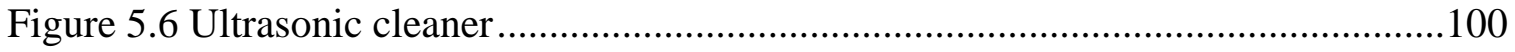

Figure 5.7 Research stereomicroscope system SZX-ZB12 ................................... 100

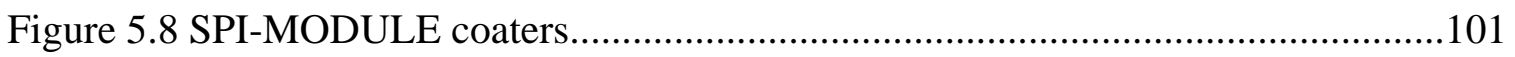

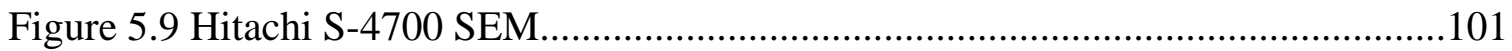

Figure 5.10 SEM images of unconditioned FRP bars ........................................... 107

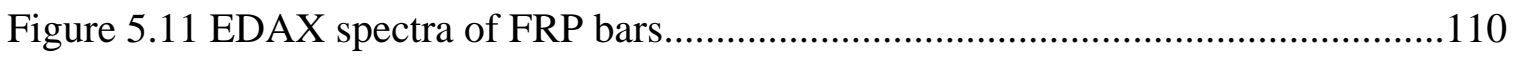

Figure 5.12 SEM images of conditioned FRP bars..................................................114

Figure 6.1 Tensile strength retention of GFRP1 bars exposed to Solution 3 .................124 
Figure 6.2 Tensile strength retention of GFRP2 bars exposed to Solution 2

Figure 6.3 Arrhenius plots of tensile strength degradation for GFRP1 bars exposed to Solution 3

Figure 6.4 Arrhenius plots of tensile strength degradation for GFRP2 bars exposed to Solution 2 . 126

Figure 6.5 Tensile strength retentions vs. exposure time for GFRP1 bars ......................128

Figure 6.6 Tensile strength retentions vs. exposure time for GFRP2 bars ......................129

Figure 6.7 Tensile strength retention vs. time and equation 6.6 fitted to the data...........131

Figure 6.8 Arrhenius plots of GFRP3 bars using equation 6.6 .......................................132

Figure 6.9 Acceleration factors with reference temperature of $20{ }^{\circ} \mathrm{C}$ using equation 6.6

Figure 6.10 Master curves for GFRP3 bars embedded in saturated concrete at $20{ }^{\circ} \mathrm{C}$ using equation 6.6 134

Figure 6.11 Tensile strength retention vs. time and equation 6.8 fitted to the data ........136

Figure 6.12 Arrhenius plots of GFRP3 bars using equation 6.8 137

Figure 6.13 Acceleration factors with reference temperature of $20{ }^{\circ} \mathrm{C}$ using equation 6.8

Figure 6.14 Master curve for GFRP3 bars embedded in saturated concrete at $20{ }^{\circ} \mathrm{C}$ using equation 6.8.

Figure 6.15 Comparisons of predictions and test results for not loaded specimens 143

Figure 6.16 Comparisons of predictions and test results for loaded specimens 143

Figure 6.17 Tensile strength retentions of GFRP3 bars in saturated concrete..................145

Figure 7.1 GFRP1 bar embedded in concrete for pullout and short beam tests ...............150

Figure 7.2 Spcimens for evaluation of FRP bar-concrete interaction...............................150

Figure 7.3 Specimens for evaluation of FRP bar-concrete interaction ............................151

Figure 7.4 Experimental setup for pullout test in the preliminary study .........................152

Figure 7.5 Specimens after the pullout test.................................................................153

Figure 7.6 Bond strength retention of GFRP1 bars in NC............................................154

Figure 7.7 Load vs. displacement curve of specimen with HPC and GFRP1 \# 3 bar after 60 day exposure in curing tank 155 
Figure 7.8 Load vs. displacement curve of specimen with HPC and GFRP1 \# 4 bar after 60 day exposure in Solution 3 at $60{ }^{\circ} \mathrm{C}$

Figure 7.9 Load vs. displacement curve of specimen with NC and GFRP1 \# 3 bar after 60 day exposure in curing tank 156

Figure 7.10 Load vs. displacement curve of specimen with NC and GFRP1 \# 4 bar after 60 day exposure in curing tank 156

Figure7.11 The typical view of GFRP bars embedded in NC and HPC after exposure..157

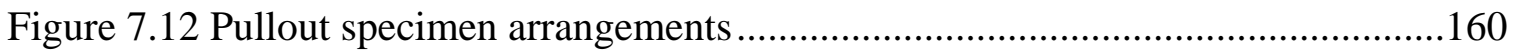

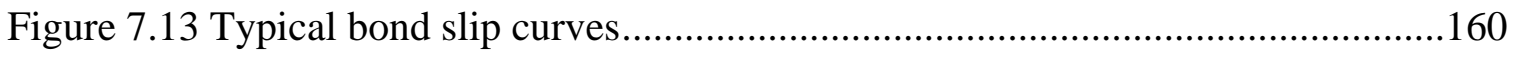

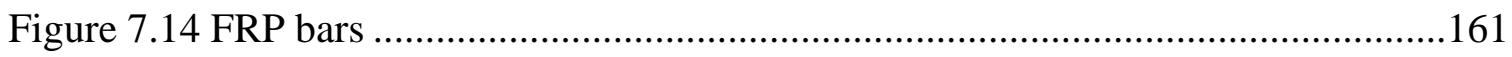

Figure 7.15 Setup for fabrication of pullout specimens............................................163

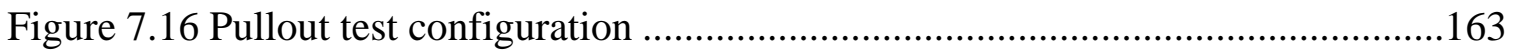

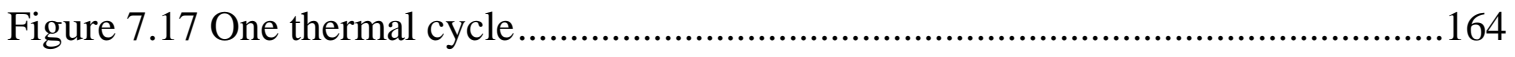

Figure 7.18 Typical bond failure modes of pullout tests ...........................................165

Figure 7.19 FRP bars extracted from concrete cylinders after exposure .......................166

Figure 7.20 Concrete strengths vs. FRP bar bond strengths .....................................167

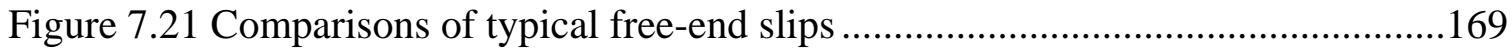

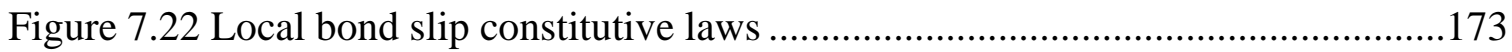

Figure 7.23 Bond stress and normal stress distribution for FRP bars in concrete ...........173

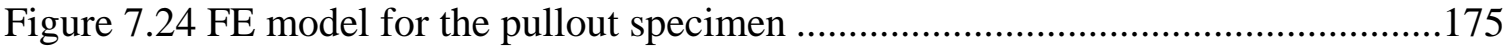

Figure 7.25 Force deflection curve for the spring elements ....................................177

Figure 7.26 Comparisons of bond slip curves from test, analytical approach (model) and

FE analysis 179 


\section{CHAPTER ONE INTRODUCTION}

This chapter presents the background and applications of fiber reinforcement polymer (FRP) bars in civil engineering. Then the research significance, objectives, and organization of this dissertation are provided.

\subsection{Background}

The degradation of steel reinforced concrete (RC) structures has been a critical issue worldwide for many years. Corrosion of steel reinforcement is the major cause of deterioration of existing RC structures. Steel in RC structures exposed to moisture, salts or aggressive chemicals is susceptible to oxidation. As the corrosion of steel bars occurs, the resultant products on bar surface have volumes that are 2 to 5 times larger than the original steel. This volume increase causes concrete to crack and spall, which in turn facilitate the migration of chemical ions, especially chloride, into concrete. The contact with corrosive chemicals leads to further deterioration of the steel. Thus, this combination of interactive deterioration of concrete and steel results in expensive outlays for repair and maintenance, as well as shorter service life of structures. In Canada, it is estimated that over $40 \%$ of bridges that are 40 years old or more and multistory parking garages are structurally deficient mainly due to corrosion. In 2000, of the 590,750 bridges in the United States, $27.3 \%$ were classified as structurally or functionally difficient mostly due to the corrosion of steel reinforcement (Balendran et al., 2002). In 2005, the American Society of Civil Engineers (ASCE) released a report estimating that an investment of $\$ 1.6$ 
trillion would be needed in the following five years to significantly improve the nation's failing roads, bridges, dams and other infrastructure.

To address the corrosion problem of steel reinforcement, various methods have been tried, such as galvanized coatings, electro-static-spray fusion-bonded (powdered resin) coatings, polymer-impregnated concrete, epoxy coatings, cathodic protection, and more recently FRP bars. Initially, FRP bars were used as an alternative reinforcement for polymer concrete due to the mismatch of thermal expansions of steel and polymer concrete. FRP bars were not considered as a viable solution for RC structures, nor were commercially available until the 1970s. In 1983, the US Department of Transportation funded the first project on FRP bars, titled "Transfer of Composite Technology to Design and Construction of Bridges" (ACI 440, 2003).

In the 1990s, the concern for deteriorating infrastructures was more prevalent. In addition, the commonly used epoxy-coated reinforcing bars did not provide an adequate answer to the corrosion problem, and though stainless steel is a good option to address the problem, it is prohibitively expensive. As a result, FRP bars have emerged as a promising solution not only for the rehabilitation of existing structures but also for the construction of new and more durable reinforced concrete structures.

\subsection{Introduction of FRP Bars}

Usually FRP, a composite material, is made of continuous fibers embedded in resin matrix. Fibers as reinforcements in composites are intended to carry loads primarily along the fiber direction to provide directional strength and stiffness. Glass, carbon, and aramid are three commercially used fibers for the manufacture of FRP bars, in which glass fiber is the most commonly used due to its low cost. Commonly available FRP 
materials have fiber volume fractions ranging from $50 \%$ to $70 \%$. The matrix material has three important roles: to transfer stress between fibers, to hold fibers together, and to protect fibers from the environmental and mechanical damage. Matrix materials may be polymers, metals or ceramics. Generally there are two kinds of polymer matrices for FRP bars: thermoset (polyester, vinyl ester, epoxy, etc.) and thermoplastic (nylon, polyethylene, etc.). In addition to fibers and matrix, fillers, additives and core materials are often added to reduce costs and improve the mechanical and/or durability performance of the composite. The performance of FRP depends on its compositions and the interaction between those compositions. Comparisons of properties of steel and FRP bars are made in Table 1.1 (ACI 440, 2003).

Table 1.1 Comparisons of properties of steel and FRP bars

\begin{tabular}{ccccccc}
\hline $\begin{array}{c}\text { Bar } \\
\text { type }\end{array}$ & $\begin{array}{c}\text { Tensile } \\
\text { strength } \\
(\mathrm{MPa})\end{array}$ & $\begin{array}{c}\text { Tensile } \\
\text { elastic } \\
\text { modulus } \\
(\mathrm{GPa})\end{array}$ & $\begin{array}{c}\text { Rupture } \\
\text { strain } \\
(\%)\end{array}$ & $\begin{array}{c}\text { Compressive } \\
\text { strength } \\
(\mathrm{MPa})\end{array}$ & $\begin{array}{c}\text { Coefficient of } \\
\text { thermal } \\
\text { expansion } \\
\left(10^{-6} / \mathrm{C}\right)\end{array}$ & $\begin{array}{c}\text { Specific } \\
\text { gravity } \\
\left(\mathrm{g} / \mathrm{cm}^{3}\right)\end{array}$ \\
\hline Steel & $483-690$ & 200 & $6.0-12.0$ & $276-414$ & 11.7 & 7.9 \\
GFRP & $483-1600$ & $35-51$ & $1.2-3.1$ & $310-482$ & $21-23$ & $1.5-2.0$ \\
CFRP & $600-3690$ & $120-580$ & $0.5-1.7$ & N/A & $74-104$ & $1.5-1.6$ \\
AFRP & $1720-2540$ & $41-125$ & $1.9-4.4$ & N/A & $60-80$ & 1.25 \\
\hline
\end{tabular}

There are many manufacturing processes available for FRP products, such as filament winding, pultrusion, vacuum compaction, bag molding, etc. Each of the fabrication processes has characteristics which are suitable to provide the best solution for a specific FRP product. Presently, most FRP bars used as reinforcements in concrete structures are produced by pultrusion. 


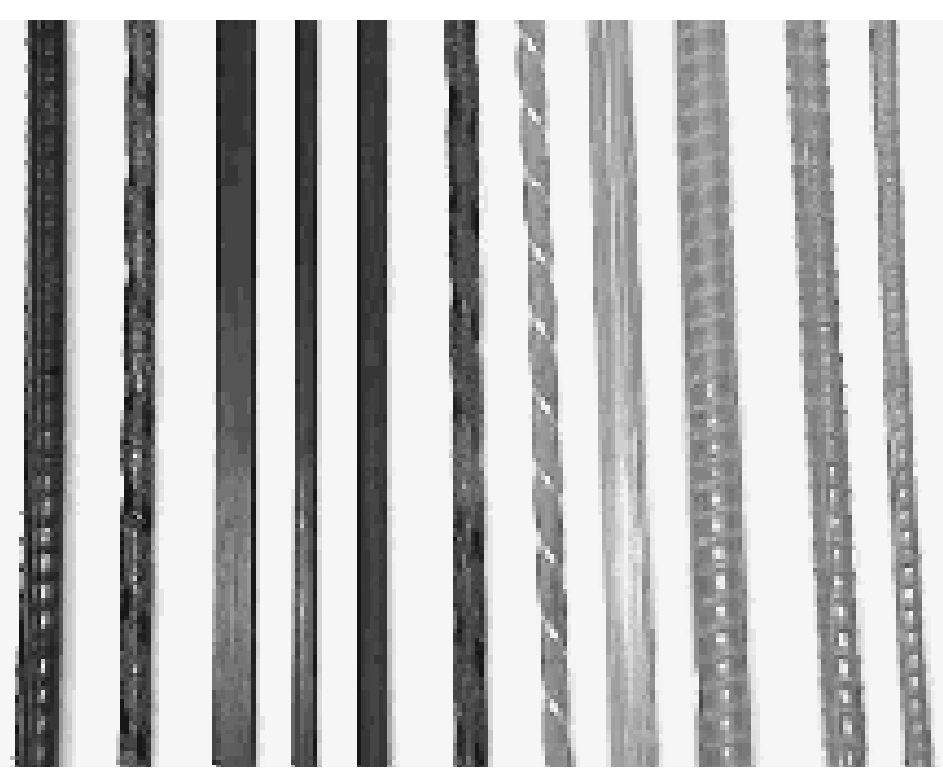

Figure 1.1 FRP bars

Commercial FRP products as shown in Fig. 1.1 and production technologies are available in USA, Canada, Japan and Europe. Manufacturers in North America offer pultruded FRP bars made of E-glass or S-glass fibers and thermoset resins (e.g., Aslan ${ }^{\mathrm{TM}}$, $\mathrm{KODIAK}^{\mathrm{TM}}$, Isorod ${ }^{\mathrm{TM}}$, and $\mathrm{VROD}^{\mathrm{TM}}$ ). In Japan, typical products are: stranded cables made of twisted carbon bundles $\left(\mathrm{CFCC}^{\mathrm{TM}}\right)$, Carbon FRP prestressing bars (Leadline $^{\mathrm{TM}}$ ), aramid/vinyl ester bars $\left(\right.$ Technora $^{\mathrm{TM}}$ ), and 2-D grid reinforcement with glass and carbon fibers $\left(\mathrm{NEFMAC} \mathrm{TM}^{\mathrm{TM}}\right)$. In Europe, there are several well known FRP products, such as Arapree $^{\mathrm{TM}}$ (ISIS, 2001).

\subsection{Application of FRP Bars}

FRP products have been widely used in civil engineering as bridge decks, reinforcing bars, and externally bonding sheets for rehabilitation. The work in this dissertation is part of a comprehensive research led by Dr. Davalos at West Virginia University that has provided internationally recognized contributions in those areas (Davalos et al., 2005, 2007a, and 2007b). 
FRP bars are commonly used in concrete as internal or near-surface-mounted (NSM) elements when applied as flexural or shear reinforcements. Though FRP products were used to reinforce concrete structure as early as the 1950s, the increased use of FRP bars emerged in the 1980s. But at that time, the main areas of applications were still limited to marine environment structures (as shown in Fig. 1.2 a); and structures wherein nonmagnetic properties were important such as magnetic resonance imaging (MRI) installations (Fig. 1.2 b), large transformer foundation pads, airport runways and electronic laboratories.

The world's first highway bridge using FRP reinforcement was built in 1986 in Germany. Since then bridges reinforced with FRP bars were constructed throughout Europe, Japan and North America. There are more than 100 projects showcasing FRP reinforcement applications in Japan. Glass-FRP (GFRP) bars have been commercially employed in over 40 structures in North American, as shown in examples given in Fig. 1.2 c-f (ACI 440, 2003). Recently FRP bars have emerged as a promising solution not only for the rehabilitation of existing structures but also for the construction of new and more durable RC structures.

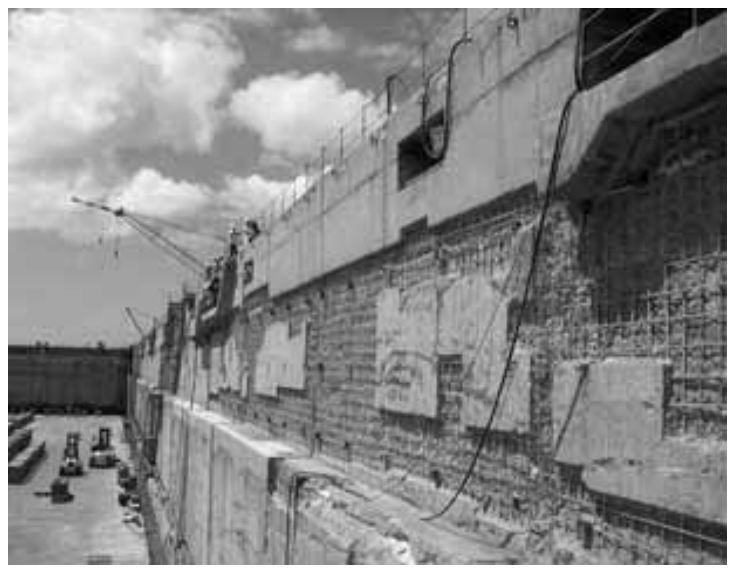

(a) sea wall restoration

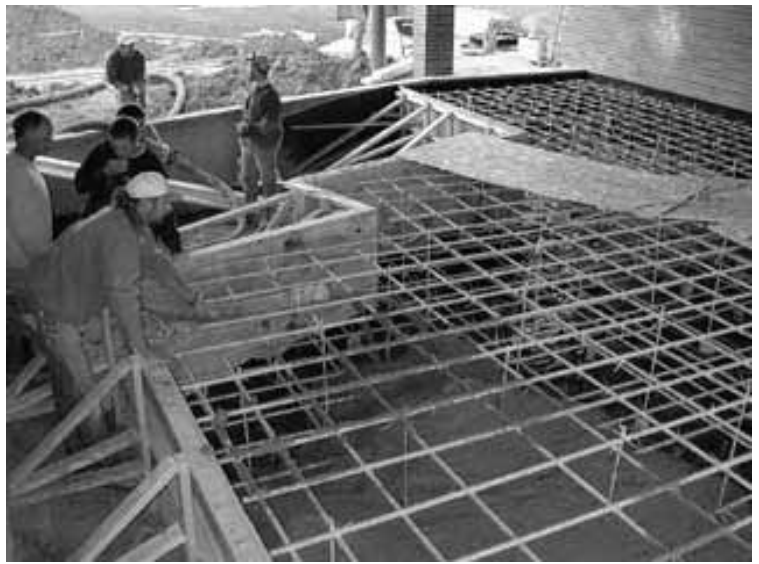

(b) MRI room foundation 


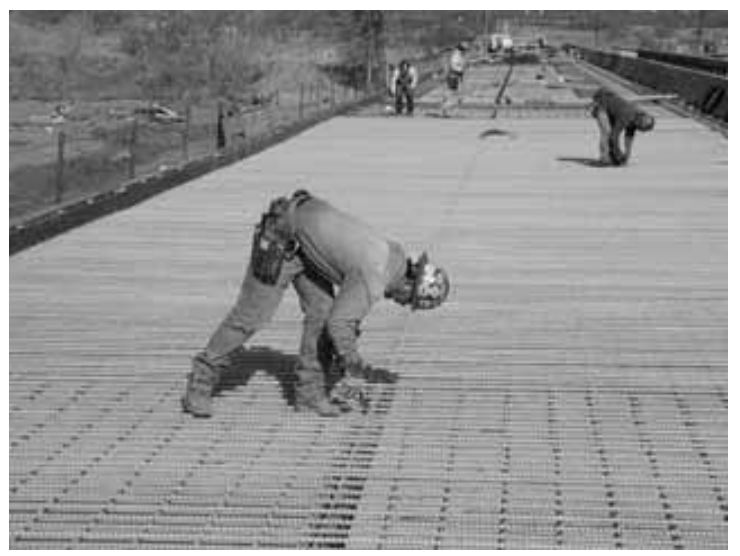

(c) highway bridge

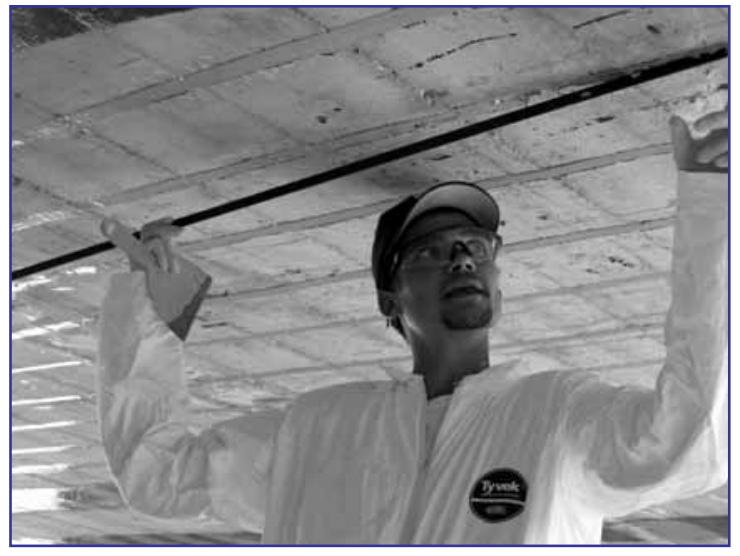

(e) NSM

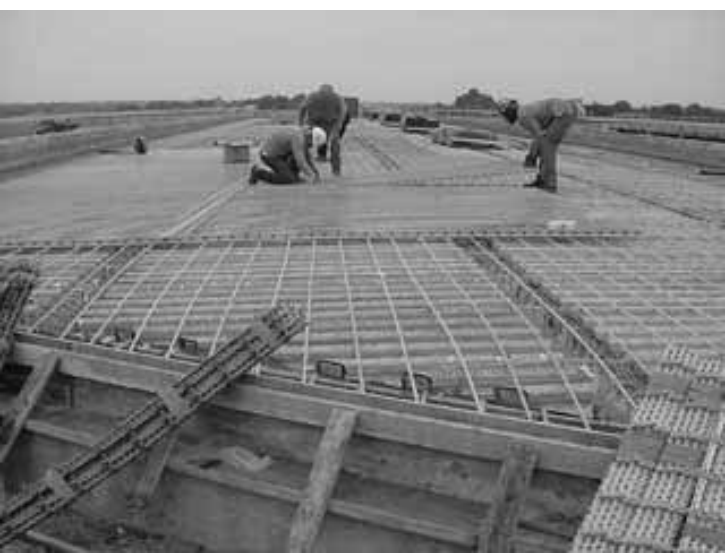

(d) highway

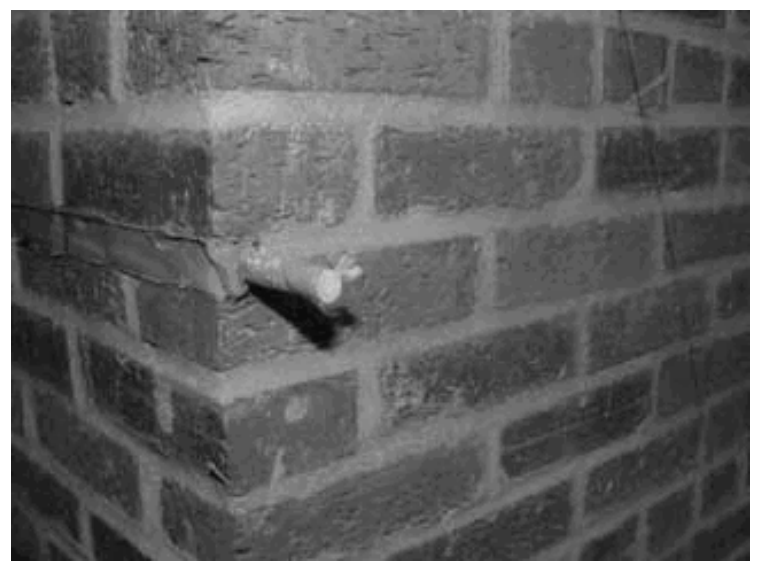

(f) Masonry strengthening

Figure 1.2 Applications of FRP bars in civil engineering (Photos from http://www.hughesbros.com/Aslan100/Aslan\%20100Pix.html)

\subsection{Research Significance}

With the enormous potential for the use of FRP bars in numerous field applications, the extended use of these new materials in concrete structures remains a challenge. High initial cost, lack of durability performance data of FRP bars in concrete, lack of design codes and experience, and lack of unified testing standards are recognized as major obstacles for acceptance of FRP bars on a broader scale in civil engineering. Due to the versatile applications of concrete in different construction fields, FRP reinforced concrete 
structures may often be exposed to wetting and drying (WD) cycles, sea-salts in hothumid climates, freezing and thawing (FT) conditions, deicing salts in cold climates, and many other severe environments. In addition to the above environmental exposure, glassFRP or GFRP bars, which are extensively used in civil engineering structures due to their low cost, are also readily attacked by concrete pore solutions having $\mathrm{pH}$ values of 12.4 to 13.7. Since the environmental attack begins at the bar surface, the FRP-concrete bond may also be affected. Data for short term test results indicated that FRP bars degraded significantly after certain environmental exposures.

There is no long-term field data available for the durability of FRP bars in concrete structures (Mufti et al. 2005). Thus, design guidelines impose conservative safety factors without the support of significant experimental results. Moreover, there are no standard methods or universally accepted long-term prediction models for the durability of FRP bars. Currently, most researchers use accelerated test methods and simulated solutions to study the durability of FRP bars and bond strength. These tests are often conducted on bare specimens directly exposed to ageing environments, which are very different from real conditions, characterized by exposure to concrete environment and under low sustained loading.

To take full advantage of capabilities of FRP bars, develop economical and safe design guides for FRP RC structures, and promote the use of FRP bars in civil infrastructure, there is urgent need for developing durability data of FRP bars and FRPconcrete bond, and also durability test methods and prediction models. 


\subsection{Objectives and Scope}

The objectives of this study may be summarized as characterization of durability performance of FRP bars and their bond with concrete, and subsequent development of prediction models for durability of FRP bars in concrete. The research includes the following five steps.

First, the durability performance of bare FRP bars is evaluated in various environmental conditions, including wetting-drying cycles, freezing-thawing cycles, sea water, alkaline solutions and tap water. To save time and cost, chemical solutions are formulated to simulate those environmental conditions. Elevated temperature is adopted to accelerate the environmental attack, and custom designed temperature controlled tanks are used to elevate the temperature of solutions. Three types of FRP bars are directly immersed in those simulated solutions at different temperatures. The tensile strength and interlaminar shear strength of FRP bars are determined before and after exposure, and are considered to be measures of durability performance of the specimens.

Second, the durability performance of GFRP bars in real concrete environment is investigated using specimens conditioned within concrete beams that are either loaded or not loaded. To accelerate the degradation, those GFRP RC beams are immersed in tap water at elevated temperatures. The GFRP bars are then extracted from beams and tested for residual tensile strengths at different exposure periods.

Third, analytical analysis including SEM and EDAX are employed to explore the degradation mechanisms of FRP bars subjected to environmental conditioning. The change of microstructure and chemical elements of conditioned specimens are examined to help understand degradation mechanisms and develop prediction models. 
Fourth, according to the above test results, prediction models based on Arrhenius concept for the durability of FRP bars are developed. A procedure is also included in the prediction models to evaluate the validity of accelerated aging tests.

Finally, the durability and behavior characteristics of interface bond of FRP bars and concrete are investigated using pullout tests. The durability performance of FRP-concrete bond is studied under environmental conditions such as tap water, hot water and thermal cycles. The bond-slip behavior and failure mechanism is also studied. Numerical methods are presented and illustrated to simulate bond-slip curves and determine development lengths according to the pullout test results.

\subsection{Organization of the Dissertation}

This dissertation is organized into eight chapters as follows:

Chapter one: The background and application of FRP bars in civil engineering are introduced. Then the research significance, objectives and scope, and organization of this dissertation are presented.

Chapter two: The material aspects of FRP bars are introduced. Then a state of the art review on the durability performance of FRP bars is provided.

Chapter three: The durability performance of bare FRP bars subjected to simulated environments is investigated. Different solutions are introduced to simulate various field conditions that FRP bars may be subjected to. The acceleration method using elevated temperature is discussed. The test methods for tensile strength and interlaminar shear strength of FRP bars are also discussed. The residual tensile strength and interlaminar shear strength of FRP bars after exposure are provided. 
Chapter four: The durability performance of GFRP bars embedded in concrete is studied. The information on specimens for FRP reinforced concrete beams, spring bracket assemblies for sustained loading, and loading levels is included. The tensile strength retentions after conditioning are listed for GFRP bars extracted from concrete beams.

Chapter five: The analytical methods of SEM and EDAX are introduced to investigate the microstructure and chemical composition change of conditioned FRP bars. The detailed sample preparation of FRP bars is also included.

Chapter six: Durability prediction models are reviewed, modified, and adopted for the durability of GFRP bars. Based on the test results of previous chapters, long term durability performance of GFRP bars in simulated solutions and real concrete are predicted using the developed procedure. Comparisons with test results from other studies are also made.

Chapter seven: The durability performance of FRP-concrete bond is studied. A preliminary durability study on FRP-concrete bond is presented first. Then in a follow up study, the discussion of pullout test arrangement and bond failure mechanisms are included, and the experimental program and test results are provided. In addition, numerical methods are presented to simulate bond-slip curves and determine development lengths.

Chapter eight: Conclusions derived from the present study are given in this chapter. In addition, recommendations for future research are also provided. 


\section{CHAPTER TWO LITERATURE REVIEW}

In this chapter, the commonly used fibers and matrices for FRP bars are introduced first. Then the degradation mechanisms of FRP bars subjected to environmental attack are discussed. Existing literature on the durability of FRP bars is reviewed. The accelerated test methods and prediction models for the durability of FRP bars are also discussed. Finally, research work on the durability performance of FRP-concrete bond is reviewed.

\subsection{Material Aspects of FRP bars}

\subsubsection{Fibers of FRP Bars}

Three types of fibers have been often used for FRP bars: glass, aramid and carbon. Table 2.1 summarizes the typical properties of fibers commonly used for the manufacture of FRP bars (compiled from ACI 440, 1996 and Uomoto et al., 2002).

\subsubsection{Glass Fibers}

Generally, glass-fibers exhibit good electrical and thermal insulation, and magnetic neutrality, but they have lower elastic modulus than steel. Due to economic advantages, glass fibers have been predominantly used in civil engineering applications. Commonly used glass fibers are introduced here. E-glass fibers are made of calcium-alumina-silicate glass and comprise about 80 to 90 percent of glass fibers used in commercial products. The boron-free modified E-glass is named as ECR-glass, which offers improved resistance to acid corrosions (ACI 440, 2003). S-glass (S for strength) has a proprietary 
magnesium alumino-silicate formulation, which leads to high strength and higher temperature performance. S-glass is three to four times more expensive than E-glass. Sglass and S-2 glass have the same composition but different surface treatments. Alkali resistant (AR) glass fibers are also available. They contain a large amount of zirconia $\left(\mathrm{ZrO}_{2}\right)$, which could potentially prevent corrosion by alkali attacks. There are also other glass fibers such as C-glass (C for corrosion) and D-glass (D for dielectric).

Table 2.1 Typical properties of fibers used in FRP bars

\begin{tabular}{cccccc}
\hline Fiber & Diameter $(\mu \mathrm{m})$ & $\begin{array}{c}\text { Density } \\
\left(\mathrm{g} / \mathrm{cm}^{3}\right)\end{array}$ & $\begin{array}{c}\text { Tensile } \\
\text { modulus(GPa) }\end{array}$ & $\begin{array}{c}\text { Tensile } \\
\text { strength(GPa) }\end{array}$ & $\begin{array}{c}\text { Elongation at } \\
\text { break }(\%)\end{array}$ \\
\hline Glass: & 10 & 2.54 & 72.4 & 3.45 & 4.8 \\
E-glass & 10 & 2.49 & 86.9 & 4.30 & 5.0 \\
S-glass & $8-12$ & 2.27 & $68.6-74.5$ & $1.8-3.4$ & $2-3$ \\
AR-glass & & & & & \\
\hline Carbon: & 7 & 1.76 & 231 & 3.65 & 1.4 \\
PAN-Carbon & 10 & 2.0 & 380 & 1.90 & 0.5 \\
T-300 & 11.9 & 1.45 & 131 & 3.62 & 2.8 \\
PITCH-Carbon & 12.0 & 1.45 & 127 & 3.6 & 2.5 \\
P-555 & 12 & 1.39 & 72.5 & 3.43 & 4.6 \\
\hline Aramid: & & & & & \\
Kelvar 49 & 10 & & & & \\
Twaron 1055 & 12.0 & & & \\
Technora & 12 & & & & \\
\hline
\end{tabular}

\subsubsection{Carbon Fibers}

Carbon fibers offer an excellent combination of strength, high modulus and low weight, but they are more brittle and expensive than glass and aramid fibers. Carbon fibers are made from pitch, petroleum and polyacrylonitrile (PAN). The fiber, an aggregate of graphite crystals, is also called graphite fiber. The properties depend on the material molecular structure and defects. The pitch carbon and PAN carbon fibers are two commercially available types of fibers. 


\subsubsection{Aramid Fibers}

Aramid fibers have good electrical and heat insulation, and are resistant to fuels, lubricants and organic solvents. Compared to glass and carbon fibers, aramid fibers have reasonable high tensile strength, a medium modulus, and a very low density. Aramid composites have better impact resistance but lower compressive strength than glass and carbon composites. Aramid fiber is a kind of organic fiber, which is poly-paraphenyleneterephthalamide (PPD-T). There are three commercially available aramid fibers:

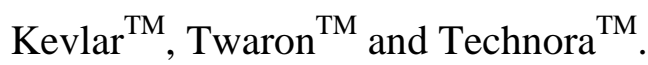

In addition to the fibers mentioned above, there are some other fibers such as polyvinyl alcohol fibers, boron fibers and organic fiber spectra. Also, FRP materials can be made of hybrid reinforcements, which include two or more types of fibers.

\subsubsection{Matrices of FRP Bars}

Generally there are two kinds of polymer matrices for FRP materials: thermoset (polyester, vinyl ester, epoxy, etc.) and thermoplastic (nylon, polyethylene, etc.). Table 2.2 summarizes the properties of commonly used matrices for FRP bars (complied from ACI 440, 1996 and Barbero, 1999). It is worth noting that the mechanical properties of polymers depend strongly on ambient temperature and loading rate. Within the glass transition temperature ( $\mathrm{Tg}$ ) region, polymers change from a hard and brittle solid to a soft and tough solid. In this region, the tensile modulus of the matrix will be reduced by five orders of magnitude. According to ASTM D883, $\mathrm{T}_{\mathrm{g}}$ is the approximate midpoint of the temperature range over which the glass transition takes place. The glass transition means the reversible change in an amorphous polymer, or in amorphous regions of partially crystalline polymer, from (or to) a viscous or rubbery condition to (or from) a hard and 
relatively brittle one. And at high loading rates, the polymeric solid behaves rigidly and brittle, but at low loading rates, the material exhibits ductility and improved toughness.

Table 2.2 Typical properties of matrices used in FRP bars

\begin{tabular}{cccccc}
\hline Matrix & $\begin{array}{c}\text { Density } \\
\left(\mathrm{g} / \mathrm{cm}^{3}\right)\end{array}$ & $\begin{array}{c}\text { Tensile } \\
\text { modulus(GPa) }\end{array}$ & $\begin{array}{c}\text { Tensile } \\
\text { strength(MPa) }\end{array}$ & $\begin{array}{c}\text { Tensile } \\
\text { Elongation }(\%)\end{array}$ & Tg (C) \\
\hline Thermoset & & & & & \\
Polyesters & $1.1-1.4$ & $2.8-3.4$ & $20.7-75.9$ & $1.4-3.3$ & - \\
Vinyl Esters & 1.12 & 3.4 & 82.7 & $5-6$ & - \\
Epoxies & $1.16-1.2$ & $1.4-3.38$ & $26.2-77.2$ & $3.1-5.2$ & $155-239$ \\
\hline Thermoplastic & & & & & 143 \\
PEEK & 1.32 & 3.24 & 100 & 50 & 90 \\
PPS & 1.36 & 3.3 & 82.7 & 5 & 217 \\
PEI & 1.27 & 3 & 105 & 60 & 243 \\
PAI & 1.4 & 2.76 & 89.57 & 30 & \\
\hline
\end{tabular}

\subsubsection{Thermosetting Matrix}

Thermosetting matrix is formed by irreversible chemical transformation of a resin into an amorphous cross-linked polymer matrix. Thermosetting resins are the most commonly used in civil engineering applications because of their favorable properties such as low cost, ease of processing (low viscous), good thermal stability and chemical resistance. Polyesters, vinyl esters and epoxies are the most popular thermosetting matrices.

Polyester resins are low viscous liquids based on unsaturated polyesters, which are dissolved in a reactive monomer, such as styrene. These resins have moderate strength and low environmental durability. Vinyl ester resins are produced by reacting epoxy resin with acrylic or methacrylic acid and have higher mechanical properties and better environmental durability than polyester resins. Usually, epoxy resins have higher mechanical properties, higher corrosion resistance and are more expensive than 
polyesters and vinyl esters. Epoxy resins are primarily used in advanced applications such as in aerospace, automobile and defense industries. Many of first generation composite products for reinforcing concrete are made of epoxy resins (Barbero, 1999).

\subsubsection{Thermoplastic Matrix}

A thermoplastic polymer is softened from solid state to be processed, and returns to solid state after being processed. Compared with the thermosetting resins, it does not undergo any chemical transformation during processing. Therefore, thermoplastic matrix can be repaired by being transited to soft stage. Thermoplastics have unlimited shelf life, and they are much more viscous than thermosettings. Polyester ether ketone (PEEK) is the most commonly used thermoplastic matrix. Other thermoplastics such as polyphenylene sulfide (PPS), Polyetherimide (PEI) and polyamide-imide (PAI) are also available.

\subsection{Degradation Mechanisms of FRP Bars}

Concrete structures are expected to last long and perform well during a period of 75 or 100 years. So FRP bars as reinforcement in concrete should have long-lasting performance, while the available knowledge and experience of durability of FRP bars is limited.

The durability of a material or structure was defined by Karbhari et al. (2001) as "its ability to resist cracking, oxidation, chemical degradation, delamination, wear, and/or the effects of foreign object damage for a special period of time, under the appropriate load conditions, under specified environmental conditions." The overall degradation of FRP includes fatigue, creep, cracking, wear, and environmental weathering. Since the focus of 
this study is on durability of FRP bars in concrete environment, only the environmental weathering of FRP materials is covered in detail in the following literature review.

\subsubsection{A General Review of Degradation of FRP Bars}

Environmental degradation of FRP materials is mainly due to oxidation, corrosion and other chemical reactions. Usually the degradation begins when free ions such as $\mathrm{OH}^{-}$, $\mathrm{Cl}^{-}$and water molecules diffuse into resin matrix of FRP materials. Through hydrolysis and polymerization, the physical, chemical and mechanical characteristics of matrix are changed. The cracks and voids in matrix will accelerate the diffusion of external agents. Surface abrasion, uncured resin, ultraviolet radiation and poor manufacturing process will also facilitate the diffusion. Then the fiber-matrix interphase will be affected by the diffused chemicals. When the matrix and interphase are affected, they cannot protect the fibers from external environment and cannot effectively transfer load among fibers. The degradation of fibers starts when the diffused chemicals reach them. Because cracks and fractures are formed in matrix and the effective fiber area is reduced by deterioration, the strength and stiffness of FRP materials decrease (Gonenc, 2003).

When FRP materials are subjected to sustained load, the degradation can be divided into three categories according to the level of sustained load (Devalapura et al., 1997 and Benmokrane et al., 2002). When the sustained stress level is sufficiently low, the viscoelastic behavior of resin allows stress relief and microcraking of resin will not occur to the extent where capillary action will dominate the degradation rate. So the stress corrosion of FRP materials is still diffusion dominated as described in the above paragraph. The so called "stress corrosion" is defined as the strength loss of materials subjected to sustained load under specific chemical environment. When the sustained 
stress is higher than some "threshold" level, the degradation of FRP materials will be dominated by crack propagation. Then the failure of FRP materials depends on the stress level, the toughness of resin matrix, and manufacture quality. A "threshold" stress of $25 \sim 30 \%$ of the ultimate strength was suggested by Benmokrane et al. (2002). When the sustained stress is very high, the degradation of FRP materials is mainly stress dominated. The material will show brittle fracture and fail due to fiber breakage, matrix cracking and interface debonding.

\subsubsection{Degradation of FRP Bar Matrices}

Most polymer matrices in FRP bars consist of molecular chains of carbon-carbon double bonds and ester groups or linkage. Many research results show that the durability of FRP materials depends on the polymer matrix. And the durability of polymer matrices depends on the environmental temperature and the loading conditions. Because the environmental temperature determines the diffusivity of polymer matrices and the loading condition determines the cracking of matrices.

At first, matrices delaminate, swell and crack due to the chemical diffusion. Due to the interruption of Van Der Waals bonds between polymer chains, the absorbed moisture will also cause plasticization of polymer, which is defined as the reductions of $\mathrm{T}_{\mathrm{g}}$ and mechanical properties of matrices. The saturated moisture contents and diffusion coefficients of FRP materials have been reported in many published literature. Then the polymers will react with the diffused chemicals. As Fig. 2.1 below shows, alkaline hydrolysis will take place in which $\mathrm{OH}^{-}$will react with ester bonds which are the weakest part in the chemical structure of the polymer (Chin et al., 1997). 

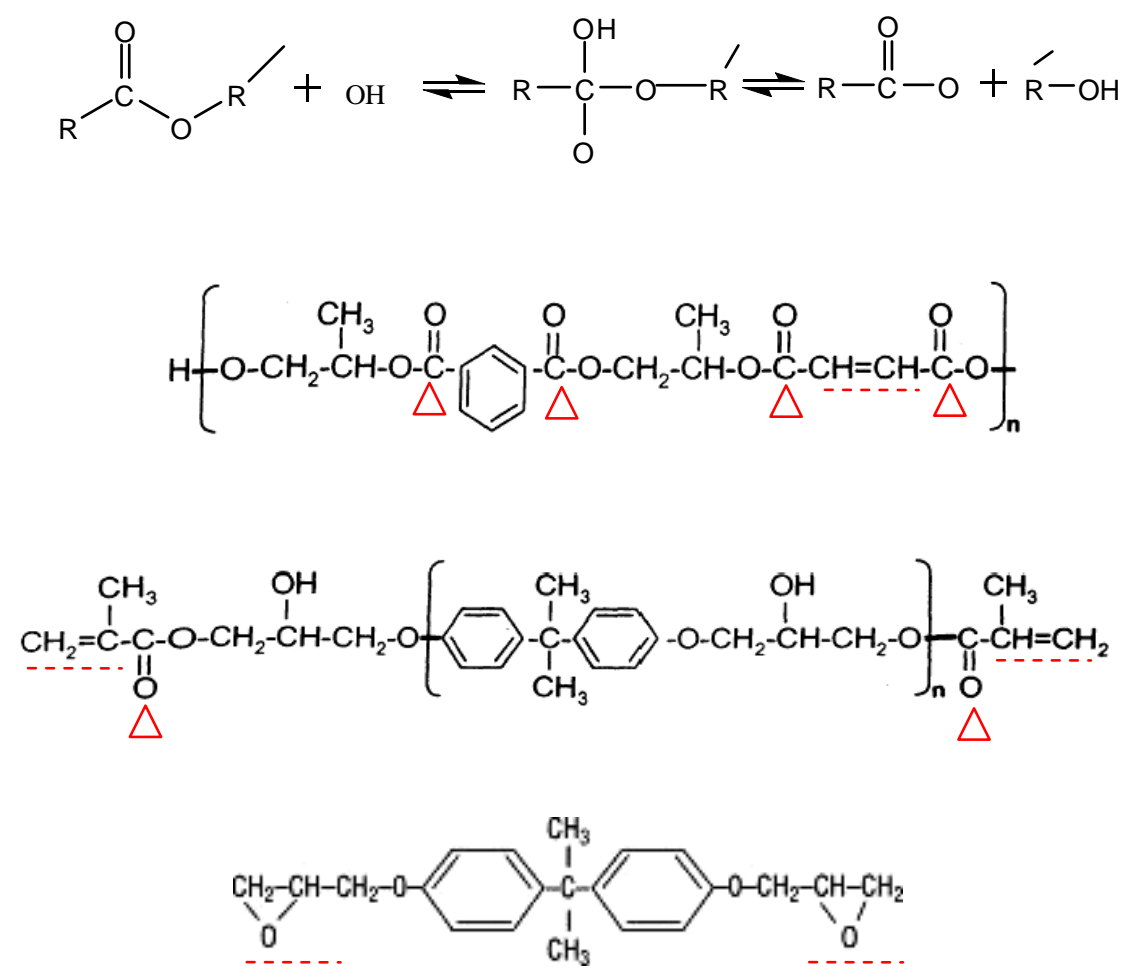

Fig 2.1 Representative chemical structure (uncured) for (a) isophthalic polyester resin, (b) vinyl ester resin, and (c) epoxy.

Polyester, vinyl ester and epoxy are the most commonly used resins in FRP reinforcements in civil engineering. Their representative chemical structures (uncured) are shown in Fig. 2.1 (Chin et al., 1997). The chemical bonds with dashed lines are reactive sites, which crosslink the polymer chains to form a highly complex three dimensional network during polymerization (also called 'curing'). The CO-O-C (with triangles as in Fig 2.1) is the ester group, which is the weakest link and susceptible to degradation by hydrolysis after polymerization. It can be derived from Fig.2.1 that vinyl ester matrix with fewer esters groups is less susceptible to hydrolysis than polyester matrix. Without ester group in molecular structures, the epoxy is not affected by hydrolysis. Results from published literature agree well with these expectations. 


\subsubsection{Degradation of FRP Bar Fibers}

Many researchers have studied the durability of fibers in FRP bars, while most studies focused on the three most commonly used fibers: glass, aramid and carbon fibers.

\subsubsection{Degradation of Glass Fibers}

Researchers have shown that the glass fibers are susceptible to attack by exposure to water, acidic, saline solution and alkaline solution, and the most severe degradation occurs in alkaline solution.

(a) Dissolution of glass in water (Charles, 1959 and Gonenc, 2003)

The diffusion of the alkali ions out of the glass structure, also known as "leaching", is the most important reaction in the dissolution of glass in water. As the equation 2.2 shows, the more alkali is added to the bulk of the glass structure, the more chemically reactive the glass fiber is in moisture environment. The byproduct silicon hydroxide $(\mathrm{SiOH})$, a gel layer with a lower density than the original glass structure, forms at the interface of glass and water. So water and alkali can diffuse more readily and thus the degradation process is accelerated.

$$
[-\underset{l}{\mathrm{Si}}-\mathrm{O}-\hat{\mathrm{Na}}-]+\mathrm{H}_{2} \mathrm{O} \rightarrow-\underset{\mathrm{I}}{\mathrm{SiOH}}+\mathrm{OH}^{-}
$$

The second important reaction is called "etching" in which the hydroxyl ions break the $\mathrm{Si}-\mathrm{O}-\mathrm{Si}$ as shown in equation 2.3.

$$
\left[\begin{array}{c}
\mathrm{I} \\
\mathrm{I}
\end{array}-\underset{\mathrm{I}}{\mathrm{Si}}-\mathrm{O}\right]+\mathrm{OH}^{-} \rightarrow-\underset{\mathrm{I}}{\mathrm{SiOH}}+\underset{\mathrm{I}}{\mathrm{SiO}}
$$


SiO-, a byproduct of above step, then reacts with water molecule and forms $\mathrm{SiOH}$, a gel on the surface of the bar as shown in equation 2.4. Then the process is slowed down by the gel on the surface.

$$
\left[\begin{array}{c}
\mathrm{S} \\
\mathrm{SiO}
\end{array}\right]+\mathrm{H}_{2} \mathrm{O} \rightarrow-\underset{\mathrm{I}}{\mathrm{Si} O H}+\mathrm{OH}^{-}
$$

From the above reactions, excessive hydroxyl ions form and the $\mathrm{pH}$ of solution is increased. The fourth reactions occur as the equation 2.5 shows. The first three reactions occur more often since there are many terminal ends in glass structures.

$$
\left[\begin{array}{c}
\mathrm{I} \\
\mathrm{S} i
\end{array}-\underset{\mid}{\mathrm{Si}}-\mathrm{O}_{2} \mathrm{O} \rightarrow 2-\underset{\mathrm{I}}{\mathrm{Si}} \mathrm{OH}\right.
$$

\section{(b) Dissolution of glass in alkaline solutions}

Several studies have been conducted to investigate the durability of FRP in alkaline solutions, since FRP materials are often used as reinforcement in concrete and the pore solution of concrete has a relative high $\mathrm{pH}$ value of 12.4-13.7.

Generally, dissolution of glass fibers in alkaline solutions is the same as the second step of dissolution of glass fibers in water (i.e. etching). As can be inferred from equation 2.2, the dissolution of glass fibers in water would eventually evolve into an alkali attack (Gonenc, 2003). But since the alkaline solution starts the reaction immediately, its effect on durability is much more severe than that of water alone.

At the same time, dissolution of calcium in the glass also occurs. This is known as a leaching of the calcium out of the bulk glass. The calcium will combine with water into a calcium hydroxide compound on the surface of glass; this compound will slow the reaction further. But the growth of calcium hydroxide crystals will cause notching of the 
glass fibers, reducing the cross section of the fiber and exposing new bulk glass for degradation (Porter and Barnes, 1998). The nucleation of calcium hydroxide on fiber surface will also lead to the embrittlement of fibers (Benmokrane et al., 2002).

\section{(c) Dissolution of glass fibers in salt solutions}

The degradation process is similar to that of alkaline solutions, but the rate of dissolution will be much lower. And the salt solution does not have much effect until its pH exceeds 9 (Porter, 1999). Systematic experiments conducted by Wickert et al. (1999) showed that: (1) significant increase in the dissolution rate of soda-lime-silica glass occurs with increasing $\mathrm{NaCl}$ concentration; (2) a rise in the amount of glass dissolved per day occurs, following an induction period that is shorten as the concentration of $\mathrm{NaCl}$ becomes higher, as a result of surface cracking and spalling.

\section{(d) Dissolution of glass fibers in acidic solutions}

Acids may attack FRP bars when they are used in sewage systems and waste water treatment facilities or as external reinforcements. An acid attack removes the alkali present in the bulk glass by exchanging hydronium ions in the acid with alkali in the glass. Metcalfe et al. (1972) explained the acid attack as illustrated in the following equation (Gonenc, 2003):

$$
[-\underset{\mathrm{I}}{\mathrm{i}-\mathrm{O}}-\stackrel{\uparrow}{\mathrm{Na}}-]+\mathrm{H}^{+} \rightarrow-\underset{\mathrm{I}}{\mathrm{SiOH}}+\mathrm{Na}^{+}
$$

\subsubsection{Degradation of Carbon Fibers}

Carbon fibers are known to be inert to chemical environments and do not absorb water. Several studies have shown that carbon fibers are highly resistant to moisture, acidic and alkali environments. But electrochemical processes, particularly galvanic 
action, will cause degradation of carbon based composite. Carbon composite can also degrade due to anodic polarization which is a result of stray currents.

\subsubsection{Degradation of Aramid Fibers}

As with most organic polymeric fibers, aramid fibers are particularly susceptible to moisture absorption. Large deterioration of flexural strength of aramid/expoxy laminates will occur in a saturated state at elevated temperature. Degradation of aramid fibers due to water absorption is similar to that of glass fibers. Sodium hydroxide and hydrochloric acid will cause dramatic accelerated hydrolysis of aramid fibers. In addition, aramid fibers are more susceptible to ultraviolet rays than glass and carbon fibers.

\subsubsection{Degradation of Interphase Region of FRP Bars}

The interphase of FRP materials, an inhomogeneous region with a thickness of about one micrometer, lies between fibers and matrix. The interphase is the weakest link most of the time and can degrade easily. Bradshaw and Brinson (1997) proposed the following damage mechanisms in the interphase region: (1) matrix osmotic cracking; (2) interfacial debonding; (3) delamination. The application of sizing or external coating of fiber surface has complicated the interphase region. Sizing with three main parts: lubricant, wetting agent and coupling agent is generally applied to the fiber surface to protect the fibers from damage due to handling and enhance the fiber-matrix adhesion. Some research (Prian and Barkatt, 1999) found that the degradation of fiber/matrix interface accounted for dramatic increase in degradation rate of FRP, which may be observed in some cases of environmental exposure after a certain time period. The leaching of fibers increases the $\mathrm{pH}$ values around fibers, which enhance the degradation of fiber/matrix interphase. Both the fiber dissolution and loss of acidic components from the matrix are accelerated. The 
deterioration and opening up of the interface regions accelerate the dissolution of chemicals and hydrolytic depolymerization of the matrix, and the formation of microscopic cracks and voids further facilitates the degradation.

\subsection{Durability Studies of FRP Bars}

To investigate the durability of FRP bars, a variety of exposure conditions, FRP materials and test methods have been employed. Generally, different solutions and conditions are used to simulate the field conditions. Elevated temperature is widely used to accelerate ageing. The properties of FRP materials as indicators of durability performance are measured before and after the exposure.

Several research studies are now in progress especially in Europe, Japan and North America. Since there is no standard test method for the durability of FRP bars, it is difficult to compare research results from different experiments. So it is important to note that results from one experiment or conclusion drawn from one project may be only valid for the specific FRP materials under the prescribed specific conditions.

\subsubsection{Environmental Effects on the Durability of FRP Bars}

Several researches have investigated the effects of acidic, humid environments, high temperatures on the chemical resistance and mechanical properties of FRP (e.g., Lewis et al., 1984 and Kasturiarachchi and Pritchard, 1983). In general, the research on effects of alkaline environment on FRP materials began in the 1990's.

Cowley and Robertson (1991) investigated the effects of the $\mathrm{pH}$ and temperature on GFRP composite in sodium hypochlorite solutions. The $\mathrm{pH}$ range they used was: 7 to $7.75,8$ to $8.5,9$ to $9.5,10$ to 10.5 and 11 to 11.5 . The experiments showed that based on 
the weight change, 4-month exposures to solutions with variable $\mathrm{pH}$ values at $99^{\circ} \mathrm{C}$ were equivalent to a continuous six-month exposure to the solution with the $\mathrm{pH}$ range of 9-9.5 at the same temperature. The increase of exposure temperature also introduced increase in corrosion rate. Zayed (1991) investigated the durability of E-glass/isophthalic polyester composite bars in concrete subjected to marine environment. Those bars were subjected to: a saturated calcium hydroxide solution; saturated calcium hydroxide and 3.5 $\%$ (by weight) sodium chloride solution; water at room temperature and $40{ }^{0} \mathrm{C}$. The 85 day exposure to calcium hydroxide-sodium chloride environment resulted in $15 \%$ loss in tensile strength, while the immersion in hot water caused $5 \%$ loss.

Raham et al. (1998) conducted experimental investigation of durability of CFRP and GFRP materials exposed to various conditions. A total of 96 carbon fiber/vinyl ester specimens and 24 glass fiber/vinyl ester specimens were custom-manufactured. The CFRP specimens subjected to $50 \%$ of their ultimate strength, and the GFRP specimens, subjected to $30 \%$ their ultimate strength, were exposed to various environments for 45 , 122 and 370 days. The experimental results showed that GFRP exposed to alkaline solution failed even within the first month due to the rapid diffusion of the hydrated hydroxyl ions $\left(\mathrm{OH}^{-}\right)$. An examination by SEM showed that many fibers remained uncoated by resin. But the Fourier Transform Infrared (FTIR) analysis showed that the bulk of resin was not chemically affected. The CFRP specimens exposed to the alkaline solution showed signs of physical damage in the form of etching, cracking and even spalling of the resin. Unlike steel corrosion, the degradation of resin occurs without any exterior signs. The following scale shows the effects of exposure conditions in the order of declining severity to CFRP specimens: 
$\mathrm{NaOH} @ 70^{\circ} \mathrm{C}$ solution > NaOH@50 $\mathrm{C}$ solution > $\mathrm{NaOH} @ 30^{\circ} \mathrm{C}$ solution > $\mathrm{NaCl} @ 50^{\circ} \mathrm{C}$ solution > NaCl@30 ${ }^{0} \mathrm{C}$ solution > Water@70 ${ }^{0} \mathrm{C}>\mathrm{Air} @ 23^{0} \mathrm{C}$

Saadatmanesh and Tannous (1998) reported a durability study on eight different GFRP bars (including E-glass and AR-glass fiber bars), two types of CFRP tendons and one type of AFRP tendon. To simulate the field environments, they designed eight different conditions: (1) water at $25^{\circ} \mathrm{C}$; (2) saturated $\mathrm{Ca}(\mathrm{OH})_{2}$ solution $(\mathrm{pH}$ value $=12$ ) at $25^{\circ} \mathrm{C}$; (3) saturated $\mathrm{Ca}(\mathrm{OH})_{2}$ solution $\left(\mathrm{pH}\right.$ value=12) at $60^{\circ} \mathrm{C}$; (4) $\mathrm{HCl}$ solution (pH value $=3$ ) at $25^{\circ} \mathrm{C} ;(5) \mathrm{NaCl} 3.5 \%$ by weight solution at $25^{\circ} \mathrm{C} ;(6) \mathrm{NaCl}+\mathrm{CaCl}_{2}(2: 1) 7 \%$ by weight solution; (7) $\mathrm{NaCl}+\mathrm{MgCl}_{2}(2: 1) 7 \%$ by weight solution; 8$)$ ultraviolet radiation at the rate of $31.7 \times 10^{-6} \mathrm{~J} / \mathrm{s} / \mathrm{cm}^{2}$. The experimental results showed that GFRP bars (both Eglass and AR-glass fiber bars) exhibited durability problems. No significant strength loss was found after exposure to $\mathrm{HCl}$ solution because of low concentration of $\mathrm{Cl}^{-}$. Due to lower chloride concentration and lower diffusivity, lesser tensile strength losses were observed in specimens exposed to sea water than those in deicing salt solution. The relative adverse effects on the tensile strength of GFRP bars in the order of increasing significance, were as follows: water, acidic solution $(\mathrm{HCl})$, sea water, salt solution (deicing salt solution) and alkali solution, respectively. Ultraviolet radiation has very limited effect on the tensile strength of GFRP bars. In contrast, CFRP and AFRP tendons exhibited good resistance to alkali and salt attack. Also, freeze-thaw cycles had limited effects on the durability of CFRP and AFRP tendons.

To further focus their study on GFRP bars, Tannous and Saadatmanesh (1998) conducted similar studies on the moisture absorption and the associated changes in mechanical properties of GFRP bars. Later on, Tannous and Saadatmanesh (1999) 
studied the durability of alkali resistant (AR) glass fiber/polyester and AR-glass/vinyl ester bars. They conducted a durability study with the same exposure conditions and test methods as the previous one. In addition to obtaining similar results, they found that the AR glass fiber did not improve the behavior of bars made for their study, when the bars were subjected to alkaline environment of concrete.

Experimental studies on the effects of laboratory simulated marine climates on the mechanical properties of several GFRP composites were also carried out by Malvar et al. (2002). The results indicated that the exposure to seawater caused the greatest deterioration as indicated by reduction in the flexural and tensile strengths. The salt fog exposure also resulted in significant strength degradation. Atmosphere exposure or submersion in an oxygen-rich seawater environment did not accelerate the deterioration compared with the salt fog exposure. Little change was observed in the glass transition temperature, $\mathrm{Tg}$. Also, moderate dry heat, ultraviolet radiation and cold storage had little effect on GFRP composites.

The freeze-thaw cycling effect on FRP bars was also studied by researchers. Haramis et al. (2000) reported that though significant degradation of ultimate strength and strain properties for pultruded glass/vinyl ester and glass/epoxy laminates after moisture saturation were observed, freeze-thaw cycle conditioning for both unloaded and loaded samples did not cause any significant changes in mechanical properties after 300 cycles. Similarly, Uomoto (2000) investigated the freeze-thaw cycle effects on CFRP, AFRP and GFRP bars. The specimens were directly immersed in a freeze-thaw water chamber ($20^{\circ} \mathrm{C}$ to $15^{\circ} \mathrm{C}$ ) for 300 cycles. Only $8 \%$ strength reduction was observed in GFRP rods. 
Micelli et al. (2001) conducted an experimental study on effects of combined condition environments on GFRP bars. The GFRP bars were subjected to four combined environmental cycles, which corresponded to a period of 8 years in regions such as continental Europe or central USA. The results showed that such combined environmental agents did not affect the mechanical properties of specimens. In another study (Stone et al., 2002), GFRP rods, laminates and sandwich panels were subjected to similar combined environmental cycles. The results showed that interlaminar shear strength of GFRP bars was almost not affected. GFRP laminates were not adversely affected. In fact, the modulus and strength of GFRP laminates increased after exposure in most cases.

Besides the exposure effects to humidity and chemical solutions, the deterioration due to ultraviolet rays was also studied by researchers. When FRP materials are used as external reinforcement of concrete structures or stored in outdoor environment, they will be exposed to ultraviolet radiation (UV), which has wavelengths ranging from 290 to $400 \mathrm{~nm}$, and comprises $6 \%$ of the total solar radiant flux which reaches the Earth's surface. The remainder of the solar radiation is composed of visible (52\%) and infrared (42\%) light. Since bond dissociation energies of most polymers are on the order of UV wavelengths, they will be greatly affected by UV radiation, but the effects of UV exposure, in the form of photodegradation, are usually limited to only a few microns of the surface (Kato et al., 1998 and Karbhari et al., 2001).

Though UV radiation and freeze-thaw will not cause significant degradation in FRP materials, matrix cracking due to residual stress effects from cycling and matrix damage 
due to UV radiation will increase moisture absorption, which in turn increases the degradation rate.

\subsubsection{Material Effects on the Durability of FRP Bars}

Durability of FRP depends on the type of resin and fiber, sizing chemistry and manufacture process. To improve the durability of FRP and identify the most suitable constituents and manufacturing, many researchers evaluated the effects of resin types, fiber types, their volume fractions, surface treatment and manufacture process on the durability of FRP bars.

Matzeg and Santrach (1991) studied the effect of glass fiber types on the corrosion resistance of FRP laminates. Five factors were studied: the glass fiber type (E vs. E-CR), the polyester resin type (isophthalic vs. bisphenol A), the laminate construction (mat/mat/mat vs. mat/woven roving/mat), the exposure media type (sodium hydroxide vs. sulfuric acid) and the acid/base ion concentration (1N vs. 2N). Takewaka and Khin (1996) conducted a durability study of seven different kinds of FRP bars in simulated concrete pore solution with $\mathrm{pH}$ value of 13.27. Not only GFRP but also CFRP and AFRP rods were susceptible to alkaline environment. The loss of strength of CFRP and AFRP rods varied according to the type of bars.

Bakis et al. (1998) conducted an experimental study on the effect of resin matrix on the tensile properties and elastic modulus of conditioned and unconditioned E-glass FRP bars. After 28-day immersion in $80^{\circ} \mathrm{C}$ saturated solution of $\mathrm{Ca}(\mathrm{OH})_{2}$ followed by 5-day drying, E-glass FRP with 100\% vinyl ester suffered least degradation in tensile strength and modulus of elasticity, while the bars with $50 \%$ vinyl ester and $50 \%$ iso-polyester had the most severe loss of tensile strength and modulus. And the bars with $20 \%$ vinyl ester 
and $80 \%$ iso-polyester had a severe loss in tensile strength but little degradation in elastic modulus.

Devalapura et al. (1998) conducted a durability study of different glass/polyester composites in acidic and alkaline environments. The environmental stress-rupture results showed that similar degradation rates were observed for E-CR, ADVANTEX and E-glass FRP bars (made by Owens Corning). But the degradation of E-glass FRP bars occurred at much lower absolute stress level. The boron free Advantex glass FRP exhibited improved corrosion resistance both in acid and basic conditions. Creep-rupture testing conducted by Greenwood (2002) also indicated that boron-free E-glass (Advantex glass) composites had superior long-term performance than traditional E-glass composites.

Experimentally produced basalt fiber reinforced plastic (BFRP) grids were evaluated for durability in alkaline environment (Coomarasamy and A.K.C Ip, 1998). Contrary of what was expected, the degradation of tensile properties of BFRP was more severe than of commercial GFRP products.

Coomarasamy and Goodman (1999) conducted a durability study of various FRP materials in concrete environment. GFRP bar samples from 5 different manufacturers and FRP grids with basalt, glass and carbon fibers were subjected to simulated concrete pore solution with a $\mathrm{pH}$ value of 13.5 at the temperature of $60{ }^{0} \mathrm{C}$. After 25 weeks exposure, the experimental results indicated that FRP with vinyl ester resins were more durable than those with polyester resins as expected. And the durability and structural integrity of these materials were heavily dependent on the manufacture process.

Benmokrane et al. (2002) conducted accelerated aging tests on over 20 types of glass fiber-reinforced polymer (GFRP) reinforcing bars, which were made from different 
combinations of constituent materials, manufacturing parameters, sizes and shapes, and surface coatings. The samples were subjected to sustained tensile loading (22-68\% of their ultimate strengths) in three types of alkaline environments. The critical durability influencing factors such as fiber and resin types, surface coating and manufacturing parameters were studied. Their experimental results showed that the higher the fiber content is, the lower the diffusibility is due to impermeability of fibers. Since vinyl ester resin contains fewer polar groups than polyester, vinyl ester and its composite showed lower diffusion and absorption. As expected the vinyl ester resin had better chemical resistance. Also the vinyl ester matrix was tougher than polyester matrix due to a longer distance between cross-links. Polyester was not recommended for use in GFRP bars. The resin of FRP bars should be fully cured before being used in concrete structures. Sand coatings were found to reduce the micro crack and macro crack in the resin coating surfaces. Advantex and AR-glass fibers showed better alkaline resistance than E-glass fibers. The stress corrosion indicated that the stress level of GFRP bar in concrete structures should be less than $25 \%$ of its guaranteed design strength.

Sen et al. (2002) presented a focused experimental investigation on the durability of E-glass/vinyl ester bars in alkaline environment. The specimens, loaded with four stress levels: $0,10,15$ and $25 \%$ of their ultimate tensile strength, were subjected to simulated concrete pore solution. After exposure for 1,3,6 and 9 months, stress rupture time of bars was recorded, and the surviving specimens were tested for residual tensile strength. Their results demonstrated the lack of good durability performance of the E-glass/vinyl ester bars tested. Unstressed and those stressed to $10 \%$ of ultimate tensile strength lost $63 \%$ to $70 \%$ of their original strength after 9-month exposure. All specimens stressed to 
$25 \%$ failed within 25 days of exposure, and five of those six bars stressed to $15 \%$ failed within 180 days. It was further observed that the resin of specimens cracked at low strain, with the range of 10 to $25 \%$ of ultimate tensile strength, possibly due to the misalignment of fibers. The results showed that resin cracking can provide additional passages for hydroxyl ions attack on fibers, but the resin cracking due to low stress level, such as $10 \%$ of ultimate strength, only play a relatively minor role.

Alsayed et al. (2002) conducted a durability study of a new generation of GFRP bars, which was manufactured through hybrid pultrusion/compression molding process. The specimens with $70 \%$ of E-glass fiber content were composed of three layers: urethanemodified vinyl ester for the two outermost layers and the unsaturated polyester resin for the interior layer. The bars coated or uncoated with cement paste (low and high alkali cement) were immersed in tap water, sea water and alkaline solutions at 23, 35, 50 and 65 ${ }^{0} \mathrm{C}$. After 6 month exposure, the preliminary results indicated that the new generation of GFRP bars had improved durability behavior.

Nkurunziza et al. (2003) conducted a short term accelerated aging test on the second generation of ISOROD glass FRP bars (76 w\% E-glass fiber and vinyl ester resin). The first 10 specimens were subjected to $30 \%$ of ultimate tensile strength immersed in deionized water at the temperature of $65.5-75^{\circ} \mathrm{C}$. The second 10 specimens were subjected to $40 \%$ of ultimate tensile strength immersed in alkaline solution $(\mathrm{pH}$ value $=13.11$ ) at the temperature of $65.5-75.5^{\circ} \mathrm{C}$. The experimental results after exposure of 60 days showed that the loss in ultimate tensile strength was insignificant. Thermogravimetric analysis/differential scanning calorimetry (TGA/DSC) showed that there was post-curing phenomena if the samples were heated at $200^{\circ} \mathrm{C}$. Micrographs of 
glass fibers and binding resin showed that glass fibers were not affected by the immersion in water and even in alkaline. The rupture of bars was mainly caused by the cohesion loss of fiber/matrix. Fourier Transform Infared (FTIR) analysis showed that the bulk resin had not been affected. Short term accelerated aging did not cause any significant degradation of the internal part of the bars.

A summary of the literature review on durability of FRP bars exposed to simulated alkaline environments is presented in Tables 2.3 and 2.4.

Table 2.3 FRP bars under unstressed condition in alkaline environments

\begin{tabular}{|c|c|c|c|c|c|c|c|}
\hline Author & Fiber & Resin & Solution & $\mathrm{pH}$ & $\begin{array}{c}\text { Duration } \\
\text { (days) }\end{array}$ & $\begin{array}{l}\text { Temp. } \\
\left({ }^{0} \mathrm{C}\right)\end{array}$ & $\begin{array}{c}\text { Strength } \\
\text { reduction } \\
(\%)\end{array}$ \\
\hline \multirow{4}{*}{ Sen et al. (2002) } & \multirow{4}{*}{ E-glass } & \multirow{4}{*}{ Vinyl ester } & \multirow{4}{*}{$\begin{array}{c}10 \mathrm{~g} \mathrm{Ca}(\mathrm{OH})_{2} \\
+8.33 \mathrm{~g} \mathrm{NaOH} \\
+23.3 \mathrm{~g} \mathrm{KOH} \text { in } 1 \\
\mathrm{~L} \text { water }\end{array}$} & \multirow{4}{*}{$\begin{array}{c}13.35 \\
\text { to } \\
13.55\end{array}$} & 30 & \multirow{4}{*}{ NR } & 50 \\
\hline & & & & & 90 & & 63 \\
\hline & & & & & 180 & & 64 \\
\hline & & & & & 270 & & 63 \\
\hline \multirow{2}{*}{$\begin{array}{l}\text { Micelli et al. } \\
\text { (2001) }\end{array}$} & \multirow[b]{2}{*}{ E-glss } & \multirow[b]{2}{*}{ Polyeseter } & \multirow{2}{*}{$\begin{array}{c}0.16 \% \\
\mathrm{Ca}(\mathrm{OH})_{2}+1 \% \\
\mathrm{NaOH}+1.4 \% \\
\mathrm{KOH} \text { in weight } \\
\text { in water }\end{array}$} & \multirow[b]{2}{*}{12.6} & 21 & \multirow[b]{2}{*}{60} & 30 \\
\hline & & & & & 42 & & 41 \\
\hline \multirow{4}{*}{$\begin{array}{l}\text { Coomarasamy } \\
\text { and Goodman } \\
\text { (1999) }\end{array}$} & \multirow{4}{*}{ glass } & \multirow{2}{*}{ Vinyl ester } & \multirow{4}{*}{$\begin{array}{c}\text { saturated } \\
\mathrm{Ca}(\mathrm{OH})_{2}+0.2 \mathrm{M} \\
\mathrm{NaOH}+0.6 \mathrm{M} \\
\mathrm{KOH} \text { in } 1 \mathrm{~L} \\
\text { water }\end{array}$} & \multirow{4}{*}{13.5} & 78 & & 45 \\
\hline & & & & & 118 & & 46 \\
\hline & & \multirow{2}{*}{ polyester } & & & 78 & 60 & 81 \\
\hline & & & & & 118 & & 85 \\
\hline \multirow{4}{*}{$\begin{array}{c}\text { Tannous and } \\
\text { Saadatmanesh } \\
\text { (1999) }\end{array}$} & \multirow{4}{*}{ AR-glass } & \multirow{2}{*}{ Vinyl ester } & \multirow{4}{*}{$\begin{array}{l}\text { Saturated } \\
\mathrm{Ca}(\mathrm{OH})_{2} \\
\text { solutions }\end{array}$} & \multirow{4}{*}{12} & \multirow{4}{*}{180} & 25 & 13 \\
\hline & & & & & & 60 & 21 \\
\hline & & \multirow{2}{*}{ polyester } & & & & 25 & 23 \\
\hline & & & & & & 60 & 28 \\
\hline
\end{tabular}


Table 2.3 FRP bars under unstressed condition in alkaline environments (Continued)

\begin{tabular}{|c|c|c|c|c|c|c|c|}
\hline Author & Fiber & Resin & Solution & $\mathrm{pH}$ & $\begin{array}{c}\text { Duration( } \\
\text { days) }\end{array}$ & $\begin{array}{l}\text { Temp. } \\
(0 \mathrm{C})\end{array}$ & $\begin{array}{c}\text { Strength } \\
\text { reduction } \\
(\%)\end{array}$ \\
\hline \multirow{4}{*}{$\begin{array}{c}\text { Tannous and } \\
\text { Saadatmanesh } \\
\text { (1998) }\end{array}$} & \multirow{4}{*}{ E-glass } & \multirow{2}{*}{ Vinyl ester } & \multirow{4}{*}{$\begin{array}{l}\text { Saturated } \\
\mathrm{Ca}(\mathrm{OH})_{2} \\
\text { solutions }\end{array}$} & \multirow{4}{*}{12} & \multirow{4}{*}{180} & 25 & 13 \\
\hline & & & & & & 60 & 20 \\
\hline & & \multirow{2}{*}{ polyester } & & & & 25 & 25 \\
\hline & & & & & & 60 & 29 \\
\hline \multirow{3}{*}{$\begin{array}{l}\text { Bakis et al. } \\
\text { (1998) }\end{array}$} & \multirow{3}{*}{ E-glass } & Vinyl ester & \multirow{3}{*}{$\begin{array}{l}\text { Saturated } \\
\mathrm{Ca}(\mathrm{OH})_{2} \\
\text { solutions }\end{array}$} & \multirow{3}{*}{$\begin{array}{l}12 \\
\text { to } \\
13\end{array}$} & \multirow{3}{*}{28} & \multirow{3}{*}{80} & 16 \\
\hline & & $\begin{array}{c}50 \% \text { vinyl } \\
\text { ester + } \\
50 \% \text { iso- } \\
\text { polyester }\end{array}$ & & & & & 29 \\
\hline & & $\begin{array}{l}\text { 20\%vinyl } \\
\text { ester + } \\
80 \% \text { iso- } \\
\text { polyester }\end{array}$ & & & & & 25 \\
\hline \multirow{2}{*}{$\begin{array}{l}\text { Devalapura et } \\
\text { al. (1998) }\end{array}$} & Advantex & \multirow{2}{*}{ Polyester } & \multirow{2}{*}{ Cement extract } & \multirow{2}{*}{11} & \multirow{2}{*}{90} & \multirow{2}{*}{60} & 6 \\
\hline & E-glass & & & & & & 14 \\
\hline \multirow{3}{*}{$\begin{array}{c}\text { Katsuki and } \\
\text { Uomoto (1995) }\end{array}$} & T-glass & \multirow{3}{*}{ Vinyl ester } & $1.0 \mathrm{~mol} / \mathrm{l} \mathrm{NaOH}$ & \multirow{3}{*}{ NR } & \multirow{3}{*}{120} & \multirow{3}{*}{40} & 72 \\
\hline & Aramid & & $2.0 \mathrm{~mol} / \mathrm{l} \mathrm{NaOH}$ & & & & 0.1 \\
\hline & Carbon & & $2.0 \mathrm{~mol} / \mathrm{l} \mathrm{NaOH}$ & & & & 0 \\
\hline Zayed (1991) & E-glass & $\begin{array}{l}\text { Isophthalic } \\
\text { polyester }\end{array}$ & $\begin{array}{c}3.5 \mathrm{w} \% \mathrm{NaCl}+ \\
\text { saturated } \\
\mathrm{Ca}(\mathrm{OH})_{2} \text { solution } \\
\text { mixture }\end{array}$ & NA & 140 & 40 & 15 \\
\hline
\end{tabular}


Table 2.4 FRP bars under stressed condition in alkaline environments

\begin{tabular}{|c|c|c|c|c|c|c|c|c|}
\hline Author & Fiber & Resin & $\begin{array}{c}\text { Load } \\
\text { (\% of } \\
\text { ultimate } \\
\text { load) }\end{array}$ & Solution & $\mathrm{pH}$ & $\begin{array}{c}\text { Duration } \\
\text { (days) }\end{array}$ & $\begin{array}{c}\text { Temperature } \\
\left({ }^{0} \mathrm{C}\right)\end{array}$ & $\begin{array}{c}\text { Strength } \\
\text { reduction } \\
(\%)\end{array}$ \\
\hline $\begin{array}{c}\text { Nkurunziza et } \\
\text { al. (2003) }\end{array}$ & $\begin{array}{c}\text { E- } \\
\text { glass }\end{array}$ & $\begin{array}{l}\text { vinyl } \\
\text { ester }\end{array}$ & 40 & $\begin{array}{c}1185 \mathrm{~g} \\
\mathrm{Ca}(\mathrm{OH})_{2}+9 \mathrm{~g} \\
\mathrm{NaOH}+42 \mathrm{gKOH} \\
\text { in } 101 \text { water }\end{array}$ & 13.11 & 60 & $65.5-75.5$ & 11 \\
\hline \multirow{4}{*}{$\begin{array}{c}\text { Sen et al. } \\
(2002)\end{array}$} & \multirow{4}{*}{$\begin{array}{c}\text { E- } \\
\text { glass }\end{array}$} & \multirow{4}{*}{$\begin{array}{l}\text { Vinyl } \\
\text { ester }\end{array}$} & \multirow{4}{*}{10} & \multirow{4}{*}{$\begin{array}{c}10 \mathrm{~g} \\
\mathrm{Ca}(\mathrm{OH})_{2}+8.33 \mathrm{~g} \\
\mathrm{NaOH}+23.3 \mathrm{~g} \\
\mathrm{KOH} \text { in } 1 \mathrm{~L} \\
\text { water }\end{array}$} & \multirow{4}{*}{$\begin{array}{l}13.35- \\
13.55\end{array}$} & 30 & \multirow{4}{*}{ NA } & 60 \\
\hline & & & & & & 90 & & 72 \\
\hline & & & & & & 180 & & 69 \\
\hline & & & & & & 270 & & 70 \\
\hline \multirow{2}{*}{$\begin{array}{l}\text { Benmokrane } \\
\text { et al. (2002) }\end{array}$} & $\begin{array}{c}\text { E- } \\
\text { glass }\end{array}$ & \multirow{2}{*}{$\begin{array}{l}\text { Vinyl } \\
\text { ester }\end{array}$} & \multirow{2}{*}{30} & \multirow{2}{*}{$\begin{array}{c}118.5 \mathrm{~g} \\
\mathrm{Ca}(\mathrm{OH})_{2}+0.9 \mathrm{~g} \\
\mathrm{KOH} \text { in } 1 \mathrm{~L} \\
\text { water }\end{array}$} & \multirow{2}{*}{12.8} & \multirow{2}{*}{140} & \multirow{2}{*}{22} & 17 \\
\hline & $\begin{array}{l}\text { AR- } \\
\text { glass }\end{array}$ & & & & & & & 0 \\
\hline $\begin{array}{l}\text { Coomarasamy } \\
\text { and Ip (1998) }\end{array}$ & glass & $\begin{array}{l}\text { Vinyl } \\
\text { Ester }\end{array}$ & 15 & $\begin{array}{c}\text { saturated } \\
\mathrm{Ca}(\mathrm{OH})_{2}+0.2 \mathrm{M} \\
\mathrm{NaOH}+0.6 \mathrm{M} \\
\mathrm{KOH} \text { in } 1 \mathrm{~L} \\
\text { water }\end{array}$ & 13.5 & 49 & 60 & 46 \\
\hline
\end{tabular}

Note: $\mathrm{NA}=$ Not Available

\subsubsection{Durability of FRP Bars in Concrete}

For a realistic evaluation of the durability of FRP bars in concrete, specimens embedded in concrete have been studied by researchers.

Sekijima et al. (1999) conducted a durability study on prestressed GFRP reinforcements (grid) embedded in prestressed concrete beams. The beams were left outdoors for 7 to 8 years. Then the GFRP reinforcements were taken out from the beams. The results indicated that the residual tensile strength changed a little, the residual tensile 
rigidities did not change, the cross section of fibers remained circular, and they were not attacked by alkali of concrete.

Since the concrete pore solution of normal concrete could create a potentially damaging environment for GFRP reinforcement due to its high alkalinity, some special concrete with low-pH internal environments were used to reduce the degradation by researchers. Svecova et al. (2002) investigated durability of GFRP embedded in low heat high performance concrete (LHHPC), which has low cement content, consequently low alkalinity with a $\mathrm{pH}$ value of 9 . Their test results showed that the degradation of GFRP embedded LHHPC was found to be lesser than that in normal concrete, but it was still considered to be significant.

\subsubsection{Creep, Relaxation and Fatigue of FRP Bars}

A number of research works on creep, relaxation and fatigue of FRP bars have been carried out. Wolff and Miesseler (1989) tested the long-term static strength of Eglass/polyester tendons at 10,000 hours. The remaining strength was about $70 \%$ of the short-term static strength. Short-term relaxation tests were performed by Chaallal et al. (1992). A stress loss of 5\% was observed for bars with a diameter of $15.9 \mathrm{~mm}$ subjected to a stress of $70 \%$ of its ultimate strength for 2000 hours. They also conducted fatigue tests which showed that the GFRP bars withstood fewer cycles than steel bars, and the GFRP endurance limit for more than one million cycles was about $120 \mathrm{MPa}$. Saadatmanesh and Tannous (1999) reported an investigation on relaxation behavior of 72 CFRP tendons exposed to various chemical solutions and temperatures. After 3000 hour duration at stress ratios of 0.4 and 0.6 , the loss of tensile force was generally less than 10\%. Furthermore, 190 specimens were examined for tension-tension fatigue. Good 
fatigue behavior was found for stress range of 100 and $107 \mathrm{MPa}$. Most of the reported research work was directed to specific materials and conditions. Generally, fibers have much more resistance to creep than resins. The orientation and volume of fibers significantly affected the creep performance of FRP bars and tendons. For FRP composite, the property of creep relaxation is generally dominated by the resin matrix. Also, composites with incomplete cure were highly susceptible to significant creep and initiation of micro cracks (Karbhari et al. 2003). In general, CFRP bars are thought to be the least prone to fatigue, creep rupture and relaxation, followed by AFRP, and then GFRP bars (ACI 440, 2003).

\subsection{Bond of FRP Bars in Concrete}

Since FRP reinforcement is complicated in types, compositions and surface treatment, the bond of FRP reinforcement depends on more factors than for steel (Tepfers and Lorenzies, 2003). Numerous studies on bond of FRP bars have been conducted.

\subsubsection{Bond of FRP Bars}

Malvar et al. (2003) summarized the previous work on the bond of FRP bars (Table 2.5) and conducted an experimental study on the bond characteristics of four different types of CFRP bars with different surface deformations embedded in lightweight concrete. The experimental results showed that small surface indentations on the FRP bars were enough to yield bond strengths comparable to that of steel reinforcement. Also radial pressure was found to be an important factor which can increase the bond strength almost three fold for the range studied. Estimated development lengths were obtained for various CFRP bars. 


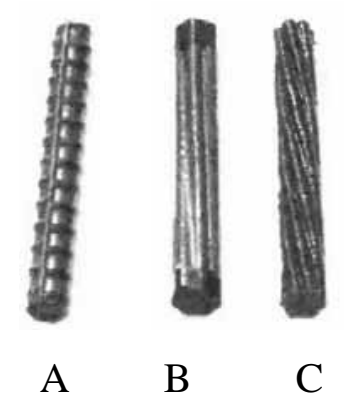

Figure 2.2 Bar types (Malvar et al., 2003)

Based on the experimental study described above by Malvar et al. (2003), Cox et al. (2003) proposed an elastoplastic bond model for bond of FRP reinforcement in concrete.

Table 2.5 Previous studies on bond of FRP bars (Malvar et. al. 2003)

\begin{tabular}{|c|c|c|c|c|c|c|c|c|}
\hline $\begin{array}{l}\text { Bar type } \\
\text { (Fig. 2.1) }\end{array}$ & Reference & $\begin{array}{c}\text { Bar } \\
\text { diameter } \\
\mathrm{mm}\end{array}$ & $\begin{array}{c}\text { Bar } \\
\text { stiffnes } \\
\text { GPa }\end{array}$ & $\begin{array}{c}\text { Bar } \\
\text { strength } \\
\mathrm{MPa}\end{array}$ & $\begin{array}{c}\text { Concrete } \\
\text { strength } \\
\mathrm{MPa}\end{array}$ & $\begin{array}{l}\text { Specimen } \\
\text { size } \mathrm{L} \times \mathrm{D} \text { or } \\
\mathrm{L} \times \mathrm{W} \times \mathrm{D}\end{array}$ & $\begin{array}{l}\text { Bond } \\
\text { strength } \\
\mathrm{MPa}\end{array}$ & $\begin{array}{c}\text { Bond } \\
\text { length }(\times \\
\text { bar } \\
\text { diameter }) \\
\end{array}$ \\
\hline A(GFRP) & $\begin{array}{l}\text { Cosenza et } \\
\text { al. (1999) }\end{array}$ & 12.7 & 42 & 770 & 39 & $127 \times 150 \times 150$ & 14.5 & $10^{*}$ \\
\hline $\mathrm{A}(\mathrm{GFRP})$ & $\begin{array}{c}\text { Shield et al. } \\
(1999)\end{array}$ & 15.9 & 42 & 427 & 29.7 & $381 \times 305 \times 457$ & 4.5 & $24^{*}$ \\
\hline $\mathrm{A}(\mathrm{GFRP})$ & $\begin{array}{c}\text { Nanni et al. } \\
(1997)\end{array}$ & 13 & 37.5 & 568 & 34.5 & $150 \times 150 \times 150$ & 17 & 2.5 and 5 \\
\hline $\mathrm{A}(\mathrm{GFRP})$ & $\begin{array}{l}\text { Rizkalla et } \\
\text { al. (1997) }\end{array}$ & 12 & 40.6 & 640 & 44.6 & -- & 21.3 & $15^{*}$ \\
\hline B & $\begin{array}{c}\text { Iyer and } \\
\text { Sivakumar } \\
(1994)\end{array}$ & 12.7 & -- & 1860 & -- & -- & -- & -- \\
\hline $\mathrm{C}$ & $\begin{array}{c}\text { Benmokrane } \\
\text { and } \\
\text { Chennouf } \\
(1997)\end{array}$ & 7.3 & 140 & 2218 & 61.6 & $150 \times 57$ & 6.21 & 13.7 \\
\hline $\mathrm{C}$ & $\begin{array}{l}\text { Tepfers et } \\
\text { al. (1992) }\end{array}$ & 12.5 & 137 & 1765 & 47.3 & $48 \times 115$ & 9.5 & 3.8 \\
\hline $\mathrm{C}$ & $\begin{array}{l}\text { Tepfers et } \\
\text { al. (1992) }\end{array}$ & 12.5 & 137 & 1765 & 44.4 & $200 \times 200 \times 200$ & 13 & 3.6 \\
\hline $\mathrm{C}$ & $\begin{array}{c}\text { Tokyo Rope } \\
\text { (1989) }\end{array}$ & 12.5 & 137 & 1158 & 47.6 & $150 \times 100 \times 100$ & 7.23 & 12 \\
\hline Any & $\begin{array}{l}\text { Sonobe et } \\
\text { al. (1997) }\end{array}$ & -- & -- & -- & -- & $100 \times 100 \times 100$ & -- & $23^{*}$ \\
\hline
\end{tabular}

*Development length 


\subsubsection{Durability of Bond in Concrete}

The continued integrity of bond is also critical for the long-lasting behavior of concrete structures reinforced with FRP bars. Research has been carried out to investigate the durability performance of bond of FRP bars.

Sustained load and alkaline environment were believed to be deleterious to the bond of FRP and concrete. But experimental results showed that sustained load does not accelerate the degradation of bond. Also, cyclic loading did not cause significant degradation of bond, either (Bakis et al., 1998a). The reason is that since concrete and FRP matrix resin are sensitive to creep, the interphase region of FRP and concrete will be changed in geometry due to sustained load, which consequently redistributes the local stresses and strengthens the FRP/concrete bond (Nanni et al., 1998). But experimental results by Katz et al. (1998) showed a 50\% loss of bond strength of GFRP/concrete due to 450,000 load cycles at service stress level. They explained the bond loss due to the delamination of external layer from the core of GFRP bars.

Experimental results also showed that freeze-thaw cyclic condition did not cause significant degradation of bond strength of GFRP/concrete and CFRP/concrete, but in the case of AFRP, a gradual reduction of bond strength was observed (Mashima and Iwamoto, 1993). Temperature and temperature cycling did not affect the bond strength of AFRP/concrete and CFRP/concrete. But for GFRP/concrete, a significant loss of strength was observed when the temperature reached beyond $40^{\circ} \mathrm{C}$ (Kanda et al., 1993). In another study (Katz et al., 1998), at a temperature of $100^{\circ} \mathrm{C}$, a reduction of $25-40 \%$ of bond strength of GFRP/concrete was observed, which was also seen in case of deformed steel bars. But at higher temperature, the reduction rate of bond strength is probably 
determined by the properties of matrix of GFRP bars. The bond of FRP reinforcement will be affected by the thermal expansion difference in the transverse direction between FRP and concrete. A loss of bond due to bursting stresses caused by transverse thermal expansion of GFRP at high temperature was observed in experiments (El-Badry and Abdalla, 1998).

The effects of combined wet/dry and thermal cycles on FRP/concrete bond were also investigated (Sen, 2003), by subjecting to this combined exposure AFRP and CFRP prestressed concrete specimens. Severe splitting bond cracks were observed in the case of AFRP. No similar cracking was observed in CFRP prestressed beams though some evidences of bond degradation were found during testing. The experimental results showed two possible reasons for deterioration: (1) mismatch in transverse thermal expansion coefficients; (2) moisture absorption by the epoxy resin (AFRP and CFRP) and fibers (AFRP). The finite element analysis indicated that moisture absorption had been the more critical parameter.

Bank et al. (1998) reported a research study on the effects of material degradation of FRP reinforcing bars on FRP/concrete bond strength and stiffness properties. The results showed good correlations between FRP material degradation and reduction in strength and stiffness of FRP/concrete bond. The model identified the resin matrix as the key parameter in the degradation of the bond properties.

Porter and Barnes (1998) found that the bond strength of GFRP reinforcement in concrete did not decrease for GFRP embedded in concrete, which were then conditioned under moisture and subjected to pullout tests. Possible explanations for this unexpected results is that the bars swelled after conditioning, and consequently, the frictional 
component of bond increase, or the degradation was slower than expected due to limited available aggressive pore solution within the bond interface (Al-Dulajian et al., 2001).

Some researchers studied the effects of preconditioning of GFRP bars, before being embedded in concrete, on the bond of FRP/concrete. The ultimate bond strength of preconditioned FRP bars even increased. Possible explanations are the rougher surface of FRP after conditioning or quicker/larger transverse expansion of FRP with moisture absorption when embedded in concrete.

But some experimental results showed that preconditioning GFRP before embedment into concrete pullout type specimens was more deleterious to the bond than conditioning the specimens after embedment (Al-Dulajian et al. 2001). Test results showed that in the case of smooth rods, the bond strength changed little, but significant reduction in bond strength due to degradation of the resin or fiber/matrix interface were observed in case of lugged FRP rods.

\subsection{Accelerated Test Methods}

Since long-term (75 to 100 years) performance data of FRP materials in civil engineering constructions are not available, accelerated tests are generally used to predict how durable FRP materials are in practice. The accelerated test shortens the duration of degradation by accelerating factors (e.g. temperature, load, and solution concentration) and uses the short-term measurements to predict the long-term behavior or service lifetime. 


\subsubsection{General Procedure}

ASTM E 632 has developed a framework for accelerated tests on materials. But only a general philosophy for conducting accelerated tests is provided. To develop an accelerated test program, it is important to note that degradation in accelerated tests must replicate those that occur in real-time and long-term applications.

The general procedures for accelerated testing of FRP materials can be summarized as following:

1) To identify material properties of interest;

2) To identify environmental degradation factors which affect these properties, and to identify the dominated degradation mechanism which is introduced by those factors and results in significant losses of material properties of interest;

3) To choose accelerating factors to speed up the effects of those environmental degradation factors. Typical acceleration factors are: temperature, humidity, high concentration of chemical environments, mechanical load and voltage;

4) To conduct accelerated tests with the chosen environmental degradation factors and acceleration factors;

5) To employ statistical or analytical models to predict long-term and real-time properties from the results obtained in the accelerated test.

6) To collect long-term data in real conditions to validate and/or modify the prediction models.

In recent years attempts have been made to develop an integrated chemical and mechanical test method. So the mechanism of degradation within FRP can be understood. Researches have attempted to relate the change of mechanical properties to the 
quantitative changes in the chemical compositions and microstructure of materials (Bank et al., 1995).

\subsubsection{Arrhenius Model}

In order to predict the long term behavior or service life-time of materials from results of accelerated tests, statistical or analytical models have been employed. There are various different models proposed in published literature. For example, Burgoyne and Guimaraes (1996) proposed a tentative statistical model based on molecular theory for lifetime prediction of parallel-lay Aramid ropes. Rostasy and Scheibe (1999) also proposed an engineering model for forecasting stress rupture strength of stressed AFRP bars embedded in concrete. The model was based on linear-elastic fracture mechanics and verified by their experiments. But presently there are no models which can take into account all degradation mechanisms and accurately predict the long-term behaviors. Among existing models, Arrhenius models and those based on Arrhenius concept are the most popular to model the degradation mechanism as a function of temperature (Gonenc, 2003). The methodology was originally developed for gases in which chemical reactions were observed to proceed more rapidly at higher temperatures than at lower ones. It uses high-temperature incubation of test specimens in order to accelerate degradation. Then the natural aging behavior of the specimens, at a site-specific lower temperature, is extrapolated from accelerated degradation data (Iskander et al., 2002). Arrhenius equation takes the form:

$$
k=A \exp \left(\frac{-E_{a}}{R T}\right)
$$

where: 
$\mathrm{k}$ : the Arrhenius degradation rate;

$E_{\mathrm{a}}$ : the activation energy of the chemical reaction;

$\mathrm{R}$ : universal gas constant $(8.3145 \mathrm{~J} / \mathrm{K} / \mathrm{mol})$.

T: temperature measured in degrees Kelvin.

A: a constant of the test conditions.

Litherland et al. (1981) used the Arrhenius model to predict the strength retention of glass fiber-reinforced cement (GRC) from an accelerated aging procedure. Their work was the most notable application of Arrhenius concept to civil engineering materials and has served as the primary example for other researchers to follow. Based on research conducted by Pilkington Brothers LTD and Iowa State University (ISU), a relation between the bath temperature (the temperature used in accelerated aging) and the number of estimated natural aging days per day in the bath was developed as (Litherland et al., 1981, Aindow et al., 1984 and Porter, 1999):

$$
\frac{N}{C}=0.183 e^{0.052(T)}
$$

where:

$\mathrm{N}$ : the predicted age in natural days;

$\mathrm{C}$ : the number of exposure days in bath at temperature of $\mathrm{T}\left({ }^{0} \mathrm{~F}\right)$.

Equation 2.8 is for the United Kingdom climate with a mean annual temperature (MAT) of $50.72{ }^{0} \mathrm{~F}\left(10.4{ }^{0} \mathrm{C}\right)$. But in order to make comparisons with data from other climates (Aindow et al., 1984) or predict aging days in other climates, an acceleration factor based on MAT was proposed as:

$$
A F=2.986 \times 10^{-19} \times e^{13.783 \mathrm{X}}
$$

The term " $\mathrm{X}$ " in equation 2.9 is calculated from $\left(\mathrm{MAT}^{0} \mathrm{C}=\left(\mathrm{MAT}^{0} \mathrm{~F}-32\right) / 1.8\right)$ : 


$$
X=\frac{1000}{50^{0} C+\left(M A T-10.4^{0} C\right)+273}
$$

For example, for Ames, Iowa with a MAT of $49.77{ }^{0} \mathrm{~F}$, the $A F=1.09$, and equation 2.10 becomes:

$$
\frac{N}{C}=A F \times 0.183 e^{0.052(T)}=0.20 e^{0.052(T)}
$$

A specification for accelerated-testing procedure to predict the service life of FRP materials was proposed by Gentry et al. (2002). The procedure also used the Arrhenius temperature dependence relationship along with moisture and elevated temperature. The procedure requires the conditioning of coupons at a minimum of 4 elevated temperatures (the maximum temperature is $0.8 \mathrm{~T}_{\mathrm{g}}$ ) in deionized water for duration of $28,56,112,224$ days. Retention of tensile strength and short beam shear strength were obtained after exposure. Then Arrhenius relationship plots were used to predict the long-term behavior of materials.

\subsubsection{Diffusion Models}

Usually the FRP materials will be subjected to low stress level, so the degradation of FRP materials will be diffusion dominated in most cases. To simulate the diffusion phenomenon, two general models have been employed to characterize the chemical diffusion through resin matrix. Single free-phase and Langmuir two-phase are two fundamental diffusion models which are based on Fick's Law (Crank, 1975). Fick's Law defines that the driving force for diffusion is the concentration gradient of the absorbent. As far as the tensile strength of composite bars and tendons are concerned, these two models (based on Fick's law of diffusion) were employed to predict the losses of tensile strength (Katsuki and Uomoto, 1995, Saadatmanesh and Tannous, 1998, and Tannous 
and Saadatmanesh, 1998 and 1999). Two assumptions are made in their studies: (1) the matrix and fibers in the depth of the damaged zone " $\mathrm{x}$ " $(\mathrm{mm})$ are ineffective in transferring tensile forces; (2) the tensile strength of undamaged zone (the inner zone without diffused chemicals) is the same as that of bars before exposure. The damaged zone depth " $x$ " (as shown in Fig 2.3) due to the diffusion of hydroxyl $\left(\mathrm{OH}^{-}\right)$and chloride $\left(\mathrm{Cl}^{-}\right)$free ions in solutions is calculated as follows:

$$
x=\sqrt{2 \times D \times C \times t}
$$

where,

C: the hydroxyl and chloride concentration;

t: the elapsed time;

D: the mass diffusion coefficient, $D=D_{0} \times \exp \left(\frac{\Delta H}{R T}\right)$;

$\Delta \mathrm{H}$ : the activation energy of diffusion;

$\mathrm{R}$ : universal gas constant $(8.3145 \mathrm{~J} / \mathrm{K} / \mathrm{mol})$.

$\mathrm{T}$ : temperature measured in degrees Kelvin.

Then the residual tensile strength of bars or tendons can be predicted from:

$$
P_{p}=P_{u}\left(1-\frac{x}{R_{0}}\right)^{2}=P_{u}\left(\frac{R_{r}}{R_{0}}\right)^{2}
$$

where:

$\mathrm{P}_{p}$ : the predicted residual tensile strength;

$\mathrm{P}_{\mathrm{u}}:$ the initial tensile strength;

$\mathrm{R}_{0}$ : the intial radius of specimen;

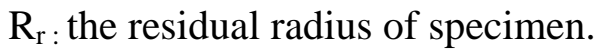


In most cases, the diffusion coefficient, $\mathrm{D}$, is obtained through the measure of moisture absorption and Fick's law. Arrhenius equation can also be applied to the diffusion coefficient.
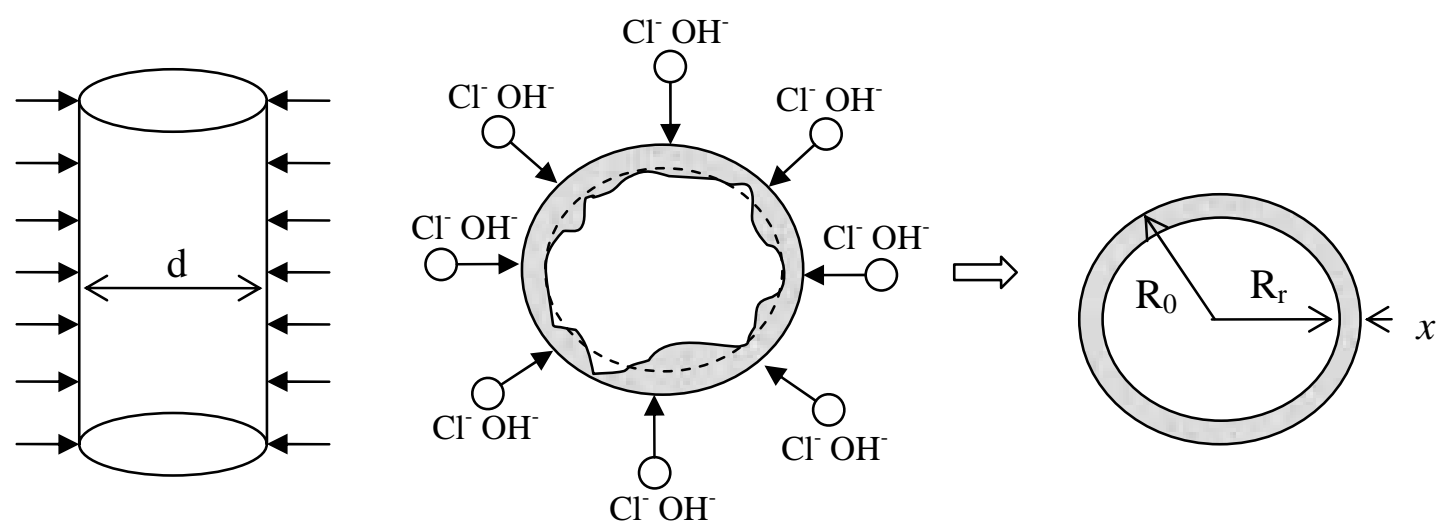

Figure 2.3 Diffusion of free ions into FRP bars

(Adapted from Tannous and Saadatmanesh, 1999) 


\section{CHAPTER THREE \\ DURABILITY OF FRP BARS IN SIMULATED ENVIRONMENTS}

This chapter describes a durability study of FRP bars in simulated environments. First, the selection of FRP specimens is discussed, and then the simulation of various field conditions is presented. Durability indicators and corresponding test methods are also described. Finally, the test results are discussed and recommendations for further study are made.

\subsection{Materials}

In this study, GFRP bars are primarily selected and CFRP bars are also selected for comparison purpose. According to the literature review, it can be found that GFRP bars are the most widely used in civil applications due to their relatively low cost. CFRP bars are also often used but their cost is high, while applications of AFRP are rarely found. Moreover, CFRP bars showed excellent durability performance in most cases, while severe degradations of GFRP bars have been found according to short term data. It has been found that GFRP bars made of E-glass fibers and vinyl ester matrix are the most often used due to their good durability performance, while those with polyester matrix are not recommended by researchers for concrete structures due to the inferior durability performance of polyester matrix.

Several companies were contacted to procure the FRP bars for this research such as Hughes Brothers Inc., Polygon, Autocon Composites and others. Finally, Hughes 
Brothers, Inc. was selected on the basis of their reputation and wide applications of their products in industry and research as reported in various publications. In this study, two types of GFRP bars made of E-glass fibers and vinyl ester matrix and one type of CFRP bars made of carbon fibers and epoxy matrix are selected as shown in Table 3.1. In Table 3.1, GFRP1 bar and CFRP bar are commercially available products, while GFRP2 bar is a new product and still in the experimental stage.

Table 3.1 Material aspects of FRP bar specimens

\begin{tabular}{cccccc}
\hline Bar type & Fiber type & Resin type & Brand name & Bar size & Diameter $(\mathrm{mm})$ \\
\hline GFRP1 & E-glass & Vinyl ester & Aslan 100 & $\# 3$ & 9.53 \\
GFRP1 & E-glass & Vinyl ester & Aslan 100 & $\# 4$ & 12.7 \\
GFRP2 & E2-glass & Vinyl ester & N/A & $\# 3$ & 9.53 \\
CFRP & Carbon & Epoxy & Aslan 200 & $\# 3$ & 9 \\
\hline
\end{tabular}

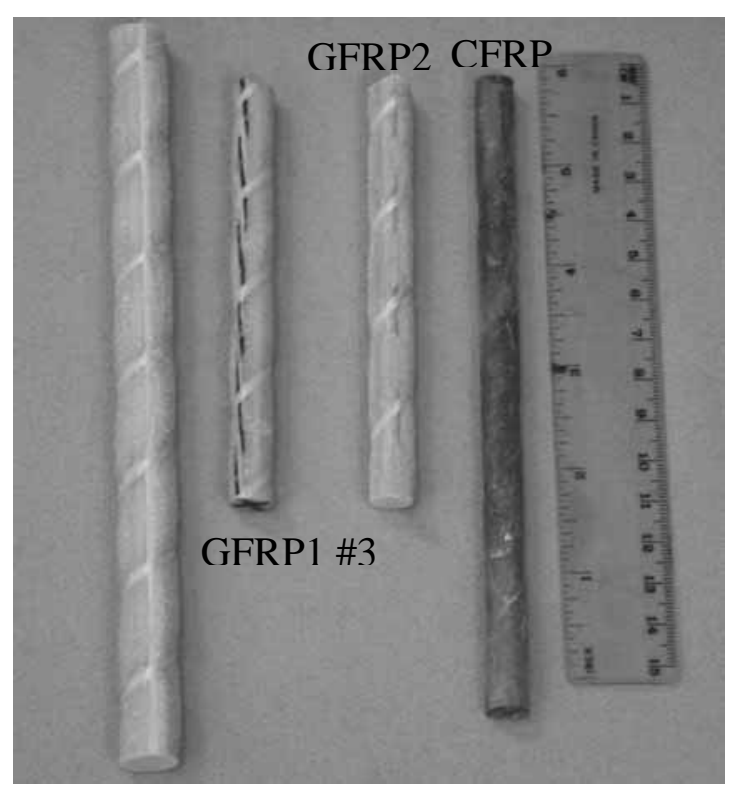

GFRP1 \#4

Figure 3.1 FRP bars 
Both GFRP1 and GFRP2 bars were helically wrapped and slightly sand coated as shown in Fig. 3.1. The surface of CFRP bars is roughened to obtain sand-blasted deformations. All these FRP bars were produced by pultrusion, which is the most popular production procedure for FRP bars and suitable for mass production.

\subsection{Environmental Conditioning}

In this section, the environmental conditions to which FRP bars may be subjected to are discussed and the corresponding simulated environments are presented.

\subsubsection{Simulated Environments}

Due to the versatile applications of concrete in different construction fields, FRP reinforced concrete structures may often be exposed to wetting and drying (WD) cycles, sea-salts in hot-humid climates, freezing and thawing (FT) conditions, deicing salts in cold climates, and many other severe environments. In addition to the above external conditions, GFRP bars, which are extensively used in civil engineering structures due to their low cost, are also readily attacked by concrete pore solutions having $\mathrm{pH}$ values of 12.4 to 13.7 (Diamond, 1981 and Anderson et al., 1989).

Moreover, it has been shown in many researches that the degradation is not merely due to the high $\mathrm{pH}$ levels, but combinations of hydroxylation, hydrolysis, and leaching owing to the presence of moisture, high $\mathrm{pH}, \mathrm{Na}^{+}$and $\mathrm{K}^{+}$ions (Shi et al., 1998 and Gowripalan and Mohamed, 1998). With the increasing use of high performance concrete (HPC), the pore solution of HPC is also simulated using the alkaline solutions. There are no standard test methods for the durability of FRP bars in those various conditions. In this study, five different solutions were simulated for various field conditions (Table 3.2): 
(1) Solution 1 was tap water to simulate high humidity. Tap water was chosen as a reference environment which can determine the extent to which the deterioration is caused by the presence of alkaline solution and water respectively at different temperatures.

(2) Solution 2 was made of sodium hydroxide $(\mathrm{NaOH})$, potassium hydroxide $(\mathrm{KOH})$, and calcium hydroxide $\left(\mathrm{Ca}(\mathrm{OH})_{2}\right)$ with a $\mathrm{pH}$ value of about 13.7 . Solution 2 is intended to simulate the concrete pore solution of normal concrete (NC).

(3) Solution 3 was a solution of sodium hydroxide, potassium hydroxide and calcium hydroxide with a $\mathrm{pH}$ value of about 12.7. Solution 3 is intended to simulate the concrete pore solution of HPC with supplementary mineral admixtures such as fly ash and silica fume.

(4) Solution 4 was a solution of sodium chloride $(\mathrm{NaCl})$ and sodium sulfate $\left(\mathrm{Na}_{2} \mathrm{SO}_{4}\right)$. This solution follows ASTM D1141 (Standard Specification for Substitute Ocean Water) to simulate ocean water.

(5) Solution 5 was a solution of sodium chloride $(\mathrm{NaCl})$ and potassium hydroxide $(\mathrm{KOH})$ with a $\mathrm{pH}$ value of about 13 . This solution with chloride concentration $\left(\mathrm{Cl}^{-}\right)$of $1.23 \mathrm{~mol} / \mathrm{L}$ is to simulate concrete pore solution with chloride from deicing salts (Tannous and Saadatmanesh, 1998).

Table 3.2 Compositions of Solutions 2 through 5

\begin{tabular}{cccccc}
\hline \multirow{2}{*}{ Solution No. } & \multicolumn{5}{c}{ Quantities in g/L (mol/L) } \\
\cline { 2 - 6 } & $\mathrm{NaOH}$ & $\mathrm{KOH}$ & $\mathrm{Ca}(\mathrm{OH})_{2}$ & $\mathrm{NaCl}$ & $\mathrm{Na}_{2} \mathrm{SO}_{4}$ \\
\hline Solution 2 & $2.4(0.06)$ & $19.6(0.35)$ & $2(0.027)$ & - & - \\
Solution 3 & $0.6(0.015)$ & $1.4(0.025)$ & $0.037(0.005)$ & - & - \\
Solution 4 & - & - & - & 30 & 5 \\
Solution 5 & - & $5.6(0.1)$ & - & $71.66(1.23)$ & - \\
\hline
\end{tabular}


In addition to simulated solutions, wetting and drying or freezing and thawing conditionings were used to simulate the field conditions of humidity and temperature fluctuations. In this study, one wetting and drying (WT) cycle included four day immersion at $60^{\circ} \mathrm{C}$ and four day dry condition at $20^{\circ} \mathrm{C}$. The number of cycles for this study was 9 (a total of 72 days). One freezing and thawing cycle included 30-minutes soak at $20^{\circ} \mathrm{C}, 90$-minutes ramp from 20 to $-20^{\circ} \mathrm{C}, 30$-minutes soak at $-20^{\circ} \mathrm{C}$ and, 90minutes ramp from -20 to $20^{\circ} \mathrm{C}$. A typical freezing and thawing (FT) cycle is schematically shown in Fig. 3.2. FT cycles were achieved using digital controlled and programmable environmental chambers (CSZ ZH-16) as shown in Fig. 3.3.

Freezing-thawing Cycle

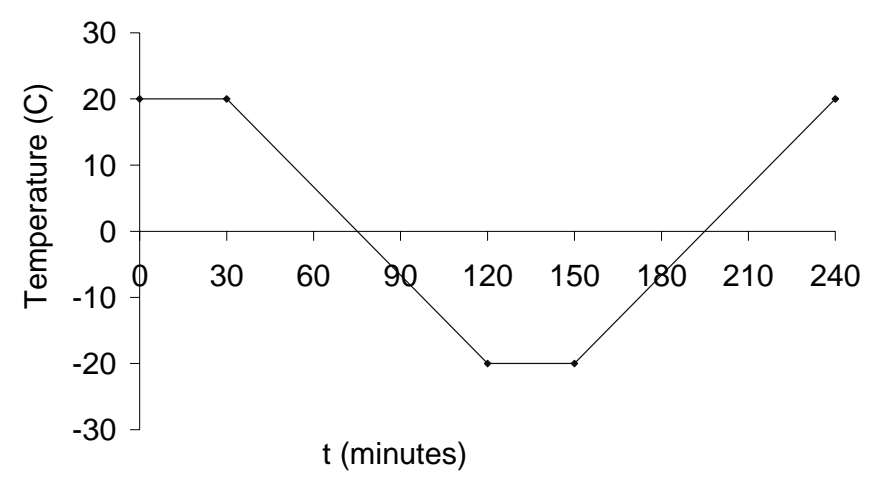

Figure 3.2 One freezing and thawing cycle
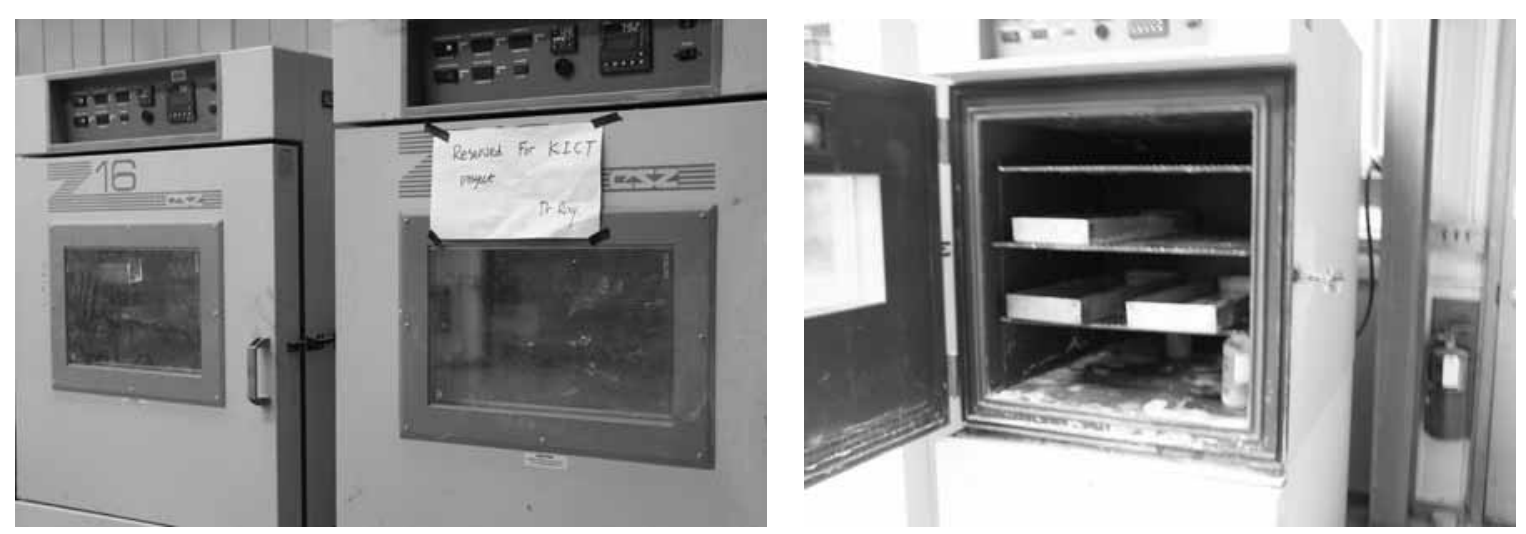

Figure 3.3 CSZ ZH-16 environmental chambers for freezing and thawing cycles. 


\subsubsection{Accelerated Test Method}

In addition to the simulated environments, elevated temperatures were also adopted to accelerate the environmental attack on FRP bars in order to save cost and time of the durability study.

Accelerated test methods have been widely used in the durability study of composite materials. The accelerated tests shorten the duration of the exposure but exacerbate the degradation by some accelerating factors. Since the rate of deterioration of FRP materials depends on the diffusion and chemical reaction according to the discussion of chapter two, and it is well known that elevated temperatures will accelerate the diffusion and chemical reaction, it is reasonable to use elevated temperature as the accelerating factor. But high temperature may introduce degradation mechanisms that FRP bars in field conditions may not undergo. According to the literature review, the temperatures of $60^{\circ} \mathrm{C}$ and $40^{\circ} \mathrm{C}$ were adopted as the elevated temperatures for the exposure. Those temperatures are well below the Tg of both vinyl ester and epoxy, which are usually above $100{ }^{\circ} \mathrm{C}$.

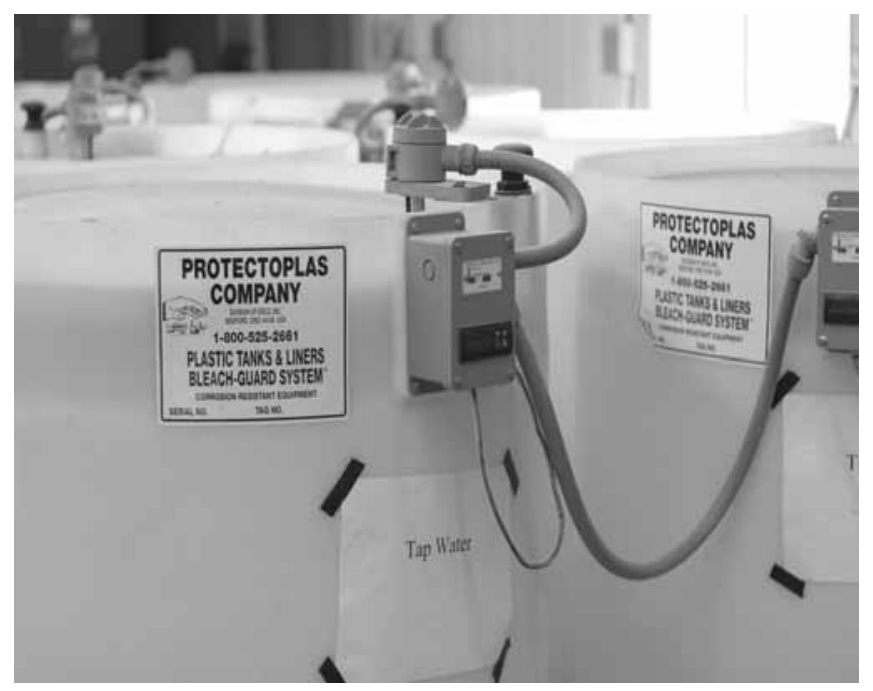

(a) Digital temperature control

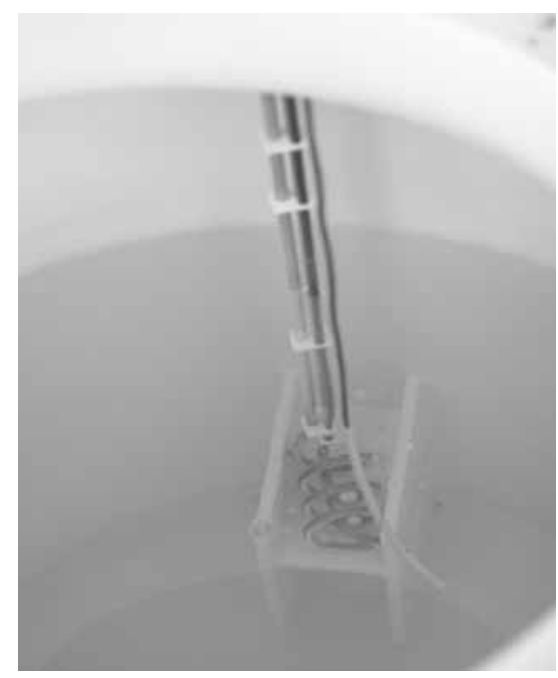

(b) Teflon coated immersion heater

Figure 3.4 Temperature controlled tank 
As shown in Fig. 3.4, eight temperature controlled tanks were custom designed for specimens exposed to solutions at elevated temperatures. Each of the $380 \mathrm{~L}$ capacity double walled temperature controlled tanks was made of one piece molded high density polyethylene. Each tank included a Teflon coated immersion heater (500 watts/120 V) with riser/junction box and digital temperature control with $+/-$ one ${ }^{0} \mathrm{~F}$ accuracy. The controls have programmable high set point, sensor short and break protection and security code restricted menus. Polypropylene heavy-wall tanks with diameter of $0.6 \mathrm{~m}$ and overall height of $1.2 \mathrm{~m}$ were used for the exposure at room temperature.

\subsection{Durability Indicators}

To evaluate the durability performance of FRP bars in this study, unconditioned and conditioned specimens were tested for tensile strength, interlaminar shear strength (ILSS) and bond strength between the FRP bar-concrete interface. The changes of those properties are considered as indicators of the durability performance. The above mechanical properties have been selected on the basis of the following considerations. FRP bars embedded in concrete should meet two basic requirements: 1) the flexural tensile strength must be enough to carry the desired tensile force; 2) the bond strength between FRP bar and concrete must be sufficient to transfer the load. The ILSS, which is greatly influenced by the polymer matrix and fiber/matrix interphase, is considered to be closely related to the bond strength between FRP bar and concrete. The ILSS is not usually used for design purpose; however it can be used for quality control, specification and comparison purposes. All these properties are critical for the successful application of FRP bars as reinforcement in concrete structures. Also, degradations of these properties have been readily observed according to the literature review. 
At the initial stage of the research project, the flexural strength was also considered as a possible indicator of the durability performance of FRP bars. But the flexural strength test was not carried out in further due to the inconsistency of the test results as discussed later. Since the modulus of elasticity of FRP bars did not change noticeably after exposures according to the literature, the test of modulus elasticity is not included in the present durability study. The durability study of FRP-concrete bond will be presented in chapter six.

\subsubsection{Tensile Test Method}

The test methods for tensile properties of FRP bars can be found in ASTM D3916, JSCE-E-531 (JSCE, 1997), CSA-S806-C (CSA-S806, 2002), and ACI 440 B.2 (ACI 440, 2004). It can be found from these standard test methods that as long as the ratio of gauge length/diameter is larger than 40 , there is no obvious effect of the gauge length on the tensile strength of the bar.

Due to the low transverse strength of FRP bars and tendons, the traditional grip for tension test of FRP bars will lead to localized premature failure within the grip zone. So in ASTM D 3916, an aluminum-alloy grip adapter is defined to avoid the high lateral compressive force in the grip region. The tensile load is mainly transferred through friction. But some published literature showed that the gripping system proposed by ASTM D 3916 was extremely difficult to adopt in many cases where the lateral rupture strength is relatively lower and the tensile strength is high. To avoid the high lateral compressive force in the grip region, a variety of grip systems have been used by researchers. The basic idea of those grips is to embed the ends of a bar into tubes, filling 
the tube with resins or mortar and transmitting the tensile force by means of shear stress in the matrix.

Considering the large amount of GFRP bars tested in this study, the following simple and inexpensive gripping system was designed. A 200-mm long steel pipe with internal diameter equal to that of FRP bar was cut lengthwise into two halves as shown in Fig. 3.5. The inner surfaces of the split pipe were coated with epoxy (as shown in Fig. 3.6). Then the split pipes were attached to the ends of FRP bars with hose clamps as shown in Fig. 3.7. Once the epoxy was cured, the tensile tests were carried out by gripping the steel pipe within the wedges of the testing machine as shown in Fig. 3.8. Due to the high tensile strength of CFRP bar, a number of commercial epoxy products were tried before the Wabo ${ }^{\circledR}$ MBrace Saturant was selected.

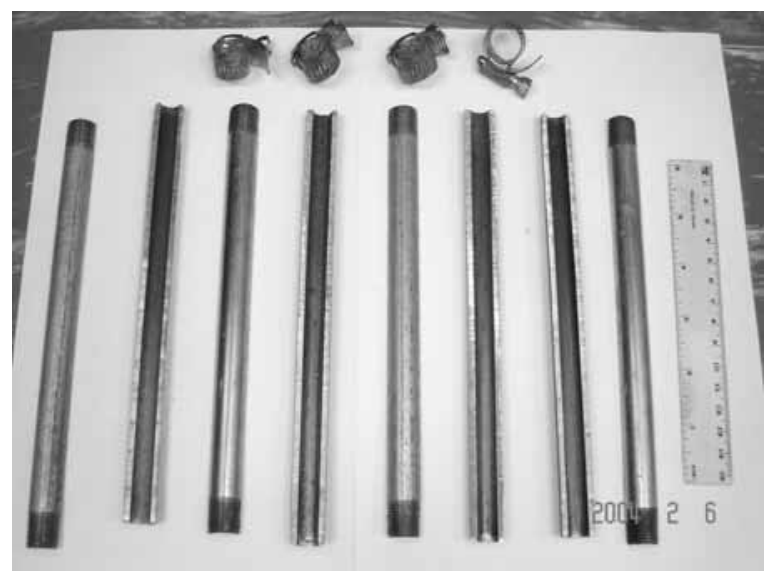

Figure 3.5 Split steel pipes and hose clamps

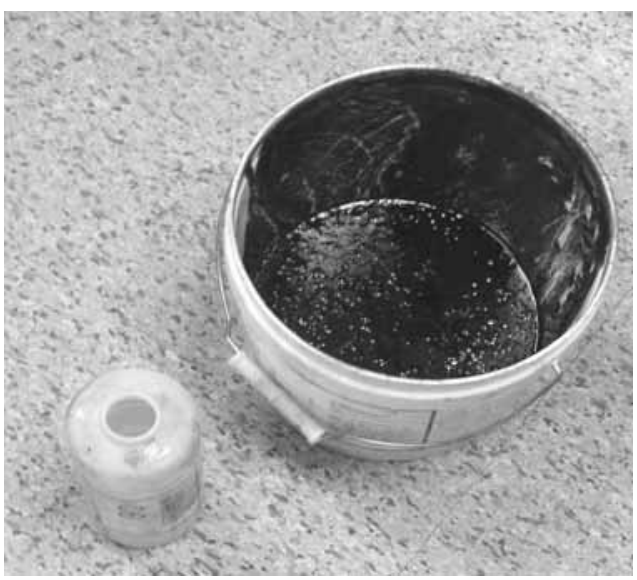

Figure 3.6 Wabo ${ }^{\circledR} \mathrm{MBrace}$ Saturant Epoxy 


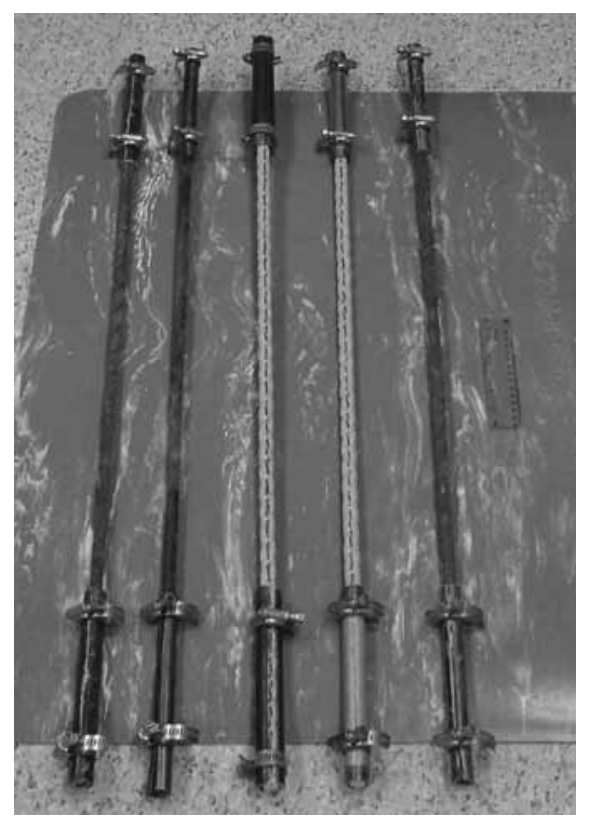

Figure 3.7 FRP bars with split steel pipes clamped on both ends
Steel pipes at the end of FRP bar

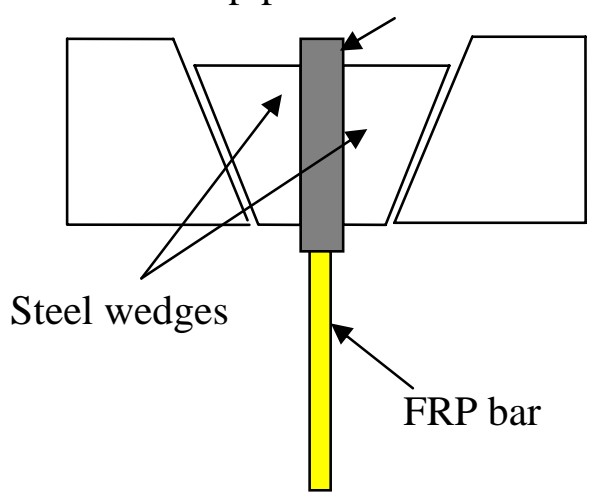

Figure 3.8 Sketch illustrating the gripping of steel pipe

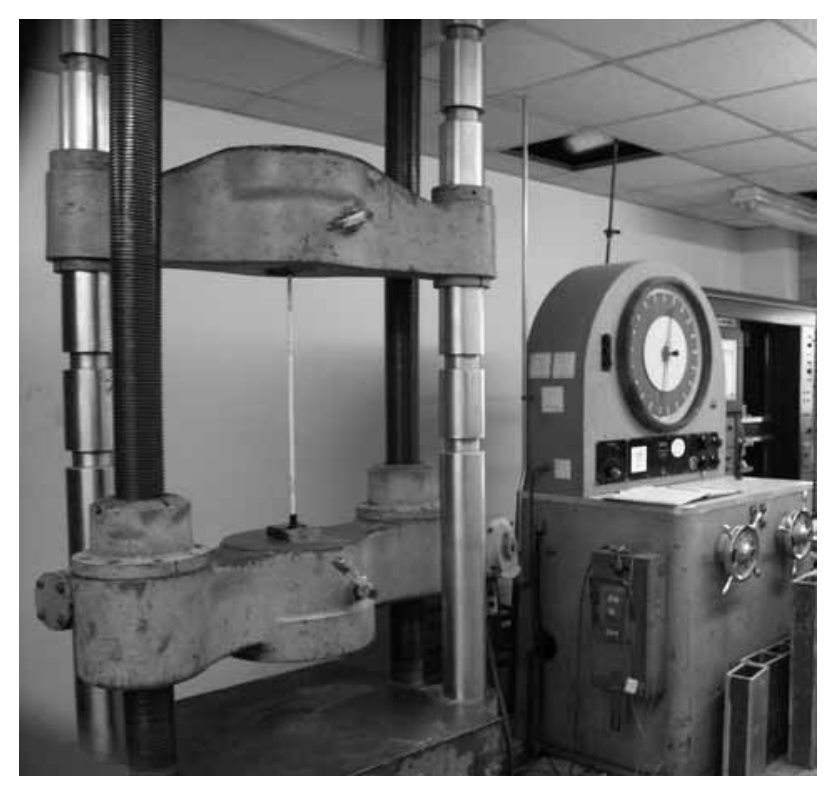

Figure 3.9 Experimental setup for tensile strength test

In this study, the test procedure followed ASTM D3916 with necessary modifications. The tests were carried out on a Baldwin Testing Machine as shown in Fig. 3.9. The loading time for the test was about 2 to 4 minutes for GFRP bars and 5 to 7 minutes for CFRP bars. 


\subsubsection{Short Beam Test}

The short beam test of FRP bars were conducted per ASTM D 4475. The objectives of the test were to determine the ILSS of FRP bars, which is dominated by the polymer matrix and fiber/matrix interphase.

The short beam tests were carried out using an 810 Material Testing System (MTS). The experimental setup for the short beam test is shown in Fig 3.10. Each specimen was aligned so that the midpoint was centered and the long axis was perpendicular to the loading nose. The loading rate for the test was $1.3 \mathrm{~mm}(0.05 \mathrm{in}.) / \mathrm{min}$. The load and movement of the loading head were recorded by a StrainSmart data acquisition system.

According to ASTM D 4475, the ratio of span/diameter could be 3, 4, 5 or 6 . But in order to achieve the shear mode of failure, the ratio of 4 was selected in this study. Larger span/diameter may result in bending failure while less span/diameter could result in crushing failure at load points and then splitting. Initially the span/diameter ratio of 3 was used. But many specimens failed in splitting beginning from the loading point during the test as shown in Fig. 3.11. The splitting failure mode was also observed in Micelli and Nanni (2004) due to the short span they chose. When the span/diameter ratio of 4 was adopted, most specimens failed in shear mode as shown in Fig.3.12. 


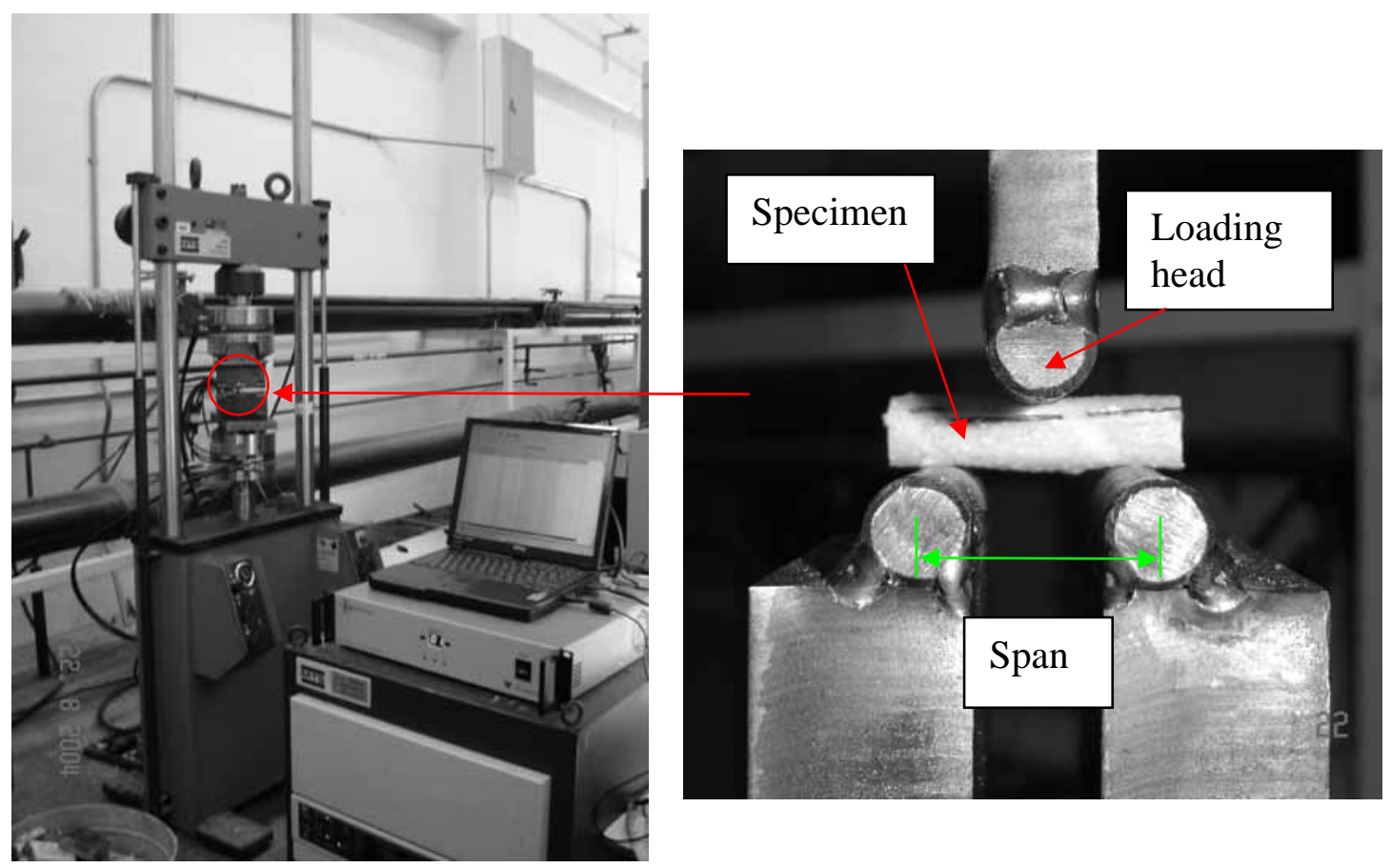

Figure 3.10 Experimental setup for short beam test

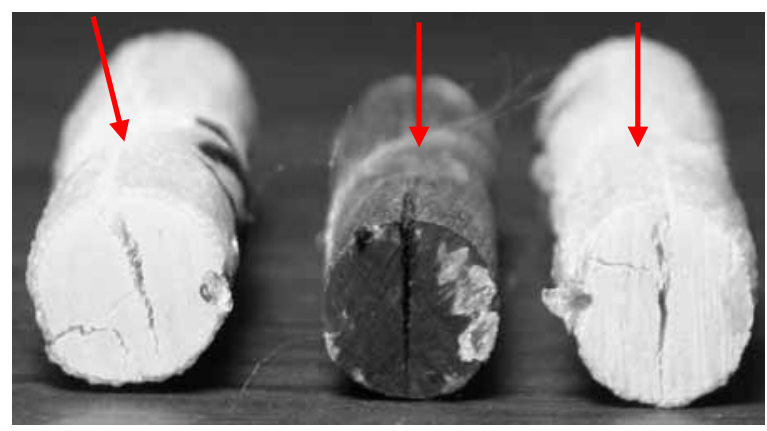

Figure 3.11 The typical splitting failure (the arrows are the loading directions)

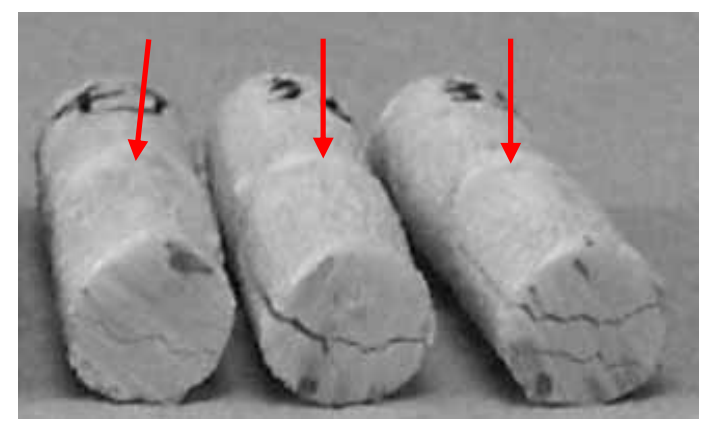

Figure 3.12 The typical shear failure (the arrows are the loading directions)

\subsubsection{Flexural Strength Test}

At the initial stage of the research project, the flexural strengths of FRP bars were also tested. The flexural strength test of FRP bars was conducted per ASTM D 4476. The objective of the test was to determine the flexural properties of FRP bars. The semicircular cross section specimens were used to eliminate the premature crushing of compression area noted in three point flexure tests on full round bars. In this study, the 
GFRP1 (bar size \# 4) bars were cut lengthwise into two halves so that the cross section of each half is smaller than a half-round section. The length of the specimen was $127 \mathrm{~mm}$ and the span was $101.6 \mathrm{~mm}$. The experiment setup is shown in Fig. 3.13. The flexural strength test was performed with an MTS machine. The loading rate was $3 \mathrm{~mm} / \mathrm{min}$. The load and movement of loading head were recorded by a StrainSmart data acquisition system.

The failure modes of flexural strength test are shown in Fig. 3.14. The results of the flexural strength test were not consistent mainly due to the following reasons: (1) different failure modes: as shown in Fig. 3.14, some specimens fail due to the rupture of fiber in the tension area; some specimens fail to the crushing of compression directly under the loading head; (2) different depths of specimens: the depth of the semi-circular cross section specimen was difficult to control because the surface of the specimen was helically wrapped and slightly sand coated. Also cutting of bars with a saw into semicircular shapes introduced errors in depths of specimens, which could affect the real flexural strength significantly.

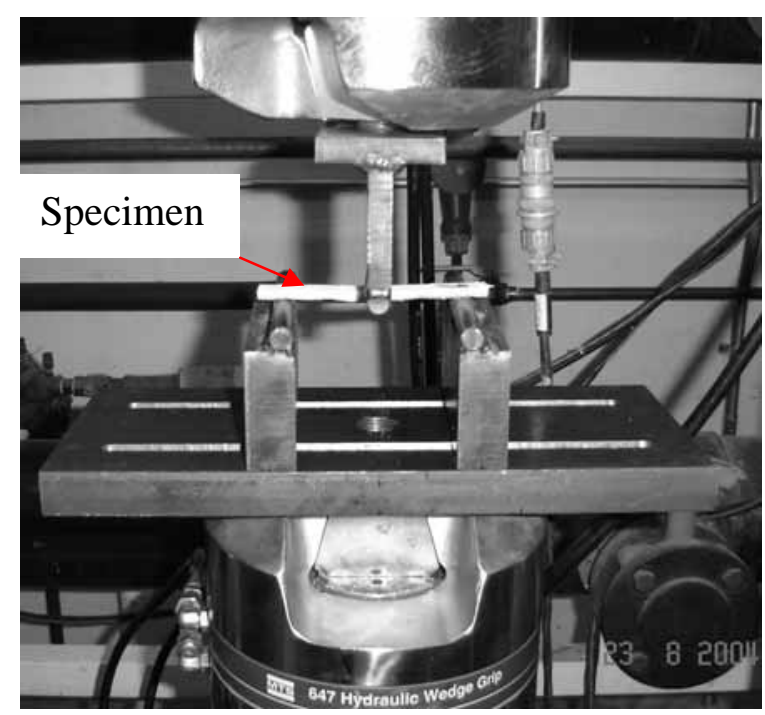

Figure 3.13 Experiment setup for flexural strength test 

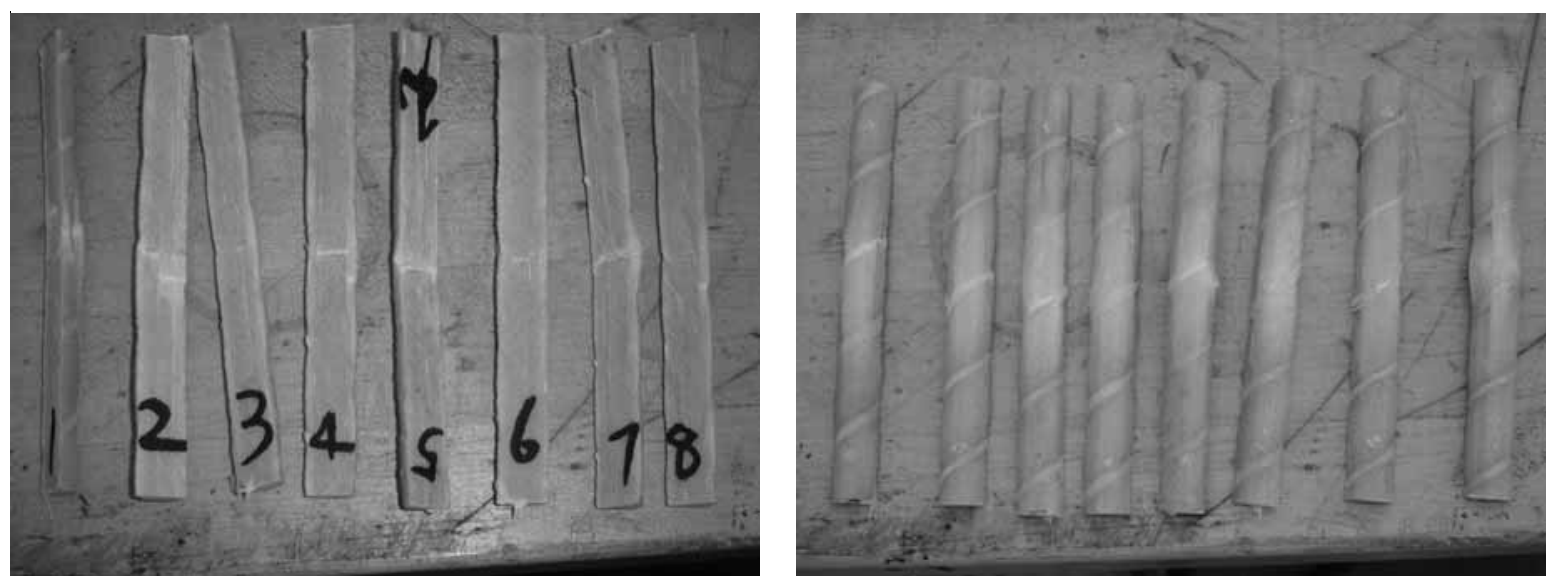

Figure 3.14 Typical flexural failure mode of GFRP1 specimens

Though the flexural test results were not consistent, the typical load vs. flexural deflection of GFRP1 bars (\#4) as shown in Fig. 3.15 can provide a general idea of the flexural performance of FRP.

Typical load vs. flexural deflection of GFRP

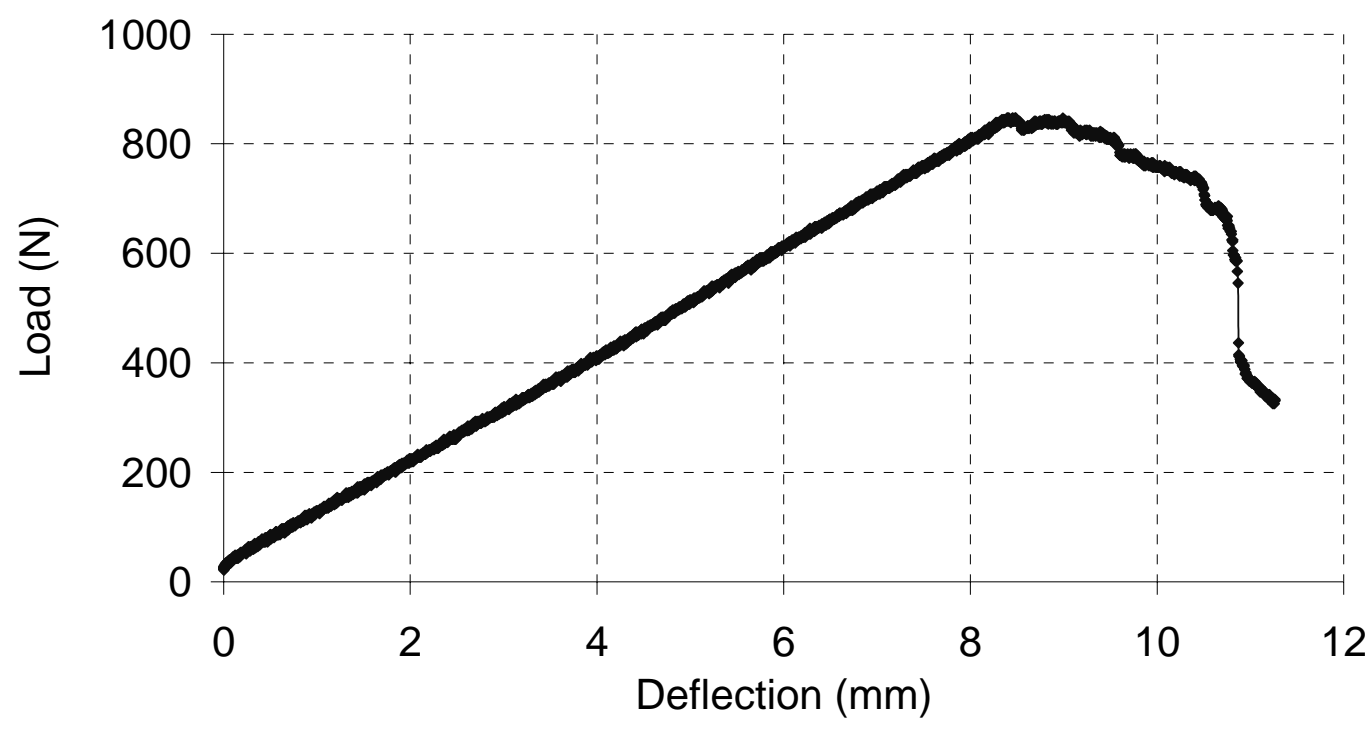

Figure 3.15 Typical load vs. flexural deflection of GFRP1 specimens 


\subsection{Experimental Program}

The tensile strength and ILSS were chosen as durability performance indicators of FRP bars. In this section, the testing plans for the tensile strength and ILSS of specimens are presented.

\subsubsection{Testing Plan for Tensile Strength}

Tensile test specimens were \#3 GFRP1, GFRP2 and CFRP bars (the type and diameters of FRP bars are given in Table 3.1) having lengths of $1.02 \mathrm{~m}$. The ratio of gauge length/diameter for tensile test is about 65 in this study. The specimens exposed to various conditions for tensile test are summarized in Tables 3.3 3.5. Based on the test results of specimens listed in Tables 3.3 and 3.4 and for illustrative purpose to develop and verify the durability prediction procedure, additional GFRP1 bars and GFRP2 bars were immersed in Solution 3 and Solution 2 as listed in Table 3.5. The justification for exposing a particular type of GFRP bars in a specific solution type will be discussed in detail later.

Table 3.3 GFRP1 specimens for tensile strength test (exposed to Solution 1, 3, 4, and 5)

\begin{tabular}{lccccccccccccccc}
\hline \multicolumn{1}{c}{ Solution type } & \multicolumn{3}{c}{ Solution 1 } & \multicolumn{4}{c}{ Solution 3 } & \multicolumn{3}{c}{ Solution 4 } & Solution 5 \\
\hline $\begin{array}{l}\text { Temperature } \\
\left({ }^{0} \mathrm{C}\right)\end{array}$ & 60 & 40 & 20 & WD & 60 & 40 & 20 & WD & 60 & 40 & 20 & WD & FT \\
Duration (days) & 70 & 70 & 120 & 72 & 70 & 70 & 120 & 72 & 70 & 70 & 120 & 72 & $\begin{array}{c}300 \\
\text { cycles }\end{array}$ \\
\hline
\end{tabular}

Note: $\mathrm{WD}=9$ wetting and drying cycles as described in section 3.2.1; FT= freezing and thawing cycles as described in section 3.2.1.

Table 3.4 FRP specimens for tensile strength test (exposed to Solution 2)

\begin{tabular}{cccccccccc}
\hline Bar type & \multicolumn{3}{c}{ GFRP 1 } & \multicolumn{3}{c}{ GFRP2 } & CFRP \\
\hline Temperature $\left({ }^{0} \mathrm{C}\right)$ & 60 & 40 & 20 & WD & 60 & 40 & 20 & WD & 60 \\
Duration (days) & 70 & 70 & 120 & 72 & 60 & 60 & 120 & 72 & 70 \\
\hline
\end{tabular}


Table 3.5 Additional GFRP specimens for tensile strength test (exposed to Solutions 2 and 3)

\begin{tabular}{ccccccc}
\hline Bar type & Solution type & Temperature $\left({ }^{0} \mathrm{C}\right)$ & \multicolumn{4}{c}{ Exposure time (days) } \\
\hline \multirow{3}{*}{ GFRP1 bars } & \multirow{2}{*}{ Solution 3 } & 60 & 60 & - & 90 & 120 \\
& & 40 & 60 & - & 90 & 120 \\
& & 20 & 60 & 70 & 90 & - \\
GFRP2 bars & Solution 2 & 60 & - & 90 & 120 & 240 \\
& & 40 & - & 90 & 120 & 240 \\
& & 20 & 60 & 90 & - & 240 \\
\hline
\end{tabular}

\subsubsection{Testing Plan for ILLS}

The specimens for short beam tests were \#3 GFRP1, GFRP2 and CFRP bars with span to diameter ratio of 4 . The numbers of specimens for ILLS are summarized in Table 3.6 .

Table 3.6 Number of specimens for short beam test

\begin{tabular}{c|c|c|c|c|c}
\hline Solution types & Temperature & Duration & GFRP 1 bars & GFRP2 bars & CFRP bars \\
\hline \multirow{3}{*}{ Solution 1 } & $60^{0} \mathrm{C}$ & 45 days & 5 & 6 & - \\
\cline { 2 - 6 } & FT & 300 cycles & 5 & 5 & - \\
\cline { 2 - 6 } & FT & 600 cycles & 5 & - & - \\
\hline Solution 2 & $60^{0} \mathrm{C}$ & 45 days & 6 & 6 & - \\
\hline Solution 3 & $60^{0} \mathrm{C}$ & 45 days & 6 & 6 & - \\
\hline Solution 4 & $60^{0} \mathrm{C}$ & 45 days & - & 5 & - \\
\hline \multirow{2}{*}{ Solution 5 } & FT & 300 cycles & 5 & 5 & 5 \\
\cline { 2 - 6 } & FT & 600 cycles & 5 & 5 & - \\
\hline
\end{tabular}

\subsection{Test Results and Discussion}

Small white blisters were observed on the external surface of GFRP bar after exposure, especially those exposed to solutions at $60{ }^{0} \mathrm{C}$ as shown in Fig. 3.16. Similar "whitening" was also observed previously by Bank et al. (1998) for GFRP bars embedded in concrete. This "whitening" was also found on the surface of GFRP bars 
exposed to Solution 1, which indicates that the whitening was not introduced by the oxidation of metal hydroxides from alkaline solutions when exposed to air.

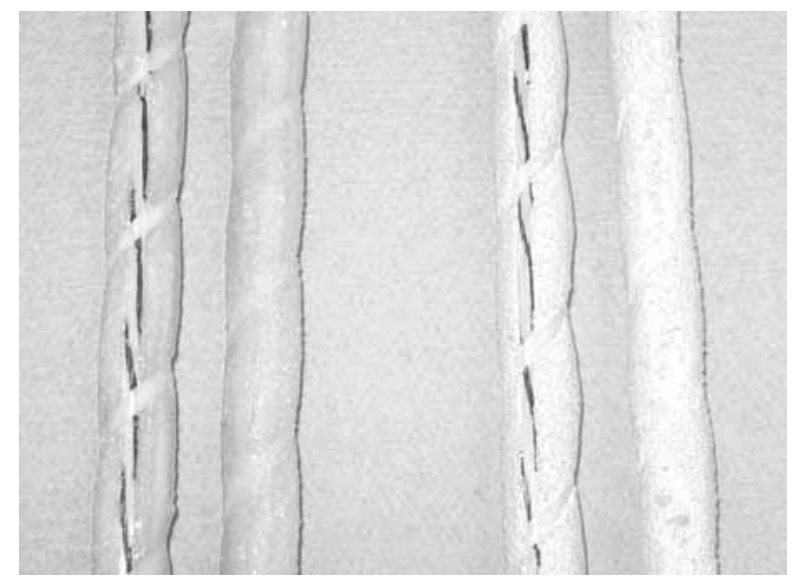

Figure 3.16 GFRP bars before and after exposure

\subsubsection{Tensile Test Results}

The tensile test results of unconditioned and conditioned specimens are summarized in Table 3.7. Each data represents three to six test results. During the tensile test, the FRP bars failed within the gauge length of the specimens (usually failed at the middle of the bar), not at the grip. The coefficients of variations (COV) of obtained tensile strengths are relatively small. So it can be concluded that the tensile test method selected in this study, including the grip system, the gauge length and loading, is reliable and effective.

During tensile test, all three types of specimens (GFRP1, GFRP2 and CFRP bars) showed an elastic behavior up to failure and failed through the delamination and rupture of fibers. The failure of both types of GFRP bars was accompanied by the separation of fibers and the rupture of the fiber bundle with spiral pattern on the deformed surface of bars as shown in Fig. 3.17. The failure of CFRP bars was catastrophic with a sudden release of stored elastic energy. The typical failure mode of CFRP bars is shown in Fig. 3.19. Similar tensile failure mode of FRP bars was also observed by Micelli and Nanni 
(2004). The failure modes of conditioned specimens did not change, but less violent failures with more delamination of fibers were observed. The typical stress vs. strain relationships for unconditioned FRP bars as shown in Figs. 3.18 and 3.20 were recorded with an MTS extensometer (to protect the extensometer, it was removed from the bars before failure occurred).

As shown in Table 3.7, after 70 day exposure to Solution 2 at $60^{\circ} \mathrm{C}$, CFRP bars experienced only $4 \%$ reduction in tensile strength. For GFRP1 bars, significant degradations were observed in conditioned specimens exposed to Solution $1 \sim 4$ at $60{ }^{\circ} \mathrm{C}$. The most severe degradation, of about $36 \%$ reduction in tensile strength, was found for GFRP1 bars after 70 day immersion in Solution 2 at $60{ }^{0} \mathrm{C}$. The tensile strength reductions for those exposed to Solutions 1,3 , and 4 at $60{ }^{\circ} \mathrm{C}$ were very close to each other (about 27\%). But at lower temperatures, more strength reductions were found for GFRP1 bars exposed to alkaline solutions (Solutions 2 and 3) than those in Solutions 1 and 4. It is also evident that the temperature of $60{ }^{\circ} \mathrm{C}$ had significantly accelerated the attack of environments on GFRP bars, while the accelerating effect of the $40{ }^{0} \mathrm{C}$ temperature was not so obvious. It is observed that for Solutions $1 \sim 4$, the degradation effect of 72-days WD cycles was less significant than 70-days continuous immersion at $60^{\circ} \mathrm{C}$. This may be due to reduced exposure time in solutions at $60^{\circ} \mathrm{C}$ in case of WD cycles. Surprisingly, after exposure to 300 cycles of FT, GFRP1 bars even gained some tensile strength. In case of GFRP2 bars, about $48 \%$ reduction in tensile strength was found for those after 70 day immersion in Solution 2 at $60{ }^{\circ}$ C. A 120 day immersion in Solution 2 at $20{ }^{\circ} \mathrm{C}$ also resulted in $45 \%$ reduction for GFRP2 bars. 


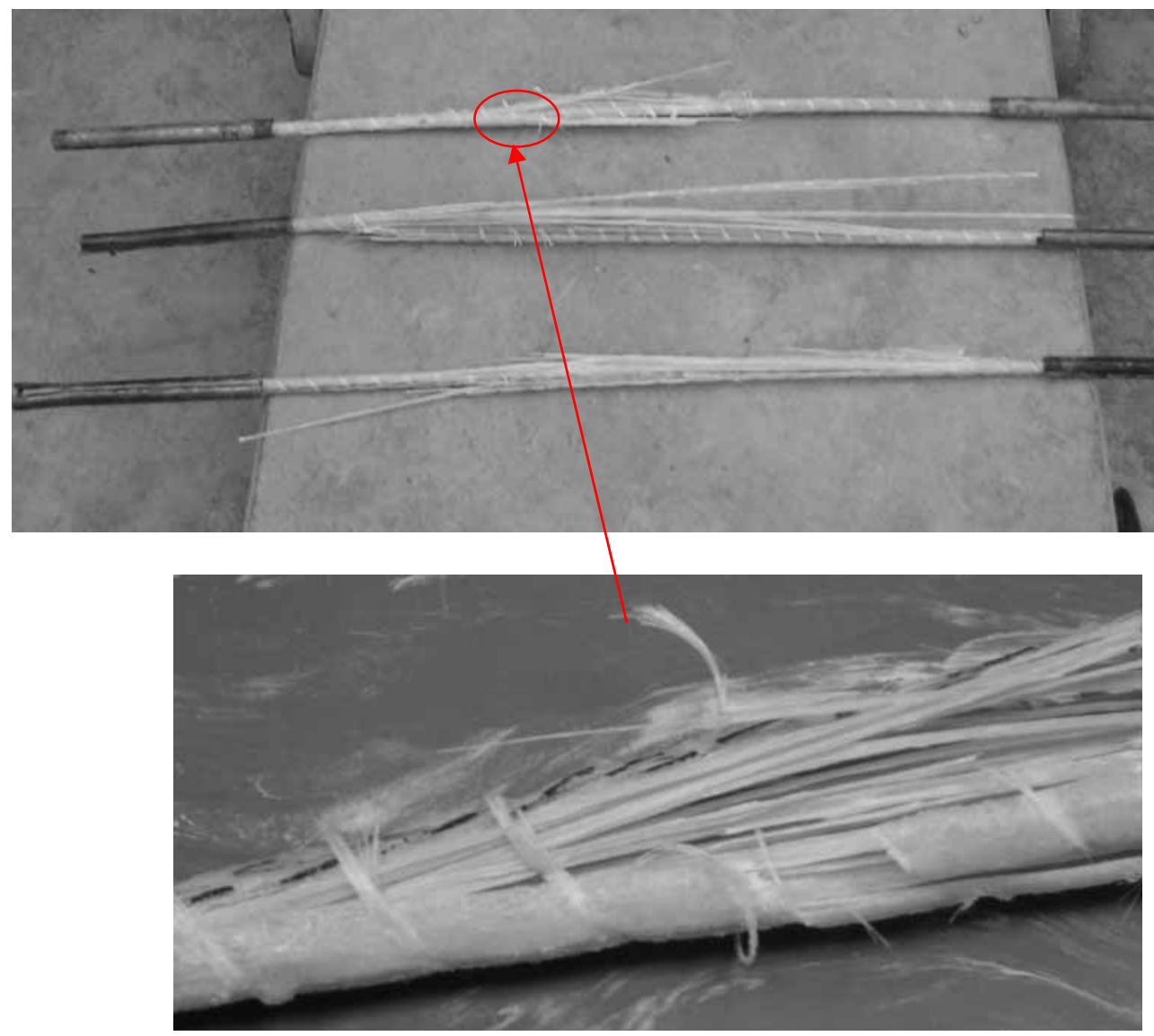

Figure 3.17 Typical failure mode of GFRP bars Load vs. strain of GFRP bar

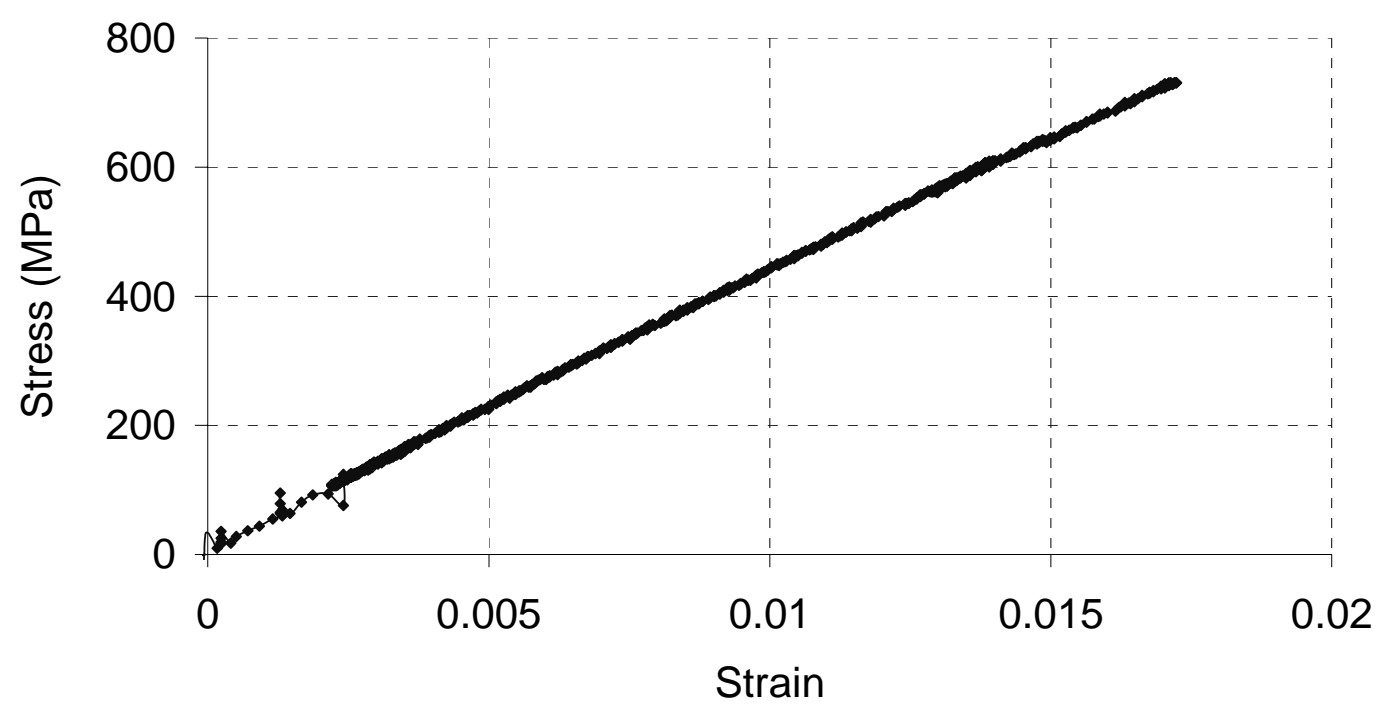

Figure 3.18 Typical stress vs. strain of GFRP bars 


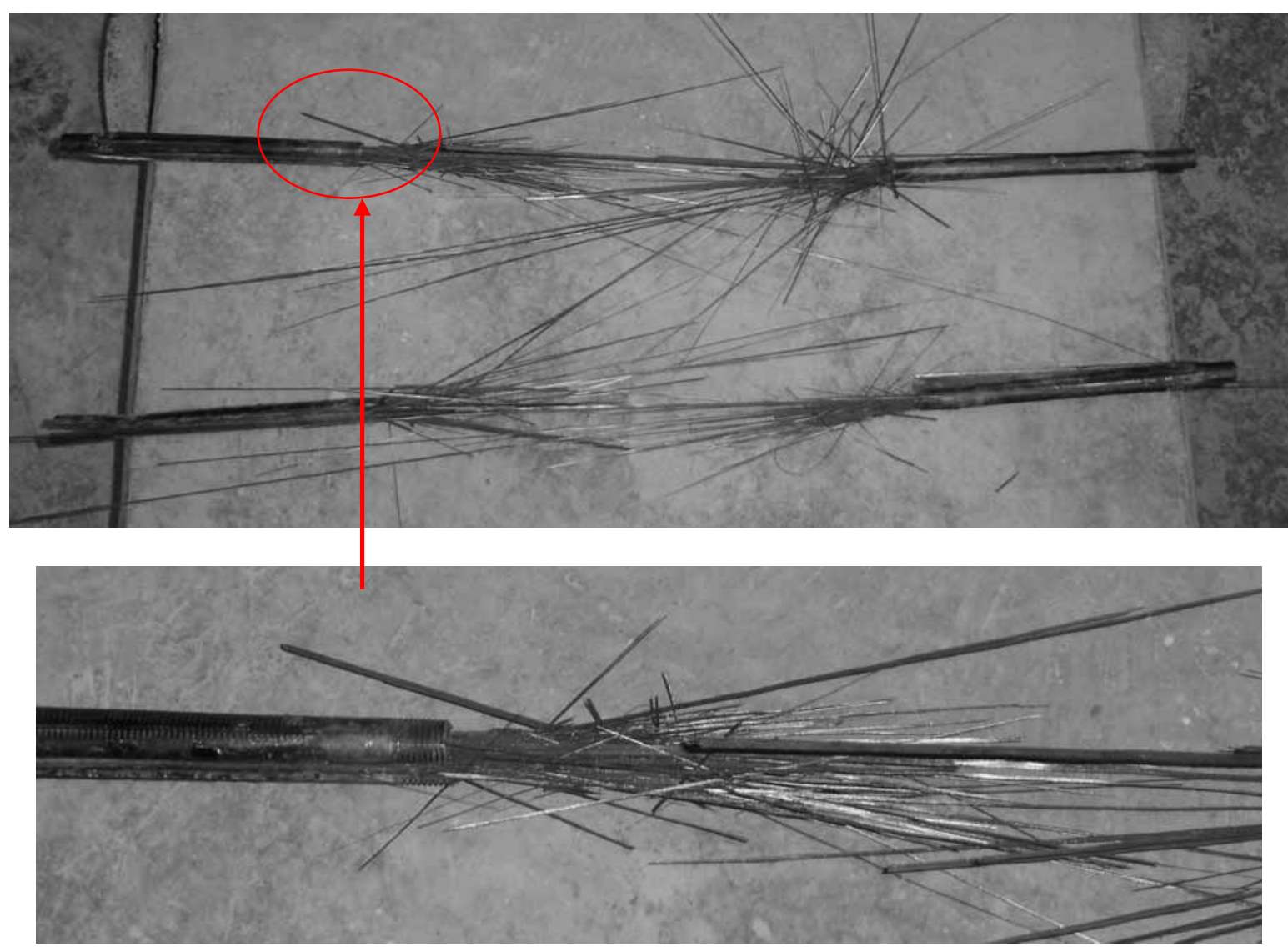

Figure 3.19 Typical failure mode of CFRP bars

Stress vs. strain of CFRP bar

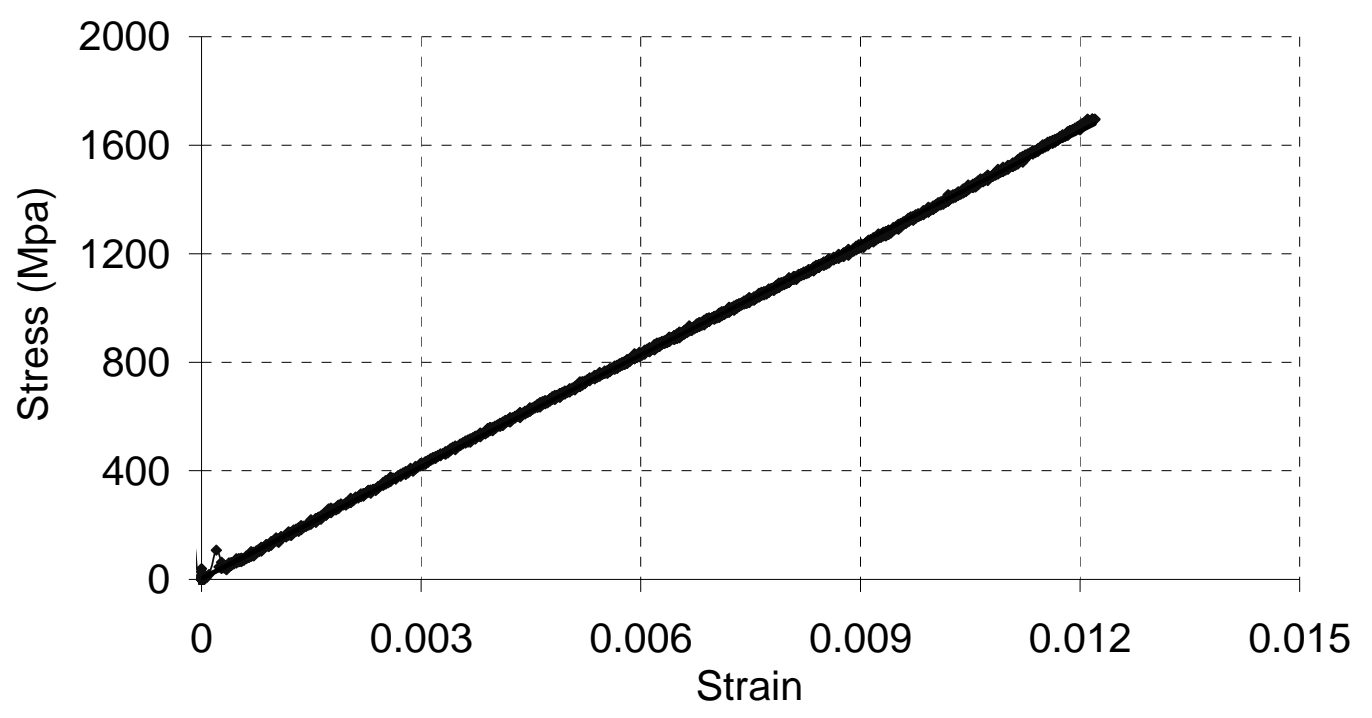

Figure 3.20 Typical stress vs. strain of CFRP bars 
Table 3.7 Environmental conditions and results from tensile tests

\begin{tabular}{|c|c|c|c|c|c|c|c|}
\hline $\begin{array}{l}\text { Bar } \\
\text { types }\end{array}$ & \multicolumn{3}{|c|}{ Environmental exposure } & $\begin{array}{c}\text { No. of } \\
\text { specimens }\end{array}$ & $\begin{array}{c}\text { Mean } \\
\text { Value of } \\
\text { tensile } \\
\text { strength } \\
(\mathrm{MPa})\end{array}$ & $\begin{array}{c}\mathrm{COV} \\
(\%)\end{array}$ & Retention \\
\hline \multirow{18}{*}{$\begin{array}{c}\text { GFRP1 } \\
\text { bars }\end{array}$} & \multicolumn{3}{|c|}{ unconditioned } & 6 & 771 & 2 & 1.00 \\
\hline & \multirow[t]{2}{*}{ Solution 1} & $60^{\circ} \mathrm{C}$ & 70 days & 6 & 544 & 7 & 0.71 \\
\hline & & $40^{\circ} \mathrm{C}$ & 70 days & 6 & 748 & 4 & 0.97 \\
\hline & \multirow{5}{*}{ Solution 2} & $20^{\circ} \mathrm{C}$ & 120 days & 3 & 732 & 2 & 0.95 \\
\hline & & WD & 72 days & 6 & 651 & 6 & 0.84 \\
\hline & & $60^{\circ} \mathrm{C}$ & 70 days & 6 & 493 & 4 & 0.64 \\
\hline & & $40^{\circ} \mathrm{C}$ & 70 days & 4 & 688 & 10 & 0.89 \\
\hline & & $20^{\circ} \mathrm{C}$ & 120 days & 4 & 664 & 7 & 0.86 \\
\hline & \multirow{3}{*}{ Solution 3} & WD & 72 days & 6 & 561 & 8 & 0.73 \\
\hline & & $60^{\circ} \mathrm{C}$ & 70 days & 5 & 564 & 6 & 0.73 \\
\hline & & $40^{\circ} \mathrm{C}$ & 70 days & 4 & 711 & 8 & 0.92 \\
\hline & \multirow{5}{*}{ Solution 4} & $20^{\circ} \mathrm{C}$ & 120 days & 4 & 713 & 10 & 0.92 \\
\hline & & WD & 72 days & 5 & 618 & 11 & 0.80 \\
\hline & & $60^{\circ} \mathrm{C}$ & 70 days & 6 & 572 & 2 & 0.74 \\
\hline & & $40^{\circ} \mathrm{C}$ & 70 days & 6 & 754 & 4 & 0.98 \\
\hline & & $20^{\circ} \mathrm{C}$ & 120 days & 4 & 751 & 4 & 0.97 \\
\hline & & WD & 72 days & 5 & 666 & 5 & 0.86 \\
\hline & Solution 5 & FT & 300 cycles & 4 & 798 & 6 & 1.04 \\
\hline \multirow{4}{*}{$\begin{array}{c}\text { GFRP2 } \\
\text { bars }\end{array}$} & \multicolumn{3}{|c|}{ unconditioned } & 5 & 925 & 3 & 1.00 \\
\hline & \multirow[t]{3}{*}{ Solution 2} & $60^{\circ} \mathrm{C}$ & 60 days & 3 & 482 & 0 & 0.52 \\
\hline & & $40^{\circ} \mathrm{C}$ & 60 days & 4 & 638 & 4 & 0.69 \\
\hline & & RT & 120 days & 4 & 507 & 7 & 0.55 \\
\hline \multirow{2}{*}{$\begin{array}{c}\text { CFRP } \\
\text { bars }\end{array}$} & \multicolumn{3}{|c|}{ unconditioned } & 5 & 2588 & 5 & 1.00 \\
\hline & Solution 2 & $60^{\circ} \mathrm{C}$ & 70 days & 4 & 2476 & 9 & 0.96 \\
\hline
\end{tabular}

Notes: FT= freezing and thawing cycles as described before; $\mathrm{WD}=9$ wetting and drying cycles as described before. $\mathrm{COV}=$ Coefficients of variation .

\subsubsection{Short Beam Test Results}

Most FRP specimens in short beam test failed in shear mode (horizontal cracks along the mid-plane of the specimens) as shown in Fig. 3.11. The conditioning did not change the failure mode of FRP bars in short beam test. Specimens after the short beam test are shown in Fig. 3.21. Since less span/diameter ratio was used by Micelli and Nanni (2004), splitting of specimens (failure due to vertical crack) was reported in their study. 


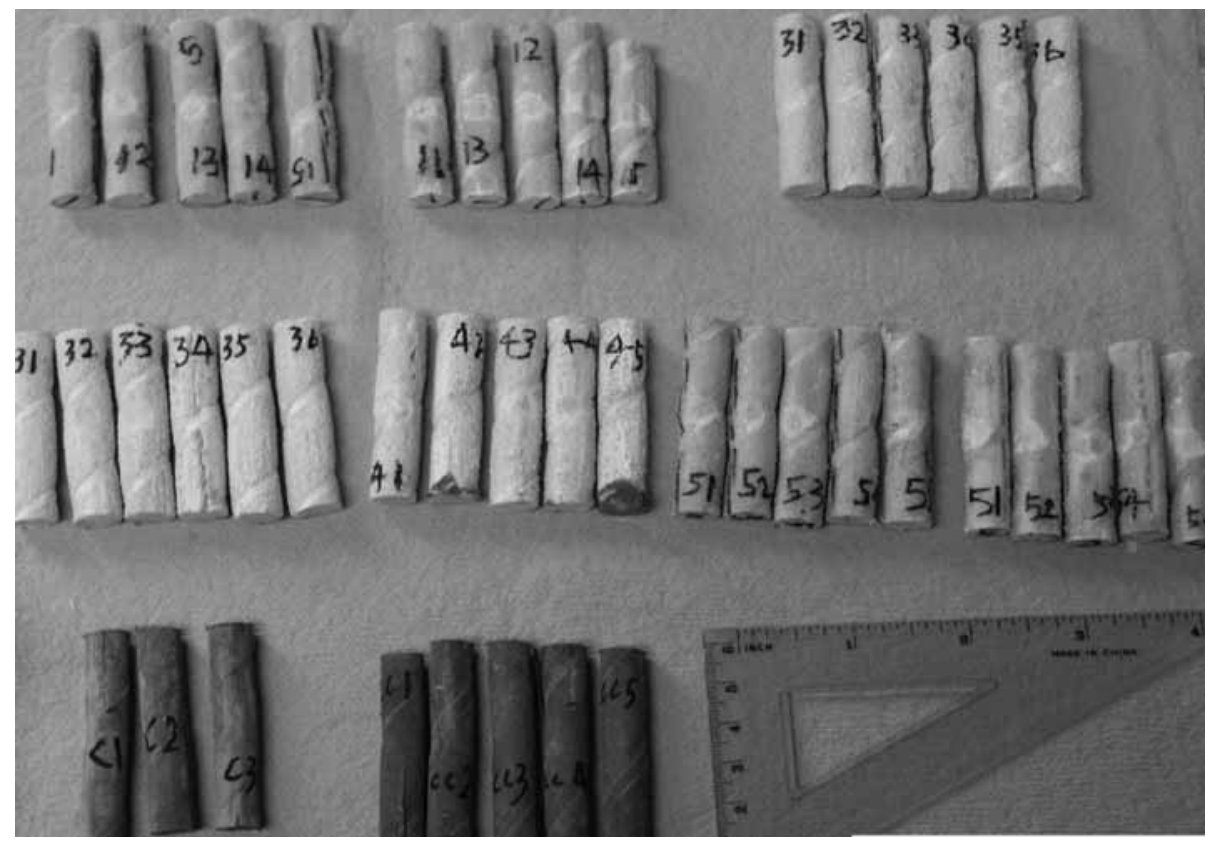

Figure 3.21 Specimens after the short beam test

The typical load vs. deflection relationships for GFRP1/GFRP2 and CFRP specimens are plotted in Figs. 3.22 and 3.23, respectively. Due to the low stiffness and strength of matrix compared to fibers for GFRP bars, there was some deformation of the specimens directly under the loading head at the initial stage of loading. This explains why the curves of load vs. deflection of GFRP bars have lower slope at the initial stage in Fig. 3.22, but after the initial deformation, there was an increase in slope as shown in the Figure. The stiffness eventually decreased because horizontal cracks (shear failure) started from the mid-plane under the loading head. Once the cracks reached the end of the specimen, shear mode failure occurred. After the shear failure (horizontal cracks), the specimen could still carry some load due to flexural strength of the specimens. Figs. 3.22 and 3.23 further indicate that GFRP specimens had more toughness (area under loaddeflection curve) than CFRP specimens. 


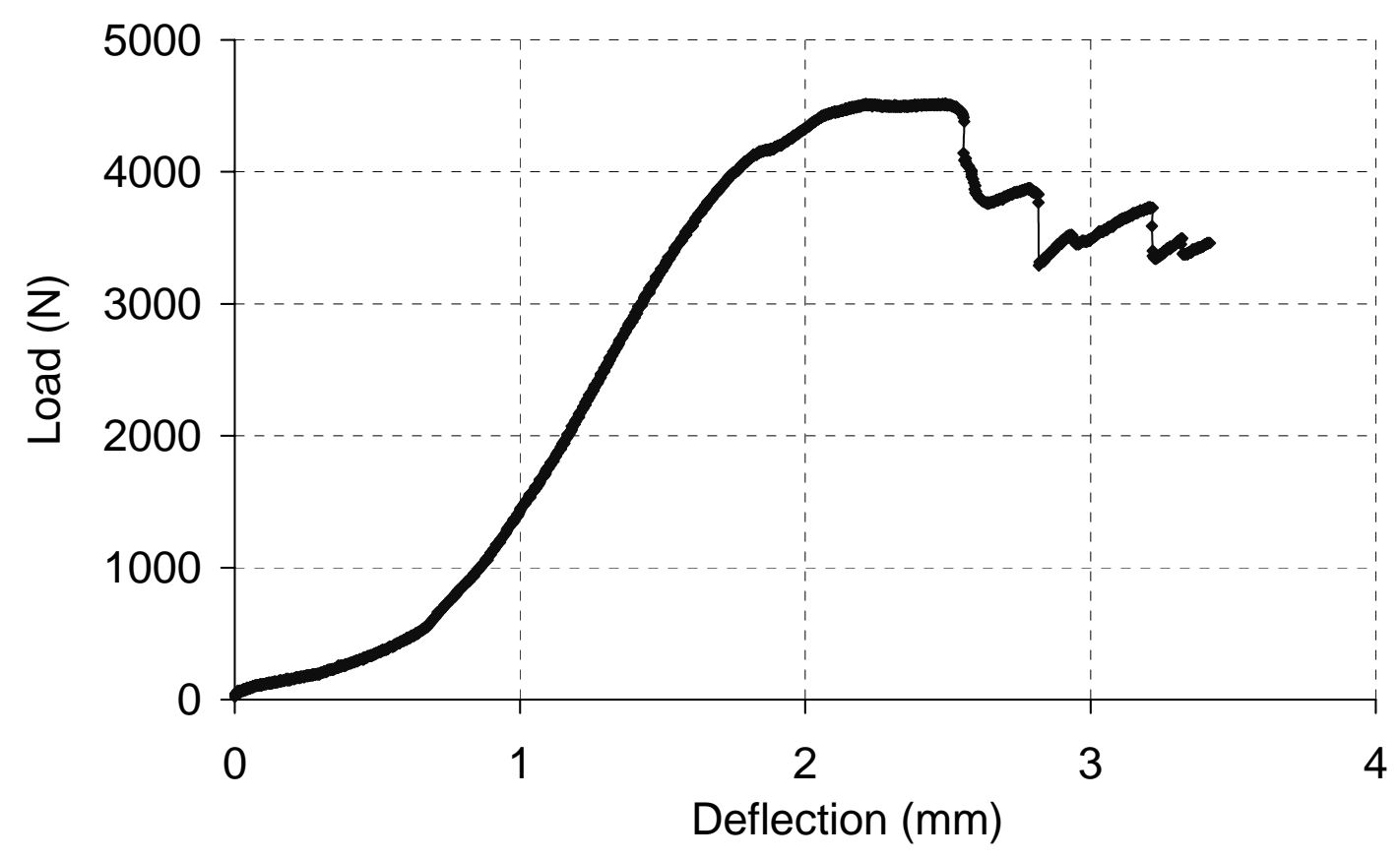

Figure 3.22 Typical load vs. deflection of GFRP specimens in short beam test

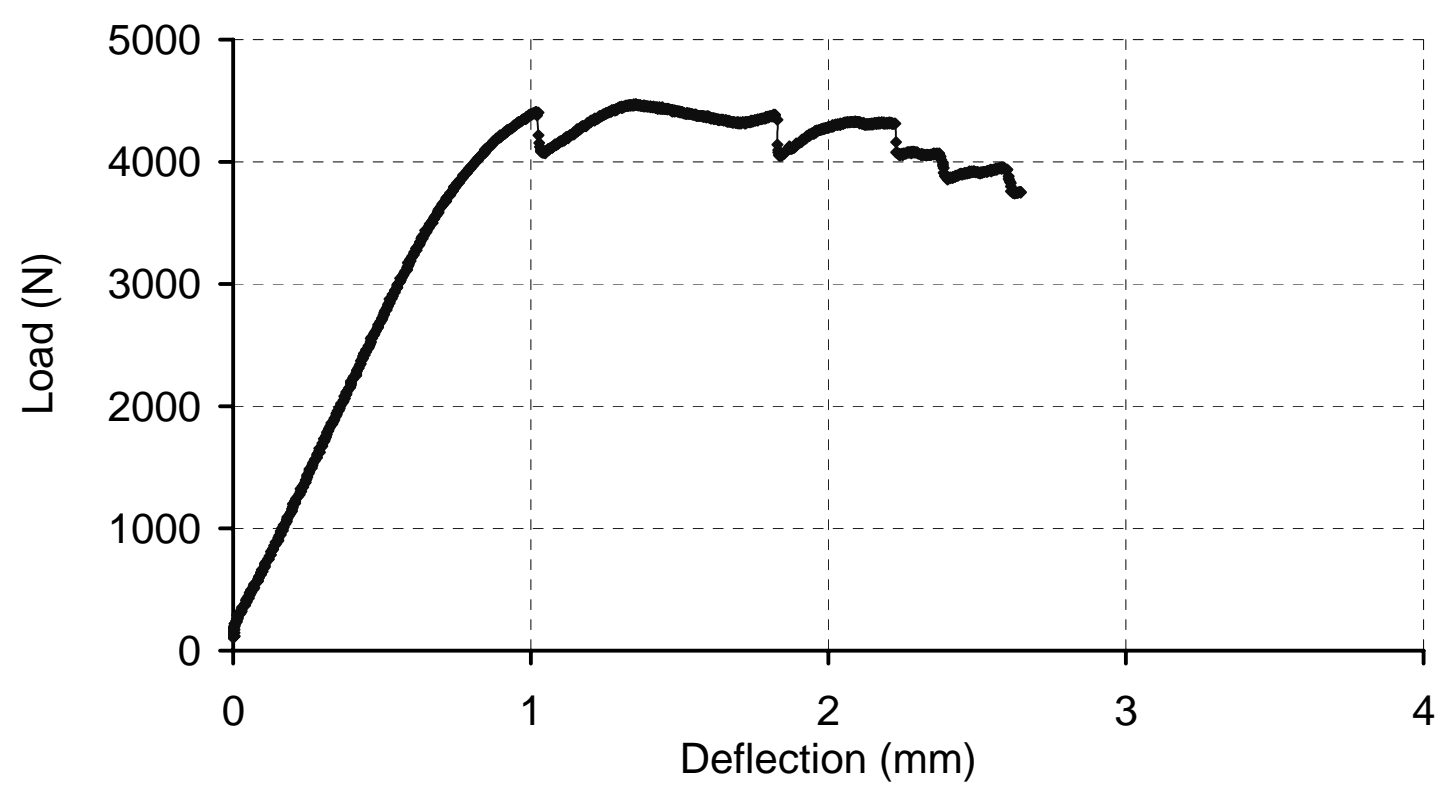

Figure 3.23 Typical load vs. deflection of CFRP specimens in short beam test 
The experimental results for short beam tests are listed in Table 3.8. Each data is an average of four to six measurements. Since GFRP1 and GFRP2 bars had the same matrix, the initial ILSS for both types of bars were the same. After 45 day exposure to Solution 2 at $60^{\circ} \mathrm{C}$, GFRP1 specimens had a reduction of $8 \%$ in ILSS, while a reduction of about $20 \%$ was observed for GFRP2 bars. The most severe ILSS reduction was found for those specimens exposed to Solution 2. In terms of ILSS, generally less strength reductions were found for GFRP1 specimens than GFRP2 specimens.

Table 3.8 Results for short beam test

\begin{tabular}{|c|c|c|c|c|c|c|c|}
\hline $\begin{array}{l}\text { Bar } \\
\text { types }\end{array}$ & \multicolumn{3}{|c|}{ Environmental exposure } & $\begin{array}{c}\text { No. of } \\
\text { specimens }\end{array}$ & $\begin{array}{l}\text { Mean } \\
\text { value of } \\
\text { ILSS } \\
(\mathrm{MPa})\end{array}$ & $\begin{array}{c}\mathrm{COV} \\
(\%)\end{array}$ & Retention \\
\hline \multirow{8}{*}{$\begin{array}{c}\text { GFRP1 } \\
\text { bars }\end{array}$} & \multicolumn{3}{|c|}{ Unconditioned } & 6 & 43 & 6 & 1.00 \\
\hline & \multirow[t]{3}{*}{ Solution 1} & $60^{\circ} \mathrm{C}$ & 45 days & 5 & 41 & 7 & 0.96 \\
\hline & & FT & 300 cycles & 5 & 44 & 4 & 1.03 \\
\hline & & FT & 600 cycles & 5 & 40 & 6 & 0.93 \\
\hline & \multirow{4}{*}{$\begin{array}{l}\text { Solution } 2 \\
\text { Solution } 3 \\
\text { Solution } 5\end{array}$} & $60^{\circ} \mathrm{C}$ & 45 days & 6 & 39 & 6 & 0.92 \\
\hline & & $60^{\circ} \mathrm{C}$ & 45 days & 6 & 42 & 2 & 0.99 \\
\hline & & FT & 300 cycles & 5 & 44 & 3 & 1.03 \\
\hline & & FT & 600 cycles & 5 & 42 & 3 & 0.97 \\
\hline \multirow{8}{*}{$\begin{array}{c}\text { GFRP2 } \\
\text { bars }\end{array}$} & \multicolumn{3}{|c|}{ Unconditioned } & 6 & 43 & 5 & 1.00 \\
\hline & \multirow[t]{2}{*}{ Solution 1} & $60^{\circ} \mathrm{C}$ & 45 days & 6 & 39 & 10 & 0.90 \\
\hline & & $\mathrm{FT}$ & 300 cycles & 5 & 37 & 5 & 0.86 \\
\hline & Solution 2 & $60^{\circ} \mathrm{C}$ & 45 days & 6 & 34 & 6 & 0.79 \\
\hline & Solution 3 & $60^{\circ} \mathrm{C}$ & 45 days & 6 & 40 & 6 & 0.94 \\
\hline & Solution 4 & $60^{\circ} \mathrm{C}$ & 45 days & 5 & 39 & 6 & 0.90 \\
\hline & \multirow[t]{2}{*}{ Solution 5} & FT & 300 cycles & 5 & 42 & 4 & 0.99 \\
\hline & & FT & 600 cycles & 5 & 39 & 4 & 0.90 \\
\hline \multirow{2}{*}{$\begin{array}{c}\text { CFRP } \\
\text { bars }\end{array}$} & \multicolumn{3}{|c|}{ Unconditioned } & 9 & 50 & 5 & 1.00 \\
\hline & Solution 2 & FT & 600 cycles & 5 & 48 & 2 & 0.96 \\
\hline
\end{tabular}

Note: $\mathrm{FT}=$ freezing and thawing cycles as described before; $\mathrm{COV}=\mathrm{Coefficients}$ of variation.

The strength gain in ILSS was found for specimens exposed to 300 cycles of FT, which was also observed previously by Stone et al. (2002). This phenomenon can 
possibly be explained by the fact that some initial range of FT cycles may actually reduce residual stresses. But the degradation effects of FT cycles increased with the cycle numbers. It was also apparent that when combined with FT cycles, the adverse effect of Solution 5 (alkaline solution with $\mathrm{Cl}^{-}$) was less than that of Solution 1 (tap water). But generally FT cycles had little effect on accelerating the attack of Solution 5 and Solution 1 on FRP bars.

\subsubsection{Summary}

Though initially GFRP2 bar had higher tensile strength and same ILSS compared to GFRP1 bar, it underwent more loss in strength due to various environmental attacks in terms of both tensile strength and ILSS. Since these two types of bars had the same matrix and were made following similar manufacturing processes, the inferior durability performance of GFRP2 bar can be attributed to lower durability performance of glass fibers and/or fiber/matrix interphase. Also, it was found that the ILSS of GFRP bars deteriorated at a slower rate than tensile strength.

The Solution 2 was the most aggressive environment to cause the deterioration of FRP bars. It was found that generally the aggressiveness of the solutions decreased in the following order: Solution 2 being the most severe followed by Solution 3, Solution 1, and Solution 4. However, at $60^{\circ} \mathrm{C}$, Solutions 1, 3, and 4 have similar aggressiveness and Solution 1 was even slightly more aggressive than Solution 3. This phenomenon may possibly be explained as follows. At the temperature of $60^{\circ} \mathrm{C}$, more water molecules in Solution 1 might have diffused into FRP bars, leading to more degradation, than simulated HPC pore Solution 3. Some researchers (Nkurunziza et al. 2005) pointed out that this may be due to the smaller size of water ions than alkaline ions. However, further 
research is needed to support this argument. It was also observed that Solution 4 was slightly less aggressive than Solution 1 . This may be explained by the characteristics of selected GFRP specimens, which are known to be impervious to chloride ions. Moreover, it is widely accepted that distilled water is more aggressive to composites than seawater (Pritchard, 2000).

\subsubsection{Tensile Test Results for Durability Prediction}

For illustrative purpose to develop and verify the prediction procedure, additional GFRP1 bars were immersed in Solution 3 and also GFRP2 bars in Solution 2. The justification for exposing a particular type of GFRP bars in a specific solution type is based on the findings from test results of Tables 3.7 and 3.8 on interactions of GFRP bars and various simulated solutions. It was observed from the test results that in terms of durability GFRP1 bars performed better than GFRP2 bars; and in terms of its reactivity with GFRP bars, alkaline solutions were more aggressive than other simulated environments and Solution 3 was less aggressive than Solution 2. Since further study is aimed to developing a procedure to evaluate the durability of GFRP bars in concrete, it is necessary to verify the validity of the procedure through at least two distinct conditions in terms of the reactivity between fiber-resin system of GFRP bars and solutions. Considering this objective, two distinct conditions are formulated, in which GFRP1 bars exposed in Solution 3 is regarded as a relatively low reactivity condition and GFRP2 bars exposed in Solution 2 is considered as a high reactivity condition. The applicability of the model by including these two distinct conditions will enable evaluating its accuracy for predicting durability from critical short-term data of accelerated tests. Additional GFRP1 bars and GFRP2 bars were immersed in Solution 3 and Solution 2 at different 
temperatures and durations. The conditioning plan is listed Table 3.5 and the test results are shown in Table 3.9. From the test results, it can be found that the tensile strength decreased with increase in exposure time for both GFRP bars at all temperatures, and degradation was more severe for specimens in solutions at higher temperatures. The details about durability prediction will be discussed in chapter six.

Table 3.9 Tensile strength retentions

\begin{tabular}{ccccccc}
\hline & \multicolumn{2}{c}{ Duration (days) } & 60 & 70 & 90 & 120 \\
\cline { 2 - 7 } GFRP1 bars & Solution 3 & $60^{0} \mathrm{C}$ & $0.76(5)$ & - & $0.66(2)$ & $0.59(1)$ \\
& & $40^{0} \mathrm{C}$ & $0.93(6)$ & - & $0.86(5)$ & $0.86(2)$ \\
& & $20^{0} \mathrm{C}$ & $0.98(5)$ & $0.97(7)$ & $0.95(4)$ & - \\
\hline \multirow{5}{*}{ GFRP2 bars } & \multicolumn{2}{c}{ Duration (days) } & 60 & 90 & 120 & 240 \\
\cline { 2 - 7 } & Solution 2 & $60^{0} \mathrm{C}$ & - & $0.44(6)$ & $0.38(1)$ & $0.23(3)$ \\
& & $40^{0} \mathrm{C}$ & - & $0.6(2)$ & $0.5(6)$ & $0.33(2)$ \\
& & $20^{0} \mathrm{C}$ & $0.82(5)$ & $0.64(9)$ & - & $0.43(6)$ \\
\hline
\end{tabular}

Note: the number in "( $)$ " is the coefficient of variation.

\subsection{Concluding Remarks}

This study is part of an ongoing durability research program on FRP reinforcing bars for concrete structures. From the test results of bare FRP bars subjected to simulated environments, the following concluding remarks and recommendations can be drawn.

CFRP bars exhibited superior durability performance. CFRP bars can be considered durable in civil applications and further durability study should be focused on GFRP bars. In general, GFRP1 bars have better durability performance than GFRP2 bars. But obvious degradations were found for both types of GFRP bars exposed to simulated environments. Durability performance of GFRP bars depend on constituents of the composites and quality of manufacturing. Alkali resistant fibers with proper sizing, if available, may be helpful in further enhancing the durability performance of GFRP bars 
in alkaline environments. In addition to the constituents of FRP bars in general, the quality of manufacturing and particularly fiber/matrix interphase does influence the durability of FRP bars, as indirectly observed from this study. It was found that the ILSS of GFRP bars deteriorated at a slower rate than tensile strength, so further study can be focused on the tensile strength retentions. Due to the inferior durability of GFRP bars, the durability performance of GFRP bar and concrete interface bond should also be investigated.

The simulated NC pore solution (with a $\mathrm{pH}$ value of 13.7 ) was the most aggressive condition for bare FRP bars. Simulated HPC environment was less aggressive to GFRP bars than simulated NC environments. The addition of chloride ions in solutions did not accelerate the environment attack on GFRP bars. Generally the aggressiveness of the solutions decreased in the following order: Solution 2 being the most severe followed by Solution 3, Solution 1, and Solution 4. However, at $60^{\circ} \mathrm{C}$, Solutions 1, 3, and 4 have similar aggressiveness, which may mainly come from water molecules of those solutions. Both WD and FT cycles had negligible effects on degradation process, and therefore, these two exposure conditions are not recommended as critical for performance tests. Further study can be focused on the durability performance of GFRP bars in alkaline environments.

Elevated temperature accelerated the degradation of bare FRP bars in simulated environments. The durability prediction model can possibly be developed by studying the acceleration effects of elevated temperatures. Moreover, the degradation of FRP bars embedded in concrete may also be accelerated by elevated temperatures. 
In this study, the degradation was significant for both types of GFRP bars in such short exposure times compared to their expected service life, while available long term data (5 8 years) showed that little degradation was found for GFRP bars in field conditions. Since in this study the bare FRP specimens were directly exposed to the solutions until testing, the reported experimental results should be considered as conservative. So it is necessary that FRP-concrete combinations be considered for testing in addition to bare FRP bars to evaluate the durability of FRP reinforcement, since the protocols of bare FRP testing are too harsh for realistic conditions. Long-term data including those exposed to outdoor environments are greatly valuable in order to validate short-term accelerated aging test results. Moreover, coupling effects of sustained load and environmental exposures should also be included in future studies in order to closely simulate real-life conditions. 


\section{CHAPTER FOUR DURABILITY OF GFRP BARS IN CONCRETE}

This chapter describes a durability study of GFRP bars in concrete environment. GFRP bar RC beams were cast and spring-bracket assemblies were fabricated to apply sustained tensile loads on concrete beams. After being conditioned in temperature controlled tanks, GFRP bars were extracted from concrete and tested for residual tensile strengths. Then based on the test results, concluding remarks and recommendations for further study are made.

\subsection{Introduction}

The test results from the previous chapter showed that bare GFRP bars subjected to simulated concrete pore solutions experienced significant loss in tensile strength, while CFRP bars exhibited superior durability performance. Similar results were also found from short term data of other studies (Sen et al., 1997, Dejke 2001, and Micelli and Nanni, 2004). So the durability performance of GFRP bars in concrete remains a concern. Moreover, there is a lack of long-term performance data for GFRP bars in concrete. ISIS Canada (Mufti et al., 2005) reported a study that no degradation was found by analytical methods for GFRP bars from several field structures for durations of 5 to 8 years. But when considering 50 to 75 year life cycle for civil infrastructure, substantial long-term data is needed to prove the acceptable durability performance of GFRP bars in concrete.

It is obvious that there is considerable difference between simulated environments and real concrete environments (Mufti et al., 2005). In the case of simulated concrete pore 
solutions, the condition can be considered as an infinite leachant volume or rapid leachant replenishment; a critical condition considering that leaching is the most important reaction in the dissolution of glass in solutions as discussed in chapter two. In this case, the hydroxyl concentration gradients between the glass and the solution remain high over the entire duration of exposure, while the solubility limit of elements such as $\mathrm{Si}$ and $\mathrm{Al}$ from glass is controlled by the hydroxyl concentration and the diffusion coefficient of matrix. But in case of concrete environment, the leachant volumes or the replenish rates within the pore solution are very small. First, the porosity of concrete is low (about 0.35 ). Second, in real application concrete members are rarely moisture saturated (usually concrete has a moisture content corresponding to $75-80 \%$ relative humidity). So the concrete pores are rarely fully saturated and the diffusion coefficients are less than those for saturated conditions. Third, the pore network in concrete is not all connected but discontinuous and very tortuous. Fourth, the $\mathrm{pH}$ value of pore solution is not kept constant as in simulated solutions but decreases as the concrete ages. Due to these reasons, the degradation of FRP bars in concrete is different from that in simulated solutions. The increase of byproducts of degradation and the decrease of concentration gradients between the FRP and pore solution will lead to reduced degradation rate and saturation of glass elements. So it is necessary to study the durability performance of GFRP bars embedded in real concrete.

Though numerous studies have been carried on the durability of GFRP bars, few tests were conducted for FRP bars in real concrete (Djke, 2001, Mukherjee and Arwikar, 2005, Almusallam and Al-Salloum, 2005). Moreover, few of them were directed to the development of life-cycle durability prediction models for FRP bars in actual concrete. 
There is no standard test method or prediction model for the durability of GFRP bar in concrete. In this chapter, a convenient testing method was adopted for the durability of GFRP bars in concrete. The testing plan was also directed to the development of durability prediction models for GFRP bars.

\subsection{Experimental Program}

\subsubsection{FRP bars}

In this study, two types of commercially available GFRP bars with $9.53 \mathrm{~mm}$ diameter (\# 3) were used. GFRP3 bars, made of E-glass and vinyl ester, were helically wrapped and slightly sand coated as shown in Fig. 4.1. GFRP4 bars were composed of a state-ofthe-art urethane-modified vinyl ester resin reinforced with specially developed corrosion resistant glass fibers. Both bars are commercially available products and widely used in FRP reinforced constructions in North America. GFRP3 bars were provided by Hughes Brothers, Inc. in USA, and GFRP4 bars were provided by Concrete Protection Products, Inc. and manufactured by Pultrall, Inc. of Canada.

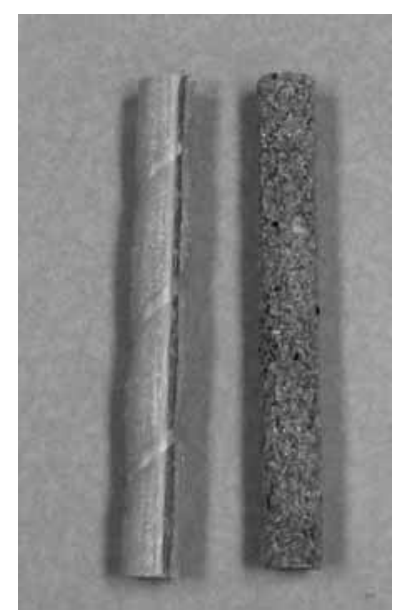

GFRP3 GFRP4

Figure 4.1 GFRP specimens 


\subsubsection{FRP Bar Reinforced Concrete Beams}

In order to investigate the effect of concrete environment on GFRP bars, concrete beams reinforced with GFRP bars were cast with cross section of $100 \mathrm{~mm} \times 100 \mathrm{~mm}$ and length of $900 \mathrm{~mm}$. The concrete mix design is listed in Table 4.1 and the 28-day compressive strength was about $53 \mathrm{MPa}$. Wood molds and concrete beams are shown in

Fig. 4.2. The concrete beam, about $22 \mathrm{~kg}$, can be easily moved by hand, and loaded beam pairs with spring brackets were immersed in temperature controlled tanks.

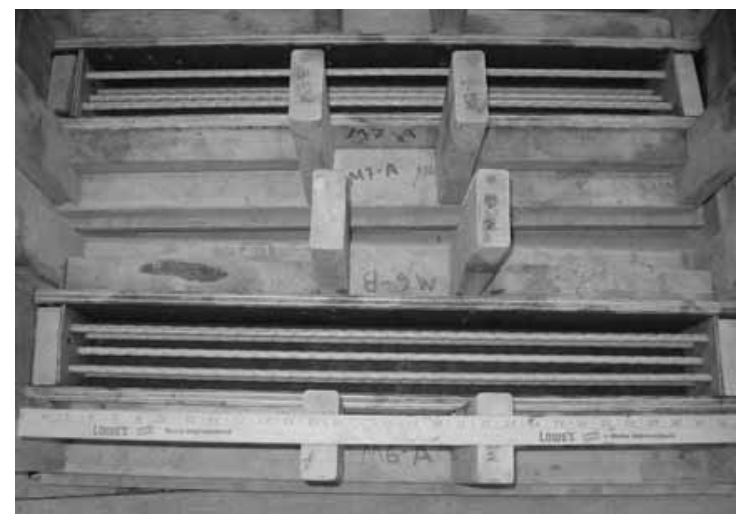

(a) wood molds

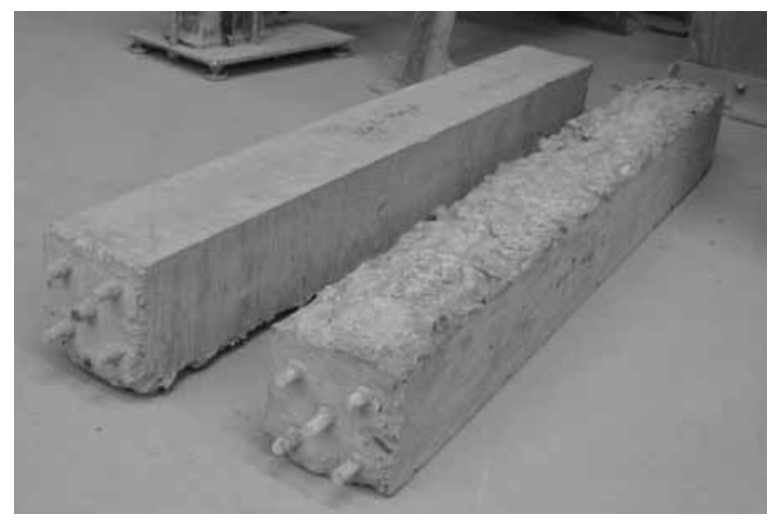

(b) concrete beams

Figure 4.2 Wood molds and concrete beams

Table 4.1 Concrete mix design $\left(\mathrm{kg} / \mathrm{m}^{3}\right)$

\begin{tabular}{ccccc}
\hline W/C & Cement & Sand & Gravel & Water \\
\hline 0.45 & 380 & 730 & 1141 & 171 \\
\hline
\end{tabular}

The wood molds and loaded concrete beams are shown in Fig. 4.3. For loaded concrete beams, spring-bracket assemblies as shown in Fig. 4.4 were fabricated to apply sustained load to concrete beams, which were reinforced with two bars on the tension side. To obtain the spring constants, springs were tested using a Baldwin machine as shown in Fig. 4.5 (a), and the typical load and displacement curve is shown in Fig. 4.5 
(b). The average spring constant is about $170 \mathrm{~N} / \mathrm{mm}$ as listed in Table 4.2.
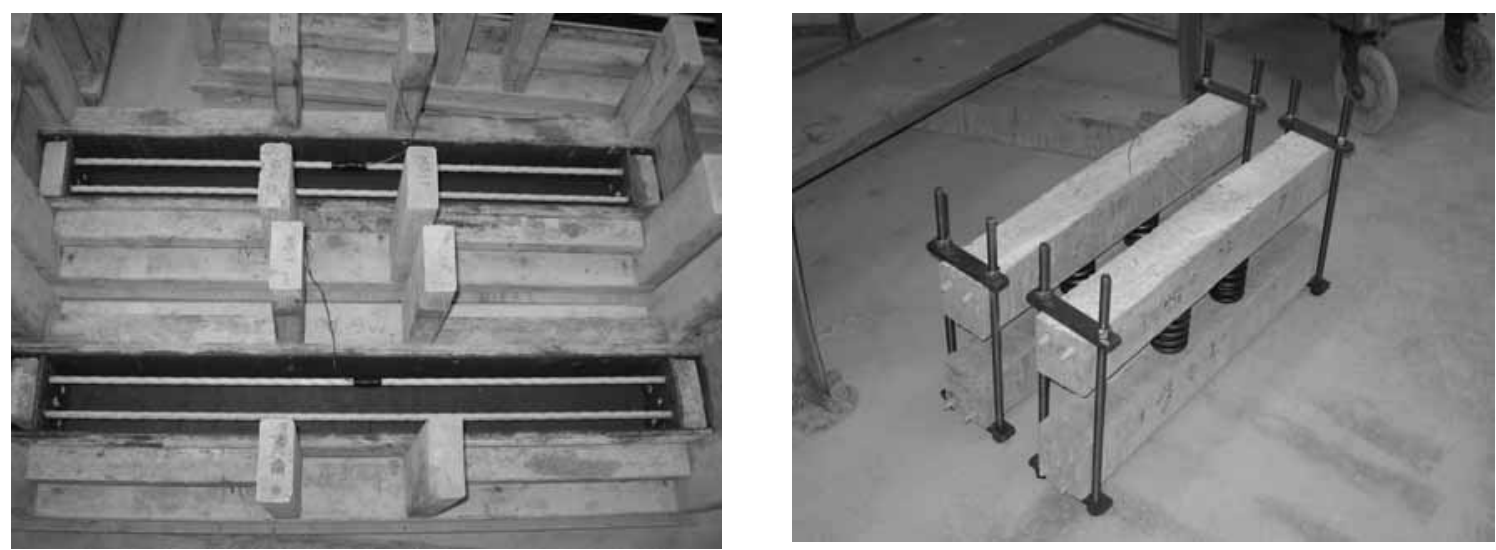

Figure 4.3 Wood molds and loaded concrete beams

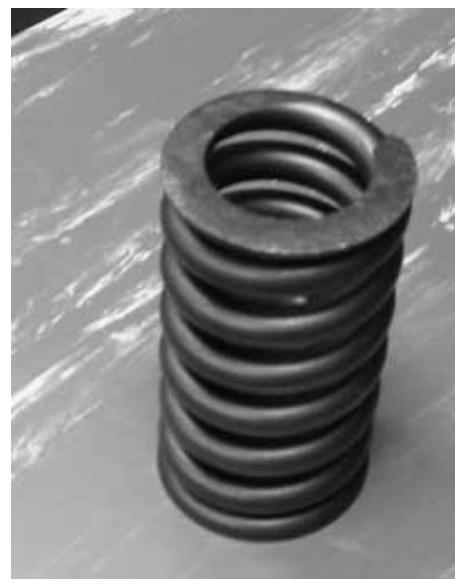

(a) spring

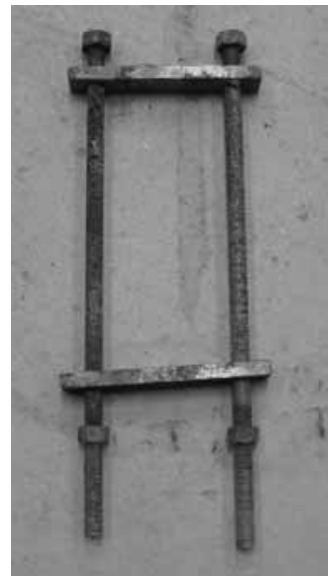

(b) bracket

Figure 4.4 Spring and brackets

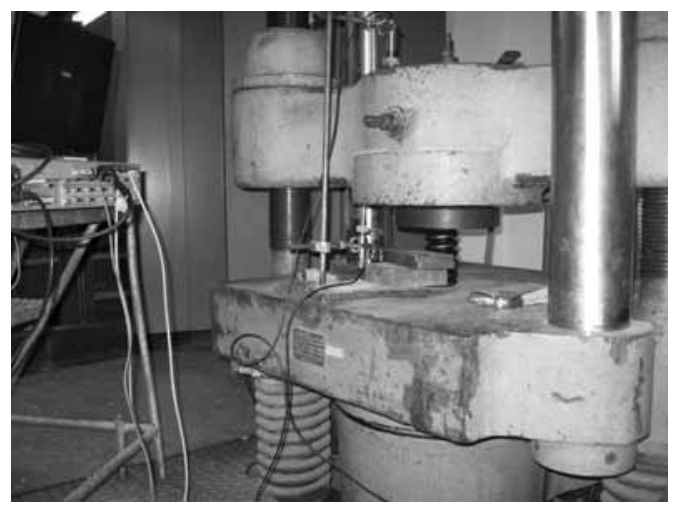

(a) Test set up for springs

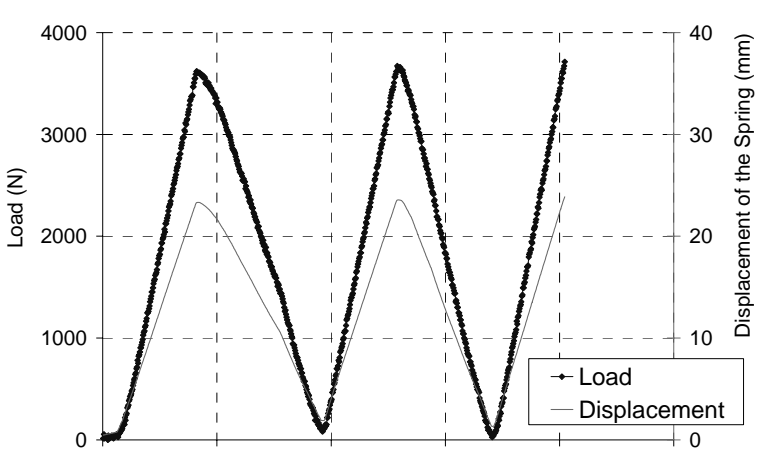

(b) Load and displacement curve

Figure 4.5 Spring constants 
Table 4.2 Spring constants (N/mm)

\begin{tabular}{ccccccc}
\hline Spring 1 & Spring 2 & Spring 3 & Spring 4 & Spring 5 & Average & COV \\
\hline 167 & 168 & 165 & 174 & 174 & 170 & 2 \\
\hline
\end{tabular}

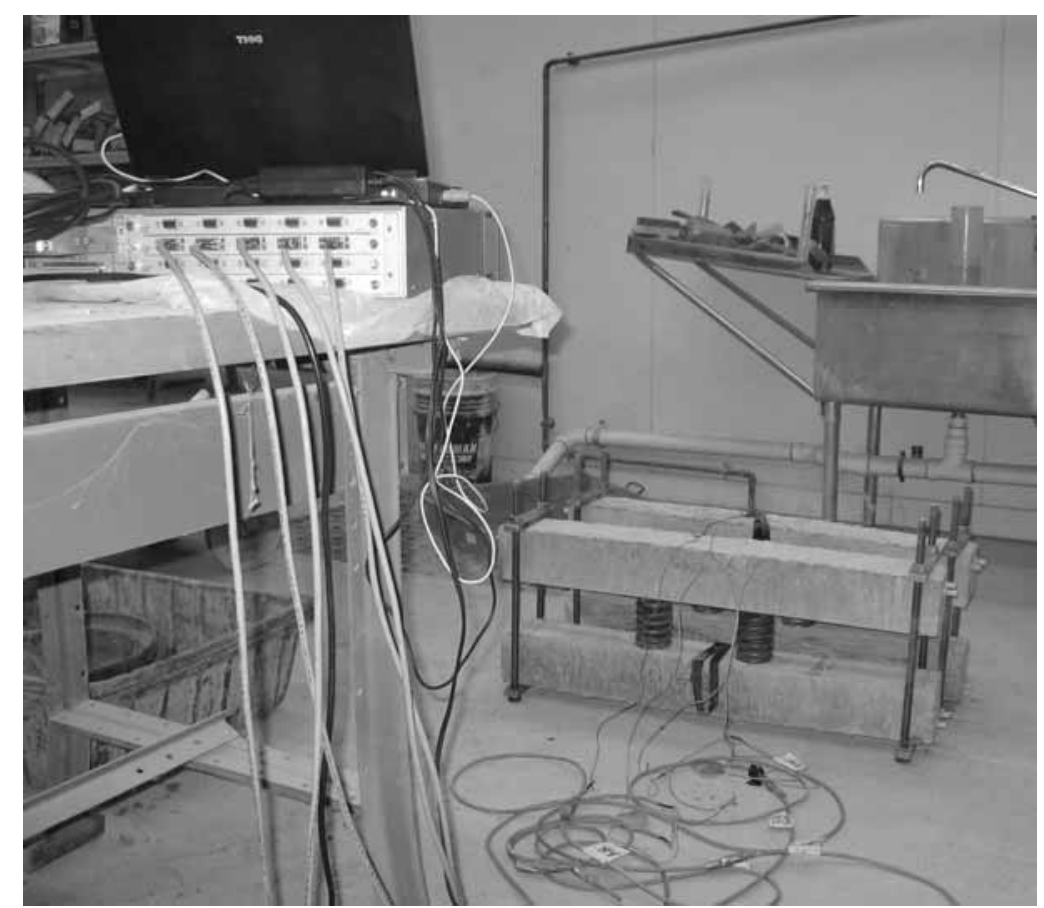

Figure 4.6 Application of load to concrete beams

Before the sustained load was applied, bending cracks were introduced in beams by subjecting them to higher load using the spring-bracket assembly. Cracking spaces were about $100 \mathrm{~mm}$. The purpose of introducing cracks was to simulate the real field conditions and achieve same load levels of FRP bars both in bottom and top beams.

The load was applied to concrete beams as shown in Fig. 4.6. The sustained load level was controlled by the axial stiffness (displacement) of the springs and strain gauges. The tensile strain level of the middle sections of GFRP bars in the loaded beams was in the range of 2000 2600 $\mu \mathrm{e}$, which corresponds to the sustained stress limit for these GFRP bars suggested by ACI Committee 440 to avoid creep rupture and fatigue fracture (ACI 
440, 2003). Due to the small size of concrete beams and lack of shear reinforcement, when the strain level of GFRP bars reached about $4000 \mu \mathrm{e}$, the beam failed in shear.

To monitor the strain level of bars in loaded beams, strain gauges were bonded on the surface of GFRP bars before they were embedded in concrete for two pairs of concrete beams. A data acquisition system was used to record the strain level of bars every half hour. For each pair of concrete beams (with two bars for each beam), the strain levels of three bars were monitored up to 2000 hours. The strain levels of bars vs. time are shown in Figs. 4.7 and 4.8. As expected, the strain changes were within $10 \%$ of the original levels, and strain levels approached constant values within 2000 hours for all six bars. Almost no changes were found for the displacements of springs. This indicated that constant sustained tensile strains in GFRP bars were successfully achieved by using the spring-bracket assemblies. In order to investigate the effects of load level on the durability of GFRP bars, a lower load level was applied to two pair of beams to achieve tensile strains of 1100 1300 $\mu$ e in GFRP bars. Even these sustained tensile strain values are much higher than what GFRP bars may be subjected to in real structures designed according to current design guidelines. One study showed that the maximum strain of GFRP bars is only about $30 \mu$ e for FRP bar RC bridge deck (EI-Salakawy et al., 2005). 


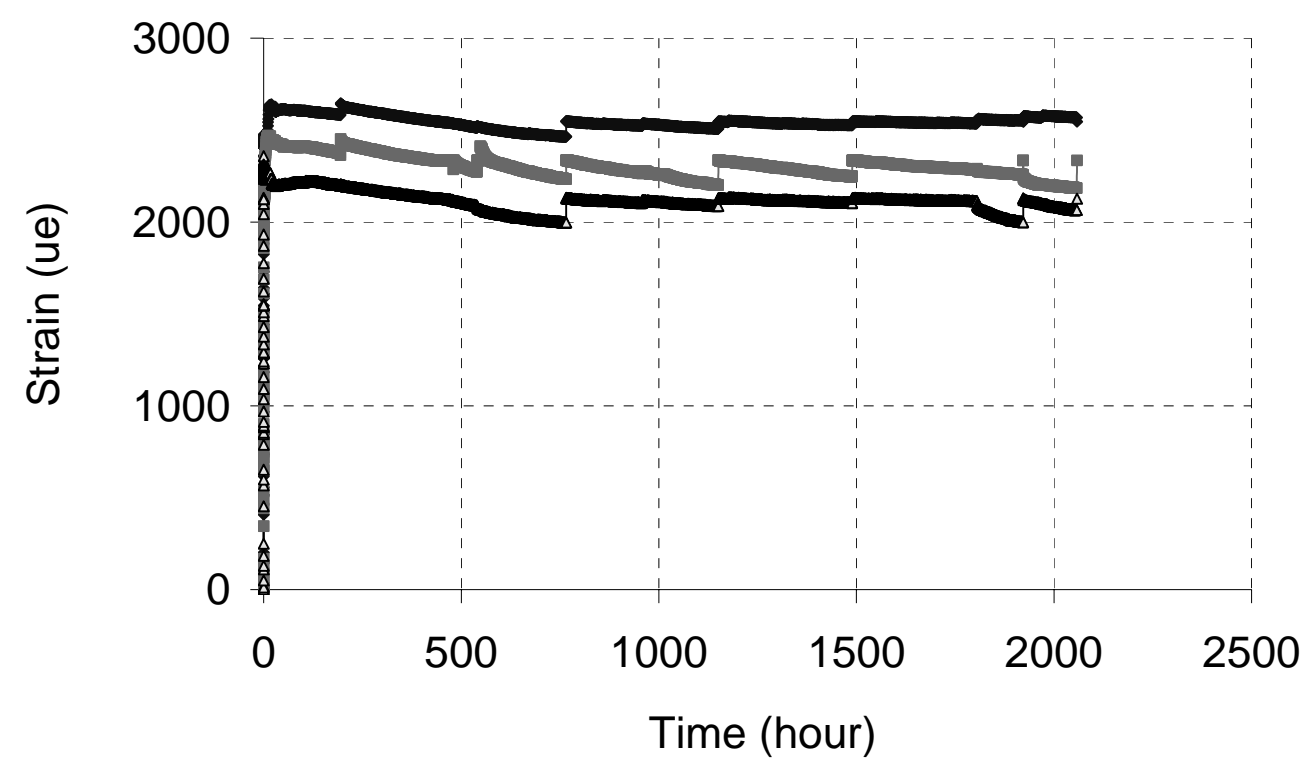

Figure 4.7 Tensile strains of bars (GFRP3) in loaded concrete beams vs. time

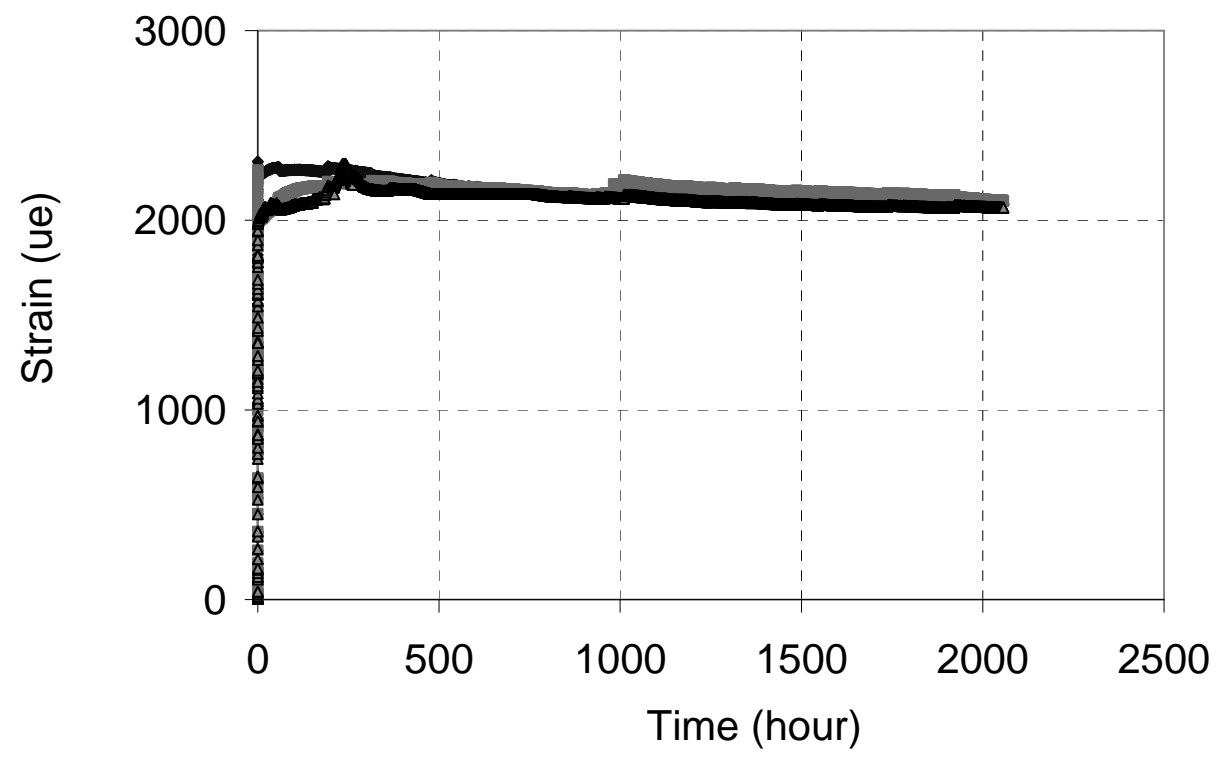

Figure 4.8 Tensile strains of bars (GFRP4) in loaded concrete beams vs. time 


\subsubsection{Testing plan}

In this study, groups of GFRP bars were tested for tensile strength before and after being conditioned for different exposure times. The test was conducted in accordance with ASTM D 3916 with some modifications, as stated in the previous chapter.

Elevated temperatures of 20, 40, 50 and $60{ }^{\circ} \mathrm{C}$ were adopted to accelerate the attack of concrete environment to specimens. Concrete beams were immersed in tap water of temperature controlled tanks as shown in Fig. 4.9, which were custom designed to introduce elevated temperature environment. Due to the limitation of space, only GFRP1 bar beams were immersed in temperature controlled tanks.

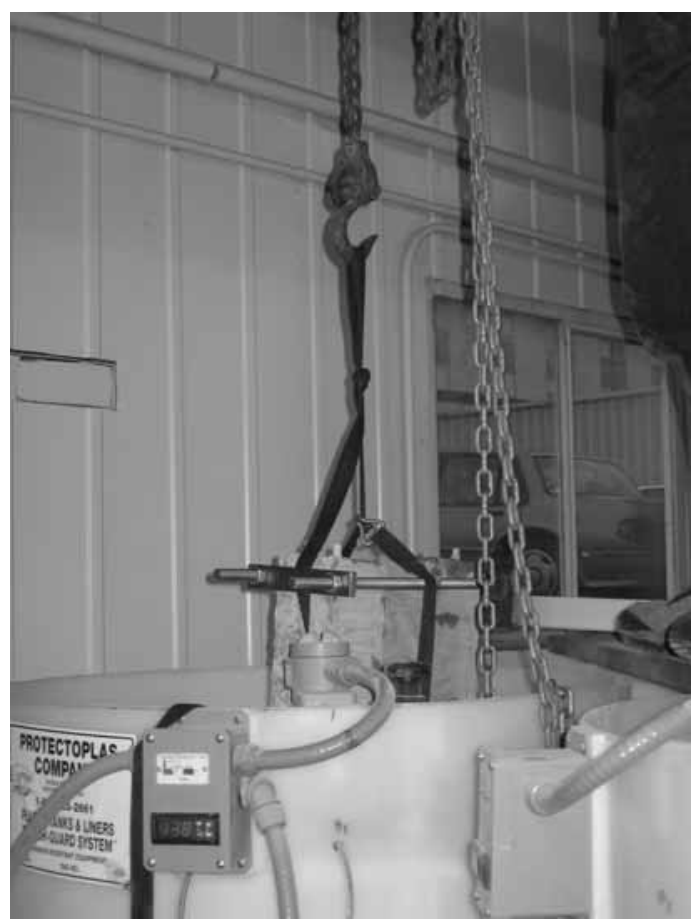

Figure 4.9 Loaded concrete beams in temperature controlled tank 
For comparison purpose, a few concrete beams and bare GFRP bars were also immersed in the tap water of curing tanks as shown in Fig. 4.10 or left in open air of concrete lab with a relative humidity of $50 \%$ and temperature of $20{ }^{\circ} \mathrm{C}$. As in the previous chapter, the GFRP1 bar reinforced concrete beams were conditioned in tap water at different temperatures and duration periods. The purpose of this arrangement is to develop prediction models possibly using Arrhenius concept. The detail about durability prediction will be presented in chapter six. The environmental exposure plan for this study is summarized in Tables 4.3 and 4.4. The bars in concrete beams were carefully extracted and tested for residual tensile strengths after conditioning.

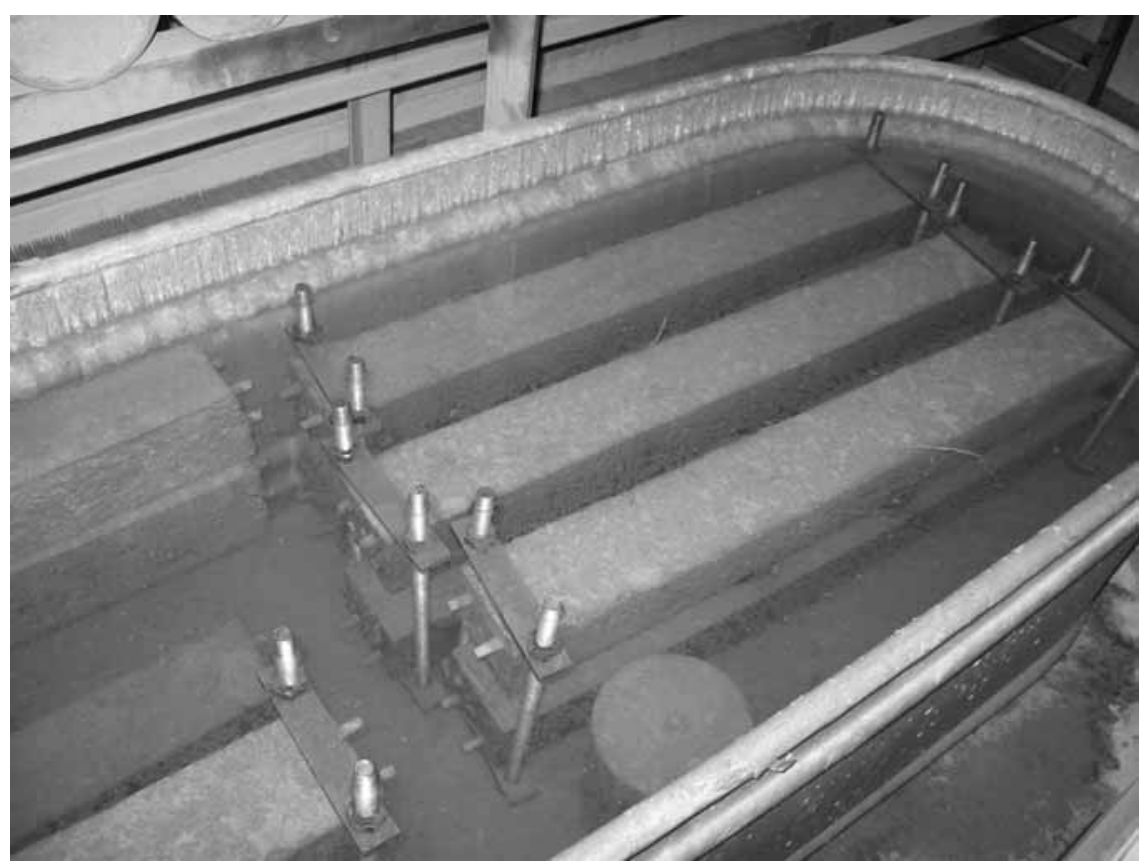

Figure 4.10 Concrete beams in curing tank 
Table 4.3 GFRP3 bars specimens in temperature controlled tanks

\begin{tabular}{lcccccc}
\hline Load type & Temperature $\left({ }^{\circ} \mathrm{C}\right)$ & \multicolumn{5}{c}{ Exposure time (days) } \\
\hline Not loaded & 60 & 30 & 90 & 150 & 210 & 270 \\
& 50 & 30 & 90 & 150 & 210 & 270 \\
& 40 & 30 & 90 & 150 & 210 & 270 \\
Loaded & 20 & 30 & 90 & 150 & 210 & 270 \\
& 60 & 90 & 120 & 170 & 210 & \\
& $60 *$ & 120 & 210 & & & \\
& 40 & 90 & 120 & 210 & & \\
\hline
\end{tabular}

* low load levels (corresponding to strains of 1100 1300 $\mu \mathrm{e}$ ) were applied to those beams;

Table 4.4 Specimens exposed to room temperature for 150 days

\begin{tabular}{lcc}
\hline Environmental exposure & GFRP3 & GFRP4 \\
\hline Bare bars in curing tank & $\sqrt{ }$ & $\sqrt{ }$ \\
Concrete beams in ambient of concrete lab & $\sqrt{ }$ & $\sqrt{ }$ \\
Loaded concrete beams in ambient of concrete lab & $\sqrt{ }$ & $\sqrt{ }$ \\
Concrete beams in curing tank & $\sqrt{ }$ & $\sqrt{ }$ \\
Loaded concrete beams in curing tank & $\sqrt{ }$ & \\
\hline
\end{tabular}

\subsection{Test Results and Discussion}

During the tensile strength test, pristine GFRP bars showed approximate linear stressstrain behavior up to failure, which was accompanied by a combination of fiber fracture and delamination as observed for GFRP1 and GFRP2 bars in the previous chapter. The typical failure of GFRP bars is shown in Fig. 4.11. Similar but less catastrophic failure accompanied by more delamination was observed for conditioned specimens. The tensile strength and modulus of elasticity for pristine GFRP3 bars were $856 \mathrm{MPa}$ and $46 \mathrm{GPa}$, respectively. Pristine GFRP4 bar had tensile strength of $841 \mathrm{MPa}$ and modulus of elasticity of $49 \mathrm{GPa}$. The percent tensile strength retentions are summarized in Figs. 4.12 
through 4.14 (the over bar represents standard deviation). Each data represents an average of three to four test results.

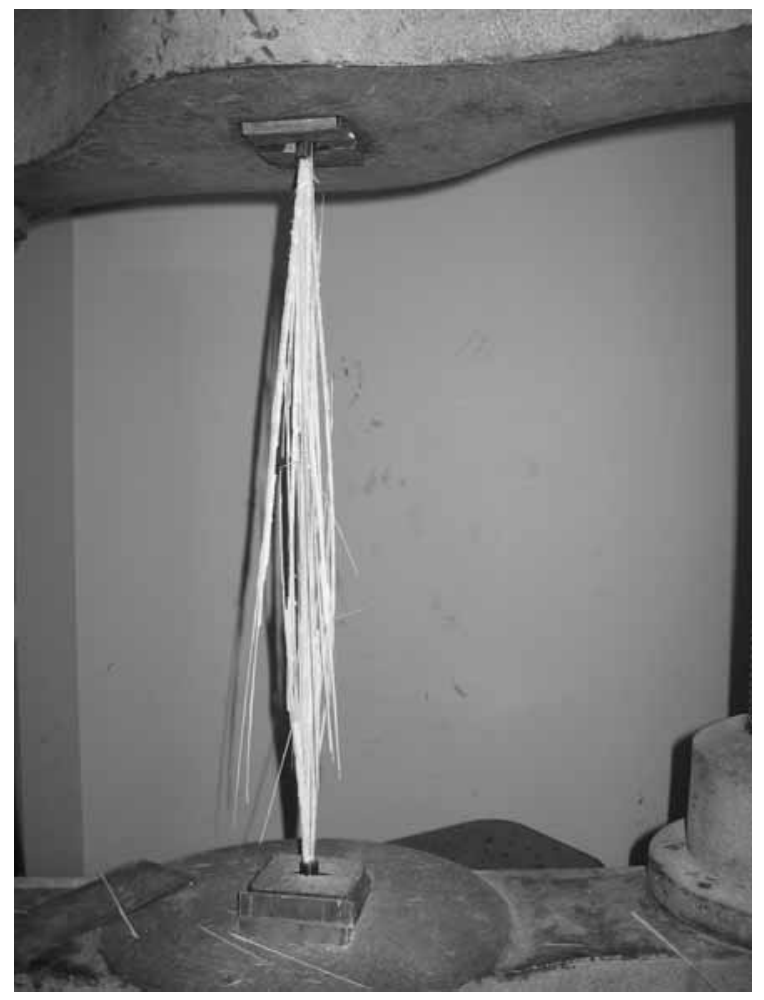

(a) GFRP3 bar

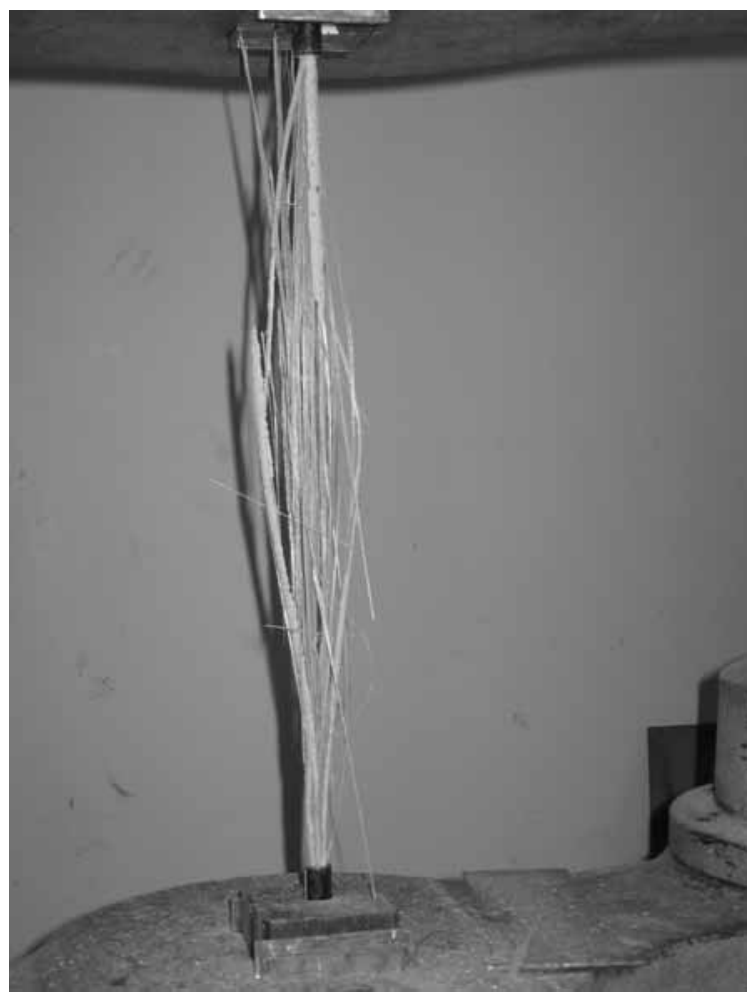

(b) GFRP4 bar

Figure 4.11 The typical failure of GFRP bars

As shown in Fig. 4.12, GFRP3 bars in loaded concrete beams experienced about $20 \%$ tensile strength reduction after being immersed in curing tank for 150 days. For all the other cases, the tensile strength retention was above $90 \%$ for both types of GFRP bars. There is almost no tensile strength reduction for those in concrete beams exposed in air of concrete lab. It can be found that saturated concrete environment is more aggressive to GFRP than water. Also, GFRP bars have better durability performance in dry concrete environment than in water or saturated concrete. It can also be found that GFRP4 bars have relatively better durability performance in concrete environment than GFRP3 bars. 


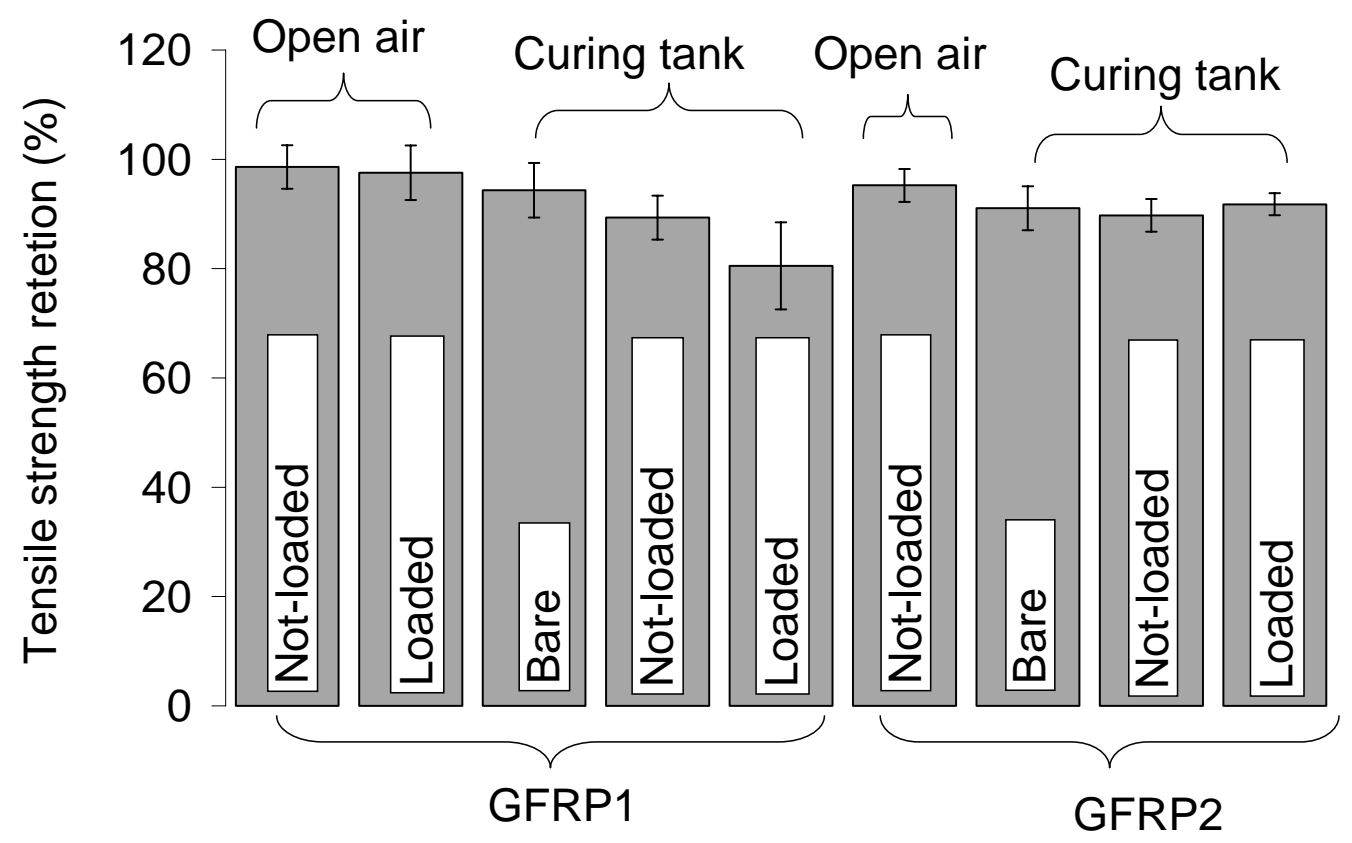

Figure 4.12 Tensile strength retentions of GFRP bars in curing tank or open air for 150 days

From Fig. 4.13, it can be observed that the tensile strength reduction for GFRP1 bars embedded in beams under both load levels is about $40 \%$ after 120 day exposure to water at $60{ }^{\circ} \mathrm{C}$. After 210 day exposure, the tensile strength reduction is about $55 \%$ for GFRP3 bars embedded in beams either loaded or not-loaded. From Fig. 4.14, the tensile strength reductions for GFRP3 bars embedded in not-loaded beams and loaded beams were close to each other. These test results show that load levels (relatively low compared to the ultimate tensile strength) had little effect on degradation rate. Sustained tension applied in this study did not result in substantially more degradation in GFRP bars in concrete. From test results shown in Figs. 4.12 to 4.14 , it can be found that compared to alkalinity and load, moisture and elevated temperature played more important roles in the environmental attack to GFRP bars. 


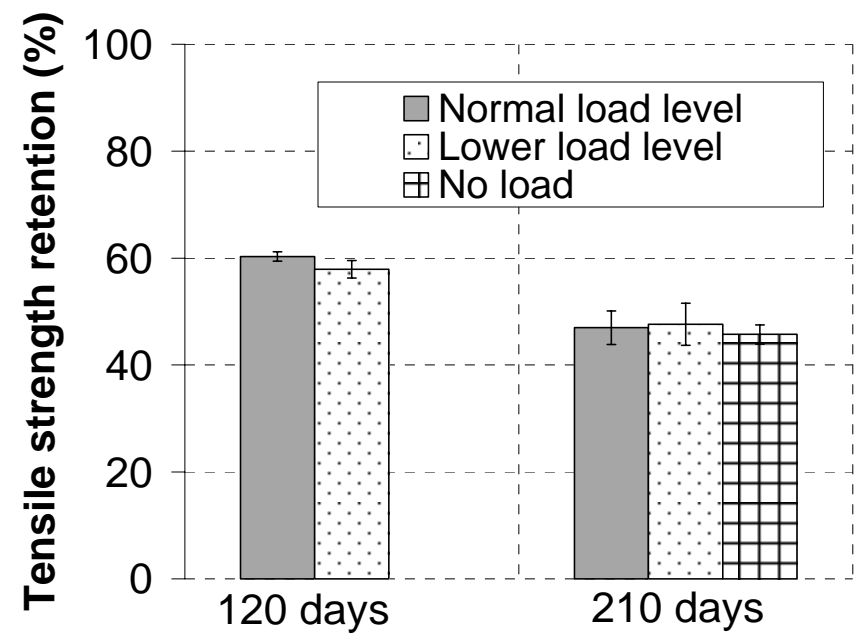

Figure 4.13 Tensile strength retention of GFRP3 bars in concrete beams under different load levels immersed in tap water at $60{ }^{\circ} \mathrm{C}$

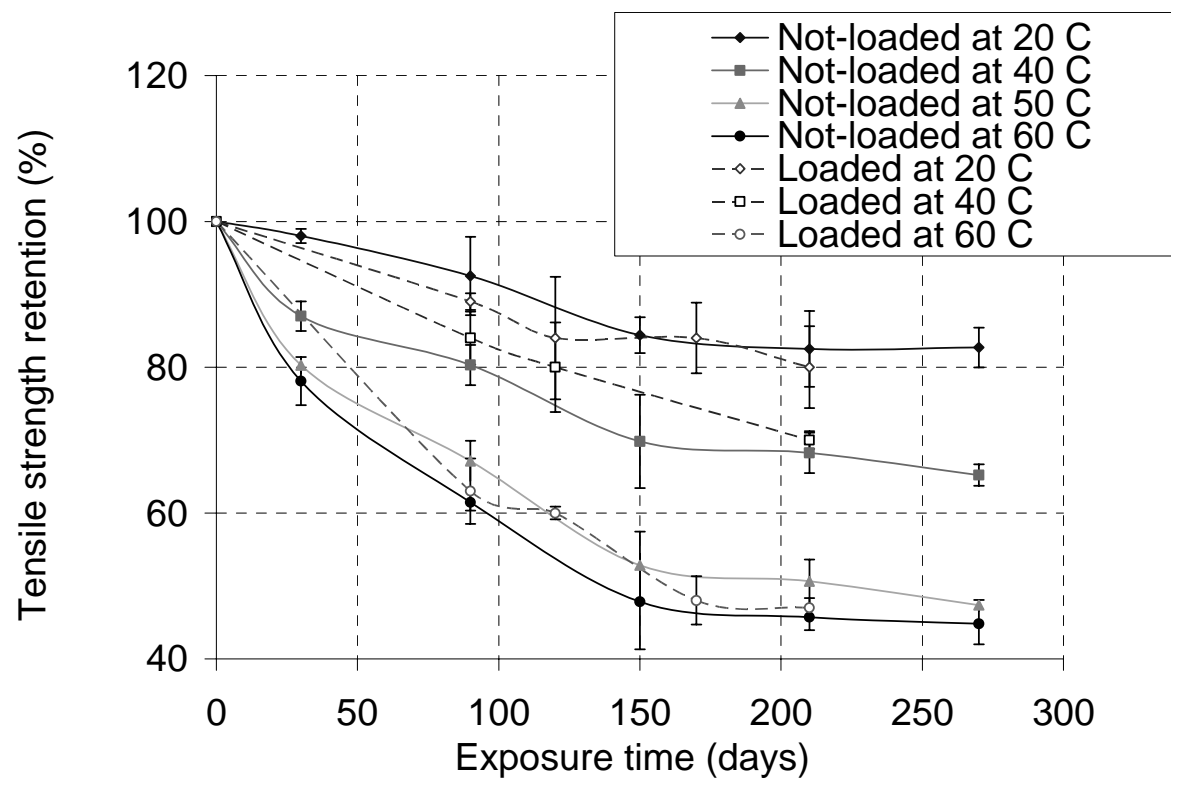

Figure 4.14 Tensile strength retentions of GFRP3 bars embedded in concrete beams exposed to tap water at elevated temperature

It is also apparent from Fig. 4.14 that the tensile strength decreased with the increase of exposure time for GFRP3 bars at all temperatures, and degradation was more severe for specimens exposed to higher temperatures. But the degradation rate decreased quickly 
as the exposure time increased. The same behavior was also found in Dejke (2001). This may be explained by the accumulation of byproducts of chemical reactions, as well as limited replenishment of alkaline solutions, and the decrease in alkalinity (reduced $\mathrm{pH}$ value) of pore solution during the degradation.

\subsection{Concluding Remarks and Recommendations}

Based on the test results in this chapter, the following concluding remarks can be made. Generally, GFRP4 bars have better durability performance than GFRP3 bars. Saturated concrete environment is more aggressive to GFRP than water, while GFRP bars had much better durability performance in dry concrete than in water or saturated concrete. According to the short term test results, different load levels applied in this study had little effect on degradation rate and sustained tension applied in this study did not result in substantially more degradation in GFRP bars. Compared to alkalinity and load, moisture and elevated temperature play more important roles in the environmental attack to GFRP bars.

The degradation rate for GFRP embedded in concrete decreased very fast as the exposure time increased. Significant tensile strength reduction was observed for those subjected to accelerated aging conditions. The reported short-term results in this chapter should be considered as conservative since GFRP bars in field conditions are subjected to lower sustained load and humidity and have thicker concrete cover in most cases.

Based on test results in this study, the following recommendation can be made. More types of GFRP bars should be studied for the long term durability prediction in order to recommend a general environmental reduction factor for GFRP bars in design guides. The effects of parameters such as humidity of concrete, load level, concrete cover 
thickness on the degradation of embedded GFRP bars should also be investigated. Long term data of GFRP bars from field conditions should be collected. A correlation should be defined between degradations of FRP bars in accelerated testing environment and natural conditions. 


\section{CHAPTER FIVE SEM AND EDAX ANALYSIS}

\subsection{Introduction}

From the results presented in previous two chapters, it can be found that the environmental conditioning of FRP bars led to reduced tensile strength and ILSS. Since FRP is composed of matrix and fibers with diameters of $5 \sim 30 \mu \mathrm{m}$, the reduction of mechanical properties must come from the degradations of matrix, fibers and/or fiber/matrix interphase. So it will be very helpful for the evaluation of degradations and the understanding of degradation mechanism if the change of microstructure and chemical elements of FRP material can be observed.

Microscopy analysis is the common method to investigate the microstructure change of FRP materials. Light has a wavelength of approximately $500 \mathrm{~nm}$. Therefore the resolution is limited when light is used as a source of illumination for the sample in light microscopy. In practice, the maximum magnification obtainable with a light microscope is 1000. Electrons have an effective wavelength of about $0.1 \mathrm{~nm}$ and so allow for much greater resolution and therefore greater magnification of the sample when they are used to view the sample in an electron microscope. So in this study, scanning electron microscopy (SEM) and energy dispersive analysis of X-ray (EDAX) were used to investigate the degradation of FRP bars.

In this chapter, the basic knowledge of SEM and EDAX is introduced first. Then the detail information of sample preparation is presented. Finally, typical results of SEM and EDAX analysis are provided and discussed. 


\subsection{Introduction of SEM and EDAX}

Before the experiment work, the basic knowledge of SEM and EDAX is introduced in this section.

SEM uses focused beam of electrons scanning over the surface of specimens. This microscope is analogous to the stereo light microscope. The typical procedure for the formation of SEM image is shown in Fig. 5.1. A high voltage is applied to heat a filament made of tungsten wire. Electrons, negatively charged, are "boiled" off and directed toward through the microscope by a series of electromagnetic lenses. Before the electron beam comes into contact with the sample, it passes through a small aperture. When the electron beam hits the sample (the energy of the beam is typically in the range 10-20 $\mathrm{keV})$, it penetrates the surface and creates a volume of excited atoms, which depends on the accelerating voltage used to create the beam and the hardness of the sample. Some electrons from the beam displace electrons from the atoms of the sample, which causes secondary electrons to be pushed back out of the sample together with X-rays. When the other electrons from the beam hit the nucleii of the atoms from the sample, they are reflected back from the sample and are called backscattered electrons. As shown in the figure, secondary electrons are collected with a detector that has a phosphoric light guide. Electrons strike the phosphor and then cause flashes of light that are picked up by a photomultiplier tube and then are converted into an electrical signal which in turn goes to a cathode ray tube (monitor screen). SEM images are produced one spot at a time in a grid-like raster pattern. By scanning a beam of electrons across the surface of a sample, an image can be formed on a monitor. Areas reflecting lots of electrons appear bright, 
while areas not reflecting many electrons appear dark. The backscattered electrons can also be used to form an image of the sample.

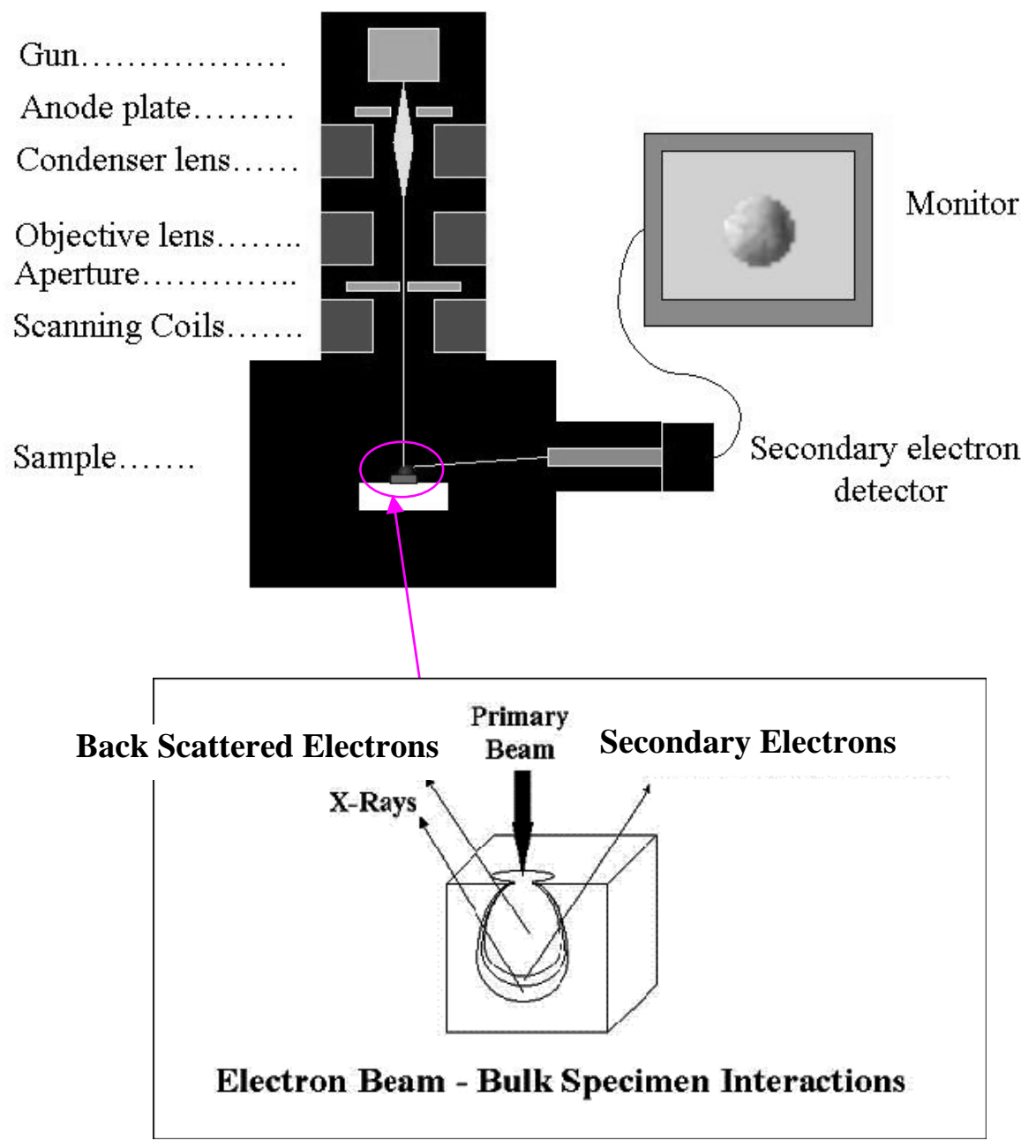

Figure 5.1 Schematic diagram of a scanning electron microscope (http://www.lifesci.sussex.ac.uk/sem/page\%202.htm)

EDAX is used in conjunction with SEM but it is not a surface science technique as SEM. As shown in Fig. 5.1, when the electron beam hits the atoms of the sample, X-rays are emitted from the surface in addition to the secondary and back scattered electrons. The energy of the X-rays emitted depends on the sample under examination. Usually, the 
X-rays are collected using the Lithium drifted silicon detector, which must be operated at liquid nitrogen temperatures. A photoelectron will be generated in the body of Si due to the strike of an X-ray on the detector. This photoelectron travels through the Si, which generates electron-hole pairs. The applied strong electric field attracts the electrons and holes to opposite ends of the detector, which generates current pulses. The size of pulse depends on the number of electron-hole pairs, which is controlled by the energy of the incoming X-ray. So the acquired X-ray spectrum can provide information on the elemental composition of the sample. Usually elements below an atomic number of 11 (Na) are difficult to be detect by EDAX. Because the Lithium drifted silicon detector is often protected by a Beryllium window. The absorption of the soft X-rays by the Be precludes the detection of elements of low atomic number.

As discussed in chapter two, the degradation of FRP bars can be due to matrix micro cracking, fiber/matrix debonding, and fiber pitting, which can be found by SEM. The hydrolysis of matrix, and leaching and etching of fibers can also be the reasons of degradation. Then the chemical compositions of glass fiber and matrix, and the chemical element distribution in the bars are changed. To maintain charge neutrality, a strong alkali migration from the concrete pore solution toward fibers would lead to the presence of $\mathrm{Na}$ or $\mathrm{K}$ in the matrix. The EDAX is supposed to detect such possible chemical changes in matrix and fibers.

\subsection{Specimen Preparation}

Before the SEM and EDAX analysis, the specimen needs to be carefully prepared. The FRP samples in this study are combinations of soft and hard materials, polymer 
matrix, glass fibers and carbon fibers. It is difficult to use a standard mechanical polishing technique to polish a junction of materials with different hardness into a mirror surface. The problems for standard mechanical polishing to FRP materials can be summarized as: (1) the soft portion is cut faster; (2) pieces of hard polish are embedded in the soft material; (3) soft materials around voids may be stretched, deformed or even cover the voids. So to obtain reliable information from the results, special care and attention must be given to sample preparation. Due to the lack of 3D analytical technique for damage diction, both cross sections and longitudinal sections of FRP bars have been investigated to increase the chances of detecting damages in specimens without using excessive large number of cross sections. The steps used in the preparation of these samples were as follows:

\section{(a) Samples from FRP bars were cut with a diamond blade saw.}

The size of the sample should fit the SEM sample holder. The length of the FRP bar sample is about $6 \mathrm{~mm}$ (a quarter of inch).

\section{(b) The FRP specimens were mounted in cups and secured with resin.}

Specimens were embedded in a resin for safer, more convenient handling and to improve the preparation results. Two different mounting techniques are available: hot compression mounting and cold mounting. But in case of hot compression mounting, a temperature of up to $200{ }^{0} \mathrm{C}$ and a force up to $50 \mathrm{kN}$ will be applied during the embedding of the specimens, which may introduce damages to samples. So in this study, codling mounting was adopted. The EpoFix kit as shown in Fig. 5.2 was purchased from Struers for the cold mounting of FRP specimens in this study. It is worth mentioning that before pour the resin into the mounting cup, the FRP specimens should be stuck to the 
bottom of the cup using some weak glue so the specimens will not float or move during the preparation. To save time for polishing, coating, microscope analysis, more than one FRP specimen was mounted in one cup. The samples removed from cups after 24 hours are shown in Fig. 5.3.

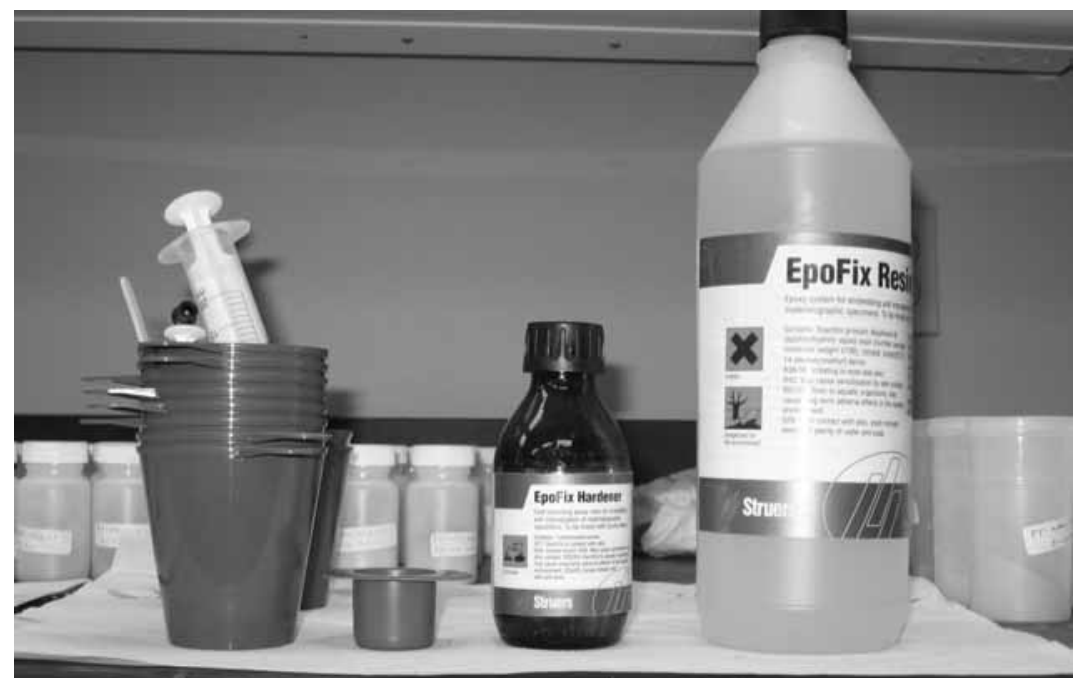

Figure 5.2 EpoFix kit

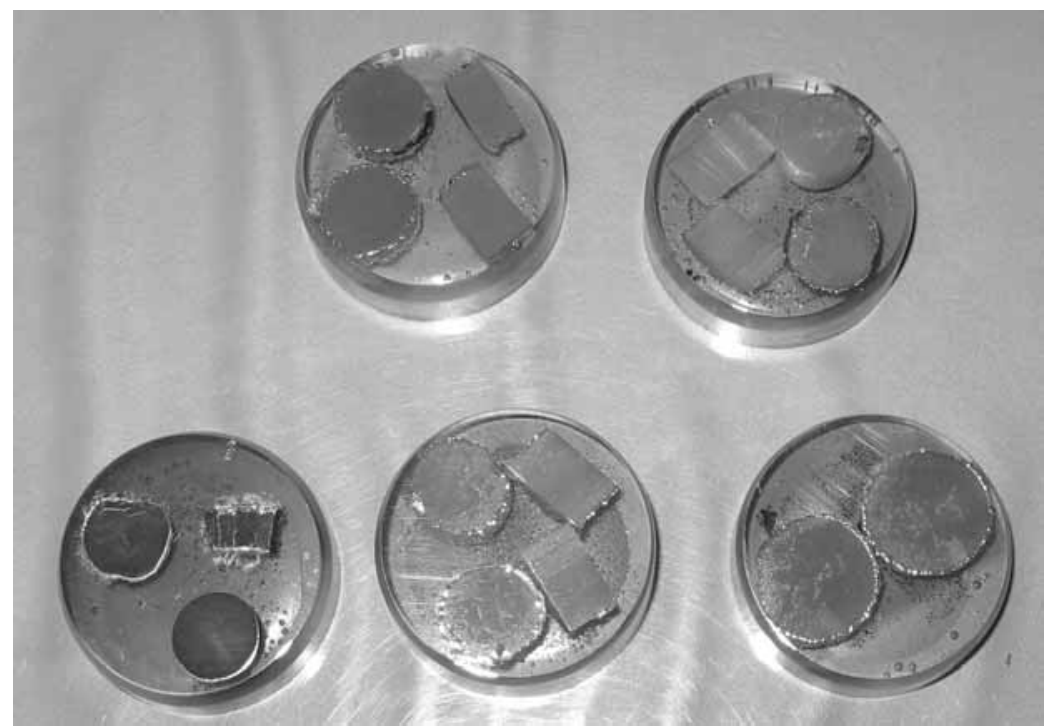

Figure 5.3 Samples for SEM and EDAX

(c) The surfaces of specimens were polished.

The sample surfaces were polished with aluminum oxide powder and slurry using a 
grinder. Since in this study, a wide range of FRP products was polished, the polishing procedure may be a little bit different for each product. The procedure may also need to be modified if different grinders, polishing discs and abrasives are used. For this study, the polishing procedure is summarized in four steps.

First, the sample was polished with MD-Piano 600, which is a resin bonded diamond grinding disc with surface finish comparable to SiC-paper grit 80 for plane grinding of materials. In the second step, the sample was polished with MD-Piano 1200 for 5 minutes, which is a grinding disc with surface comparable to SiC-Paper grit 1200 for fine grinding of materials. In the third step, a MD- Mol disc (Taffeta woven $100 \%$ wool surface) with aluminum oxide powders (particle diameter of $3.0 \mu \mathrm{m}$ ) as polishing paste was used to polish the sample for 3 minutes. In the final step, the sample was polished with a MD-Mol disc and the paste of alumina slurry (particle diameter of $0.3 \mu \mathrm{m}$ ) for 2 minutes. For each step, the grinder worked at $150 \mathrm{rpm}$, forces about $5 \sim 15 \mathrm{~N}$ were applied to the sample and water was used as lubricant. After each step, the sample was cleaned in the bath of an ultrasonic cleaner for 1 minute. It is worth mentioning that to avoid contamination different polishing discs should be used for different abrasive pastes (i.e. different particle diameters). To check the quality of polishing, optical microscope was employed to study the polished surface before the sample was coated for SEM analysis.

To perform the polishing procedure above, equipment and consumables were purchased. TegraPol-31 grinder as shown in Fig. 5.4 is a sturdy machine with a single $300 \mathrm{~mm}$ magnetic disc unit designed for intensive use and for the preparation of many or large samples with two speeds (150/300 rpm). MD disc series were also purchased. The polish abrasives, aluminum oxide powder and alumina slurry as shown in Fig. 5.5, were 
provided by Electron Microscopy Sciences. The ultrasonic cleaner as shown in Fig. 5.6 uses ultrasonic energy in the form of sound waves to introduce millions of tiny bubbles in the solution every second. These bubbles expand and collapse rapidly to create a mechanical scrubbing action to loosen and scrub dirt off the object. The bubbles can even work their way into holes and hidden cavities. Stereomicroscope system SZX-ZB12 was used for optical microscopy analysis.

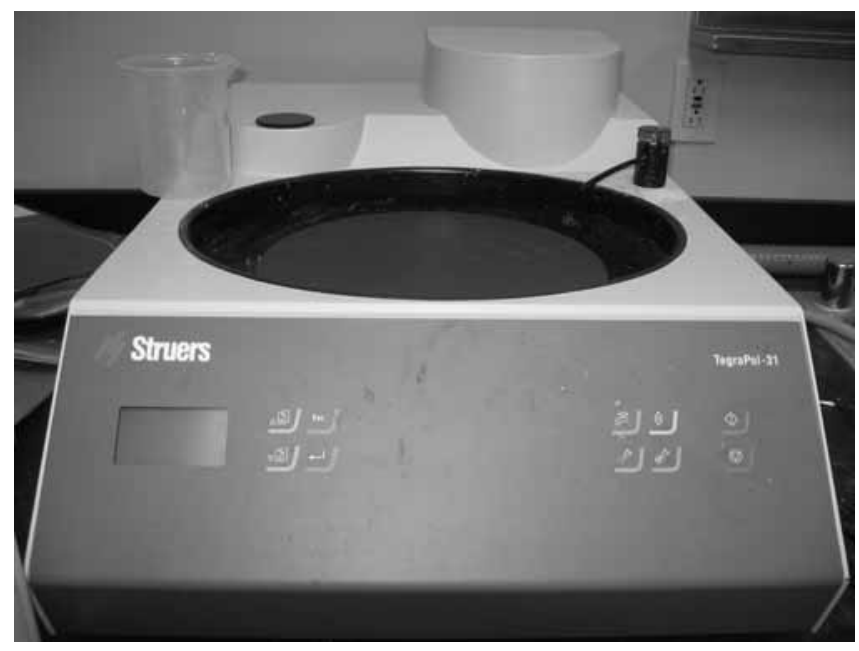

Figure 5.4 TegraPol-31 grinder

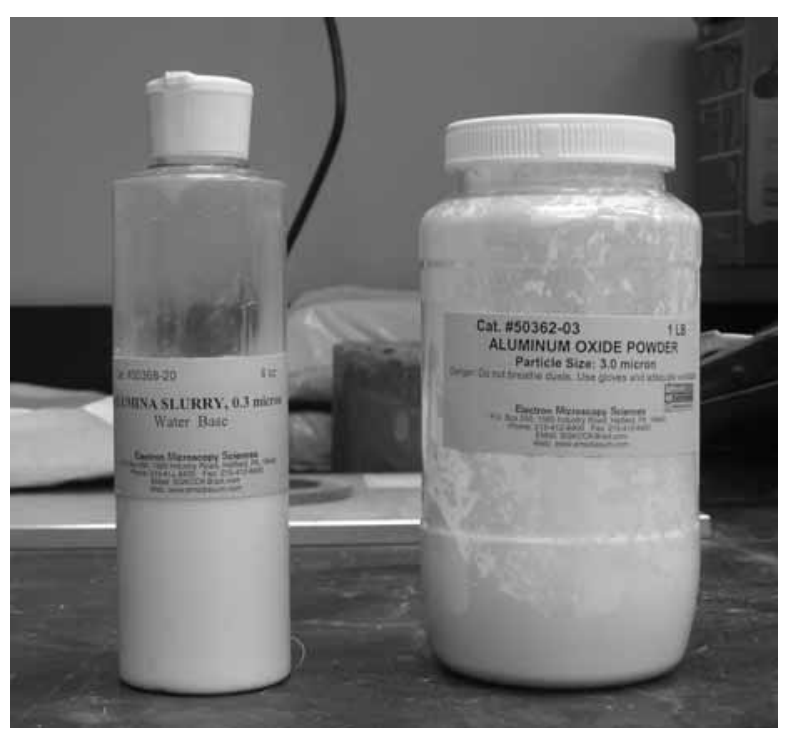

Figure 5.5 Abrasives 


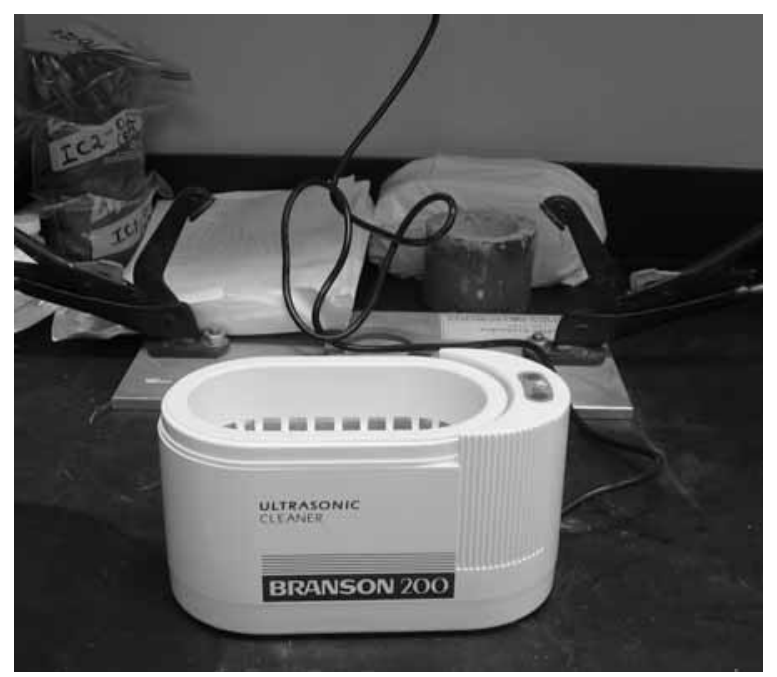

Figure 5.6 Ultrasonic cleaner

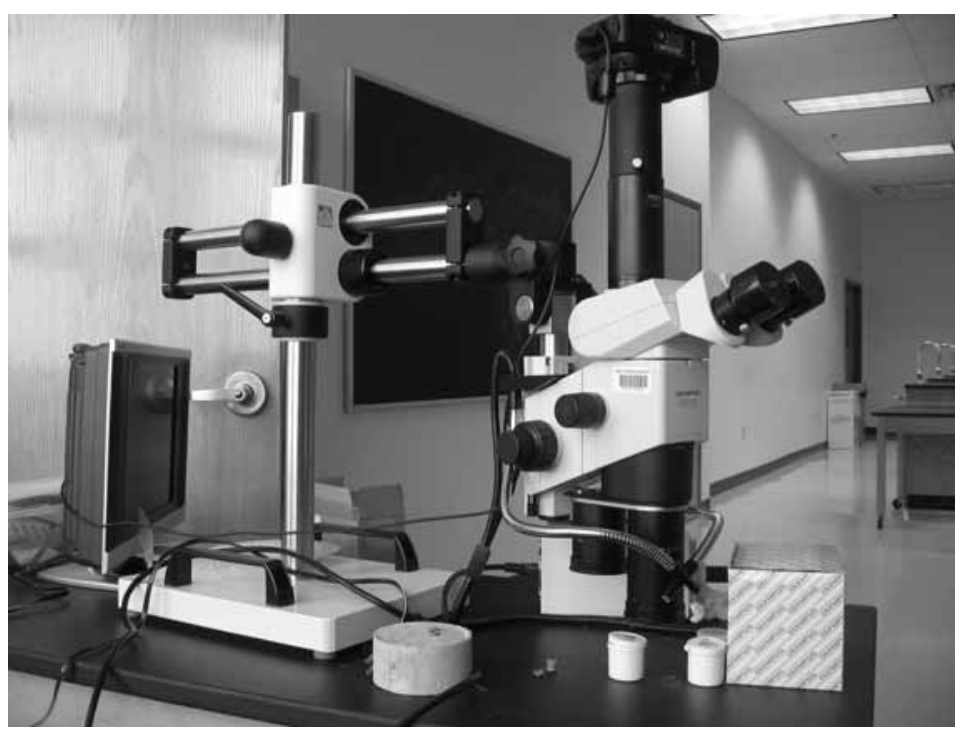

Figure 5.7 Research stereomicroscope system SZX-ZB12

\section{(d) Sample coating and mounting}

Since SEM will hit the sample surface with electron beams, if the sample is nonconductive, it is necessary to coat with a thin layer of gold or similar material on sample surface. The coating does not make the sample itself conductive but helps to stop charging effects. Two coating techniques are popular: sputter coating (gold) and carbon coating. In this study, the FRP samples were coated with gold. The coating was carried 
out using the coater as shown in Fig. 5.8. The thickness of coating layer depends on the time of coating. In this study, the sample surface was coated with $20 \mathrm{~nm}$ gold. After coating, the sample was stuck to an aluminum stub using double sided sticky tapes. Then the stub was placed into the specimen holder of SEM as shown in Fig. 5.9.

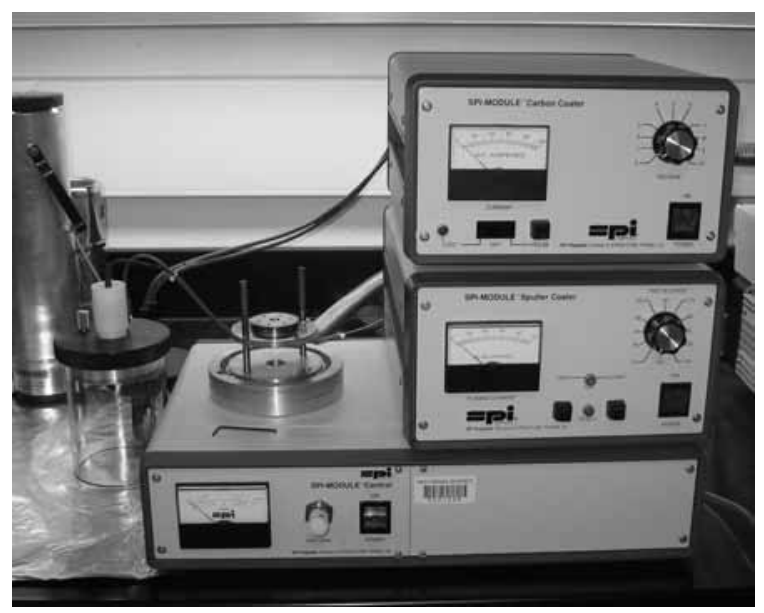

Figure 5.8 SPI-MODULE coaters

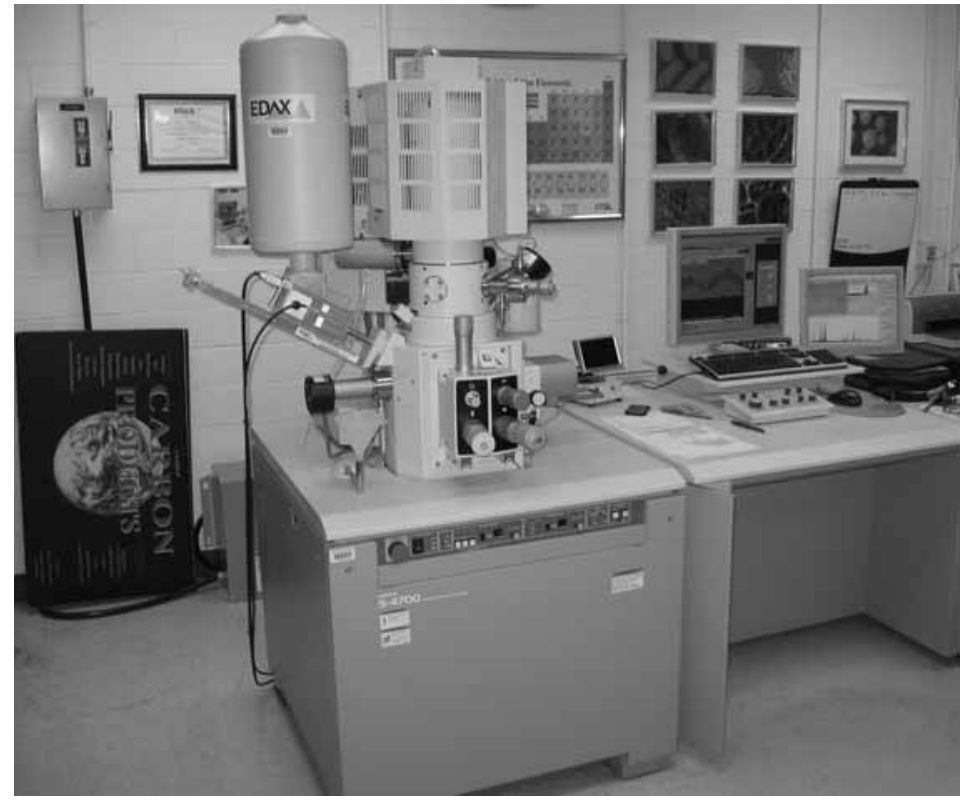

Figure 5.9 Hitachi S-4700 SEM 


\subsection{Results and Discussion}

Since SEM and EDAX can only check very limited sections of specimens each time, voids or degradation may be much localized, only typical results from several samples for same conditions are presented here.

\subsubsection{Unconditioned Specimens}

The typical SEM images and EDAX spectra of unconditioned FRP bars are presented in Figs. 5.10 and 5.11, respectively. From Fig. 5.10 (a) (e), it can be found that the diameter of glass fibers is in the range of $15 \sim 30 \mu \mathrm{m}$, while carbon fibers have a diameter of about $7 \mu \mathrm{m}$. The fiber diameter in GFRP1 and GFRP3 bars is more uniform than that of fibers in GFRP2 and GFRP4 bars. More hard polish embedded in matrices was found for GFRP1, GFRP2 and GFRP3 bars than GFRP4 and CFRP bars.

For comparison purpose, more unconditioned samples were analyzed. As shown in Fig. 5.10 (f) (i), many more voids were observed in matrix of GFRP3 bars than that of GFRP4 bars. The transverse section of the bar (along the fiber direction as shown in Fig.5.10 $\mathrm{h}$ and i) shows that these voids are localized. GFRP1 band GFRP2 bars have similar voids distribution as GFRP3 bars. GFRP1, GFRP2 and GFRP3 bars have the same vinyl ester matrix and were provided by the same manufacturer, while GFRP4 bars have urethane-modified vinyl ester resin matrix and was provided by another manufacturer. Since samples are unconditioned, the voids must be due to the manufacture.

From the EDAX spectra of Fig. 5.11, it can be found that glass fibers of all four types of GFRP bars are composed of almost same chemical elements. But small difference in alkaline metal elements such as $\mathrm{Na}$ and $\mathrm{Mg}$ was found in those fibers. For CFRP bars, the 
only element found is carbon in the fiber. Since the spectra of matrices of all FRP bars are same (as discussed in section 2.2.2, all matrices are composed of $\mathrm{C}$, $\mathrm{O}$, and $\mathrm{H}$ ), only one spectrum of matrices is shown as in Fig. 5.11(f). It should be pointed out that the element $\mathrm{Au}$ in all spectra is from the coating not from the samples.

Though all four types of GFRP bars are called E-glass/vinyl ester bar, there are difference in chemical compositions and properties of fibers and matrices, which may lead to significant difference in durability performance. Since more voids were found in the matrix of GFRP1, GFRP2 and GFRP3 bars, GFRP4 bars may have better durability performance.

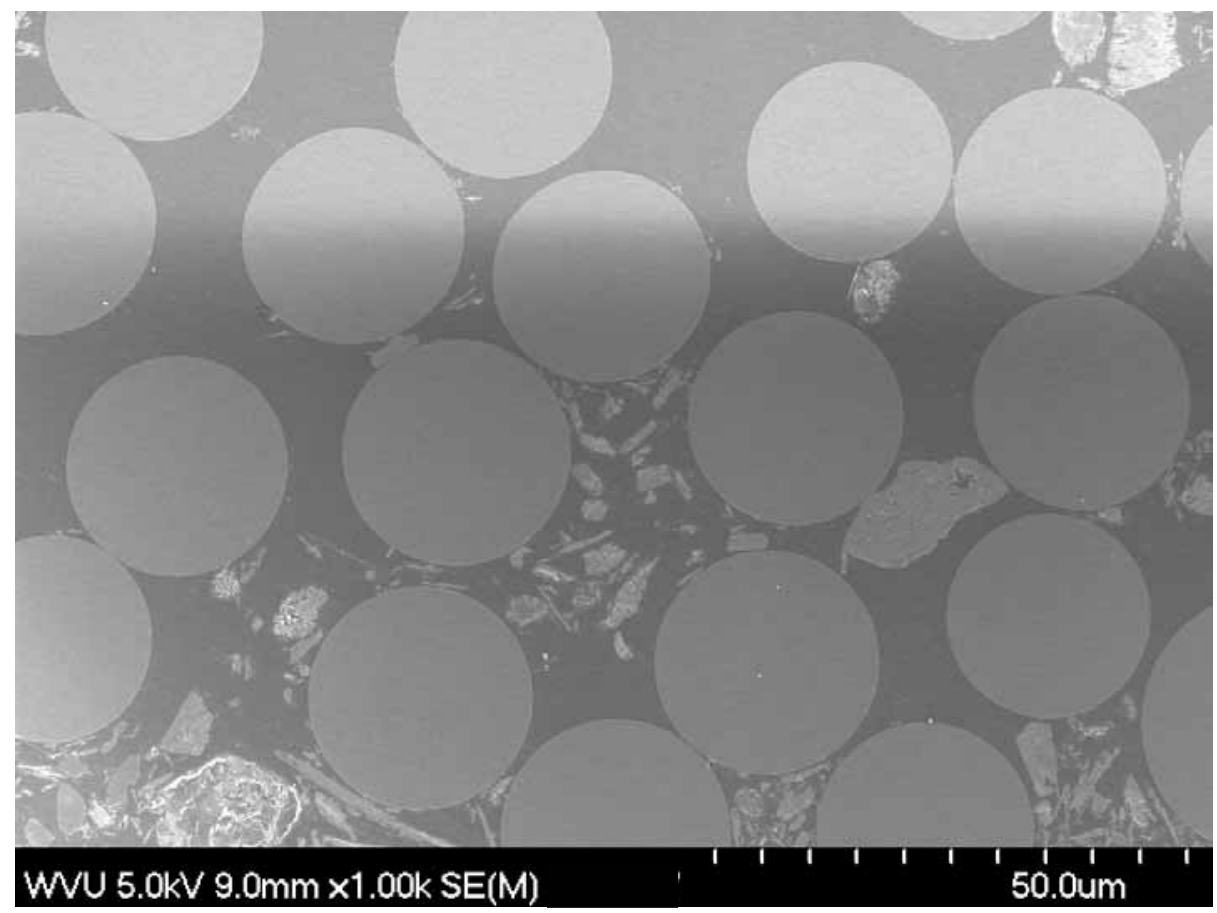

(a) GFRP1 bar 


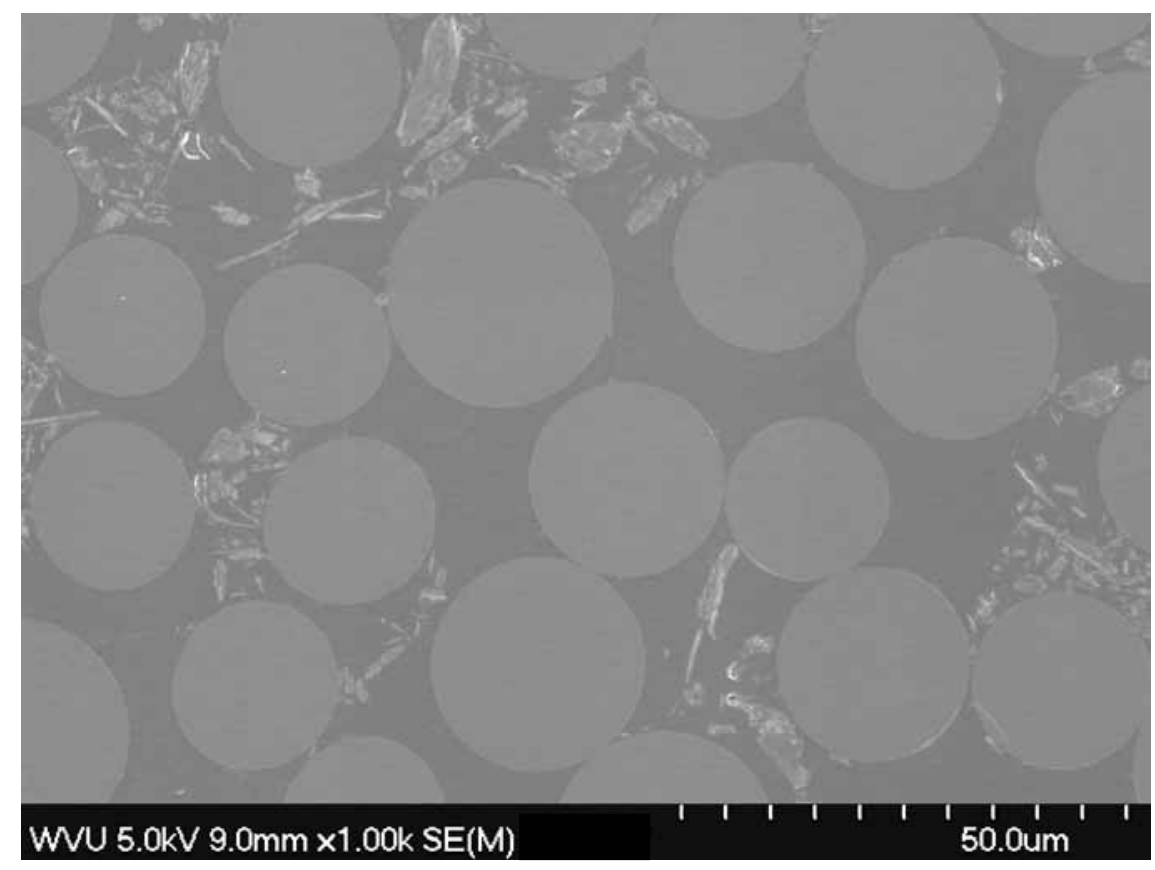

(b) GFRP2 bar

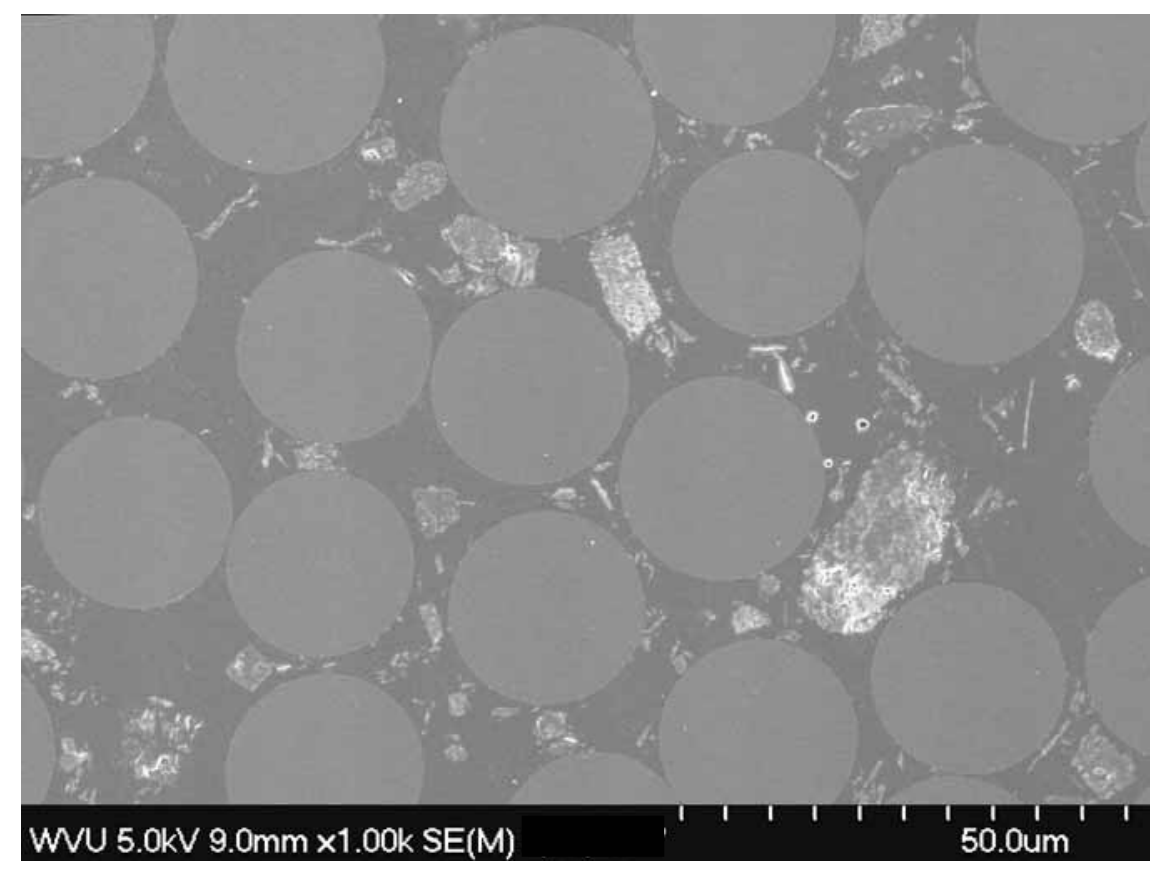

(c) GRP3 bar 


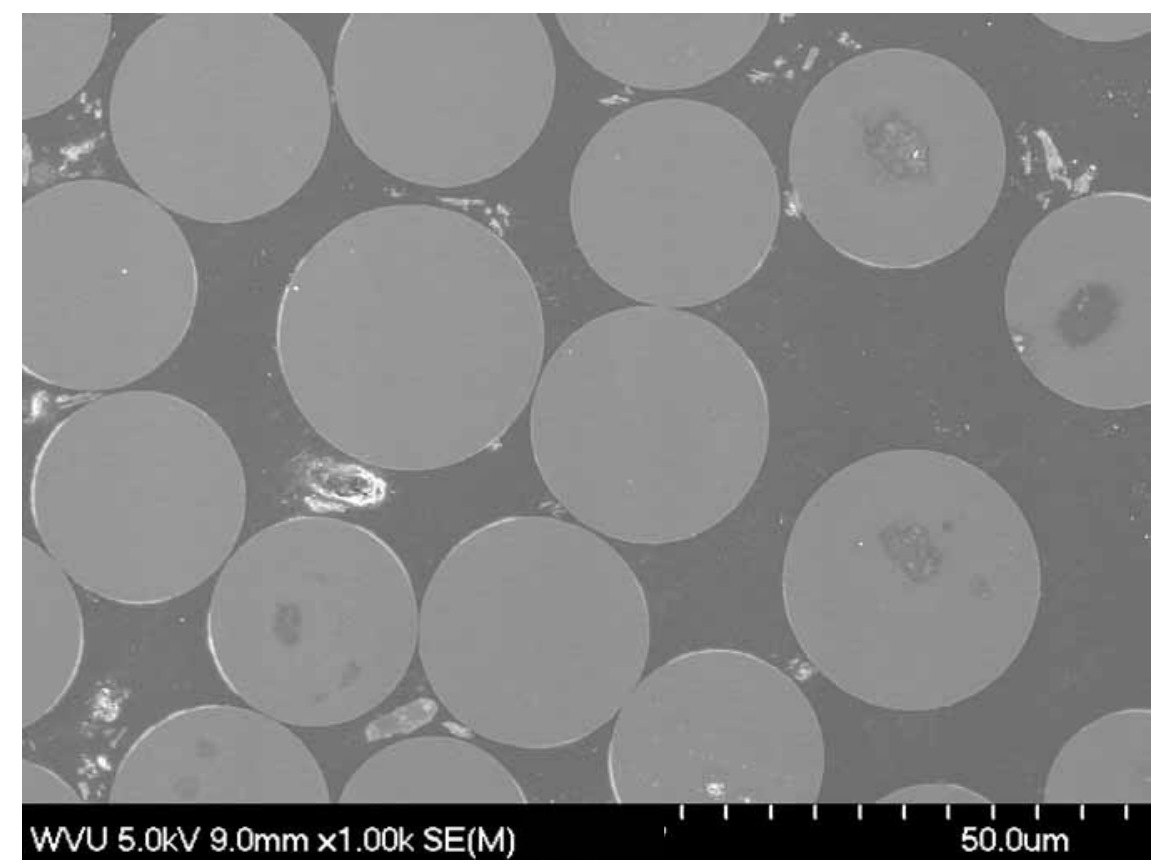

(d) GFRP4 bar

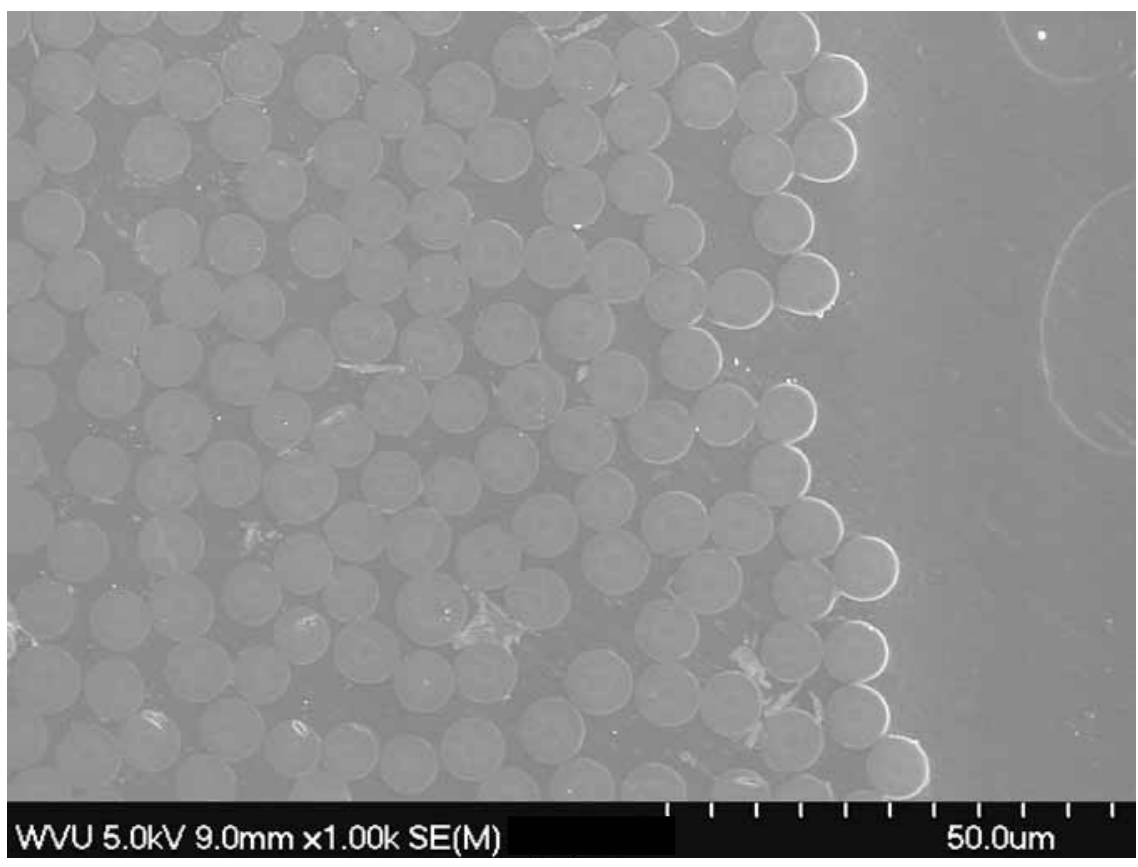

(e) CFRP bar 


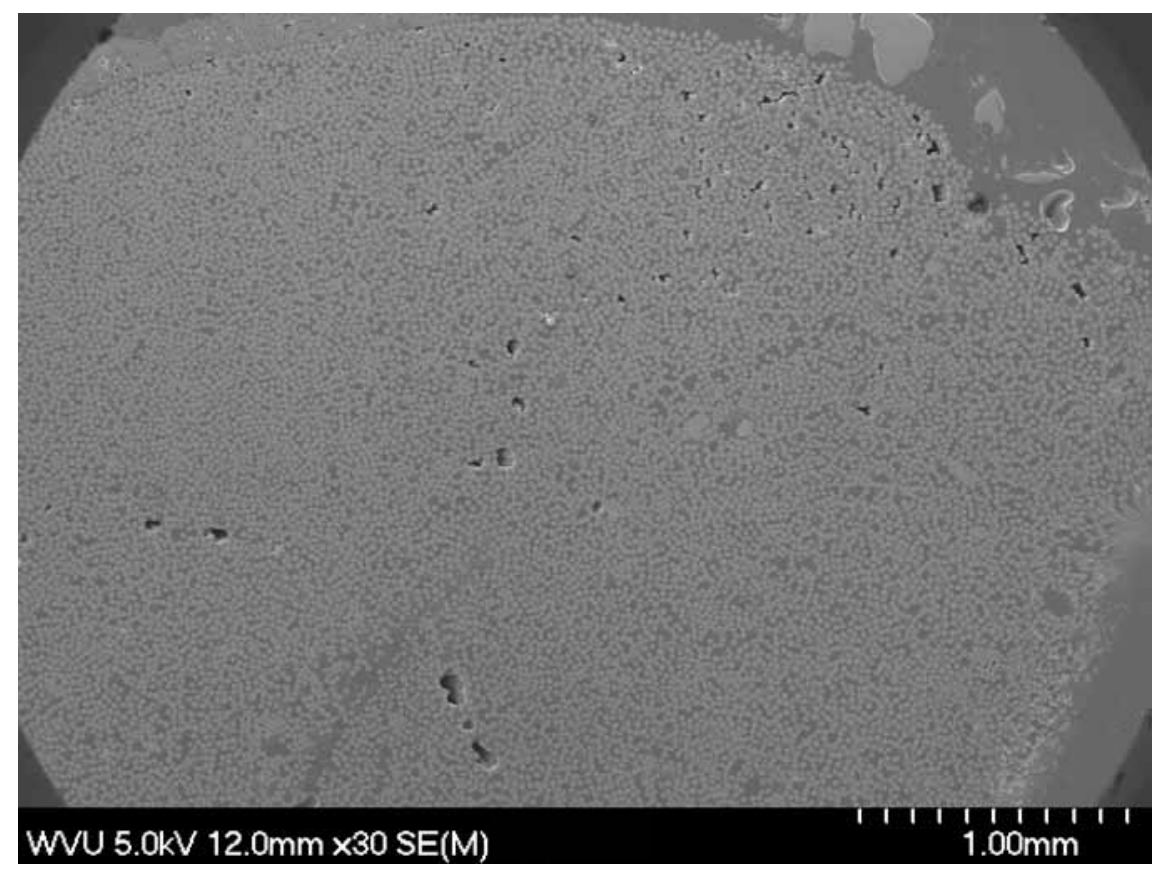

(f) GFRP3 bar

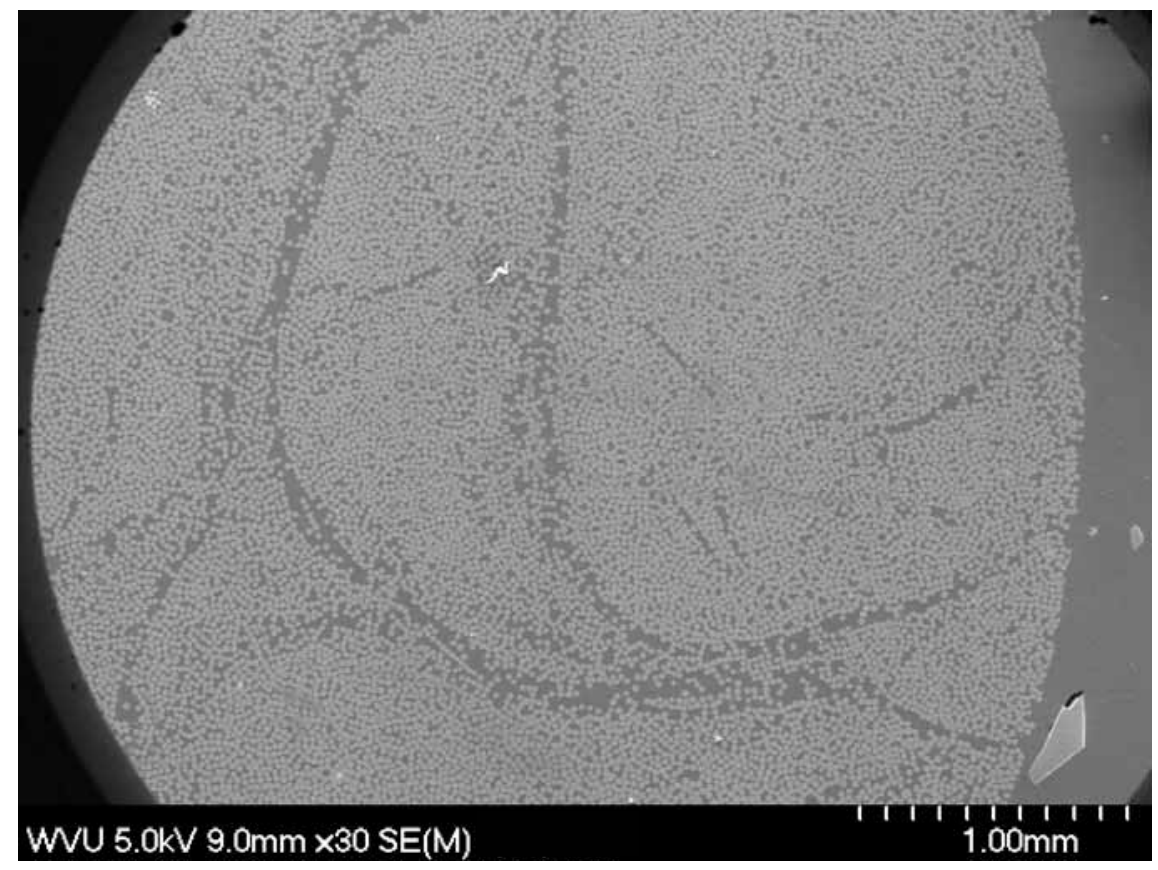

(g) GFRP 4 


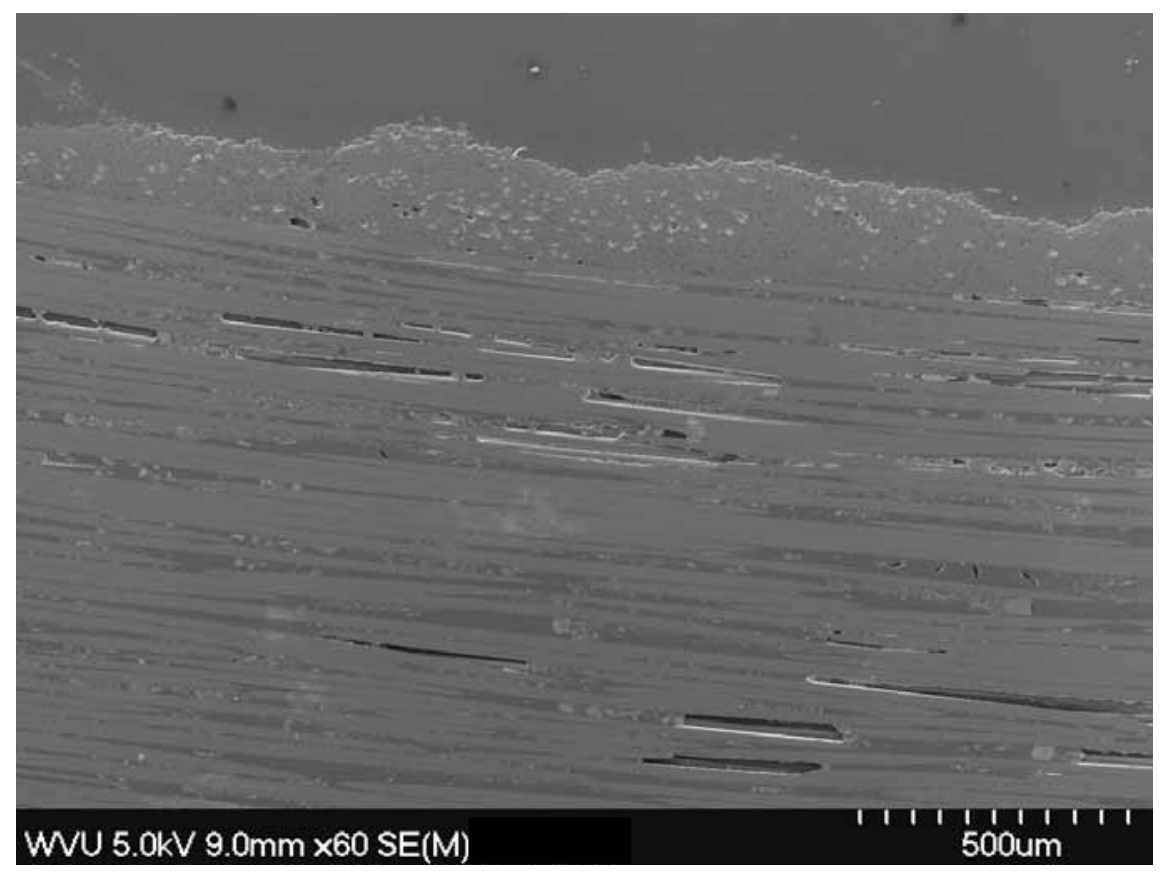

(h) GFRP3 bar (lengthwise)

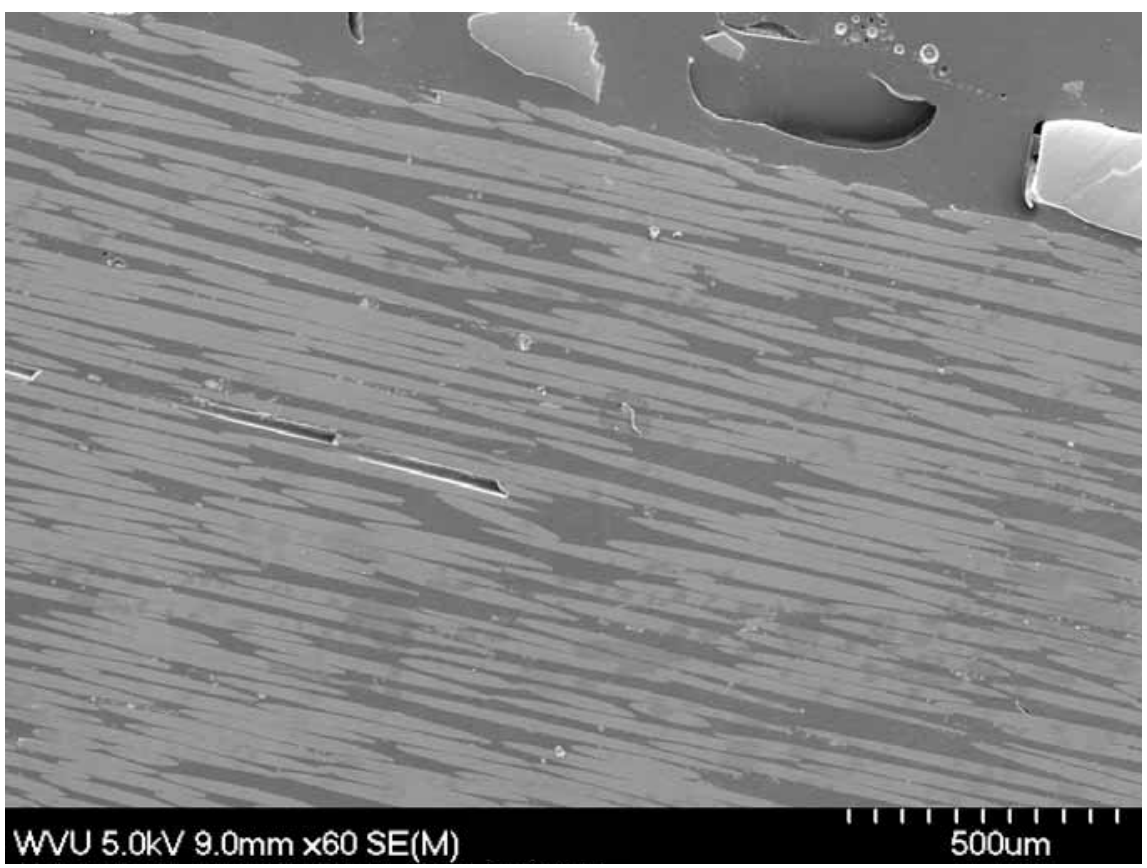

(i) GFRP 4 bar (lengthwise)

Figure 5.10 SEM images of unconditioned FRP bars 


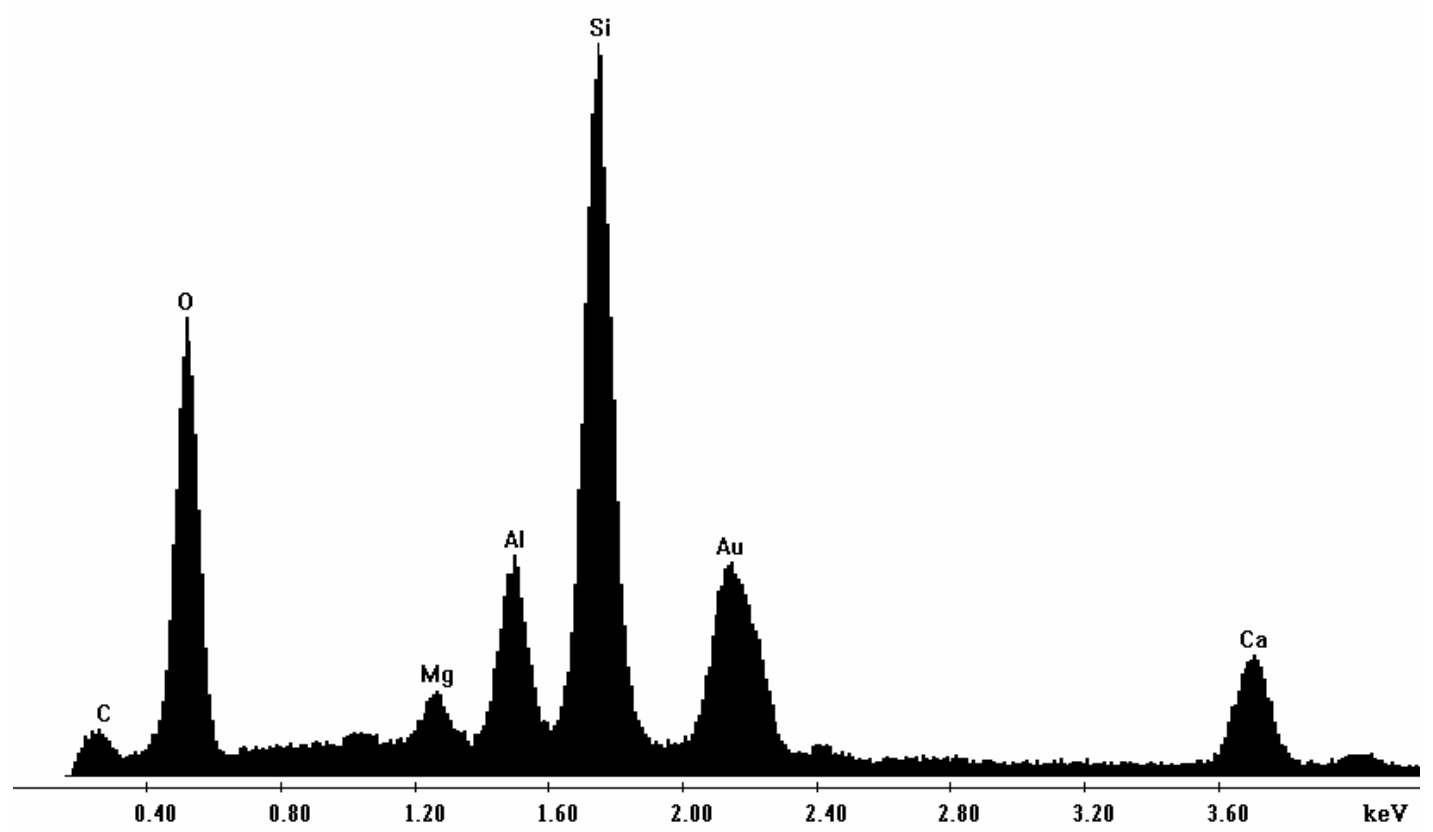

(a) GFRP1 fiber

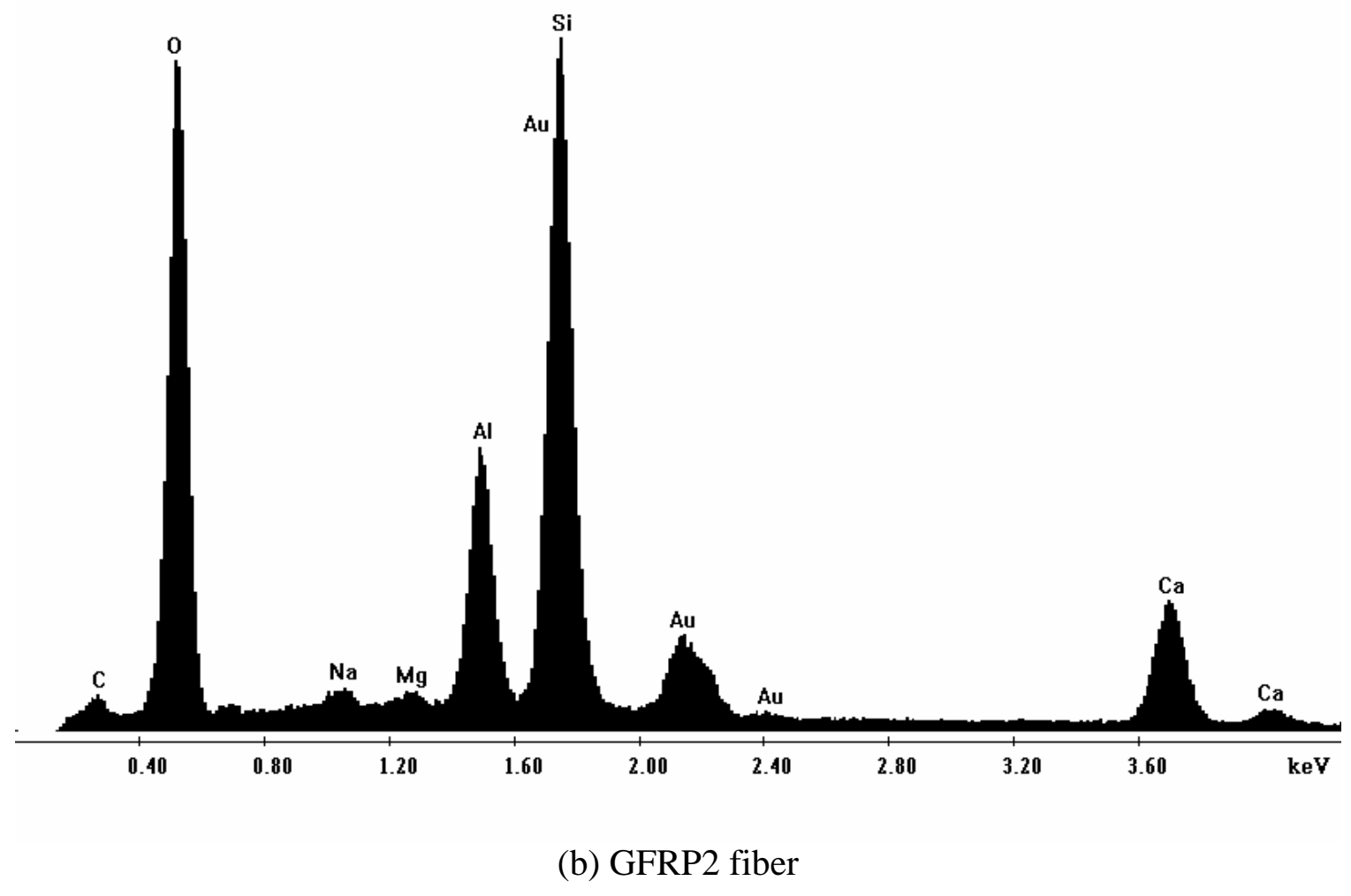



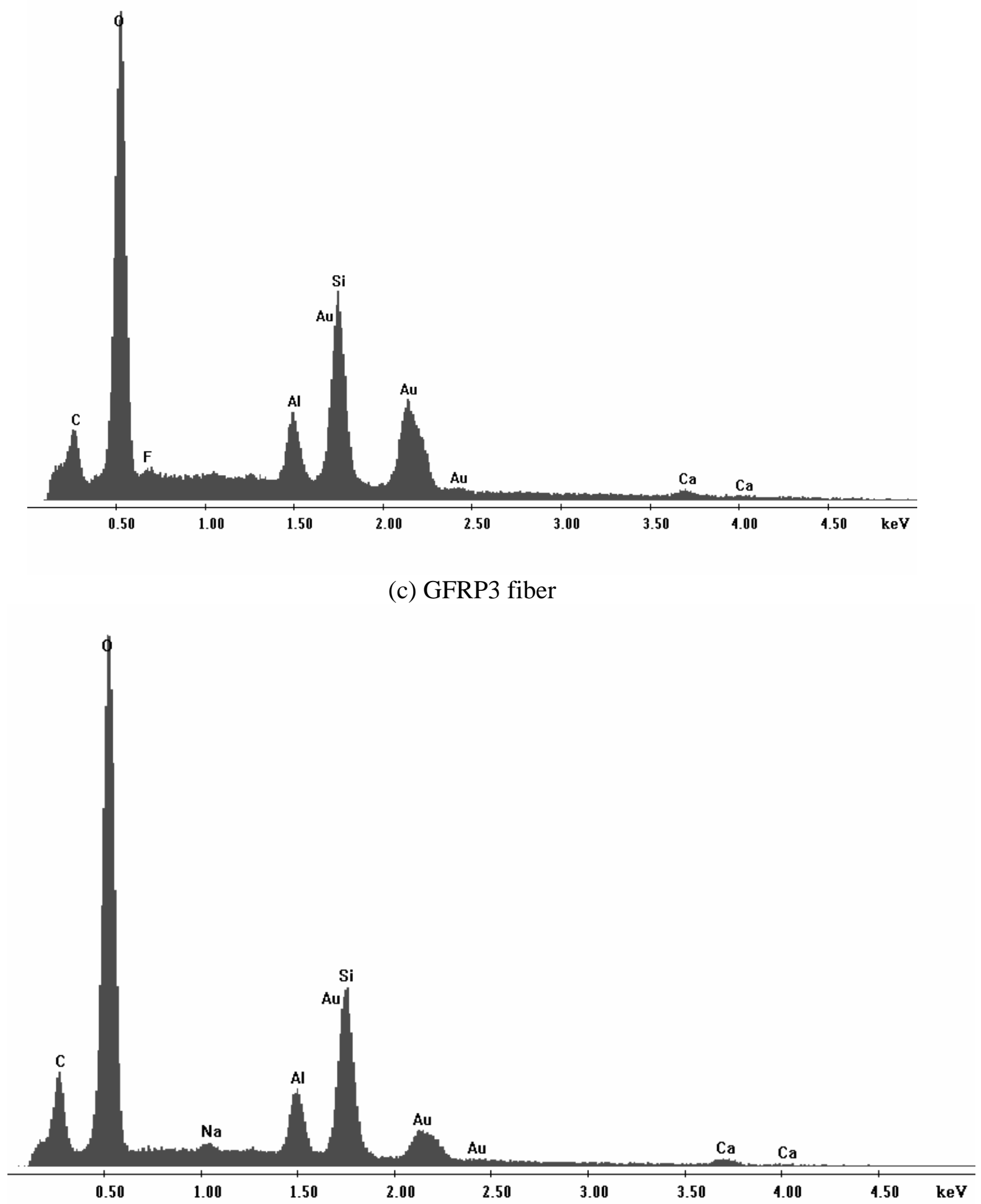

(d) GFRP4 fiber 


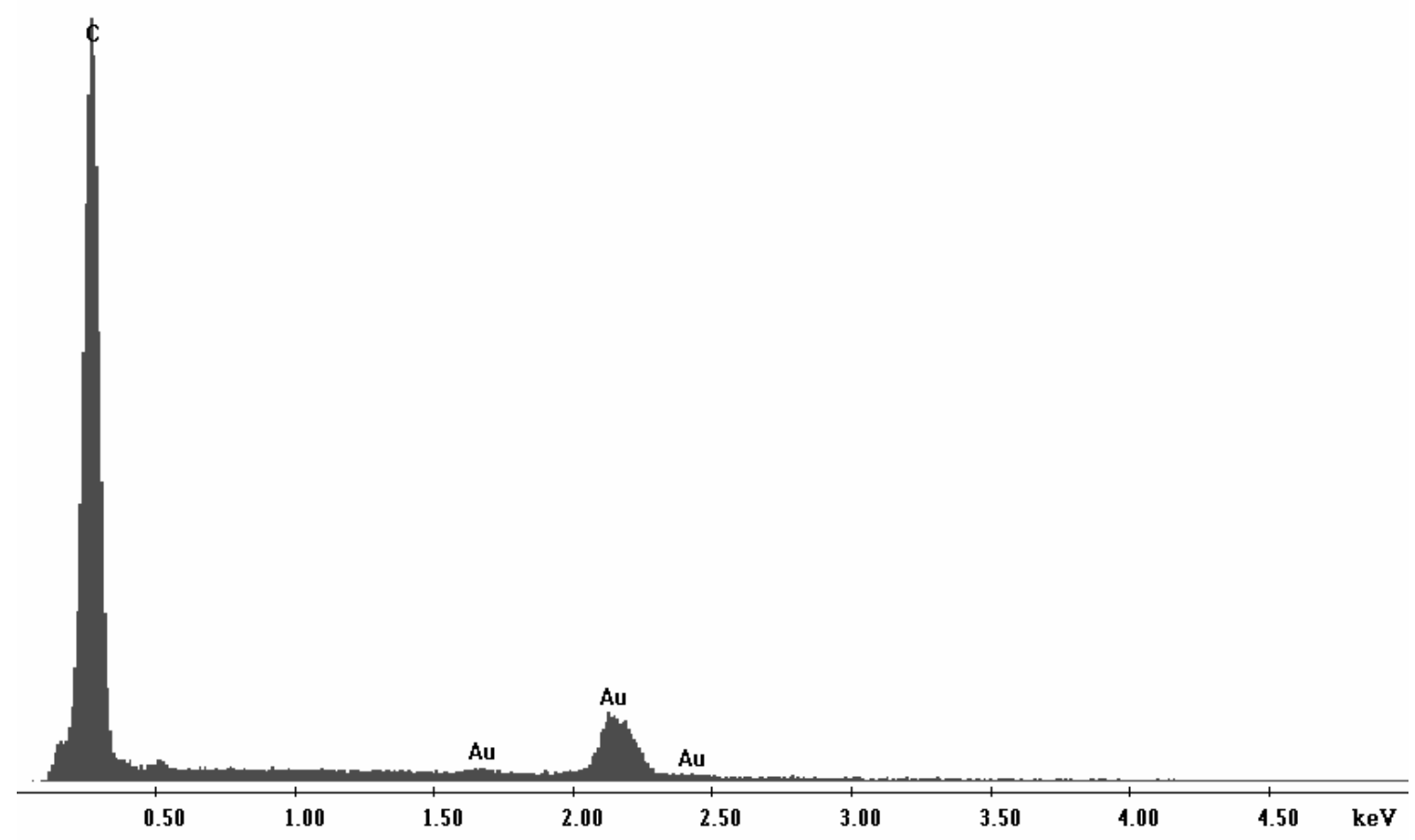

(e) CFRP fiber

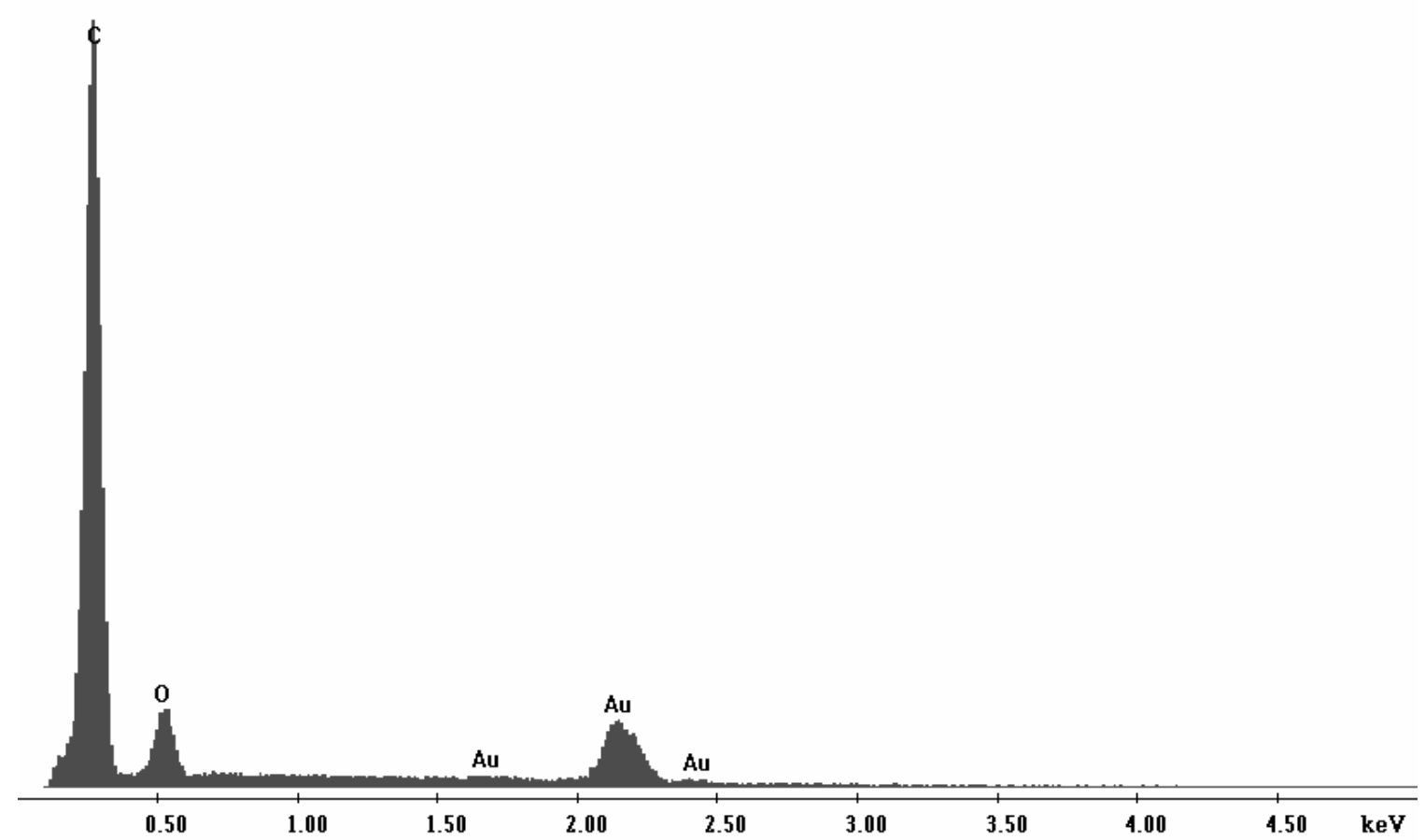

(f) Matrices

Figure 5.11 EDAX spectra of FRP bars 


\subsubsection{Conditioned Specimens}

After the environmental conditioning, FRP bars will degrade. The typical SEM images of conditioned FRP bars are shown in Fig. 5.12. For conditioned GFRP3 bars, as shown in Fig. 5.12 (a) there is a distinct increase in the number and sizes of voids compared to Fig. 5.10 (f). Moreover, voids are developed progressively toward the core of the bar section. The transverse section of conditioned bar (Fig. $5.12 \mathrm{c}$ ) also shows the increase of number and size of voids along the fiber direction compared to Fig. 5.10 (h). The same situation was also observed by Murkherjee and Arwikar (2005). A closer look at the voids as shown in Fig.5.12 (b) and (d) reveal that the matrix is damaged and the interface is disintegrated, while the degradation of fibers is not so obvious. Similar results have been observed by Raham et al. (1998). For GFRP4 bars, as shown in Fig. 5.12 (e), there is delminiation of fiber/matrix interface, especially for fibers close to the edge. Though degradation of matrix of CFRP bars was observed, the carbon fibers seem intact as shown in Fig. 5.12 (f). The conditioned CFRP sample was specially prepared by exposing it in Solution 2 at $60{ }^{0} \mathrm{C}$ for two years due to its excellent durability performance.

The EDAX analysis of conditioned specimens did not detect any difference in chemical elements. The reasons for this may be as following: (1) only the quantities of chemical elements changed, which is not investigated in this study; and/or (2) the degradation is highly localized and much more EDAX analysis is needed to be done to detect the change. 


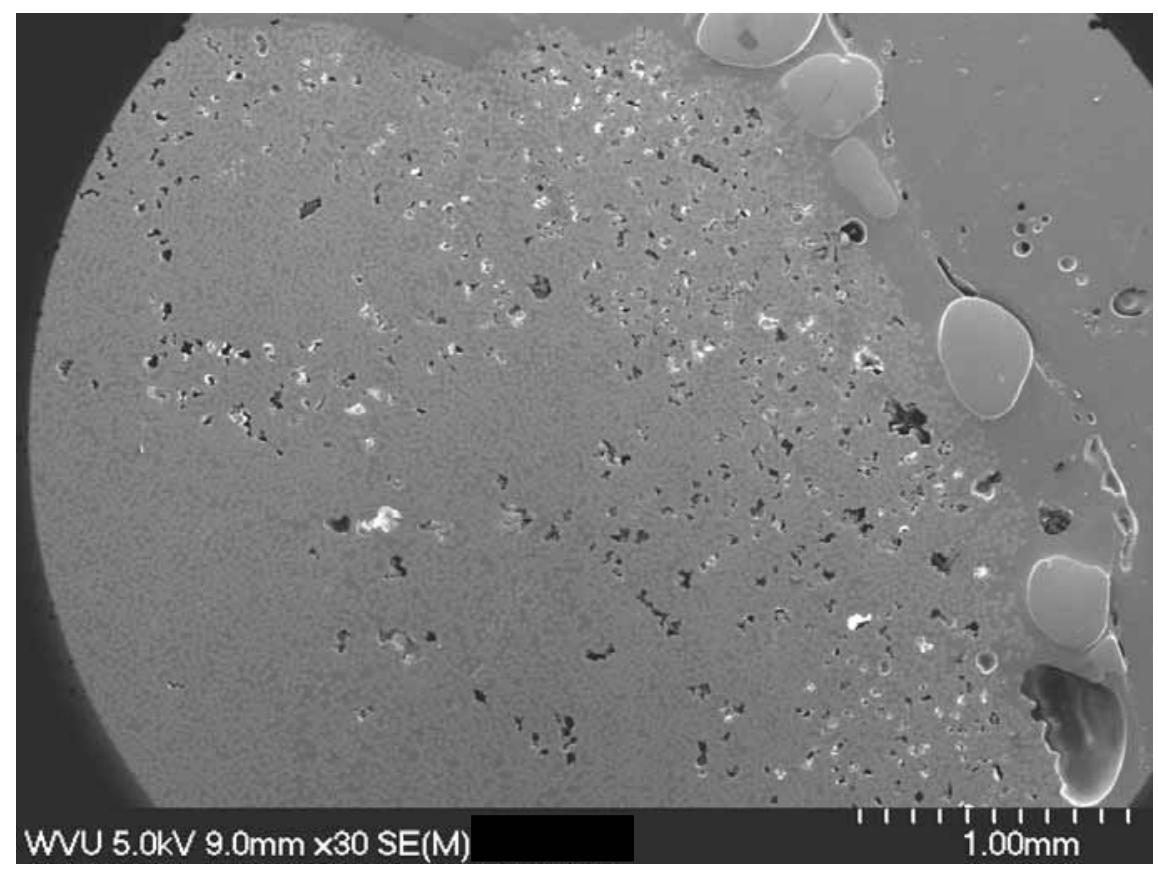

(a) GFRP3 conditioned

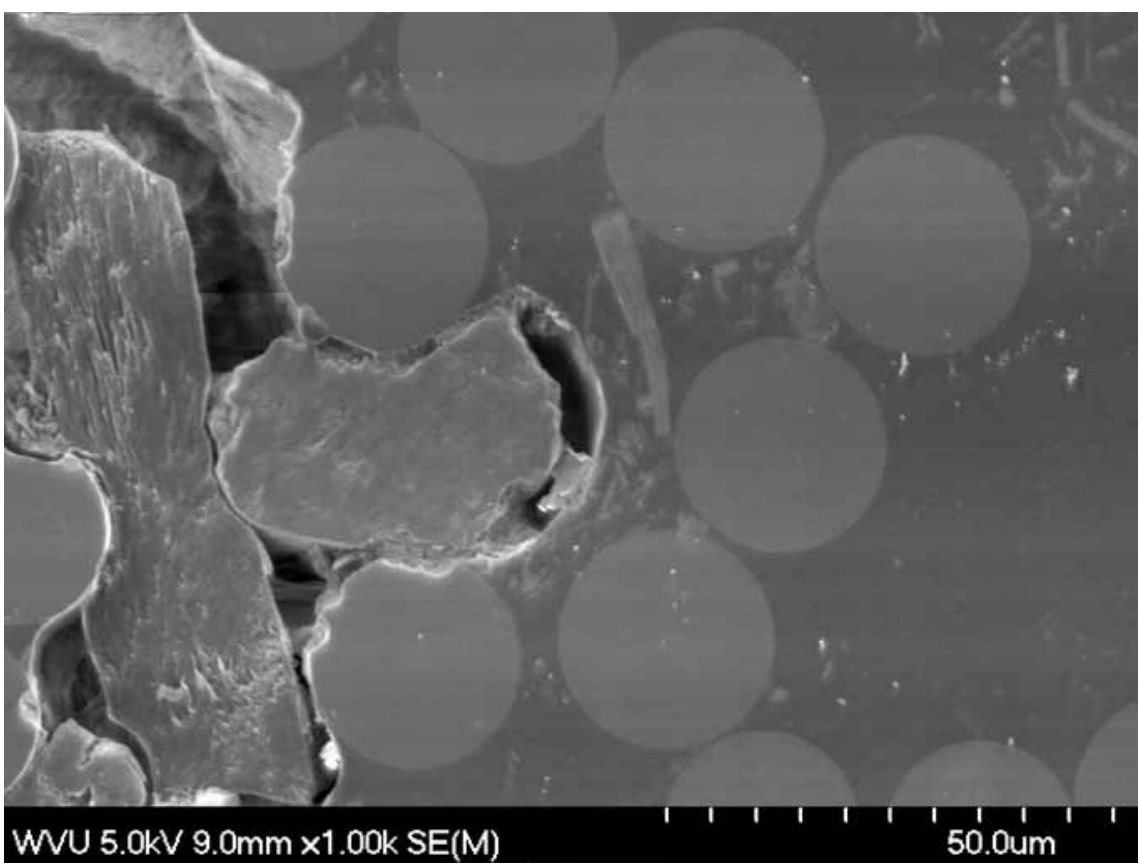

(b) GFRP3 conditioned 


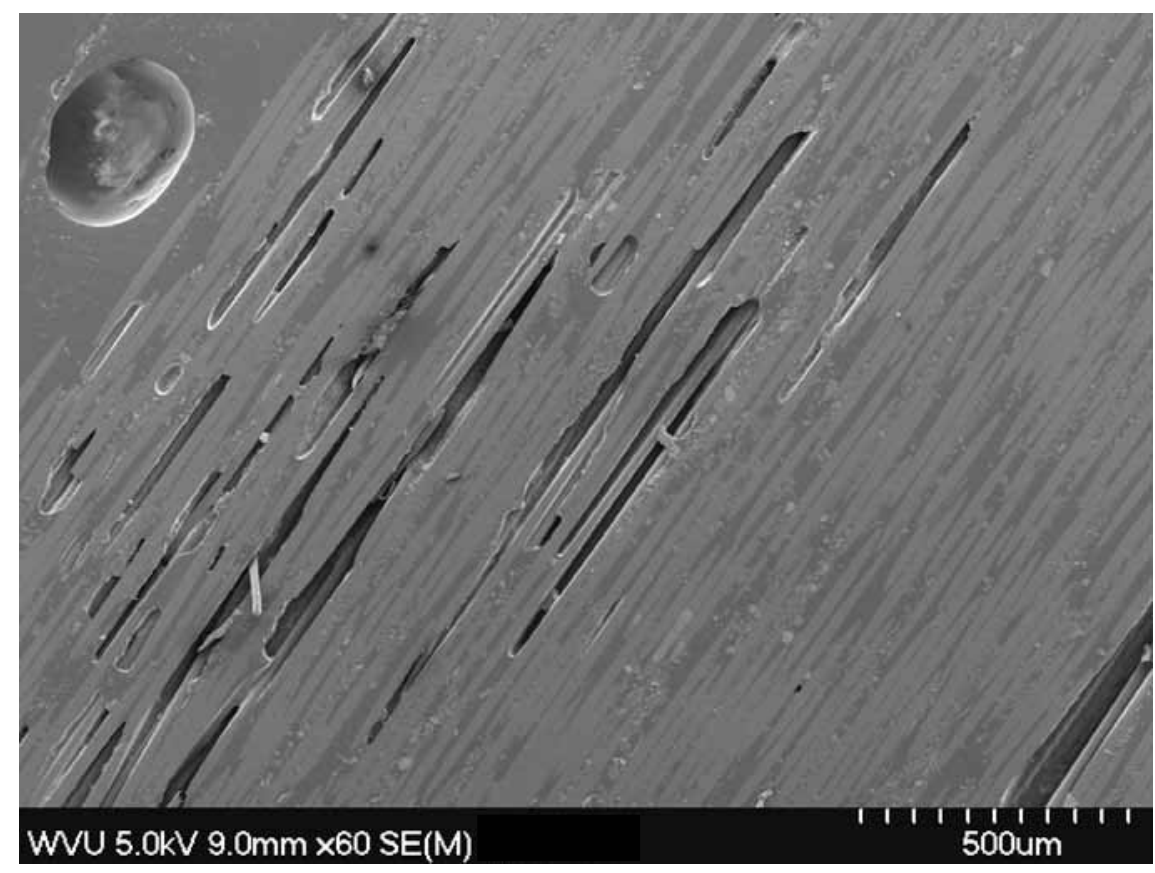

(c) GFRP3 bars conditioned

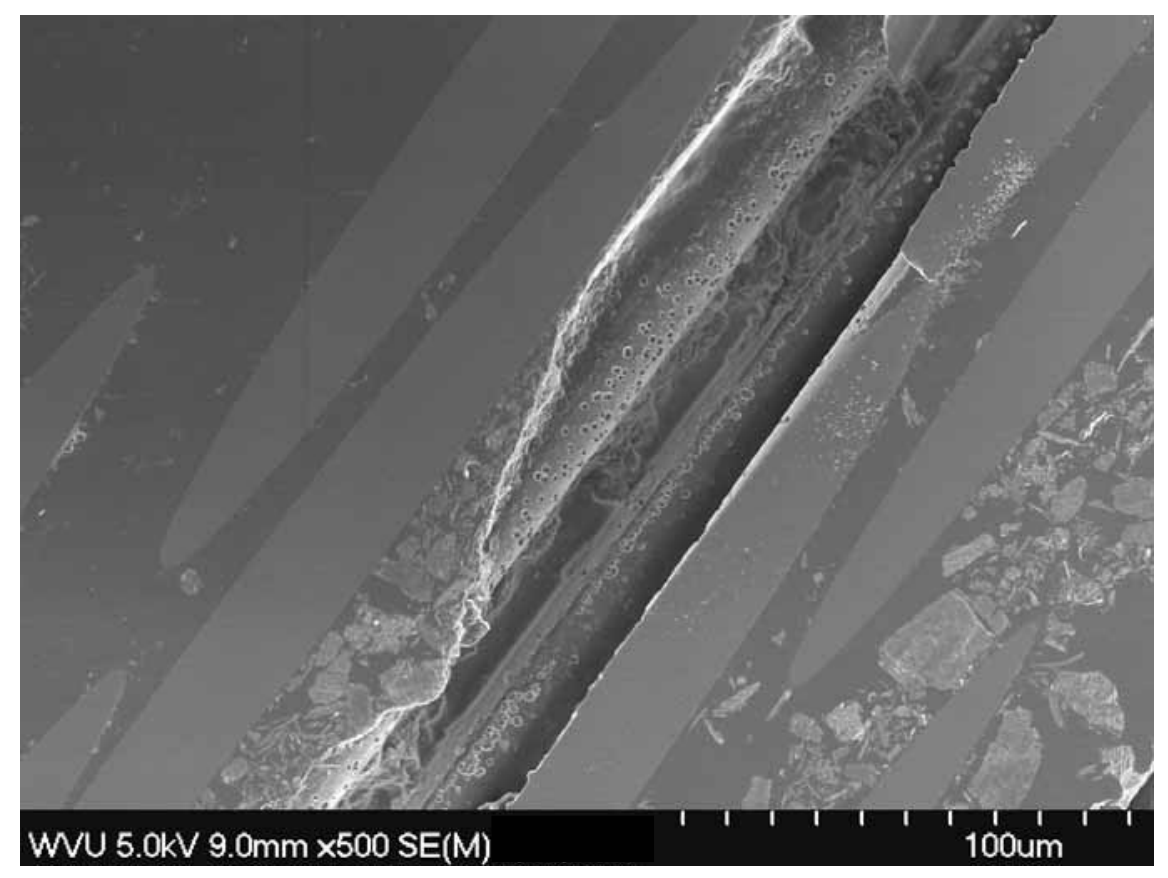

(d) GFRP3 bars conditioned 


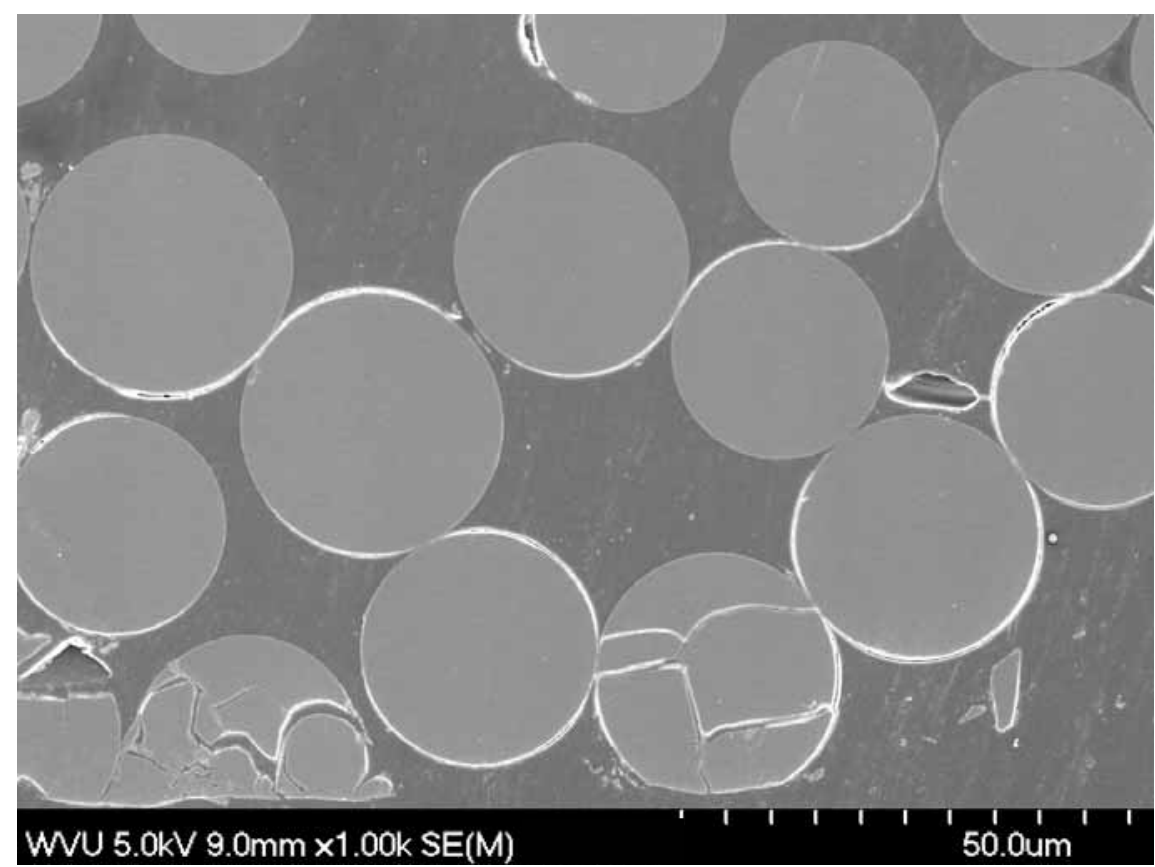

(e) GFRP4 bars conditioned

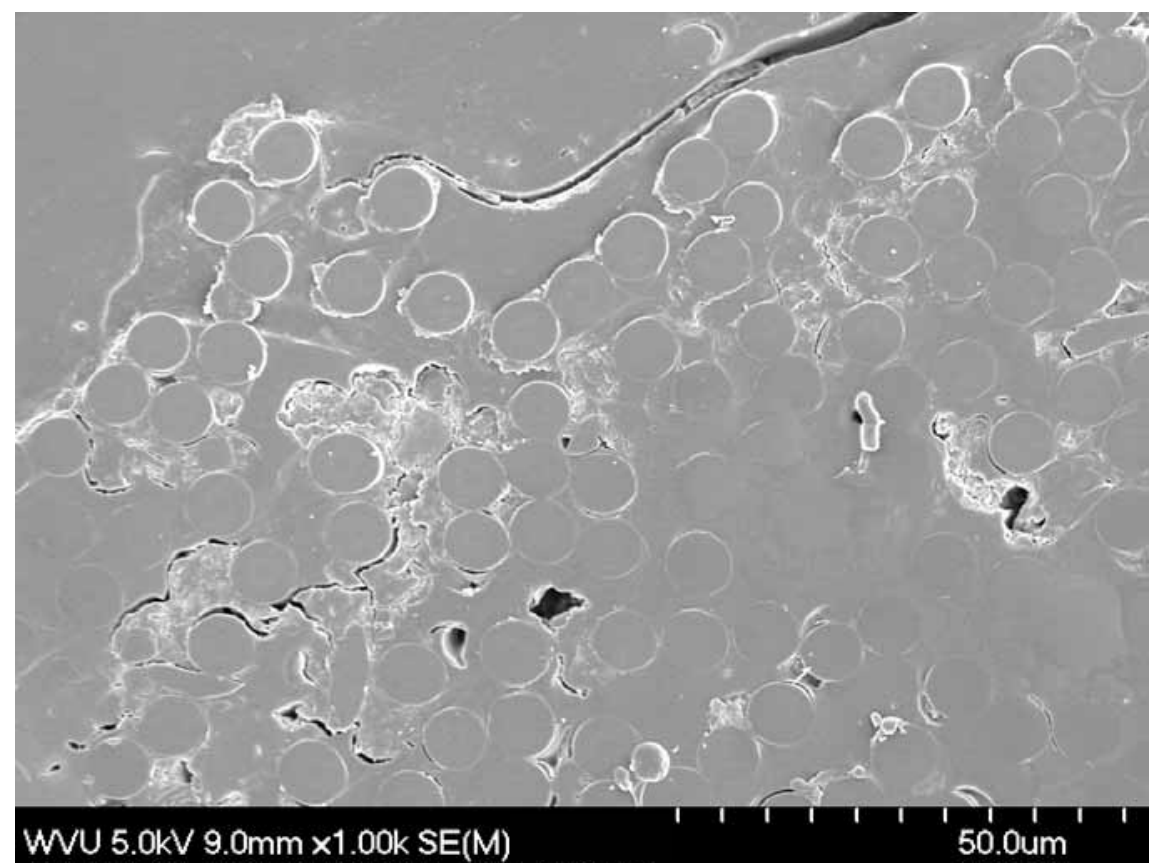

(f) CFRP conditioned

Figure 5.12 SEM images of conditioned FRP bars 


\subsection{Concluding Remarks}

According to the results of this study, the following concluding remarks can be made. Though they were called E-glass/vinyl ester bars, GFRP specimens used in this study still had difference in chemical compositions or manufacture quality, which may lead to significant difference in their performance. The deterioration of matrices and/or fiber/matrix interphase was obvious after conditioning. The matrices of GFRP1, GFRP2 and GFRP3 bars were "softer" and had more voids than those of GFRP4 and CFRP bars. GFRP4 bars should have relatively better durability performance than other GFRP bars, which agreed well with the results of mechanical test presented in previous chapters. The chemical composition change of FRP bars due to condition is difficult to be detected by EDAX.

It is worth noting that the voids and defects of GFRP bars due to manufacture and/or degradation were highly localized. This fact supports the argument that the environmental conditioning may degrade significantly the strength but not the stiffness of FRP bars because the strength is determined by local weakness while the stiffness demonstrates the overall stress-strain characteristics of the bar. More research can be done to improve the manufacture quality and develop durable matrix and fibers for GFRP bars. The unification of FRP material compositions will benefit the investigation of degradation mechanism using analysis methods. 


\section{CHAPTER SIX \\ DURABILITY PREDICTIONS}

The test results presented in previous chapters are all short-term data. In order to predict the long term performance of FRP bars from those results, appropriate prediction models should be employed. In this chapter, the available durability prediction models are discussed first. Then a durability prediction procedure is developed and verified using the test results of this study. According to the developed model and test results, the durability performance of GFRP bars in concrete is predicted.

\subsection{Introduction}

There are various prediction models proposed for the durability of composites in published literature. But presently there are no universally agreed prediction models for the long-term behaviors of FRP materials. Among existing models, those based on Arrhenius concept are the most popular, which describes the degradation rate as a function of temperature as discussed in section 2.5.2. In the following sections, three typical types of prediction models for FRP materials are discussed.

The first type of prediction model was as presented by Bank et al. (2003). This type of model was based on Arrhenius relation, and the relationship between residual strength and time is assumed as:

$$
Y=a \log (t)+b
$$

where $\mathrm{Y}$ is the property retention (\%), and $\mathrm{t}$ is the exposure time, while $a$ and $b$ are regression constants. This model was first developed for the residual strength of glass 
fiber concrete (GRC) and has been successfully applied to the durability prediction of GRC with data of ten years (Litherland et al., 1981). It is also the most widely used prediction model for FRP bars. The time shift factor prediction method developed by Dejke (2001) and the prediction procedure using the time-temperature superposition provided by Caceres et al. (2000) can also be included in this type of model. But there are intrinsic limitations for this model. First, it is only a phenomenological representation of test data and there is no hypothesis concerning the degradation mechanism. Second, according to the assumed relationship (equation 6.1), the strength approaches infinity at time zero. When this method was applied to GFRP bar test results, researchers (Gonenc, 2001) found that the "Arrhenius plots" were not parallel to each other, which indicated that the degradation mechanism changed with the exposure time, violating the fundamental assumption of Arrhenius relation of maintaining consistent degradation mechanism.

The second type of model was also first developed for GRC (Beddow et al., 2002). The degradation mechanism in this model is assumed as the stress corrosion of glass fibers. As shown in equations 6.2 and 6.3, a static fatigue model was adopted to describe the relationship of strength retention and exposure time.

$$
Y=1 / \sqrt{1+k t}
$$

where $\mathrm{Y}$ is the property retention (\%), and $\mathrm{t}$ is the exposure time, and $k$ is function of temperature, stress and solution concentration as shown in equation 6.3.

$$
k=k_{T} k_{0} \exp \left(-\frac{E_{a}}{R T}\right)
$$

where $k_{\mathrm{T}}$ is a function of temperature, $k_{0}$ accounts for the $\mathrm{pH}$ of environment and initial state of fibers, $E_{a}$ is activation energy, $R$ is the gas constant, $T$ is the absolute temperature. 
The difficulty with this model is that as shown in equation $6.3, k_{\mathrm{T}}$ is a function of exposure temperature. Thus, for example when the activation energy was calculated using equation 6.4, the effect of this factor was ignored in Beddow et al. (2002) without any explanation (i.e. the last term in the right side of equation 6.4 was ignored).

$$
\ln \left(k_{2}\right)=\ln \left(k_{1}\right)-\frac{E_{a}}{R}\left(\frac{1}{T_{1}}-\frac{1}{T_{2}}\right)+\ln \left(\frac{k_{T_{1}}}{k_{T_{2}}}\right)
$$

where $k_{1}, k_{2}, k_{\mathrm{T} 1}$ and $k_{\mathrm{T} 2}$ are values corresponding to the temperatures of $\mathrm{T}_{1}$ and $\mathrm{T}_{2}$.

The third type of model is based on moisture absorption as discussed in section 2.5.3. The tensile strength retention is described as equation 6.5 .

$$
Y=100\left(1-\frac{\sqrt{2 D C t}}{r_{0}}\right)^{2}
$$

where $\mathrm{Y}$ is the property retention (\%), $\mathrm{t}$ is the exposure time, $D$ is the diffusion coefficient, and $C$ is the concentration of solution. In this case, diffusion models based on Fick's law were employed to correlate the losses in tensile strength with the moisture absorption of FRP bars. This type of model can also be used to consider the acceleration effect of elevated temperature, since the diffusion coefficient, $D$, can be related with the exposure temperature using Arrhenius relation as discussed in section 2.5.3. One obvious limitation of this model is that the assumption used may not be accurate, since the affected area of FRP bars (the area with diffused chemicals) may not be completely degraded and can still carry some load. The second limitation is that this model can not be applied to specimens exposed to water, since the concentration of solution (C) in equation 6.5 is required in the prediction procedure. The third limitation of this model is that the measure of moisture absorption is a difficult task. During the degradation of FRP, 
byproducts of chemical reaction are leaching out, and voids and defects are filled with solutions. So the weight change may not accurately represent the moisture absorption.

From the literature, it can be found that most models are based on Arrhenius relation and were developed from or successfully applied to test results of bare FRP bars exposed to simulated solutions. No prediction has been made using test results from GFRP bars embedded in concrete and subjected to sustained loading. Those models were developed for different types of FRP bars and exposure conditions. Moreover, no long-term data is available to validate the prediction models. In this study, a durability prediction procedure is developed and verified using two distinct conditions, in which bare GFRP1 bars exposed in Solution 3 is regarded as a relatively low reactivity condition and bare GFRP2 bars exposed in Solution 2 is considered as a high reactivity condition as presented in chapter three. Then a model is adopted for GFRP bars embedded in concrete according to the test results in chapters four and five. Finally, the durability performance of GFRP bars embedded in concrete under sustained load is predicted using developed models.

\subsection{Durability Predictions}

\subsubsection{Degradation Mechanisms}

In order to predict the durability performance of GFRP bars from short term data, a prediction model based on the knowledge of degradation mechanism need to be developed. Though the degradation of GFRP bars exposed to water and alkaline solutions has been investigated by several studies (Byars et al., 2003), there is still no clear understanding of the mechanism involved. 
The first and second models reviewed in section 6.1 were successfully applied for GRC, but they may not be applicable to GFRP bars in this study. This may be due to the difference between the degradation mechanisms of GRC and GFRP bars. For GRC, the volume fraction of fibers is about $5 \%$, which is very small compared to that of GFRP bars (usually above 60\%). Moreover, the fibers in GRC are in direct contact with pore solution of concrete, but for GFRP, the polymer matrix acts as a barrier to external environmental agents. So in the case of GFRP degradation, the accumulation of byproducts is easier and the availability of alkaline solution is more limited. When the first model was applied to test results of this study, the "Arrhenius plots" were not parallel to each other as found by other researchers (Gonenc, 2001). The fundamental assumption of the second model is the stress corrosion of glass fibers, which may not be suitable for GFRP bars. From the analytical analysis of chapter five, it was determined that the matrix and fiber/matrix interface were severely damaged. Since the fiber/matrix interface is critical for the load transfer between fibers, the dominant degradation mechanism of GFRP bars can be assumed as fiber/matrix debonding. The analytical analysis results of Raham et al. (1998) also support this assumption. The failure accompanied by delamination of conditioned specimens, observed in this study and other studies (e.g. Debaiky et al., 2006), also supports this argument. So it will be reasonable to develop prediction models for GFRP bars based on the assumption that the dominant degradation mechanism is the debonding at the fiber/matrix interface. According to the literature survey, one model was developed by Phani and Bose (1987) to predict flexural strength retention of composite laminate by using acousto-ultrasonic technique. The relationship between strength retention and exposure time was defined as 


$$
Y=\left(100-Y_{\infty}\right) \exp (-t / \tau)+Y_{\infty}
$$

where, $Y_{\infty}$ are tensile strength retentions (\%) at exposure times of infinity, and $\tau$ is a characteristic time dependent on temperature. This procedure may be modified and adopted for tensile strength retention prediction of GFRP bars.

According to the test results in this study, the tensile strength decreased with the increase of exposure time. So it may be also reasonable to consider the whole GFRP bar as a glass fiber. It is well established that the extent of glass dissolution can be described with the following equation:

$$
f=\beta t^{\alpha}
$$

where $f$ is the rate of change, $\beta$ is the rate constant, $\alpha$ is recognized as a parameter to indicate material's response to exposure. Equation 6.7 is a common expression used to describe rate of changes in the material properties with time (Prian and Barkatt, 1999). In some degradation processes, significant changes of macrostructure of the material, for example cracking, occur, and the degradation rate has a superlinear relationship with time (i.e. $\alpha>0$ ). In case of a constant-rate degradation, $\alpha$ will be zero. It is recognized that the dissolution of glass in basic solutions has a constant rate. For degradations where protective layers are formed, the degradation rate has a sublinear dependence on time (i.e. $\alpha<0$ ). To formulate the prediction model for GFRP bars, it is assumed that the ultimate tensile load capacity of the GFRP bars is proportional to the unaffected cross sectional area. So from equation 6.7 , the tensile capacity retention $(\%)$ of bars vs. time can be defined as:

$$
Y=100\left(1-\frac{\int_{0}^{t} f d t}{r_{0}}\right)^{2}=100\left(1-\frac{\beta t^{\alpha+1}}{(\alpha+1) r_{0}}\right)^{2}=100\left(1-c t^{\alpha+1}\right)^{2}
$$


where $\mathrm{Y}$ is the property retention $(\%), \mathrm{t}$ is the exposure time, $\mathrm{r}_{0}$ is the radius of the total cross section, and $\mathrm{c}$ is a factor accounting for temperature, solution concentration and other experimental conditions. It can be found that if $\alpha=-0.5$ is assumed for equation 6.8 , it will be equivalent with equation 6.5 , which is the prediction equation based on moisture absorption. In case of GFRP bars, the glass fibers are protected by polymer matrix, and it is reasonable to assume that the material constant $\alpha$ is less than zero, such as -0.5 . So it may be expected that the third prediction procedure discussed in section 6.1 may be successfully applied to some data. But by using equation 6.8 , the difficult task of moisture absorption test does not have to be carried out and the strength retention of specimens exposed to water can also be predicted. Since the factors $c$ and $\alpha$ in equation 6.8 can be determined for each specific conditions, this equation can be more widely used and probably provides more accurate predictions.

\subsubsection{Prediction Procedure}

From the discussion of previous sections, it can be concluded that equations 6.6 and 6.8 may be used to develop prediction procedures for the durability of GFRP bars. According to the test results of this study, the prediction procedure can be based on Arrhenius concept. Accordingly, it is assumed that there is only one dominant degradation mechanism in GFRP bars, which will not change with time and temperature during the exposure, but the degradation rate will be accelerated with the increase of exposure temperature. So the degradation rate can be described by the Arrhenius relation (equation 2.7), which can be transformed into:

$$
\frac{1}{k}=\frac{1}{A} \exp \left(\frac{E_{a}}{R T}\right)
$$




$$
\ln \left(\frac{1}{k}\right)=\frac{E_{a}}{R} \frac{1}{T}-\ln (A)
$$

From equation 6.9 , it can be found that the degradation rate $k$ can be expressed as the inverse of time needed for a material property to reach a given value. From equation 6.10 it can be further observed that the logarithm of time needed for a material property to reach a given value is a linear function of $1 / T$ with the slope of $E_{a} / R$. In this section, the durability prediction procedure is developed using the test results of bare GFRP bars in simulated alkaline solutions (from chapter three). OriginPro7.5 was used for data analysis and curve fitting. The general procedure is presented as follows by using equation 6.6 and test results from chapter three.

For the first step, the relationship between tensile strength retention (the percentage of residual strength over original tensile strength) of GFRP bars and exposure time was defined as:

$$
Y=100 \exp \left(-\frac{t}{\tau}\right)
$$

where $\mathrm{Y}$ is the tensile strength retention value $(\%), \mathrm{t}$ is the exposure time and $\tau$ is $1 / k$ as expressed in equation 6.9. Equation 6.11 was modified from equation 6.6 by assuming that bare GFRP bars degraded completely at infinite exposure time in alkaline solution. The data of Figs. 6.1 and 6.2 (test results from chapter three) were used in equation 6.11 in order to obtain the coefficient $\tau$ by regression analysis. Corresponding $\tau$ values and coefficients of determination $\left(\mathrm{R}^{2}\right)$ are summarized in Table 6.1, with all regression lines having a correlation coefficient above 0.86. Thus, the time to reach a given tensile strength retention at different temperatures can be approximately calculated through equation 6.11 . 


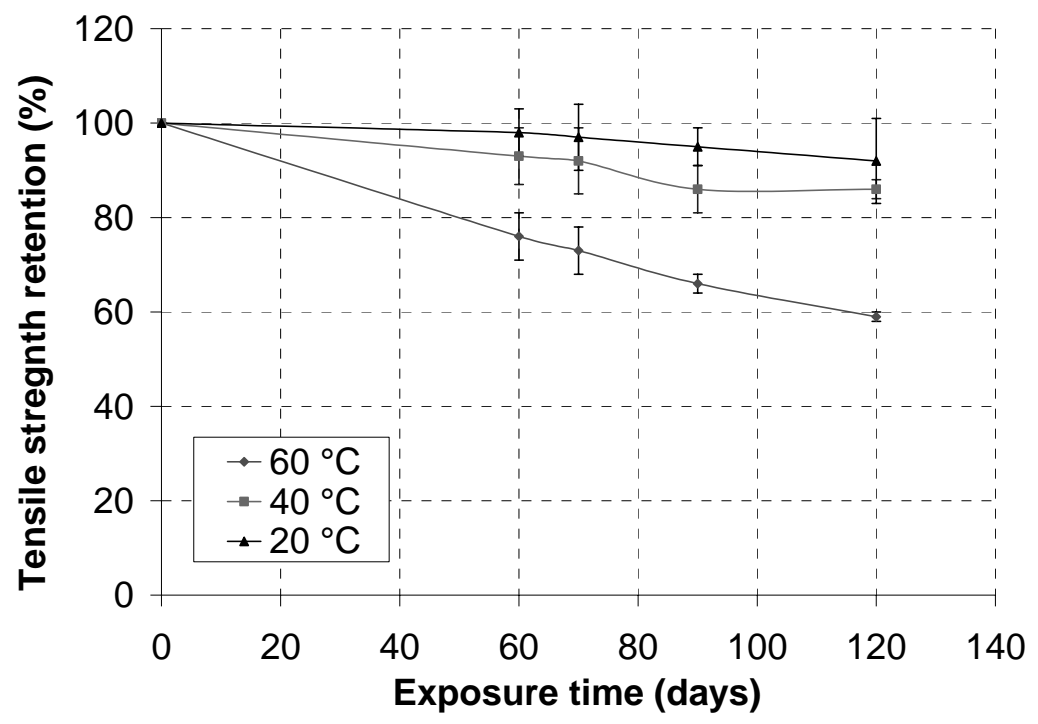

Figure 6.1 Tensile strength retention of GFRP1 bars exposed to Solution 3

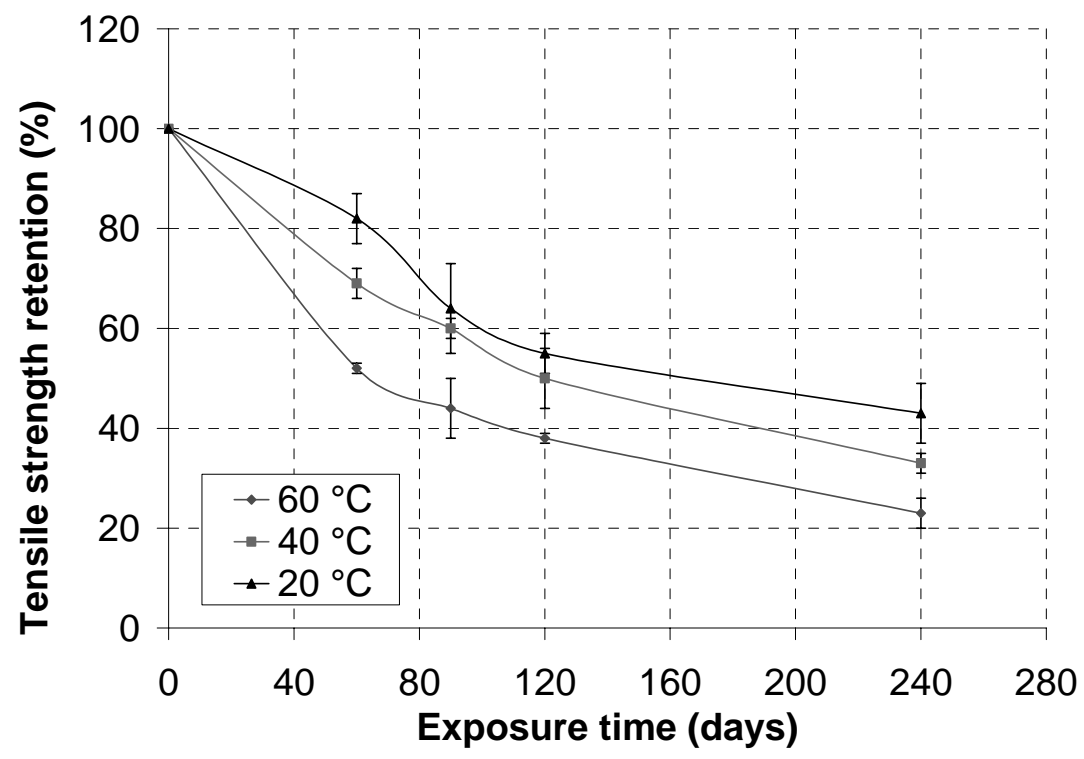

Figure 6.2 Tensile strength retention of GFRP2 bars exposed to Solution 2 
Table 6.1 Coefficients of regression equations for GFRP tensile strength retention

\begin{tabular}{cccccc}
\hline & \multicolumn{2}{c}{ GFRP1 bars in Solution 3 } & & \multicolumn{2}{c}{ GFRP2 bars in Solution 2 } \\
\cline { 2 - 3 } \cline { 5 - 6 } Temperature $\left({ }^{0} \mathrm{C}\right)$ & $\tau$ & $\mathrm{R}^{2}$ & & $\tau$ & $\mathrm{R}^{2}$ \\
\hline 60 & 222 & 0.98 & & 143 & 0.86 \\
40 & 714 & 0.92 & & 200 & 0.96 \\
20 & 1667 & 0.88 & & 256 & 0.92 \\
\hline
\end{tabular}

In the second step, the Arrhenius relationships were obtained by plotting the natural $\log$ of time to reach $50 \%, 60 \%, 70 \%, 80 \%$ tensile strength of GFRP bars vs. 1/T (the inverse of exposure temperature) in Figs. 6.3 and 6.4. Straight lines were fitted to the data with the assumption that the degradation rate was a function of temperature as expressed in equation 6.10. Equation 6.9 was also fitted to the data of Table 6.1 to obtain $\mathrm{E}_{\mathrm{a}} / \mathrm{R}$. From the analysis, the regression coefficients $\left(E_{a} / R\right)$ and $R^{2}$ are listed in Table 6.2. The coefficients of determination for all regression lines were close to 1 , and straight lines in Arrhenius plots for different strength retentions were nearly parallel to each other (the slopes of straight lines are $\mathrm{E}_{\mathrm{a}} / \mathrm{R}$ ). This implies that the Arrhenius relation can be used to describe the degradation rate of GFRP bars, as the degradation mechanism may not change with temperature and time during exposure in the range tested. Moreover, equation 6.11 can be used to describe the time and temperature dependence of tensile strength for GFRP bars exposed to alkaline solution.

Table 6.2 Coefficients of regression equations for Arrhenius plots

\begin{tabular}{cccccc}
\hline & \multicolumn{2}{c}{ GFRP1 bars in Solution 3 } & & \multicolumn{2}{c}{ GFRP2 bars in Solution 2 } \\
\cline { 2 - 3 } \cline { 5 - 6 } Tensile strength retention & $\mathrm{E}_{\mathrm{a}} / \mathrm{R}$ & $\mathrm{R}^{2}$ & & $\mathrm{E}_{\mathrm{a}} / \mathrm{R}$ & $\mathrm{R}^{2}$ \\
\hline $50 \%$ & 4891 & 0.98 & & 1420 & 0.98 \\
$60 \%$ & 4892 & 0.98 & & 1423 & 0.98 \\
$70 \%$ & 4891 & 0.98 & & 1420 & 0.98 \\
$80 \%$ & 4892 & 0.98 & & 1420 & 0.98 \\
$\begin{array}{c}\text { For equation 6.9 based on } \\
\text { data in Table 6.1 }\end{array}$ & 4899 & 0.98 & & 1415 & 0.98 \\
\hline
\end{tabular}




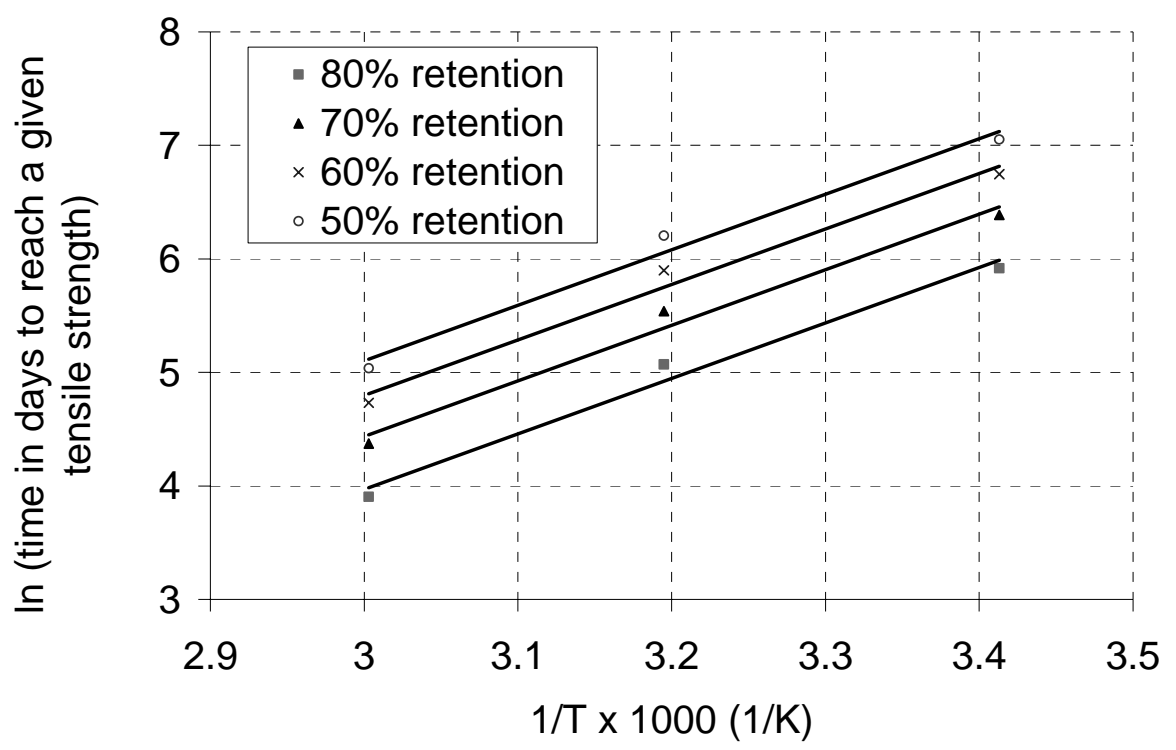

Figure 6.3 Arrhenius plots of tensile strength degradation for GFRP1 bars exposed to Solution 3

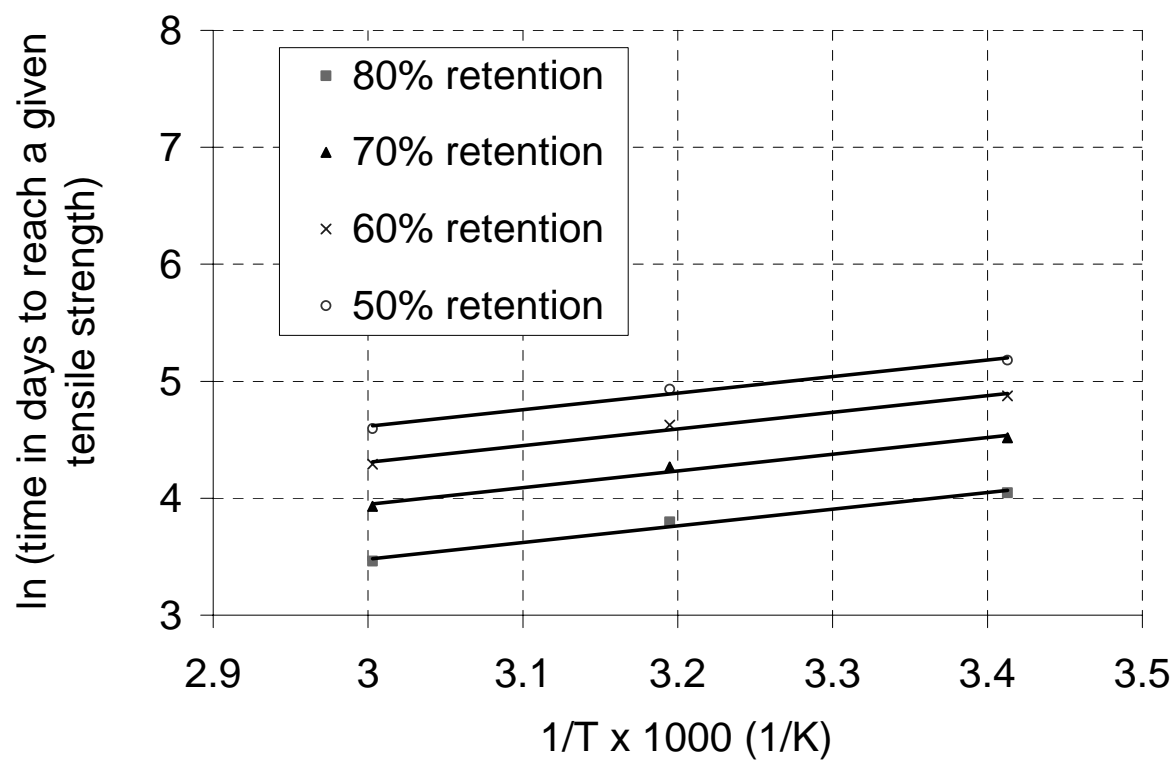

Figure 6.4 Arrhenius plots of tensile strength degradation for GFRP2 bars exposed to Solution 2 
For the third step, the acceleration factor (AF) for the same solution at two different temperatures can be obtained from previous Arrhenius plots. The AF can be expressed as:

$$
A F=\frac{t_{0}}{t_{1}}=\frac{c / k_{0}}{c / k_{1}}=\frac{k_{1}}{k_{0}}=\frac{A \exp \left(\frac{-E_{a}}{R T_{1}}\right)}{A \exp \left(\frac{-E_{a}}{R T_{0}}\right)}=\exp \left[\frac{E_{a}}{R}\left(\frac{1}{T_{0}}-\frac{1}{T_{1}}\right)\right]
$$

where, $\mathrm{AF}$ is the acceleration factor; $\mathrm{t}_{1}$ and $\mathrm{t}_{0}$ are the times required for some property to reach a given value at temperatures of $\mathrm{T}_{1}$ and $\mathrm{T}_{0}$, respectively; $\mathrm{c}$ is a constant; $\mathrm{k}_{1}$ and $\mathrm{k}_{0}$ are the degradation rates at temperatures of $T_{1}$ and $T_{0}$, respectively as expressed in equation 6.9. For example, for $70 \%$ retention of tensile strength of GFRP1 bars (as shown in Fig 6.3), the AF for Solution 3 at $60{ }^{\circ} \mathrm{C}$ in relation to $20{ }^{\circ} \mathrm{C}$ can be calculated, $\mathrm{AF}=7.5$. Since the fitted lines are parallel to each other (Figs. 6.3 and 6.4), the acceleration factor remains constant for all strength retention values, such as those shown from $50 \%$ to $80 \%$, at each specified temperature level, either 40 or $60{ }^{0} \mathrm{C}$. The $\mathrm{AF}$ values with reference temperature $\mathrm{T}_{0}=20{ }^{0} \mathrm{C}$ are listed in Table 6.3. Therefore, equation 6.12 can be fitted to data in Table 6.3 to obtain the AF values for other temperatures based on the reference temperature of $20{ }^{0} \mathrm{C}$.

Table 6.3 Values for acceleration factors (reference temperature is $20{ }^{\circ} \mathrm{C}$ )

\begin{tabular}{ccc}
\hline Temperature $\left({ }^{0} \mathrm{C}\right)$ & GFRP1 in Solution 3 & GFRP2 in Solution 2 \\
\hline 60 & 7.50 & 1.80 \\
40 & 2.33 & 1.28 \\
20 & 1.00 & 1.00 \\
\hline
\end{tabular}

For the fourth step, once the AF values for 60 and $40{ }^{\circ} \mathrm{C}$ were obtained, Figs. 6.1 and 6.2 were transformed into Figs. 6.5 and 6.6 by multiplying exposure times at 60 and 40 ${ }^{0} \mathrm{C}$ with corresponding $\mathrm{AF}$ values. Master curves for tensile strength retention vs. 
exposure time at $20{ }^{0} \mathrm{C}$ were obtained by fitting equation 6.11 to data in Figs. 6.5 and 6.6. As listed in Table 6.4, these data have correlation coefficients of 0.85 and 0.98 , respectively. Interestingly, the values for $\tau$ correspond exactly to those at $20{ }^{0} \mathrm{C}$ given in Table 6.1; this close correlation also confirms the validity of this procedure. The master curves can be used to predict the tensile strength retention of bars at any exposure time at $20{ }^{0} \mathrm{C}$. Master curves at other exposure temperatures can also be built following the third and fourth steps of the prediction procedure.

Table 6.4 Coefficients of regression equations for master curves

\begin{tabular}{ccc}
\hline Bar type and Solution type & $\tau$ & $\mathrm{R}^{2}$ \\
\hline GFRP1 bars in Solution 3 & 1667 & 0.98 \\
GFRP2 bars in Solution 2 & 256 & 0.85 \\
\hline
\end{tabular}

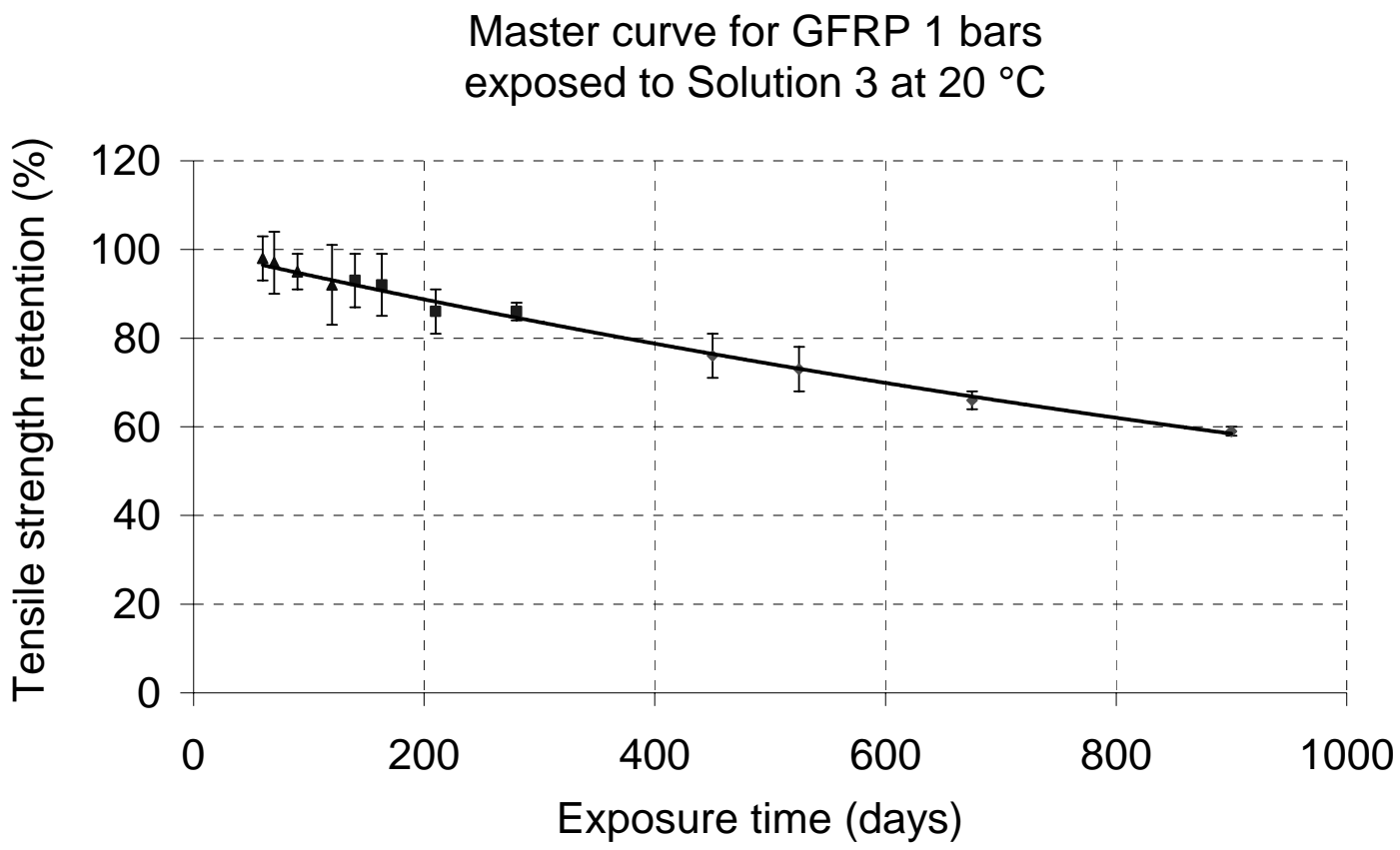

Figure 6.5 Tensile strength retentions vs. exposure time for GFRP1 bars 


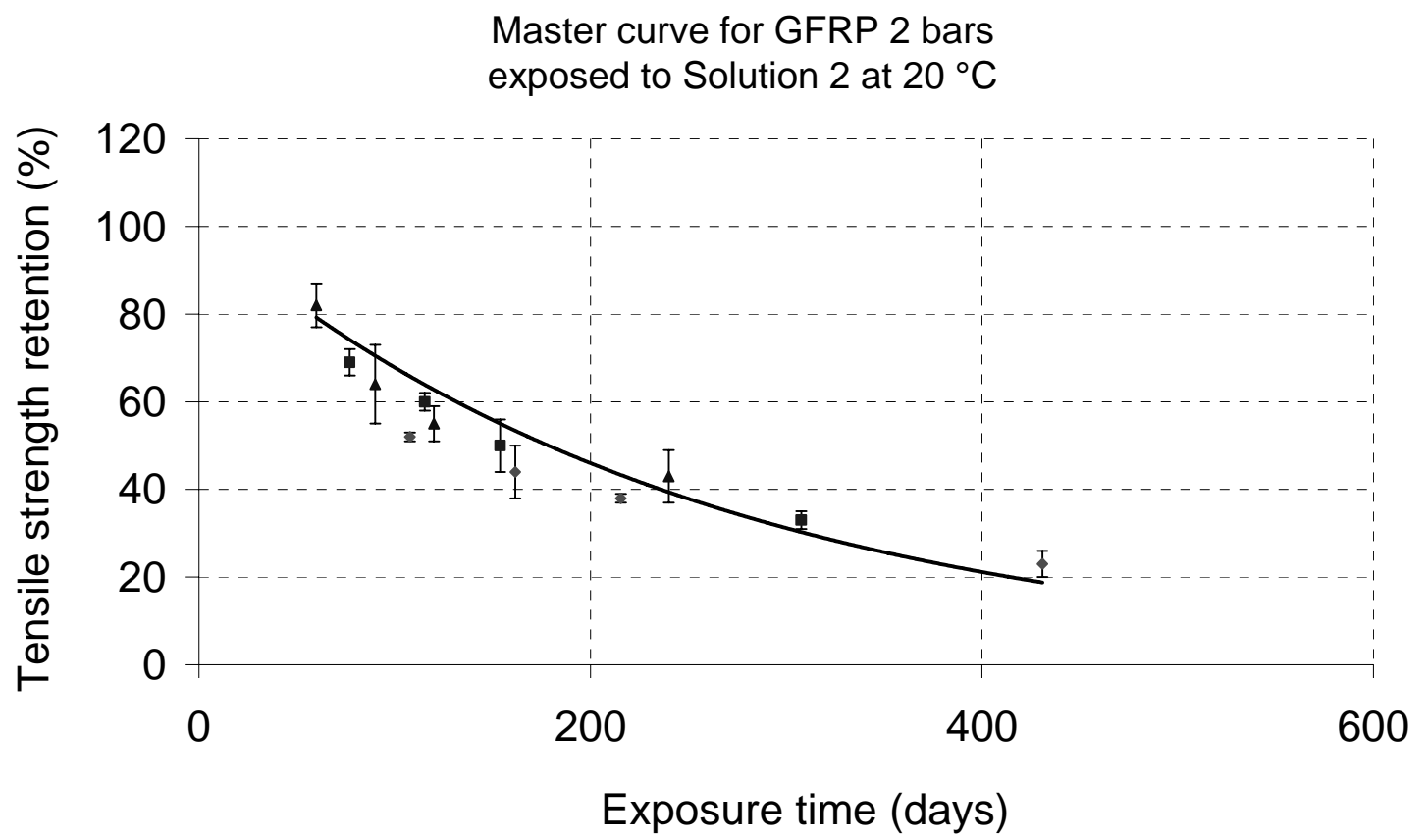

Figure 6.6 Tensile strength retentions vs. exposure time for GFRP2 bars

It is worth noting that the first and second steps in the above prediction procedure are the Arrhenius analysis which can be used to determine the validity of accelerated test. If the fitted straight lines in Arrehenius plots had low coefficient of determination (e.g. $\mathrm{R}^{2}$ $<0.8)$ and/or were not parallel to each other, one would infer that the degradation mechanism would have changed with temperature and/or time, indicating that the accelerated tests are not valid and the procedure could not be used to predict long-term behavior.

The proposed procedure can be easily carried out by defining simple plots and performing regression analysis. The results indicate that increasing the number of exposure temperatures and using longer exposure durations in accelerated tests can lead to more precise predictions. The results of this section have been published in Chen et al. (2006). 


\subsubsection{Durability Prediction of GFRP bars in Concrete}

In section 6.2.2, a general procedure for the durability prediction of GFRP bars was developed. In this section, the prediction will be modified and applied to the test results of GFRP bars embedded in not-loaded and loaded concrete beams (data in Fig. 4.14), respectively. In the first step of the procedure, equations 6.6 and 6.8 have been used instead of equation 6.11 in the following predictions, respectively.

When equation 6.6 is fitted to the test results of Fig. 4.14, the fitted curves as shown in Fig. 6.7 have $\mathrm{R}^{2}$ above 0.99 for results of both not-loaded and loaded beams. The results for the first step of prediction are summarized in Table 6.5. In the second step, the Arrhenius plots as shown in Fig. 6.8 are built from equation 6.6 with parameters of Table 6.5. The $\mathrm{R}^{2}$ for all regressions are above 0.93 and the straight lines are parallel to each other, indicating that the accelerated aging tests are valid and this model can be applied to the test results for durability prediction. For the third step, from the slopes of straight lines of Arrhenius plots as listed in Table 6.6, the activation energy values for not-loaded and loaded specimens were found. The acceleration factors with the reference temperature of $20{ }^{0} \mathrm{C}$ can be obtained as listed in Table 6.7. Equation 6.12 is also fitted to the data in Table 6.7 as shown in Fig. 6.9. Then Fig. 4.14 was transformed into Fig. 6.10 by multiplying the exposure times at elevated temperatures with corresponding acceleration factors. Then by fitting equation 6.6 to data in Fig.6.10, master curves were built for GFRP3 bars embedded in not-loaded and loaded saturated concrete at $20{ }^{0} \mathrm{C}$, respectively. As listed in Table 6.8, these curves have correlation coefficients of 0.98 and 0.99 , respectively. Also, values for $\tau$ and $\mathrm{Y}_{\infty}$ correspond exactly to those at $20{ }^{\circ} \mathrm{C}$ given in Table 6.5. 


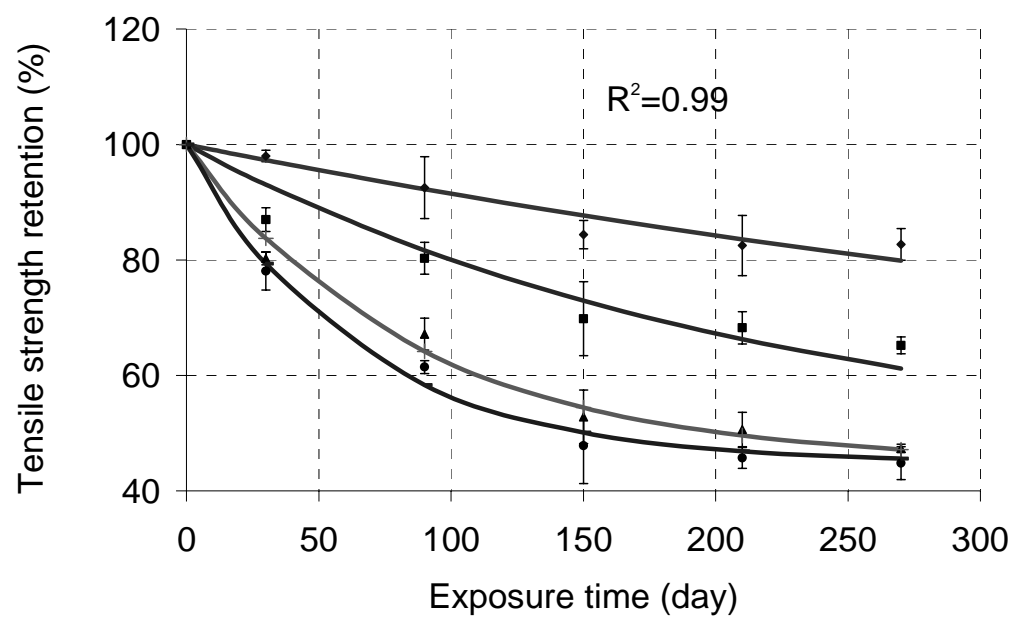

(a) Concrete beam

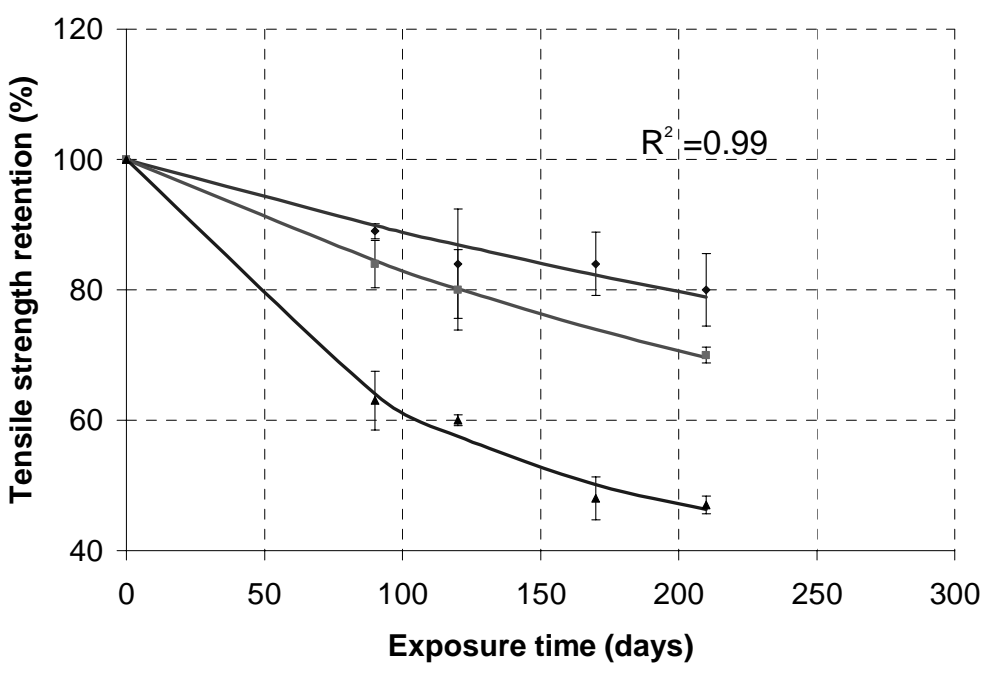

(b) Loaded concrete beam

Figure 6.7 Tensile strength retention vs. time and equation 6.6 fitted to the data

Table 6.5 Coefficients of regression equations for the tensile strength retention of GFRP3 bars using equation 6.6

\begin{tabular}{ccccccc}
\hline Temperature $\left({ }^{\circ} \mathrm{C}\right)$ & 20 & 40 & 50 & 60 & & \\
\hline Coefficients & & & $\tau$ & & $\mathrm{Y}_{\infty}$ & $\mathrm{R}^{2}$ \\
\hline Not-loaded concrete beams & 595 & 223 & 86 & 64 & 45 & 0.99 \\
Loaded concrete beams & 503 & 310 & N/A & 103 & 38 & 0.99 \\
\hline
\end{tabular}




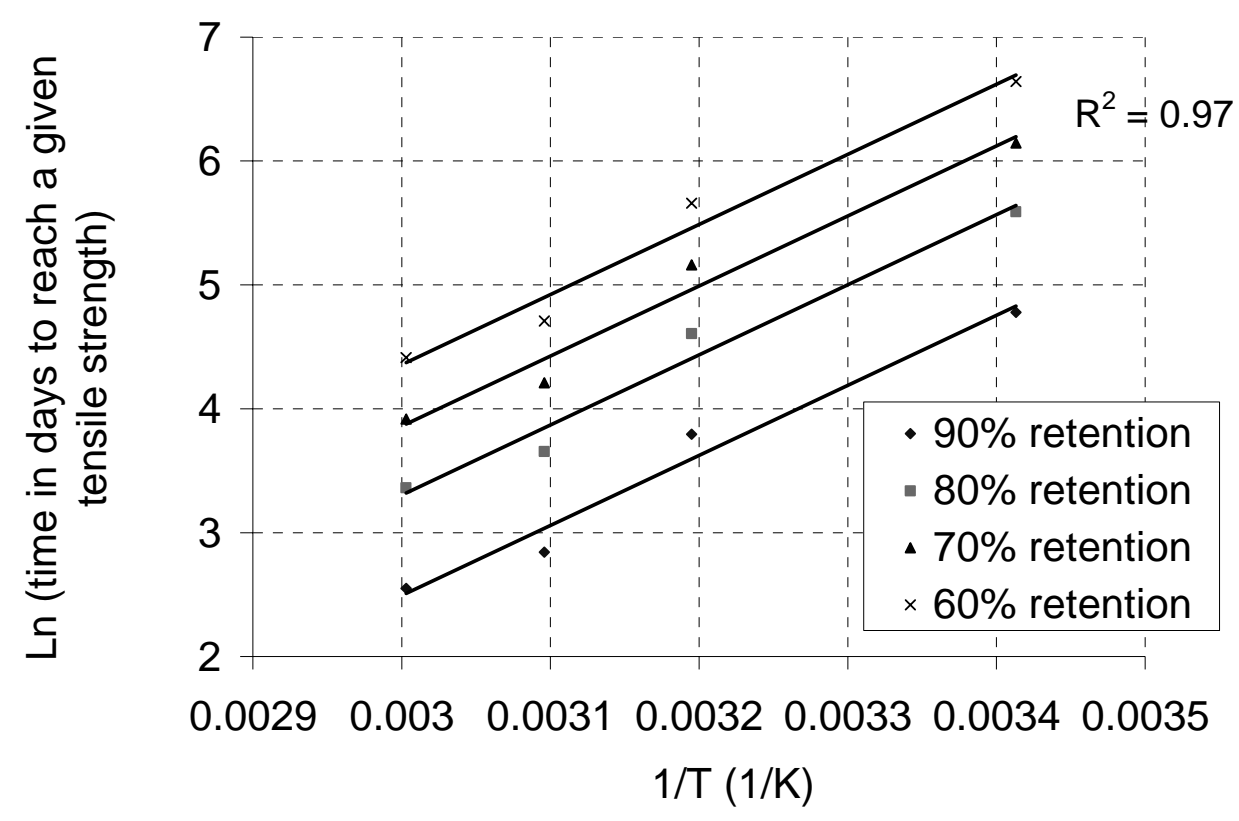

(a) Not-loaded concrete beam

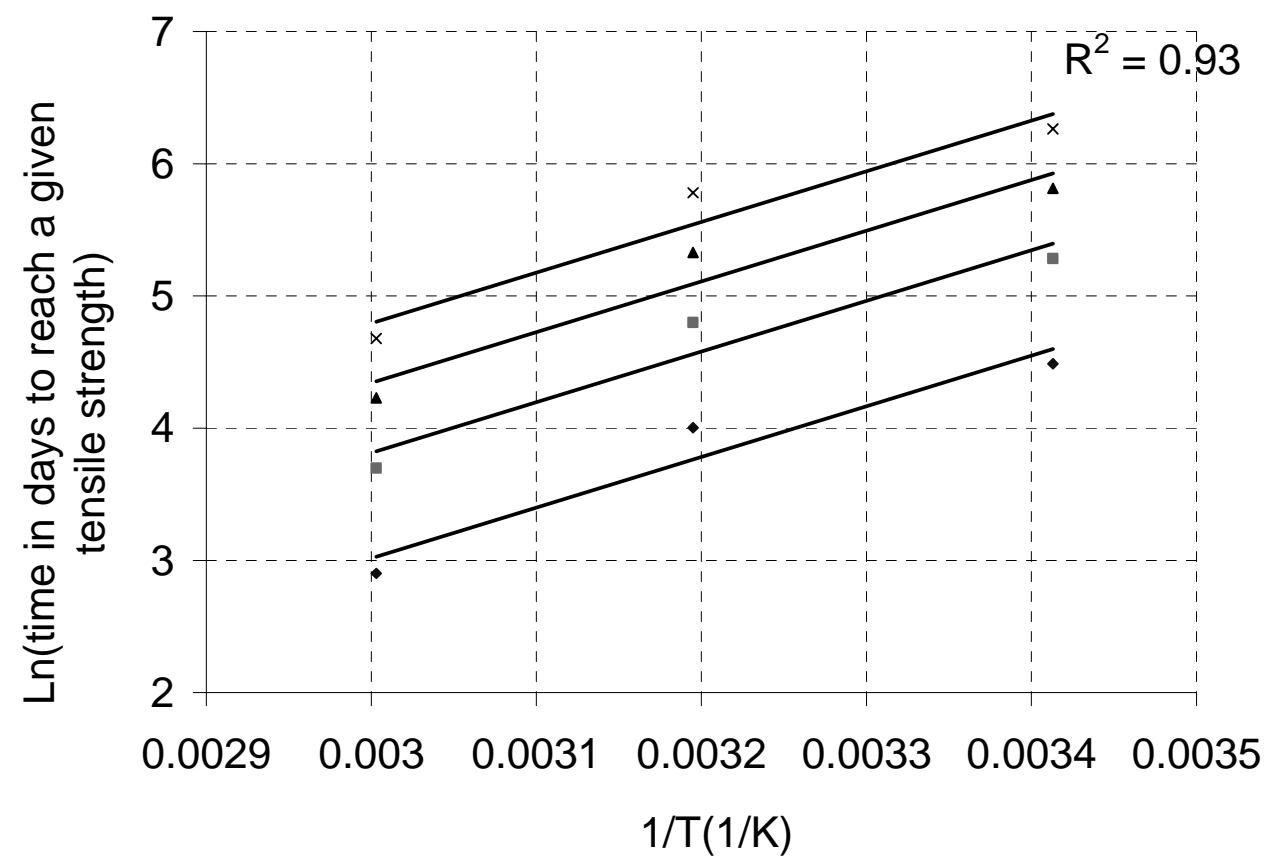

(b) Loaded concrete beam

Figure 6.8 Arrhenius plots of GFRP3 bars using equation 6.6 
Table 6.6 Coefficients of regression equations for Arrhenius plots of GFRP3 bars using equation 6.6

\begin{tabular}{cccccc}
\hline & \multicolumn{2}{c}{ not-loaded beam } & & \multicolumn{2}{c}{ loaded beam } \\
\cline { 2 - 3 } \cline { 5 - 6 } Tensile strength retention & $\mathrm{E}_{\mathrm{a}} / \mathrm{R}$ & $\mathrm{R}^{2}$ & & $\mathrm{E}_{\mathrm{a}} / \mathrm{R}$ & $\mathrm{R}^{2}$ \\
\hline $60 \%$ & 5659.5 & 0.97 & & 3831.4 & 0.93 \\
$70 \%$ & 5659.5 & 0.97 & & 3831.4 & 0.93 \\
$80 \%$ & 5659.5 & 0.97 & & 3831.4 & 0.93 \\
$90 \%$ & 5659.5 & 0.97 & & 3831.4 & 0.93 \\
For equation 6.9 based on & 5659.5 & 0.97 & & 3831.4 & 0.93 \\
data in Table 6.5 & & & & \\
\hline
\end{tabular}

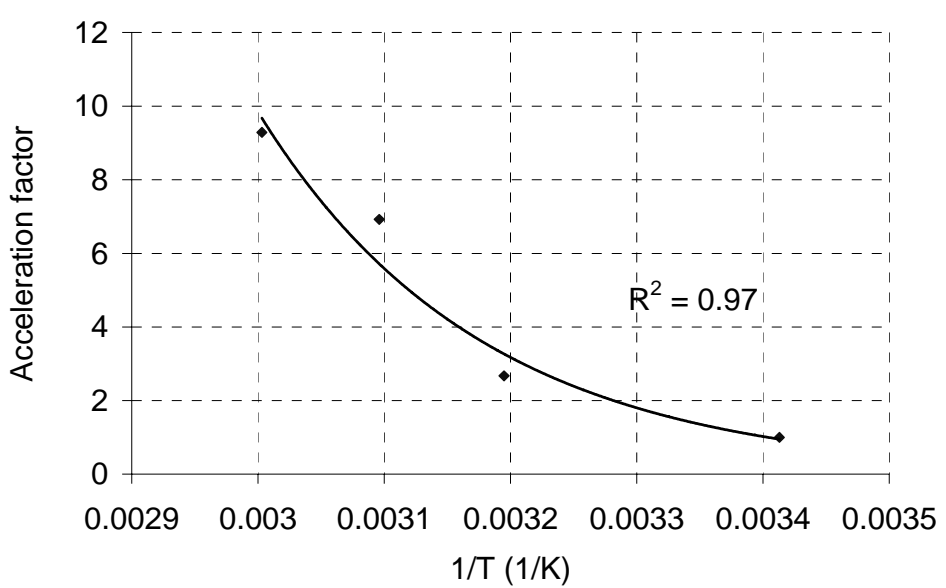

(a) Not-loaded concrete beam

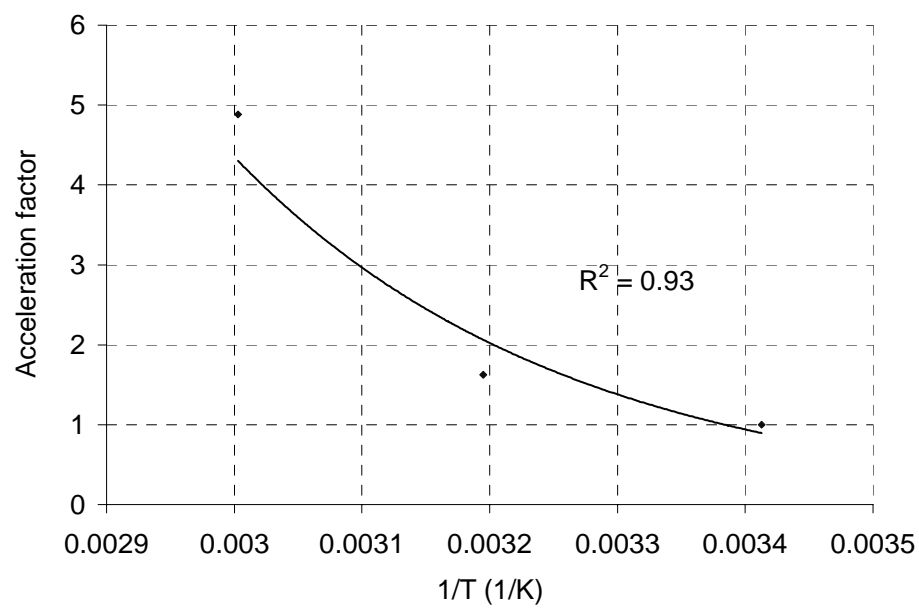

(b) Loaded concrete beam

Figure 6.9 Acceleration factors with reference temperature of $20{ }^{0} \mathrm{C}$ using equation 6.6 
Table 6.7 Values for acceleration factors (with reference temperature of $20{ }^{\circ} \mathrm{C}$ ) of GFRP3

bars using equation 6.6

\begin{tabular}{ccccc}
\hline Temperature $\left({ }^{0} \mathrm{C}\right)$ & 20 & 40 & 50 & 60 \\
\hline Not-loaded concrete beam & 1.00 & 2.67 & 6.92 & 9.29 \\
Loaded concrete beam & 1.00 & 1.62 & N.A. & 4.88 \\
\hline
\end{tabular}

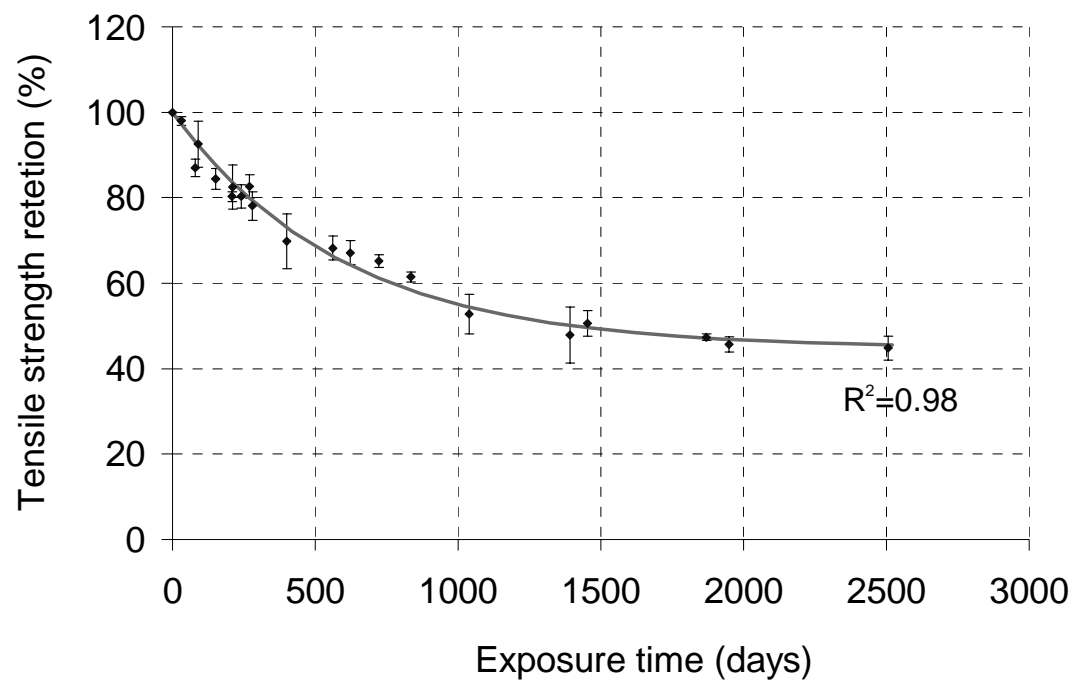

(a) Not-loaded concrete beam

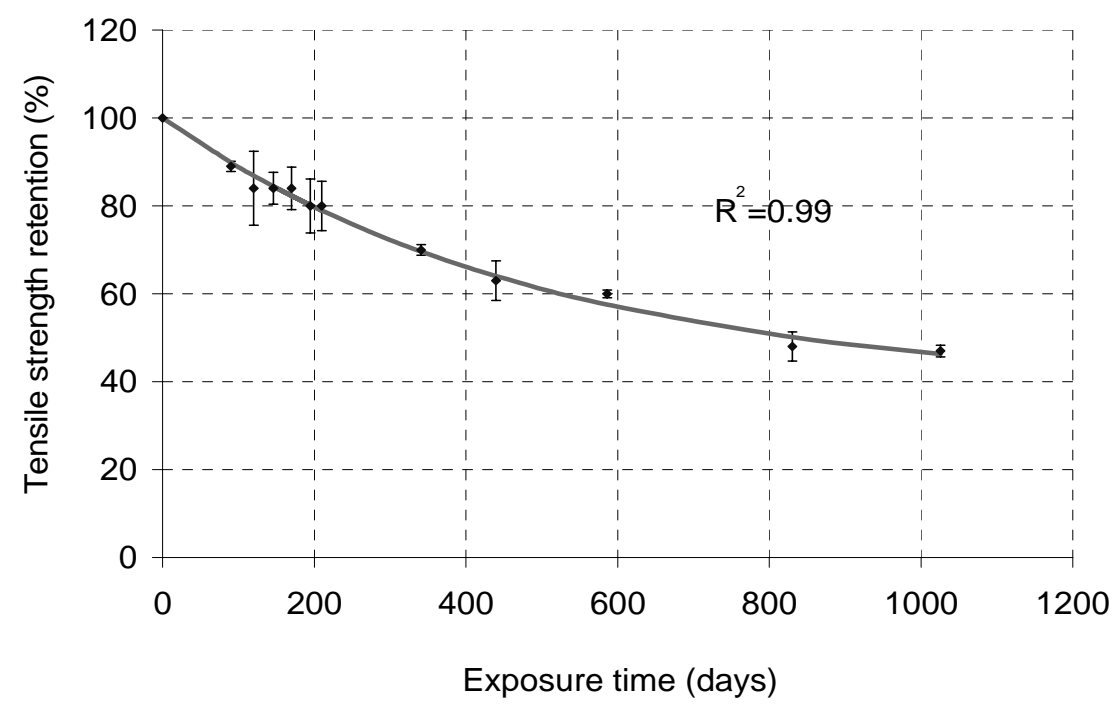

(b) Loaded concrete beam

Figure 6.10 Master curves for GFRP3 bars embedded in saturated concrete at $20{ }^{\circ} \mathrm{C}$ using equation 6.6 
Table 6.8 Coefficients of regression equations for master curves of GFRP3 bars using equation 6.6

\begin{tabular}{cccc}
\hline Bar type and Solution type & $\tau$ & $\mathrm{Y}_{\infty}$ & $\mathrm{R}^{2}$ \\
\hline Not loaded beam & 595 & 45 & 0.98 \\
Loaded beam & 503 & 38 & 0.99 \\
\hline
\end{tabular}

When equations 6.8 is fitted to the test results of Figure 4.14, the fitted curves as shown in Fig. 6.11 have $\mathrm{R}^{2}$ above 0.99 for both not-loaded and loaded specimens in concrete. The results for the first step of prediction are summarized in Table 6.9. Then following the prediction procedure of section 6.2.2, Arrhenius plots are built from Fig. 6.11 as shown in Fig. 6.12, where the straight lines with $\mathrm{R}^{2}$ values above 0.95 are parallel to each other for both not-loaded and loaded specimens, which indicates that the accelerate aging tests are valid and this model can also be applied to the results of this study. The coefficients of regression equations for Arrhenius plots are summarized in Table 6.10. Then acceleration factor curves and master curves were also built as shown in Figs. 6.13 and 6.14, respectively. The values for acceleration factors (with reference temperature of $20{ }^{\circ} \mathrm{C}$ ) are listed in Table 6.11. Also, the values of $\mathrm{c}$ and $\alpha$ for the master curves are listed in Table 6.12. 


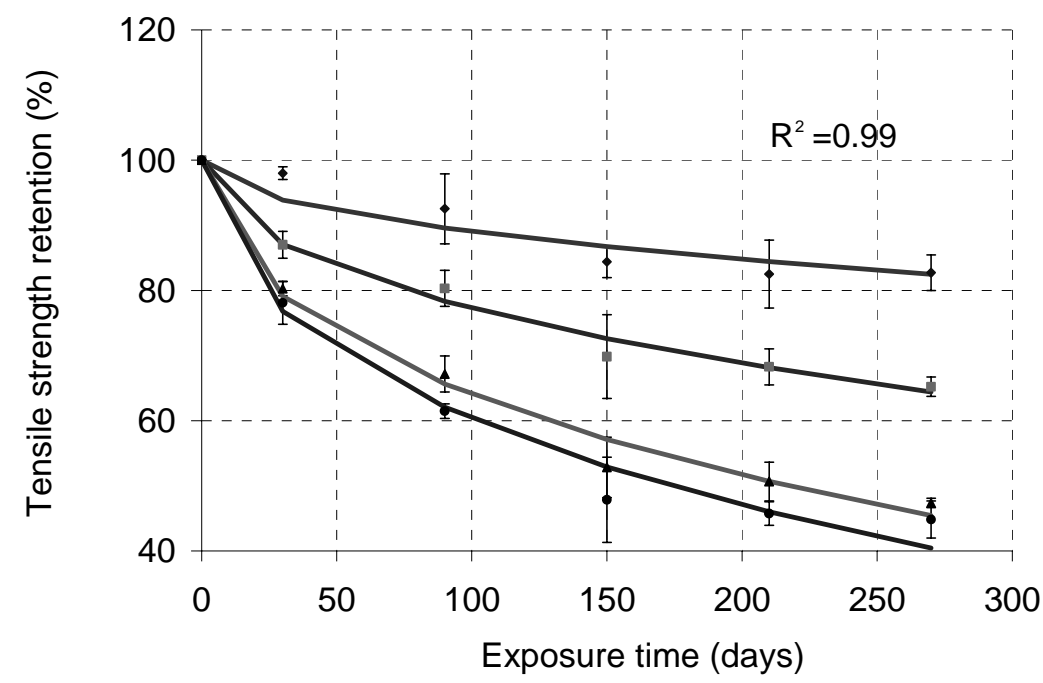

(a) Not-loaded concrete beam

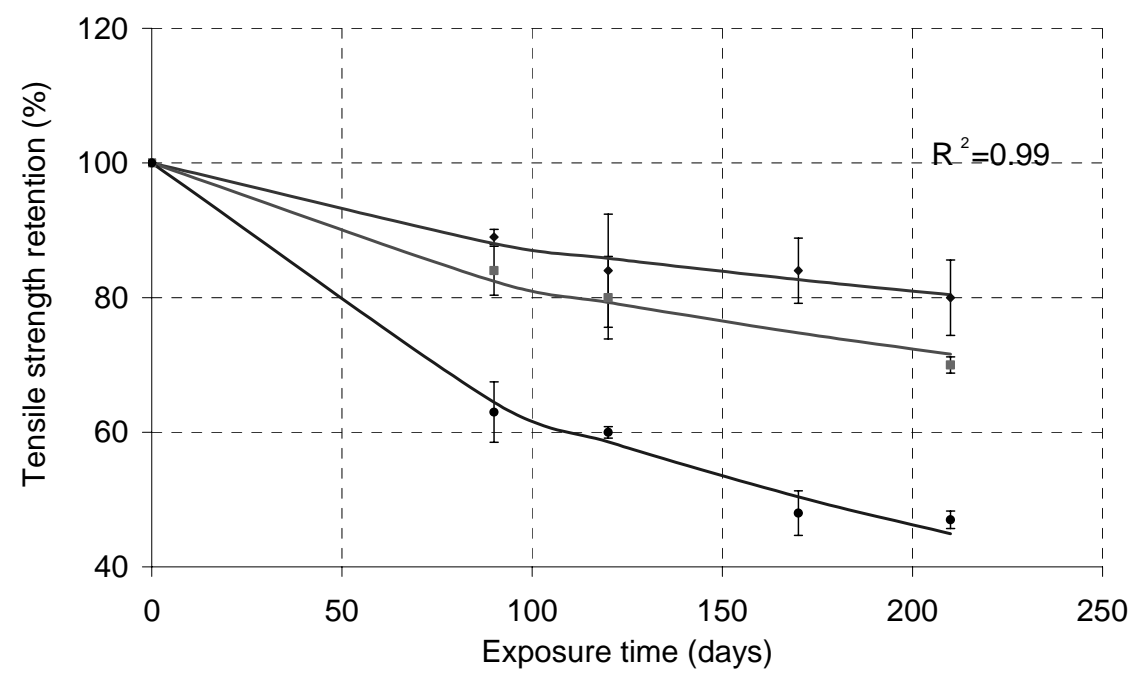

(b) Loaded concrete beam

Figure 6.11 Tensile strength retention vs. time and equation 6.8 fitted to the data Table 6.9 Coefficients of regression equations for tensile strength retention of GFRP3 bars using equation 6.8

\begin{tabular}{ccccccc}
\hline Coefficients & \multicolumn{3}{c}{$\mathrm{c}$} & $\alpha$ & $\mathrm{R}^{2}$ \\
\hline Temperature $\left({ }^{0} \mathrm{C}\right)$ & 20 & 40 & 50 & 60 & & \\
\hline Not-loaded concrete beams & 0.0059 & 0.0126 & 0.0209 & 0.0233 & -0.509 & 0.99 \\
Loaded concrete beams & 0.0040 & 0.0060 & N/A & 0.0129 & -0.393 & 0.99 \\
\hline
\end{tabular}




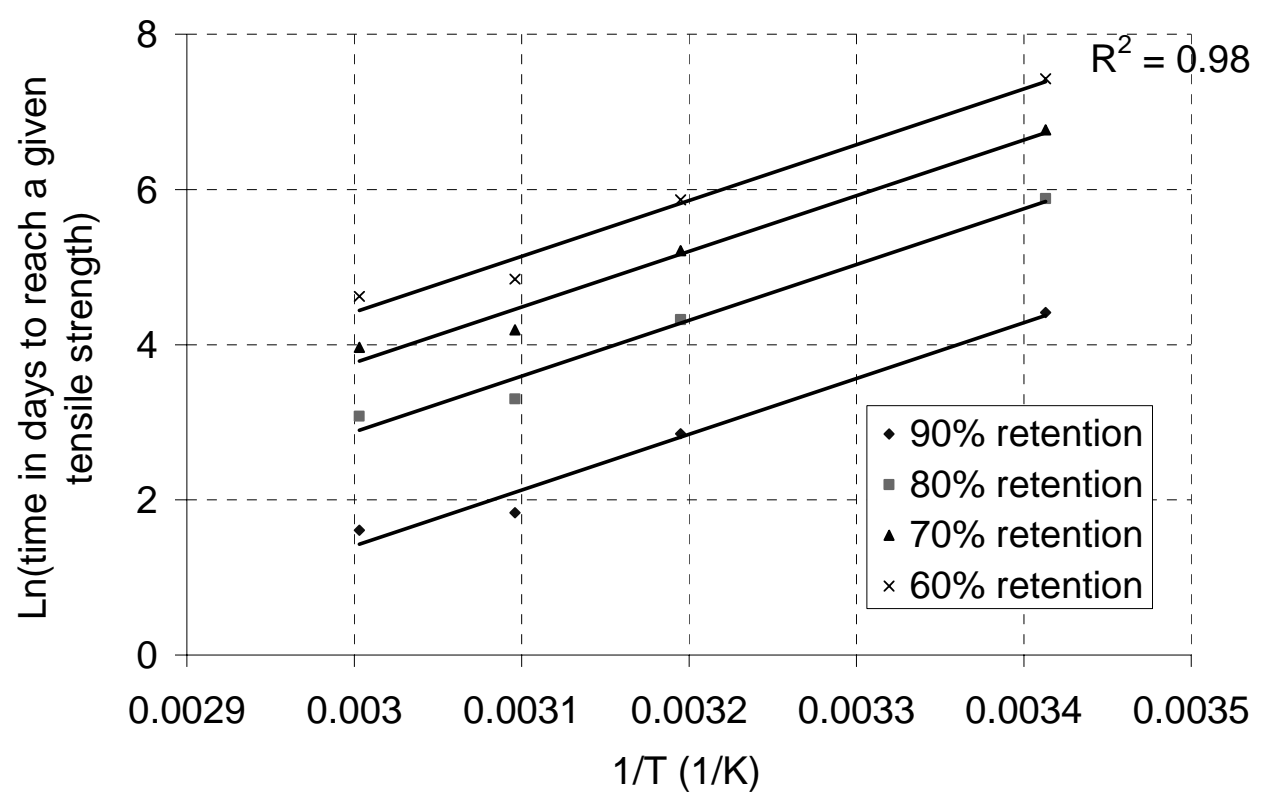

(a) Not-loaded concrete beam

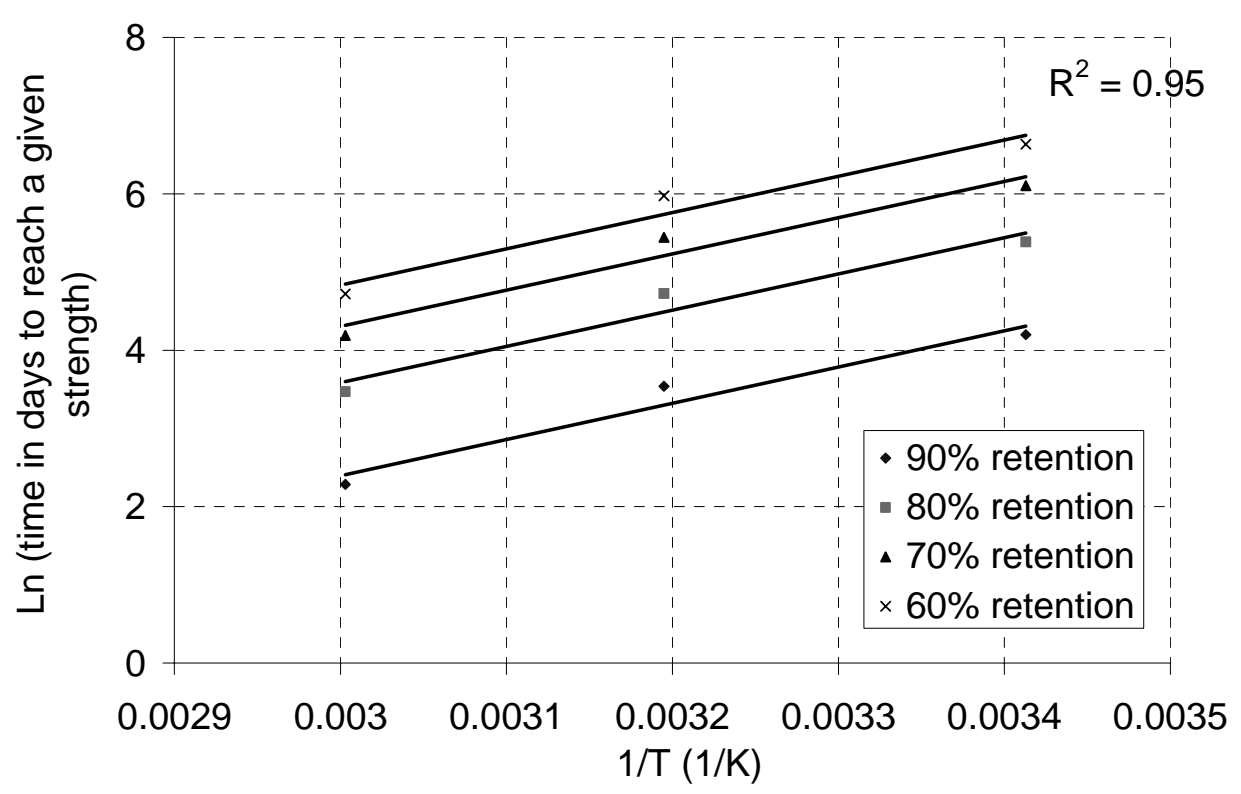

(b) Loaded concrete beam

Figure 6.12 Arrhenius plots of GFRP3 bars using equation 6.8 
Table 6.10 Coefficients of regression equations for Arrhenius plots of GFRP3 bars using equation 6.8

\begin{tabular}{cccccc}
\hline & \multicolumn{2}{c}{ not-loaded beam } & & \multicolumn{2}{c}{ loaded beam } \\
\cline { 2 - 3 } \cline { 5 - 6 } Tensile strength retention & $\mathrm{E}_{\mathrm{a}} / \mathrm{R}$ & $\mathrm{R}^{2}$ & & $\mathrm{E}_{\mathrm{a}} / \mathrm{R}$ & $\mathrm{R}^{2}$ \\
\hline $60 \%$ & 7186.3 & 0.98 & & 4634.1 & 0.95 \\
$70 \%$ & 7186.3 & 0.98 & & 4634.1 & 0.95 \\
$80 \%$ & 7186.3 & 0.98 & & 4634.1 & 0.95 \\
$90 \%$ & 7186.3 & 0.98 & & 4634.1 & 0.95 \\
For equation 6.9 based on & 7186.3 & 0.98 & & 4634.1 & 0.95 \\
data in Table 6.5 & & & & \\
\hline
\end{tabular}

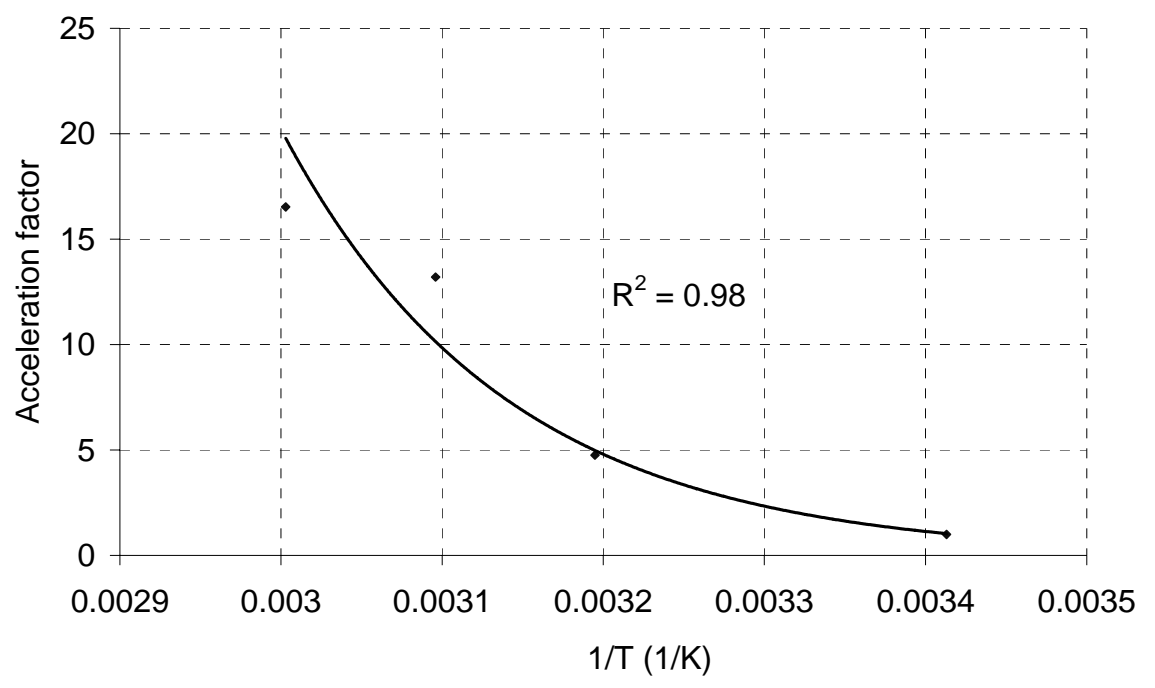

(a) Not-loaded concrete beam

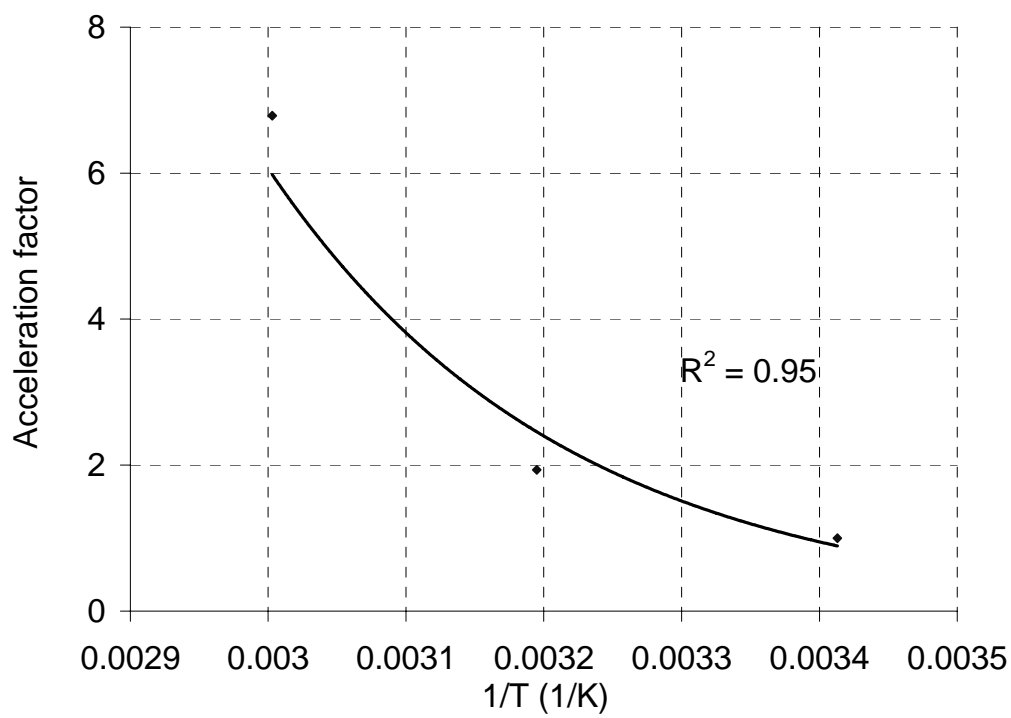

(b) Loaded concrete beam

Figure 6.13 Acceleration factors with reference temperature of $20{ }^{0} \mathrm{C}$ using equation 6.8 
Table 6.11 Values for acceleration factors (reference temperature is $20{ }^{\circ} \mathrm{C}$ ) for GFRP3 bars using equation 6.8

\begin{tabular}{ccccc}
\hline Temperature $\left({ }^{0} \mathrm{C}\right)$ & 20 & 40 & 50 & 60 \\
\hline Not loaded beam & 1 & 4.76 & 13.20 & 16.52 \\
Loaded beam & 1 & 1.93 & N.A. & 6.79 \\
\hline
\end{tabular}

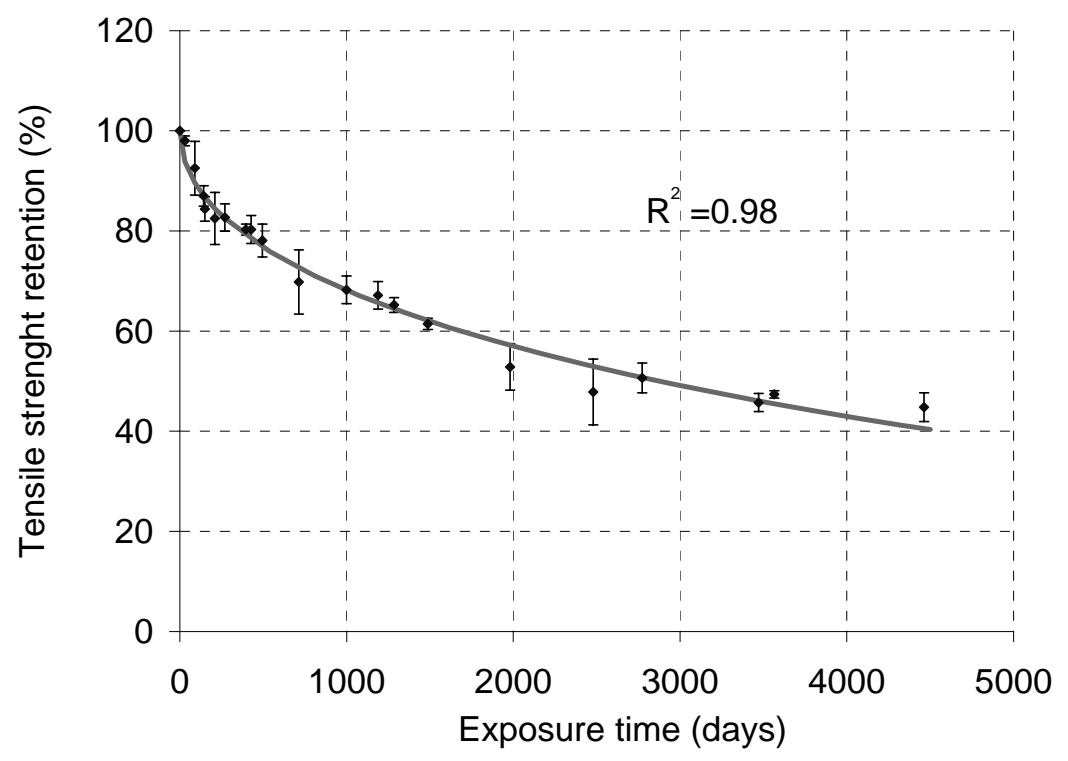

(a) Not-loaded concrete beam

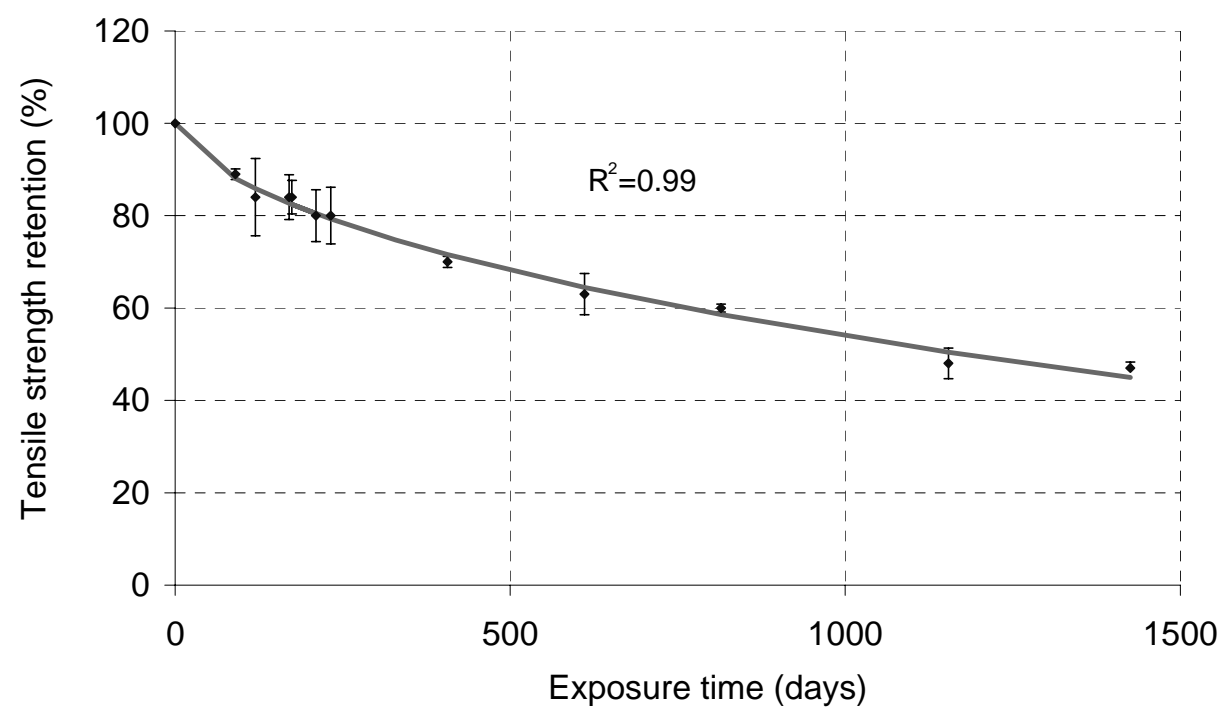

(b) Loaded concrete beam

Figure 6.14 Master curve for GFRP3 bars embedded in saturated concrete at $20{ }^{0} \mathrm{C}$ using equation 6.8 
Table 6.12 Coefficients of regression equations for master curves using equation 6.8

\begin{tabular}{cccc}
\hline Bar type and Solution type & $\mathrm{c}$ & $\alpha$ & $\mathrm{R}^{2}$ \\
\hline Not-loaded concrete beam & 0.0059 & -0.509 & 0.98 \\
Loaded concrete beam & 0.0040 & -0.393 & 0.99 \\
\hline
\end{tabular}

It is worth noting that for equation 6.8 , the $\alpha$ value for not-loaded specimens is found as -0.51 , while for loaded specimens the value is -0.39 . For GFRP specimens of this study, as shown in Fig. 4.14, the degradation rate decreased rapidly with exposure time. So it is reasonable that the $\alpha$ values obtained from the prediction were less than zero. Since the applied load facilitated the environmental attack, the $\alpha$ value for loaded specimens was relatively larger than that of not-loaded specimens.

Using the obtained master curves for GFRP bars in concrete, the tensile strength retentions are predicted for GFRP3 bars after 50 year exposure in saturated loaded or notloaded concrete at $10{ }^{0} \mathrm{C}$. When equation 6.6 is applied, the retentions are about $38 \%$ for loaded condition and $45 \%$ for not-loaded condition, respectively. When equation 6.8 is applied, the retention for not-loaded specimens is $25 \%$, but the loaded specimens fail since the strength retention is not enough to carry sustained load within the 50 year exposure.

\subsection{Discussion}

The activation energy values obtained from previous predictions are compared with those of other studies as listed in Table 6.13. The types of fibers, matrices and exposure conditions for other studies are also described. Activation energy is not a measure of durability but a parameter relating the temperature and degradation of materials, and describing the material response to environmental agents. Since the applied load 
facilitated the environmental attack, the activation energy values for loaded specimens are lower than those of not-loaded. The activation energy values from this study compare well with those of other studies with E-glass fiber/vinyl ester composites. When GFRP1 and GFRP2 bars were directly exposed to simulated pore solutions, the degradation was much faster and resulted in lower activation energy values. It is also apparent from Table 6.13 that GFRP with matrix of polyester had inferior durability performance.

Table 6.13 Comparison of activation energy values

\begin{tabular}{|c|c|c|c|}
\hline Prediction models & Bar type & Exposure conditions & $\begin{array}{c}\text { Activation energy } \\
(\mathrm{kJ} / \mathrm{mol})\end{array}$ \\
\hline Equation 6.6 & GFRP1 & Solution 3 & 41 \\
\hline Equation 6.6 & GFRP2 & Solution 2 & 12 \\
\hline Equation 6.6 & GFRP3 & Saturated concrete & 47 \\
\hline Equation 6.6 & GFRP3 & $\begin{array}{l}\text { Loaded and saturated } \\
\text { concrete }\end{array}$ & 32 \\
\hline Equation 6.8 & GFRP3 & Saturated concrete & 60 \\
\hline Equation 6.8 & GFRP3 & $\begin{array}{l}\text { Loaded and saturated } \\
\text { concrete }\end{array}$ & 39 \\
\hline Dejke 2001 & $\begin{array}{l}\text { E-glass and vinyl } \\
\text { ester (gray) }\end{array}$ & Saturated concrete & 52 \\
\hline Dejke 2001 & $\begin{array}{l}\text { E-glass and vinyl } \\
\text { ester (FIBERBAR) }\end{array}$ & Saturated concrete & 69 \\
\hline Beddow et al. 2002 & $\begin{array}{l}\text { AR-glass fiber and } \\
\text { polyester }\end{array}$ & water & 39 \\
\hline Beddow et al. 2002 & $\begin{array}{l}\text { AR-glass fiber } \\
\text { reinforced concrete }\end{array}$ & water & 90 \\
\hline Phani and Bose 1987 & $\begin{array}{l}\text { E-glass and } \\
\text { polyester }\end{array}$ & water & 12 \\
\hline
\end{tabular}

For comparison purpose with test results of other studies, master curves from equation 6.6 and 6.8 are produced as shown in Figs. 6.15 and 6.16. Given the differences in FRP material, concrete, concrete cover thickness, and loading conditions, the master curves of this study provide predictions in good agreement with test results from other studies, especially for loaded specimens. For results of not-loaded specimens, it can be observed that the master curves can be low boundary envelopes of tensile strength 
retentions for test results of other studies. This may be due to the more aggressive exposure used in this study. because for example in Dejke (2001), only the middle portions of the bars were embedded in saturated concrete, and in Almusallam and AlSalloum (2005), the concrete cover was thicker than that of this study. For loaded specimens, the sustained load in Murkherjee and Arwikar (2005) was about the same as that of this study, while the load applied in Almusallam and Al-Salloum (2005) was about twice of the load in this study. The field data of 18 and 30 months from Murkherjee and Arwikar (2005) were obtained from specimens subjected to the hot and humid environment of Bomay, India (the year average temperature is about $27{ }^{0} \mathrm{C}$ ). The exposure time needed to reach $61.4 \%$ retention for the master curve from equation 6.6 is 2.2 times as much as in natural conditions. This ratio may even increase with the exposure time. It is obvious that the master curves give very conservative predictions compared to the limited field data available. This may be explained by the fact that natural condition is less aggressive to GFRP bars due to temperature fluctuations and lower humidity.

It can also found from Figs 6.15 and 6.16 that the predicted tensile strength retention from equation 6.8 deviates from test results and master curves of equation 6.6 with the increase of exposure time, especially at temperature of $60{ }^{\circ} \mathrm{C}$, which can also be observed at lower temperatures but for longer exposure times. The deviation may be due to assumed degradation mechanism of equation 6.8, which can not accurately describe the degradation of GFRP bars in this study. This may also be due to the inaccurate assumption of the equation 6.8, which ignores the contribution of affected area in the cross section. Both equations 6.6 and 6.8 account for the decrease of degradation rate 
with exposure time, but equation 6.6 predicts that the degradation almost stops after a period of time, which is also supported by the test results from other studies as shown in Fig.6.15. It may also be reasonable to predict that the slope of strength vs. exposure time plot for loaded specimen test results will also be close to zero after a certain period of time.

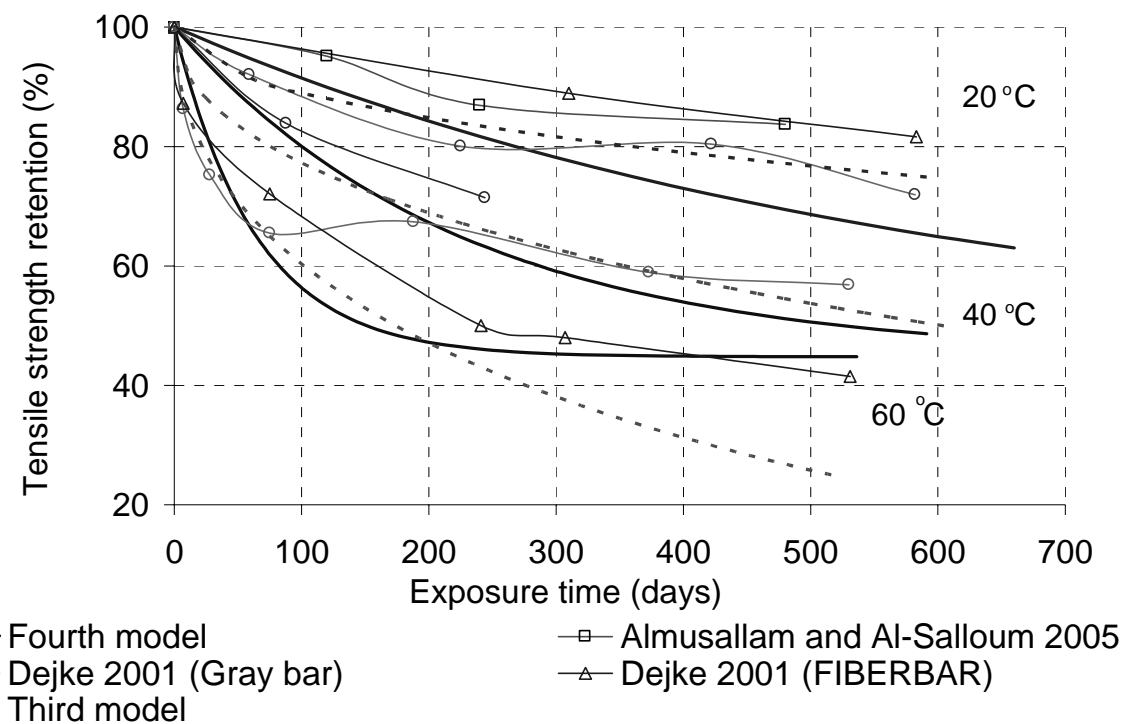

Figure 6.15 Comparisons of predictions and test results for not loaded specimens

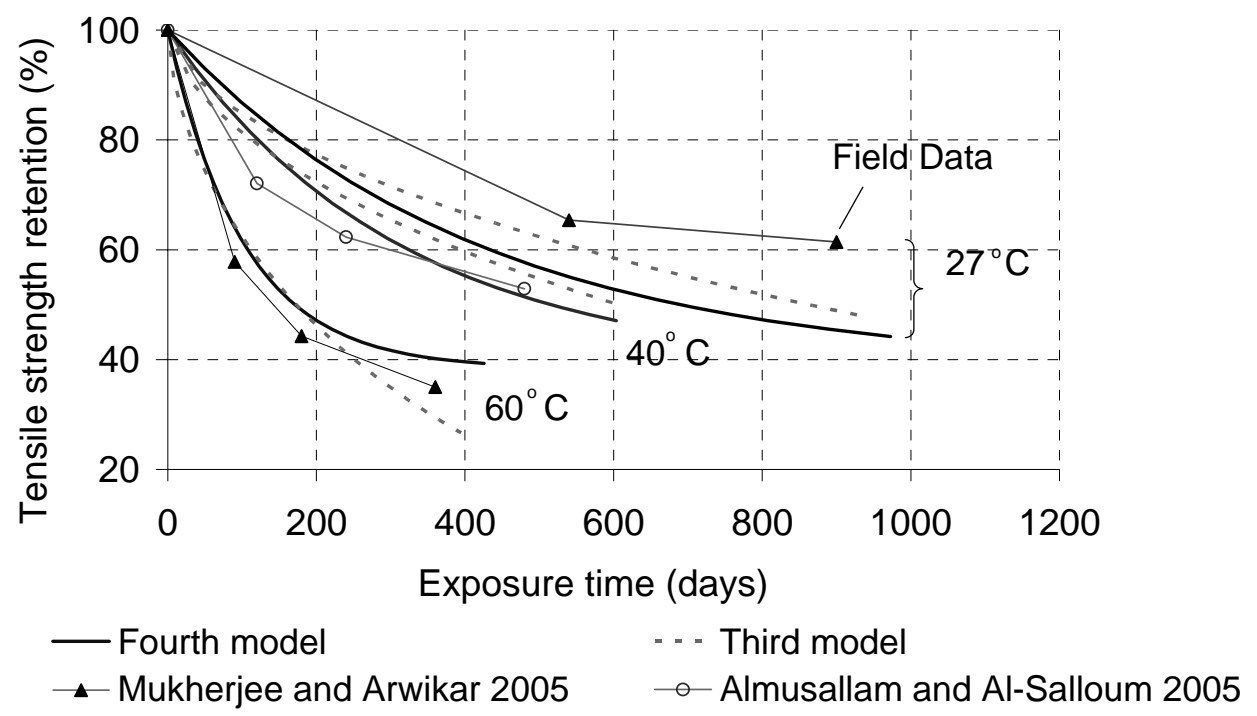

Figure 6.16 Comparisons of predictions and test results for loaded specimens 
The tensile strength retentions for GFRP bars in saturated concrete at different exposure temperatures are predicted using the fourth model as shown in Fig. 6.17. The master curves for not-loaded specimens have similar shapes as for loaded specimens, and for clarity of results only the portions of the curves after 4000 days are shown. As shown in Fig. 6.17, degradation rates decrease rapidly and approach to zero. The master curves for different temperatures converge to constant values with the increase of exposure times for specimens either not-loaded, after about 7000 days (19 years), or loaded, after about 4000 days (11 years). The convergence occurs earlier in case of loaded specimens. The values of parameters for those master curves are listed in Table 6.14 , where the long-term retentions $\left(\mathrm{Y}_{\infty}\right)$ are $45 \%$ for not loaded and 38\% for loaded cases. The design tensile strength and creep rupture stress limit of GFRP bars according to ACI 440 (2003) are also shown in Fig. 6.17; for both limits, an environmental reduction factor of 0.7 was applied. From this figure, one can conclude that the environmental reduction factor for design tensile strength of GFRP bars from ACI 440 (2003) is unconservative, while the creep rupture stress limit may be too conservative, although this limit may still be applied for long-term and heavily sustained critical load situations; a case that will require further study. However, when considering in-situ conditions, the concrete may not be completely saturated, also the moisture from outside the concrete may not be in direct contact with bars, and the temperature and sustained load may not be constant as is the conditioning exposure used in this study. And therefore, the strength reduction may be significantly less than as predicted in Fig. 6.17, which can be adjusted as additional reliable field data for long-term performance becomes available. 


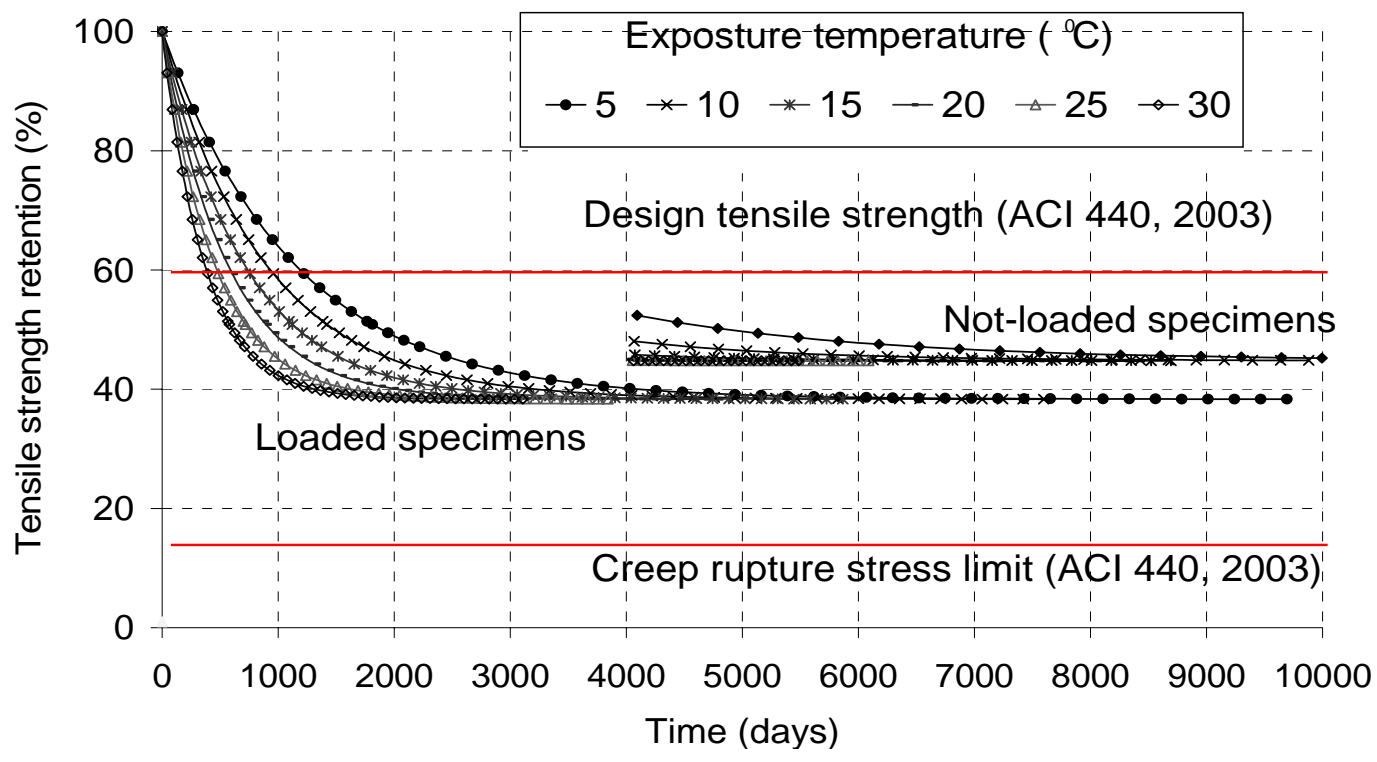

Fig. 6.17 Tensile strength retentions of GFRP3 bars in saturated concrete

Table 6.14 Parameters for master curves of GFRP3 bars as shown in Fig. 6.17

\begin{tabular}{cccccccc}
\hline Temperature $\left({ }^{0} \mathrm{C}\right)$ & 5 & 10 & 15 & 20 & 25 & 30 \\
\hline Parameters & \multicolumn{7}{c}{$\tau$ (days) } \\
\hline Not-loaded concrete beams & 2065 & 1441 & 1018 & 728 & 527 & 384 & 45 \\
Loaded concrete beams & 1139 & 893 & 706 & 563 & 451 & 365 & 38 \\
\hline
\end{tabular}

\subsection{Concluding Remarks}

The prediction procedure in this study can be used for short term data of GFRP bars successfully and efficiently. Equations 6.6 and 6.8 have been successfully employed to describe the relationship between strength retention and exposure time, respectively. There is a dominant degradation mechanism for GFRP bars in alkaline media, which does not appear to change with temperature or time. Elevated temperature can be used to accelerate the degradation of GFRP bars in alkaline environment. Further, the temperature dependence of degradation rate can be described by Arrhenius equation (equation 2.7). 
Due to the complexity of degradation mechanism, no degradation model has been proposed to simulate exactly the degradation of GFRP bars in alkaline media. The accelerated test method and prediction procedure used in this study can be good options to assess the long-term durability performance of GFRP bars. This procedure may also be used for FRP materials exposed to other conditions.

From the master curves of bare GFRP bars in simulated solutions, after 1156 day exposure in Solution 3 at $20{ }^{0} \mathrm{C}$, the tensile strength retention of GFRP1 bars will drop to $50 \%$. For GFRP2 bars exposed to Solution 2 at $20{ }^{\circ} \mathrm{C}$, the tensile strength retention will be $50 \%$ only after 178 days. For GFRP bars in simulated solutions, the degradations were significant for both GFRP1 and GFRP2 bars in such short exposure times compared to their expected service life. Based on a diffusion model, similar trend was also predicted for GFRP bars directly exposed to alkaline solution by Sen et al. (2002). The predicted service life for a specific E-glass/vinyl ester reinforcement used by the U.S. navy was only between 1.6 to 4.6 years.

Equation 6.6 gives more reasonable predictions than equation 6.8 according to the discussion in the previous paragraphs. Until further data on tensile strength retention are collected from samples in field concrete structures, the current environmental strength reduction factor in ACI 440 (2003) can be viewed as unconservative for design tensile strength and conservative for creep rupture stress limit. But the master curves give very conservative predictions and correction factors are needed for the prediction of FRP bars in field conditions. The sustained load had accelerated the environmental attack, though this situation was not so obvious when only the short term test results were considered. 
It is worth noting that if the master curve for prediction is developed for one type of GFRP bars in a specific exposure condition, it may not be applicable to other types of GFRP bars used in different environments. 


\section{CHAPTER SEVEN \\ DURABILITY OF FRP-COCNRETE BOND}

\subsection{Introduction}

In order to enhance the acceptance of FRP bars in the construction industry, all aspects of their structural behavior must be continued to be studied to guarantee their safe application. Bond development is also a critical aspect for their successful application as reinforcement in concrete structures. Bond characteristics affect the mechanism of load transfer between the reinforcements and concrete, and control design parameters, such as reinforcement development length, required thickness of concrete cover, concrete crack spacing and crack width.

The bond of traditional steel reinforcement in concrete depends on many factors, such as the geometry of a concrete member, the confinement provided by concrete, the placement of a bar in the cross section of concrete member, the bond-stress distribution along the bond length and the pullout resistance. It has been found that due to the variety of types, compositions and surface treatments of FRP bars, their bond behavior in concrete is more complicated and quite different from that of steel reinforcement (Bank et al., 1998 and Achillides and Pilakoutas, 2004). Moreover, the bond strength and stiffness may also degrade under long term service environments. Since it was shown in previous chapters and other studies that FRP bars, especially GFRP bars, are susceptible to environmental attack, the degradation of FRP bars in concrete may lead to reduced bond capacity and stiffness. It is recognized that bond strength will be reduced 
significantly when subjected to high temperatures. Also, the effect of considerable transverse thermal expansion of FRP bars on bond remains a concern among researchers.

In this study, a preliminary durability study on the bond of GFRP bars was conducted first. Then an extensive durability investigation was carried out on FRP bar bond by exposing pullout specimens to tap water, hot water and thermal cycles. Finally, numerical methods were proposed to simulate the bond-slip curves of FRP bars and determine the development length.

\subsection{Preliminary Durability Study on the Bond of GFRP Bars}

The preliminary durability study on the bond of GFRP bars was carried out on the initial stage of the research in this dissertation as a part of evaluation of FRP bar-concrete interaction.

\subsubsection{Specimens}

For the preliminary study, GFRP bars were embedded in concrete cylinders as shown in Fig.7.1. The specimen dimensions are listed in Table 7.1. Section 1 was used for pullout test to evaluate bond strength, and section 2 was used for splitting tension test to evaluate bar conditions and the bar embedded in section 2 was also for short beam test. This type of specimen enables the simultaneous tests for pullout, short beam and even microscopic evaluations to be performed on FRP materials subjected to the same environmental condition, since they are embedded in the same concrete cylinder. The specimens were fabricated by positioning the bars vertically through a wood frame as shown in Fig.7.2. The concrete mix designs used for this preliminary study are listed in Table 7.2. 


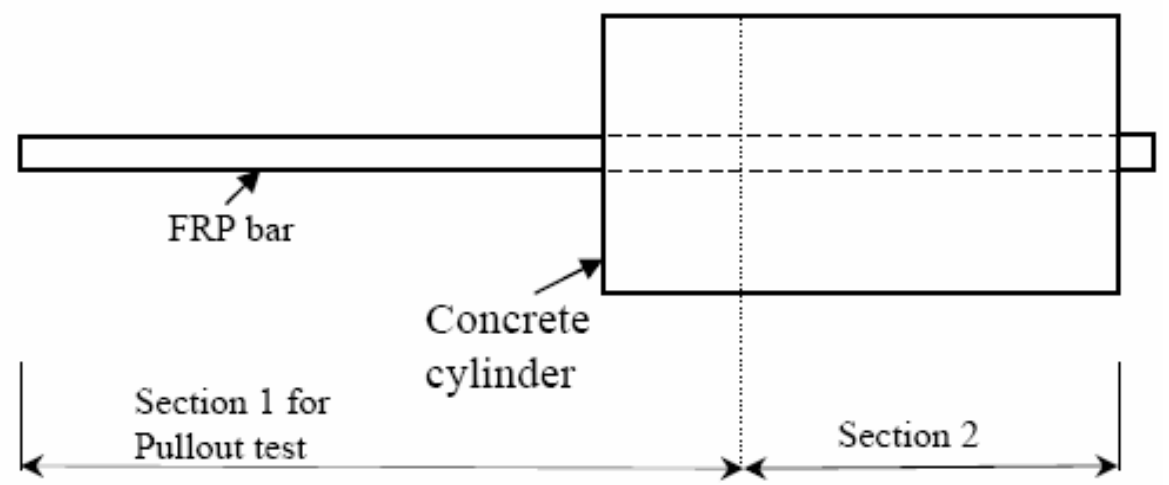

Figure 7.1 GFRP1 bar embedded in concrete for pullout and short beam tests

Table 7.1 Specimens for evaluation of FRP concrete interaction

\begin{tabular}{ccccc}
\hline $\begin{array}{c}\text { Bar } \\
\text { types }\end{array}$ & $\begin{array}{c}\text { Bar } \\
\text { size }\end{array}$ & $\begin{array}{c}\text { Total embedded } \\
\text { length }(\mathrm{mm})\end{array}$ & $\begin{array}{c}\text { Concrete cylinder } \\
\text { dimension }(\mathrm{mm})\end{array}$ & $\begin{array}{c}\text { Length of Section 1 } \\
(\mathrm{mm})\end{array}$ \\
\hline GFRP1 & $\# 3$ & 305 & $\emptyset 152 \times 305$ & $5 \times$ bar diameter \\
GFRP1 & $\# 4$ & 305 & $\emptyset 152 \times 305$ & $5 \times$ bar diameter \\
\hline
\end{tabular}

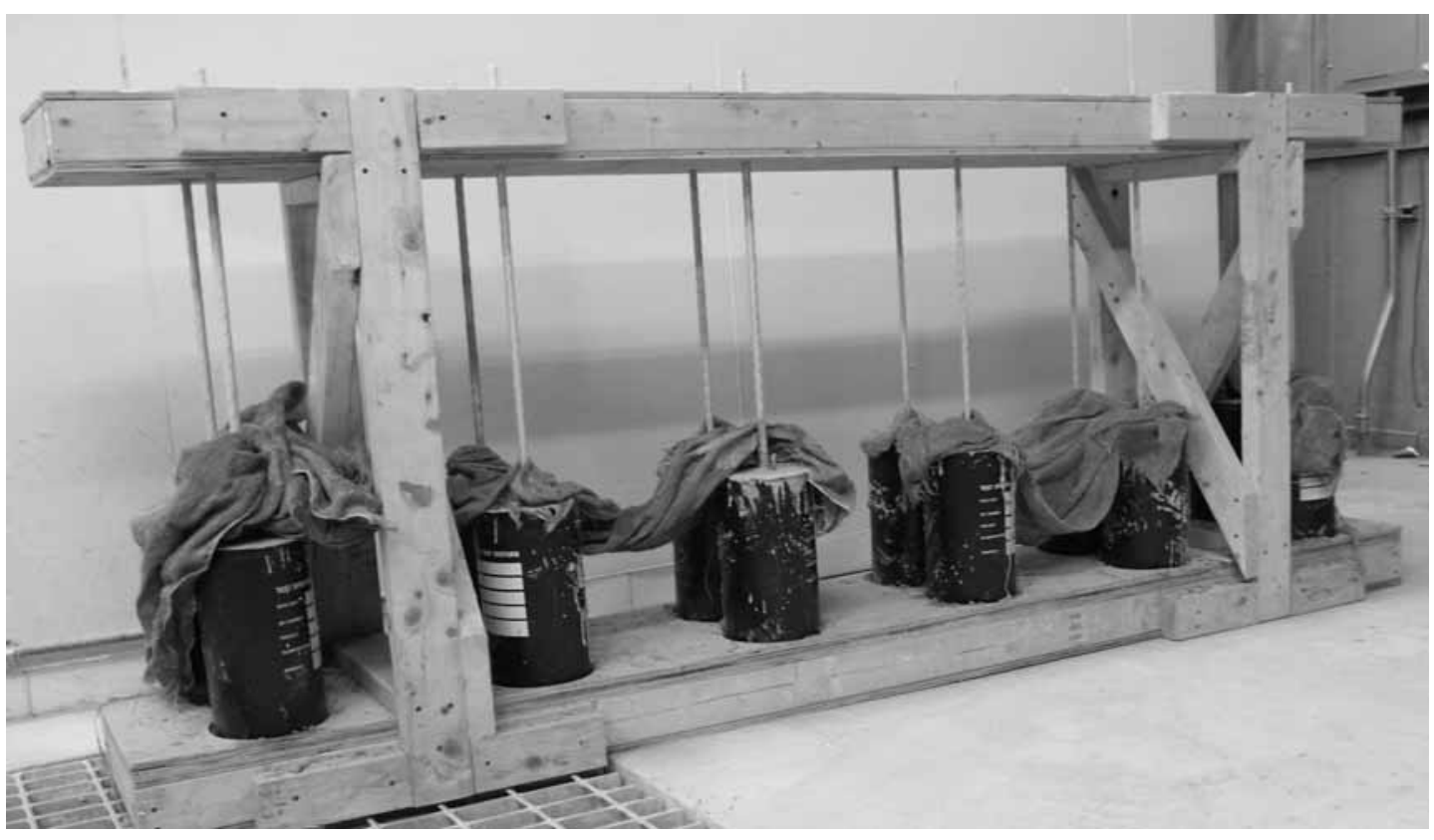

Figure 7.2 Spcimens for evaluation of FRP bar-concrete interaction 
Table 7.2 Concrete mix design $\left(\mathrm{kg} / \mathrm{m}^{3}\right)$

\begin{tabular}{ccccccccc}
\hline $\begin{array}{c}\text { Concrete } \\
\text { Type }\end{array}$ & W/C & Water & Cement & Sand & Gravel & Slag & $\begin{array}{c}\text { Silica } \\
\text { fume }\end{array}$ & $\begin{array}{c}28 \text { day } \\
\text { compressive } \\
\text { strength (MPa) }\end{array}$ \\
\hline NC & 0.55 & 175 & 320 & 703 & 1054 & 0 & 0 & 20 \\
HPC & 0.35 & 157.5 & 292.5 & 672 & 999 & 135 & 22.5 & 65 \\
\hline
\end{tabular}

Note: $\mathrm{NC}=$ normal concrete; $\mathrm{HPC}=$ high-performance concrete

\subsubsection{Testing Plan}

The specimens were dismantled from the wood frame and subsequently demolded one day after casting. After 28 days of curing under water, one set of specimens were immersed in Solution 3 (the detail information for the solution can be found in Chapter 3) at $60^{\circ} \mathrm{C}$ for testing at the end of 60 day exposure. The rest of specimens were kept in a curing tank as control. After being conditioned, they were cut into two parts as shown in Fig.7.3. The testing plan is summarized in Table 7.3.

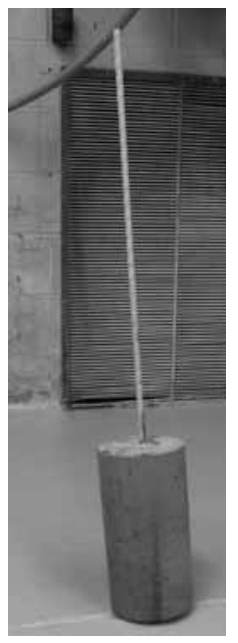

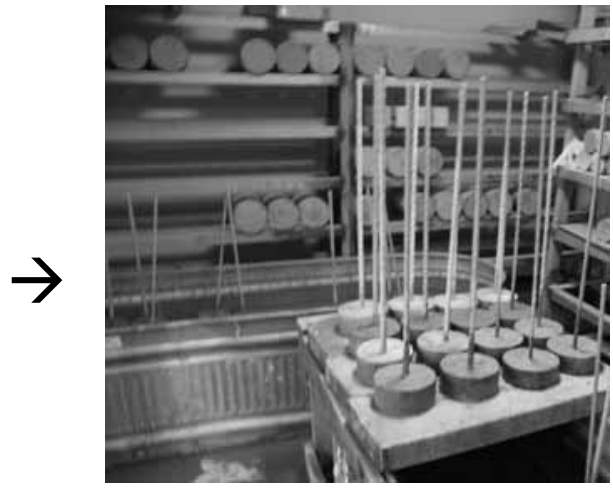

Section 1

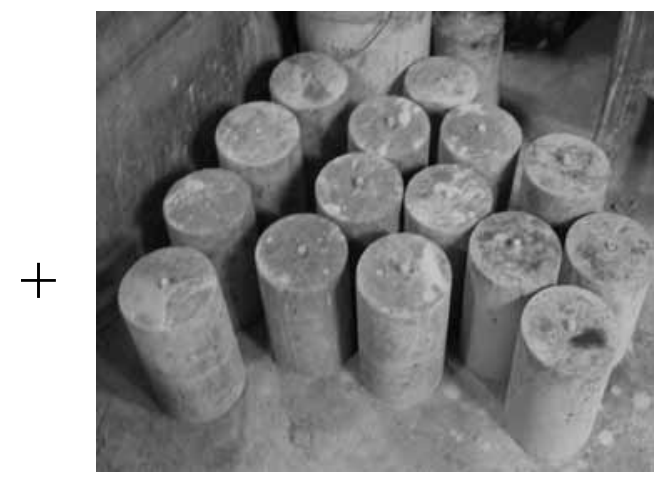

Section 2

Figure 7.3 Spcimens for evaluation of FRP bar-concrete interaction 
Table 7.3 Testing plan for the evaluation of FRP bar-concrete interaction

\begin{tabular}{|c|c|c|c|c|c|}
\hline & Temperature & Duration (days) & Bar size & $\mathrm{NC}$ & $\mathrm{HPC}$ \\
\hline \multirow{2}{*}{ Solution 1} & Room & \multirow{2}{*}{60} & GFRP1 \#3 & 2 & 2 \\
\hline & temperature & & GFRP1 \#4 & 2 & 2 \\
\hline \multirow{2}{*}{ Solution 3} & \multirow{2}{*}{$60^{0} \mathrm{C}$} & \multirow{2}{*}{60} & GFRP1 \#3 & 2 & 2 \\
\hline & & & GFRP1 \#4 & 2 & 2 \\
\hline
\end{tabular}

\subsubsection{Test Results and Discussion}

The pullout test was carried out on a Baldwin machine using the arrangement as shown in Fig. 7.4. The specimens after pullout test are shown in Fig. 7.5. All specimens with HPC failed due to the splitting of the concrete cylinders prior to the bars being pullout. For specimens with NC, however, all specimens failed due to bond failure.

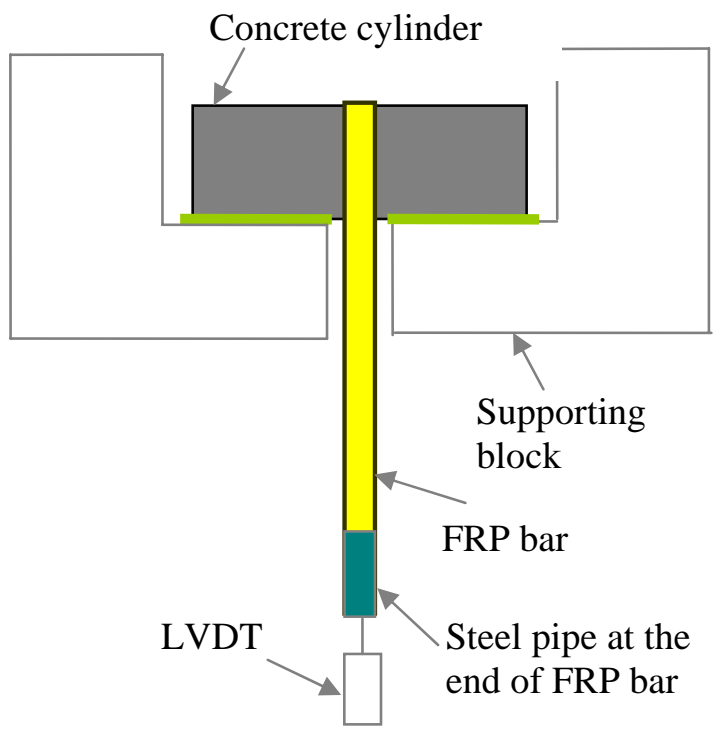

Figure 7.4 Experimental setup for pullout test in the preliminary study

The splitting of HPC was because of very high force needed to pull the bars out of the concrete. So this set of data can not be used to determine the pullout bond strength of bars. The pullout test arrangement adopted in this preliminary study should be modified to obtain bond strength without the failure of concrete. 


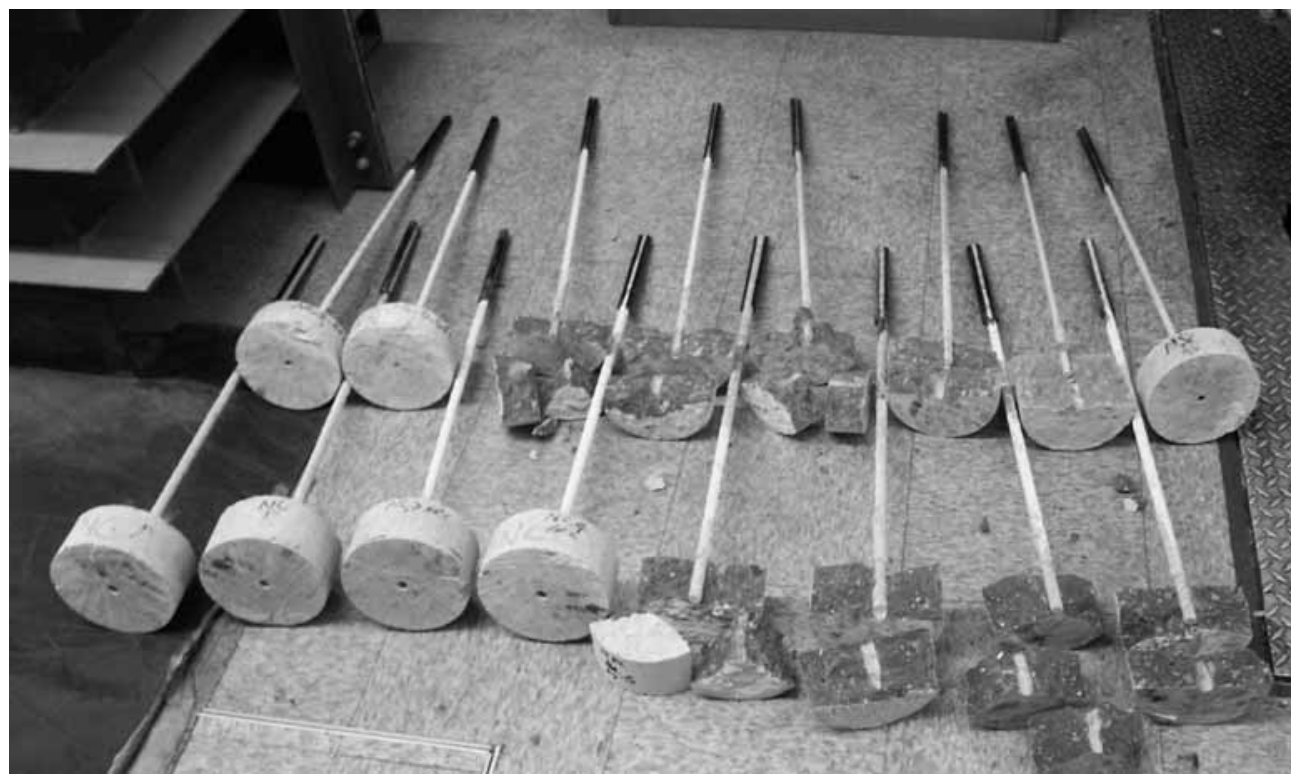

Figure 7.5 Specimens after the pullout test

The bond strengths are summarized in Table 7.4. The bond strengths are low compared to the bond strength of $11.6 \mathrm{MPa}$ provided by the bar manufacturer, which was obtained from specimens with a 14 day concrete compressive strength of $45 \mathrm{MPa}$. The degradation effects of alkaline solution at $60{ }^{\circ} \mathrm{C}$ are shown in Fig. 7.6 (each column is based on an average of two test results). The specimens retained about $88 \%$ of bond strength of the companion specimens after the 60 day exposure.

Table 7.4 Bond strength of GFRP1 bars in NC (MPa)

\begin{tabular}{ccccccc}
\hline Exposure & Temperature & Duration (days) & Bar size & 1 & 2 & Average \\
\hline \multirow{2}{*}{ Water } & \multirow{2}{*}{ Room Temp. } & 60 & GFRP1 \#3 & 5.62 & 5.93 & 5.78 \\
& & & GFRP1 \#4 & 4.83 & 5.88 & 5.36 \\
\multirow{2}{*}{ Solution 3 } & \multirow{2}{*}{$60^{\circ} \mathrm{C}$} & 60 & GFRP1 \#3 & 4.52 & 5.62 & 5.07 \\
& & & GFRP1 \#4 & 4.74 & 4.48 & 4.61 \\
\hline
\end{tabular}




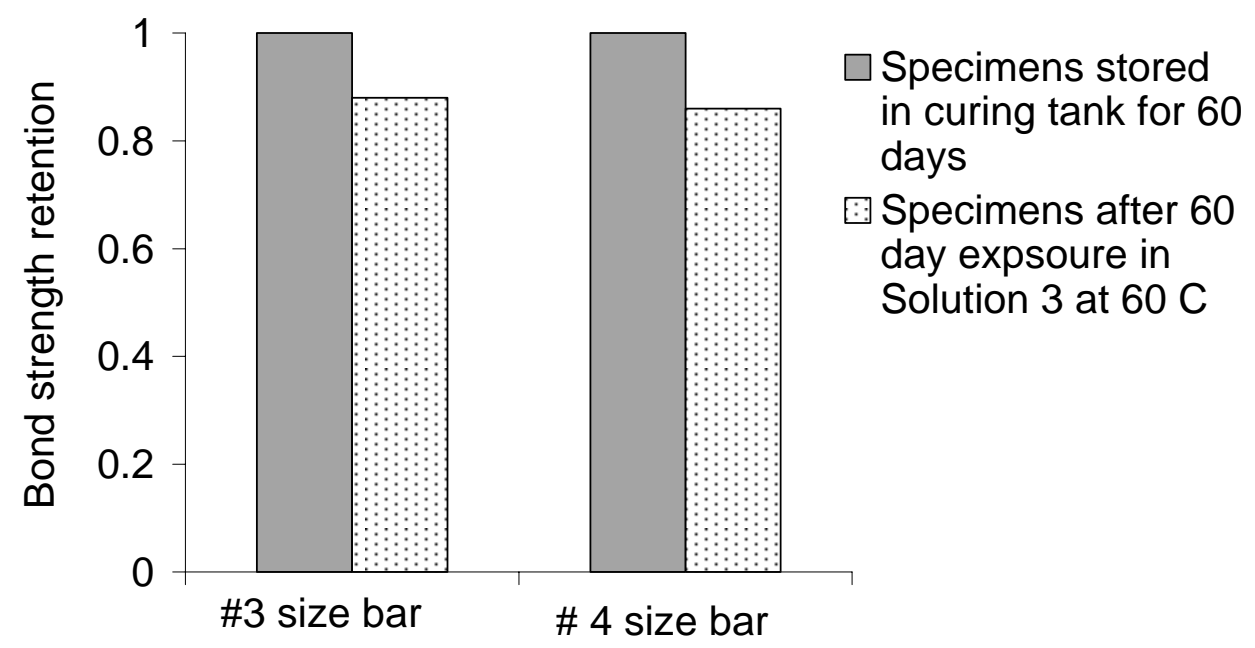

Figure 7.6 Bond strength retention of GFRP1 bars in NC

The typical load vs. displacement curves are shown in Figs. 7.7 through 7.10. It can be observed that part of the displacement is due to the elongation of FRP bars. As for the specimens with HPC, the specimens failed by splitting before the slipping of the bars occurred, the load dropped to zero immediately after the splitting. For specimens with NC, after the slip, the specimens could still carry some load due to the helically wrapped and sand coated surface (the deformation of the surface), which was more pronounced in case of larger diameter bar (No. \# 4). A comparison of displacements measured on bars during pullout test (as shown in Figs. 7.7 through 7.10) indicates that for a given amount of tensile force, the FRP bars within NC displaced more than those embedded in HPC, although in this case failure was caused by concrete fracture. The significantly higher resistance load against bond failure, and lower displacements for a given level of load, indicate that HPC by virtue of its stronger matrix offered significantly higher resistance to displacement. This implies that the bond strength (or pullout strength) of FRP bars is dependent not only on the shape, surface characteristics and size of FRP bars, but also on the type of concrete in which it is embedded. 


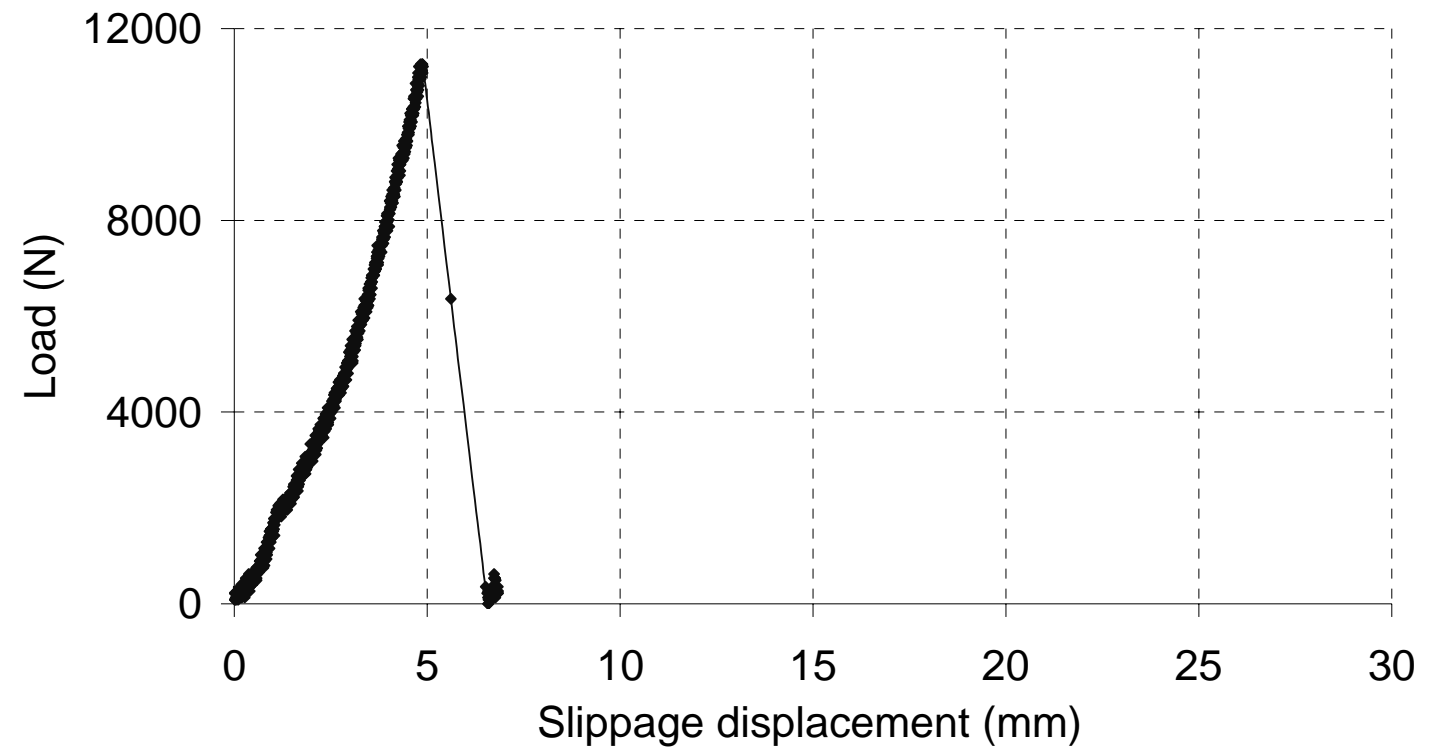

Figure 7.7 Load vs. displacement curve of specimen with HPC and GFRP1 \# 3 bar after 60 day exposure in curing tank

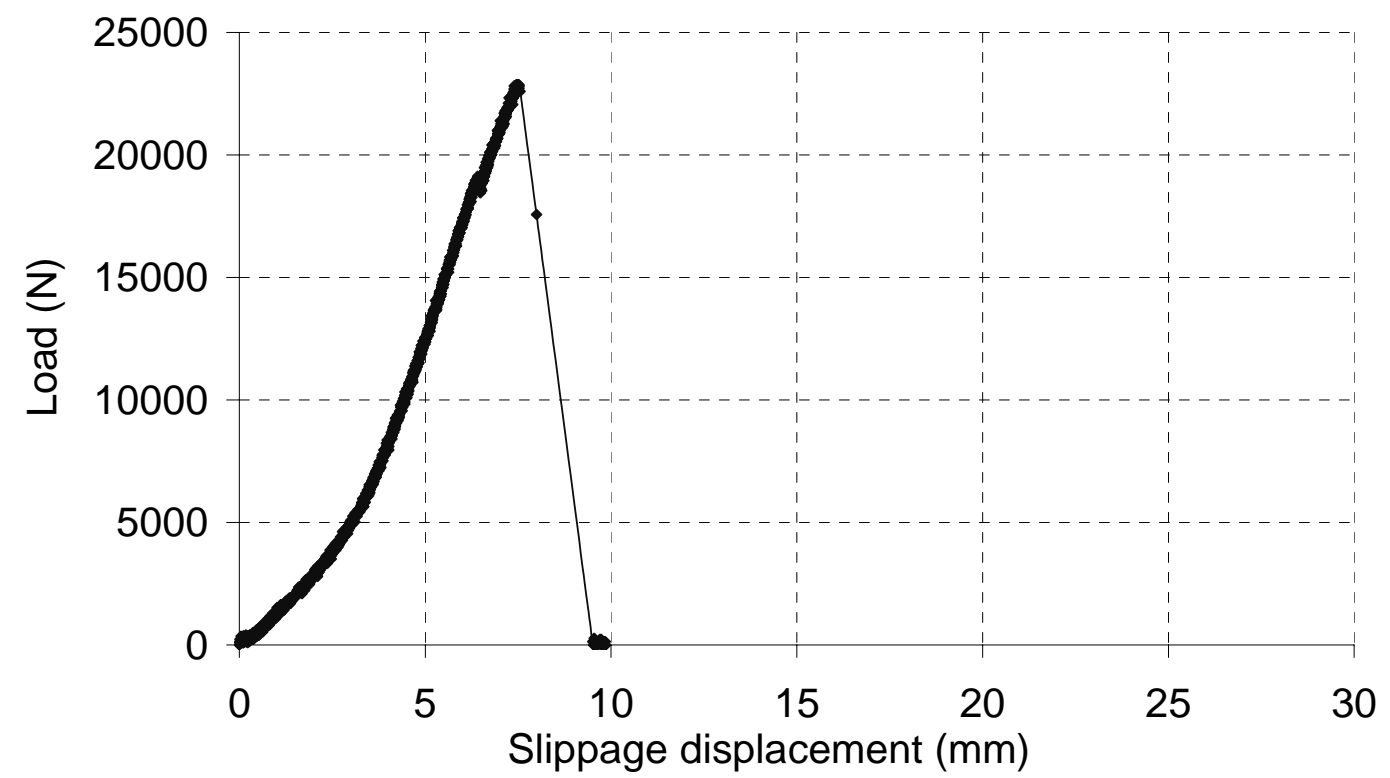

Figure 7.8 Load vs. displacement curve of specimen with HPC and GFRP1 \# 4 bar after 60 day exposure in Solution 3 at $60{ }^{\circ} \mathrm{C}$ 


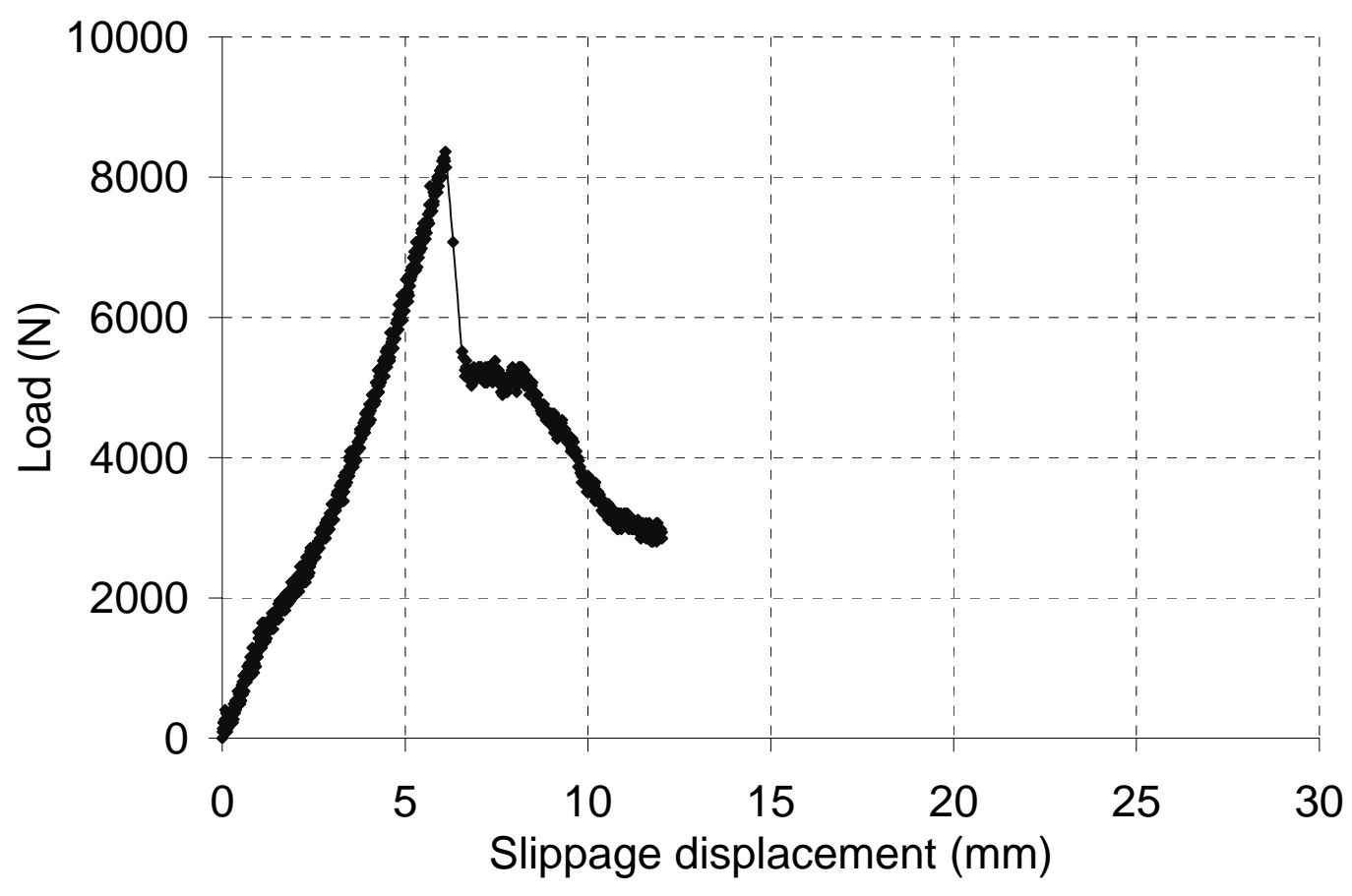

Figure 7.9 Load vs. displacement curve of specimen with NC and GFRP1 \# 3 bar after 60 day exposure in curing tank

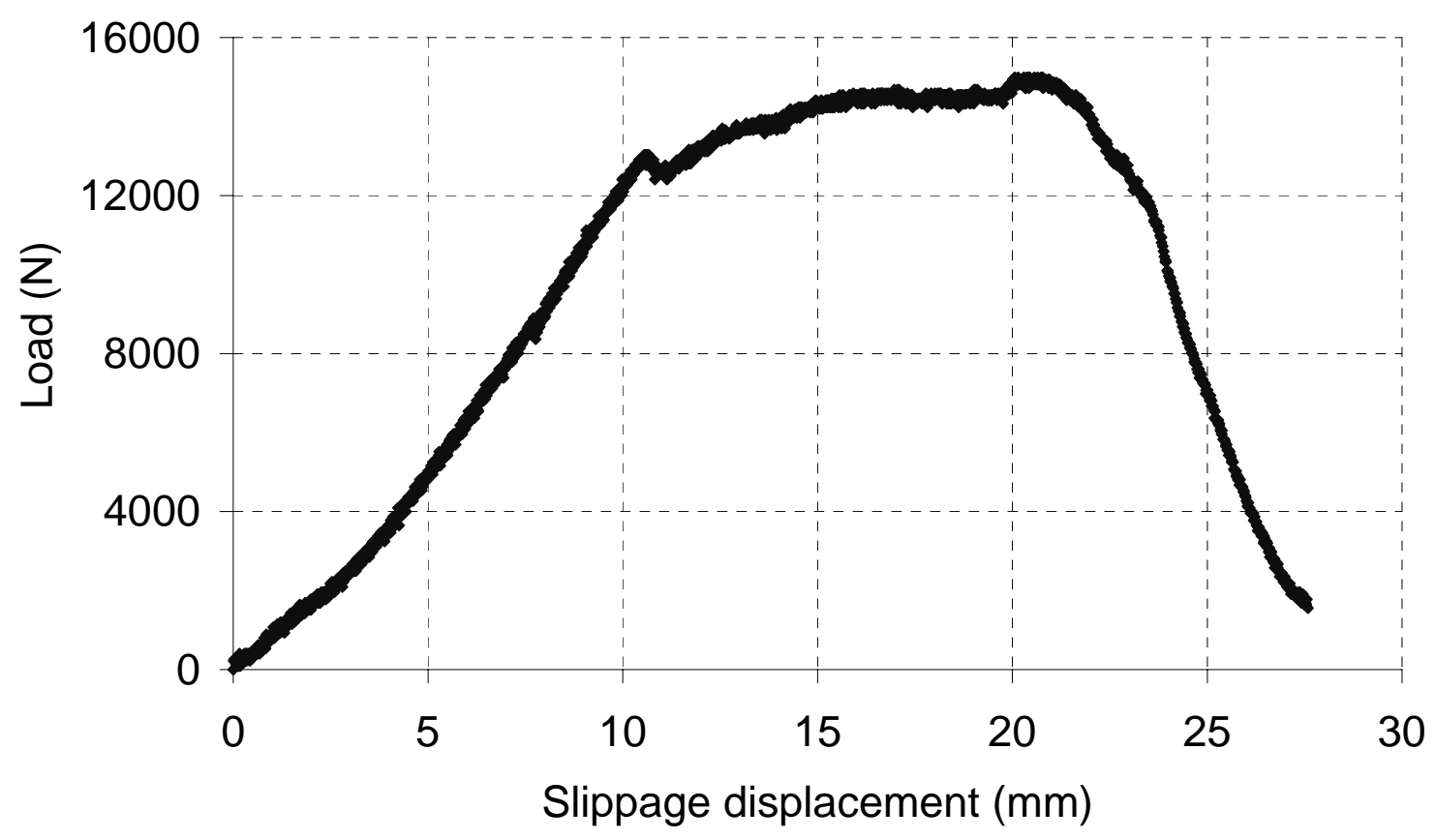

Figure 7.10 Load vs. displacement curve of specimen with NC and GFRP1 \# 4 bar after 60 day exposure in curing tank 
In addition, the section 2 of the specimen as shown in Fig. 7.1 was split. Typical views of GFRP bars embedded in NC and HPC are shown in Fig. 7.11. As shown in Fig. 7.11 (a), a whitish deposit was observed on the surface of GFRP bars embedded in NC. This is similar to those formed on the bare FRP bars that were conditioned in solutions as shown in Fig. 3.16. However, there was no color change found on the surface of GFRP bars embedded in HPC. This may be due to the precipitations from pore solutions of NC in which the pores were much larger, whereas in case of HPC, the pores being finer, the solutions could not reach the surface of FRP bar during 60 days of exposure.

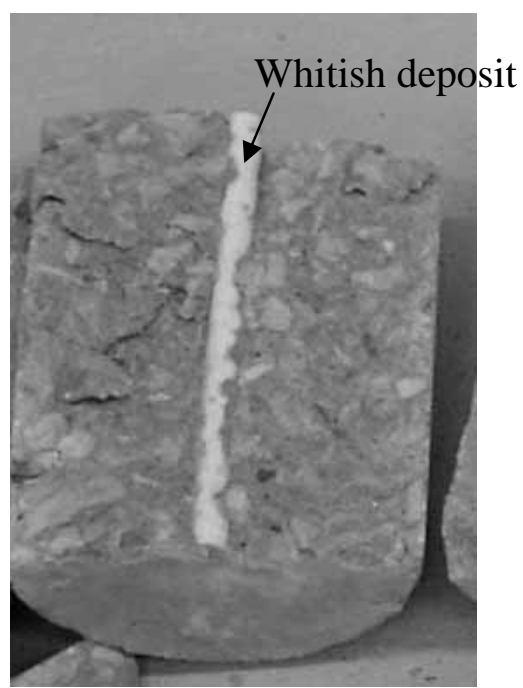

$\mathrm{NC}$

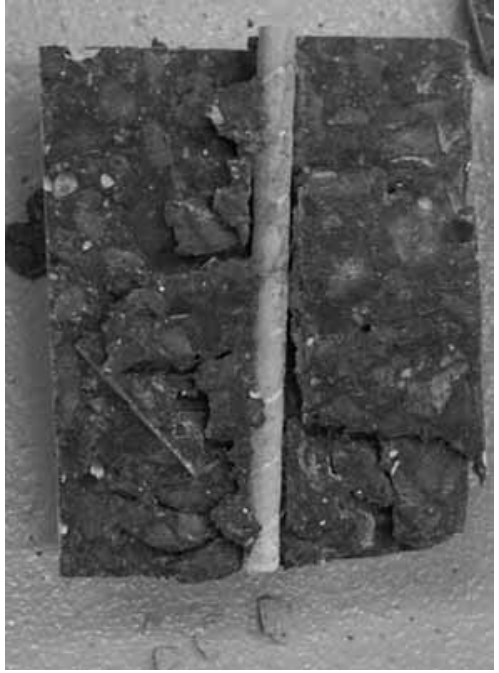

HPC

Figure 7.11 Typical views of GFRP bars embedded in NC and HPC after exposure

Based on the test results of this preliminary study, the following concluding remarks and recommendations can be made. The bond strength and bond slip behavior of GFRP bars also depended on the concrete strength. The elevated temperature and alkalinity also accelerated the degradation of bond. Since the bond failure was due to both the concrete shear failure and FRP bar surface failure, the decrease of concrete strength after exposure in Solution 3 may have caused the reduction in bond capacity. Less degradation may be 
found for those bars embedded in HPC than in NC. From the test results, the following improvement or recommendation can be made for future study. The pullout test arrangement should be modified to prevent the concrete splitting in case of high strength concrete. The concrete strength change due to the conditioning should also be considered when the durability of bond is investigated. The bond failure mechanism needs to be studied. More environmental conditions should be investigated for their effects on the bond strength.

\subsection{Further Study on the Bond of FRP Bar}

In this subsequent study, the bond behaviors of different types of FRP bars under direct pullout conditions are investigated. The environmental effects of thermal cycles, moisture and elevated temperature on bond behaviors are evaluated.

\subsubsection{Pullout Test Arrangement}

Considerable research efforts have been conducted on the bond behavior of FRP bars in concrete. Pullout tests, beam tests and splice tests are the most commonly used test procedures to evaluate the bond behavior of FRP bars. As an economical and simple procedure for the evaluation of bond performance, the pullout test is widely adopted. But it was found that the pullout tests usually gave unconservative bond strength values. This is because of the compression stress induced in the surrounding concrete (usually under tension in practical conditions) and the confining action exerted by the reaction. The splitting of concrete is usually avoided by the thickness of concrete cover during the pullout test. 
The bond failure mode of FRP bars for pullout tests is usually different from that of steel deformed bars. One study (Achillides and Pilakoutas, 2004) found that for concrete strength greater than about $30 \mathrm{MPa}$, the bond failure of FRP bars also occurred on the surface of the bar, not just in concrete as in the case of steel bars. So the bond strength of FRP bars was not controlled by the concrete strength but depended on the interlaminar shear strength of the FRP bar surface. When concrete strength was less than $15 \mathrm{MPa}$, shear cracks developed in the surrounding concrete during bond failure in both cases of FRP and steel bars. So the bond strength in such cases mainly depended on the shear strength of concrete. In the preliminary study, since the concrete strength was about 20 $\mathrm{MPa}$, the bond capacity was partly dependent on concrete strength. In current design guidelines (ACI 440, 2003 and CSA-S806, 2002), the equations of development length of FRP bars were formulated by assuming that the bond strength is proportional to the square root of concrete compressive strength. So it will be reasonable to impose a limit on the bond strength in design codes irrespective of the concrete compressive strength according to the pullout resistance of FRP bars, which can be treated as the maximum possible bond capacity.

For pullout tests of steel bars and FRP bars, two specimen arrangements as shown in Fig. 7.12 are commonly used. It can be seen from Fig. 7.12 that the one proposed by Losberg (1963) is more convenient for the measurement of the free end slip. So many researchers adopted this arrangement. But when Losberg's arrangement is used for FRP bars embedded in concrete with compressive strength higher than certain value, the bond failure mainly occurs in the surface of FRP bars as discussed in previous paragraphs. After the slip occurs at the free end, the undamaged part enters the embedment length 
zone, which increases the resistance to pullout load. This wedging action of undamaged bar may increase the bond strength and/or residual bond strength. The typical bond-slip curves with these two pullout arrangements from published literature are illustrated in Fig. 7.13. This wedging action can be the reason for the difference of residual bond strengths as shown in Fig. 7.13. This phenomenon can be avoided by using the RILEM arrangement, and is not important for steel bars since the bond failure occurs in surrounding concrete in that case. This wedging action affects the calculation of development length using test results from Losberg's arrangement.

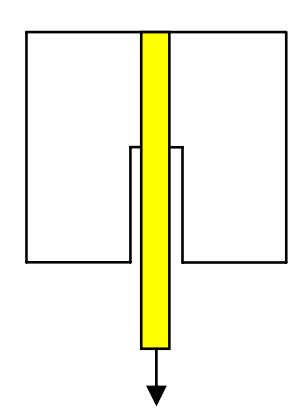

RILEM (1978)

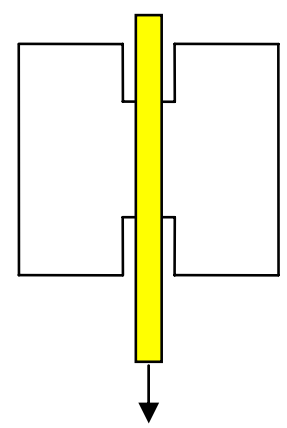

Losberg (1963)

Figure 7.12 Pullout specimen arrangements

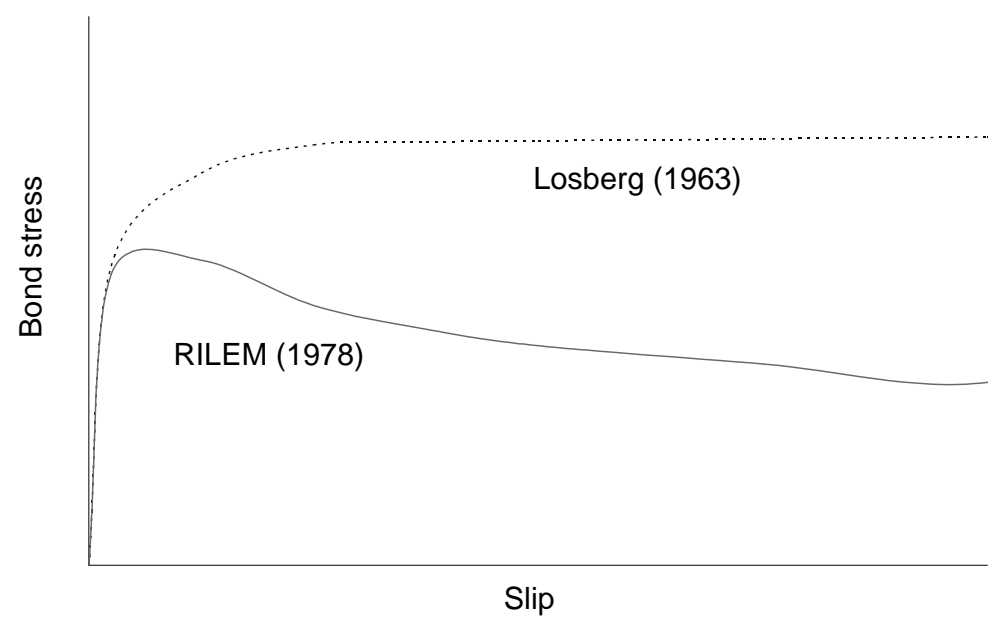

Figure 7.13 Typical bond slip curves 


\subsubsection{Testing Procedure and Results}

\subsubsection{Experimental Program}

\section{(a) Material}

Four types of FRP bars as shown in Fig.7.14 were used in this study. The surface of GFRP3 and GFRP1 (\#4) bars are helically wrapped and slightly sand coated. The spiral glass fibers were twisted around the bar. And they decrease the amount of transverse thermal expansion and increase the interlock with the concrete. The GFRP4 bar has a sand-coated surface. The surface of CFRP bars is roughened to obtain sand-blasted deformations. The detailed properties of FRP bars are listed in Table 7.5. The thermal expansion coefficients of reinforcing bars and concrete are summarized in Table 7.6. Concrete was cast in four batches with the mix design $\left(\mathrm{kg} / \mathrm{m}^{3}\right)$ : 380 cement, 730 sand, 1140 aggregate, and 171 water. The 28-day compressive strengths are in the range of 57 to $63 \mathrm{MPa}$.

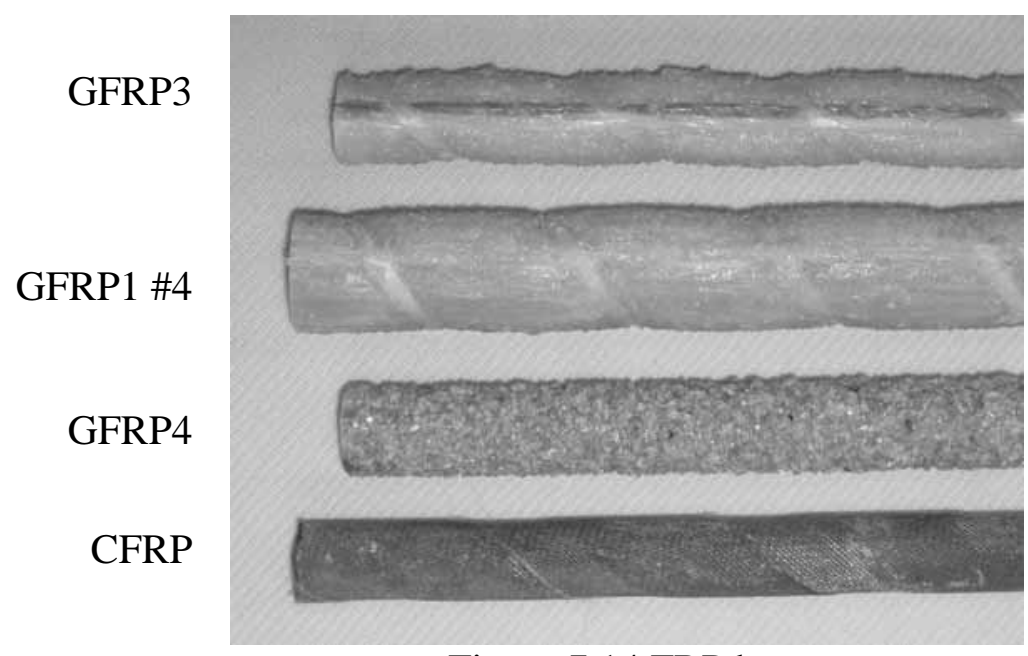

Figure 7.14 FRP bars 
Table 7.5 the properties of FRP bars

\begin{tabular}{cccccc}
\hline Bar type & Fiber & Matrix & Diameter $(\mathrm{mm})$ & $\begin{array}{c}\text { Tensile } \\
\text { strength } \\
(\mathrm{MPa})\end{array}$ & $\begin{array}{c}\text { Young's Modulus } \\
(\mathrm{GPa})\end{array}$ \\
\hline GFRP3 & E-glass & Vinyl ester & 9.53 & 856 & 45.8 \\
GFRP1 (\#4) & E-glass & Vinyl ester & 12.70 & 690 & 40.8 \\
GFRP4 & E-glass 2 & Vinyl ester 2 & 9.53 & 840 & 49.4 \\
CFRP & Carbon & Epoxy & 9.00 & 2587 & 124 \\
\hline
\end{tabular}

Table 7.6 Coefficients of thermal expansion for reinforcing bars and concrete $\left(\times 10^{-6} /{ }^{0} \mathrm{C}\right)$

\begin{tabular}{cccccc}
\hline Direction & Concrete & Steel & GFRP3, 1(\#4) & GFRP4 & CFRP \\
\hline Longitudinal & $7.2-10.8$ & 11.7 & 6.58 & $5.5-6.4$ & $-9.0-0.0$ \\
Transverse & $7.2-10.8$ & 11.7 & 33.7 & $35-37$ & $74-104$ \\
\hline
\end{tabular}

\section{(b) Specimens}

The FRP bars were cut into $900 \mathrm{~mm}$ lengths and concrete cylinders had heights of $150 \mathrm{~mm}$ and diameters of $150 \mathrm{~mm}$. The FRP bars were concentrically embedded in concrete cylinders with bond lengths of five times bar diameters. In order to control the bond length, the FRP bars were prepared with a bond breaker, which consisted of soft plastic tubing to prevent the contact of the FRP and concrete. These specimens were fabricated by positioning the bars vertically through the wood frame as shown in Fig. 7.15. The specimens were removed from the plastic mold one day after casting and then cured in a curing tank for 27 days before they were subjected to the environmental conditioning as described in the next section. To consider the effects of environmental conditioning on the concrete strength and bond interface, additional concrete cylinders and FRP bars embedded in concrete cylinders were prepared. These specimens were also subjected to the environmental conditioning as the pullout specimens.

The schematic arrangement of the pullout test is shown in Fig. 7.16. LVDTs were used to measure the slips at both free and loaded ends. The elongations of FRP bars need 
to be subtracted from the data recorded by LVDT2. There is a $10 \mathrm{~mm}$ wooden plate between the concrete cylinder and supporting block to prevent bending or movement due to the irregularities at the contact surface of the cylinder during loading. The pullout tests were carried out using a Baldwin machine. The load was applied in a deflection control mode with a maximum rate of about $0.15 \mathrm{kN} / \mathrm{s}$.

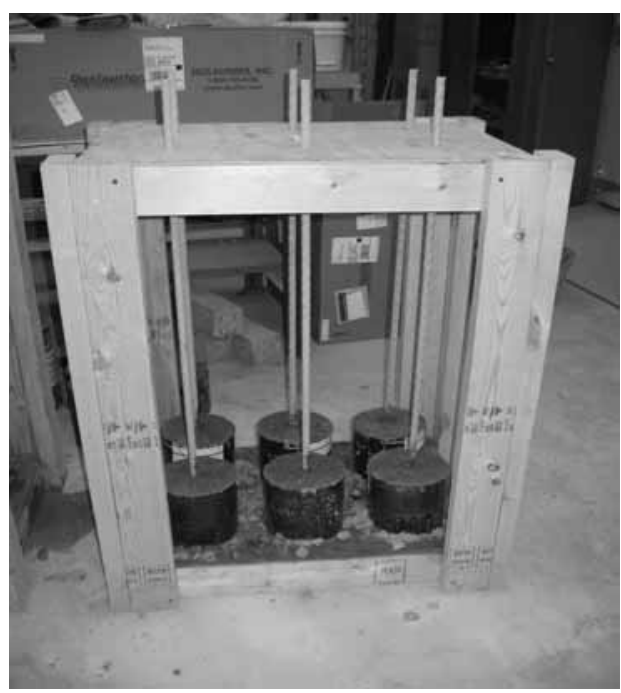

Figure 7.15 Setup for fabrication of pullout specimens

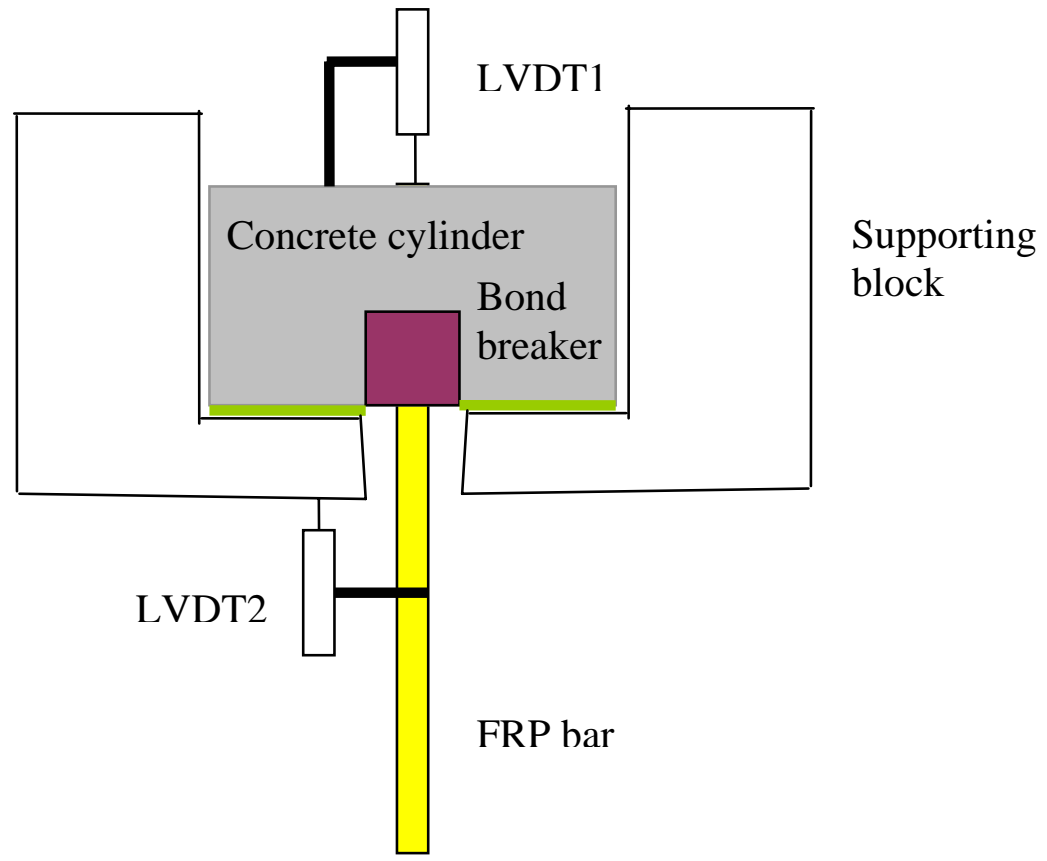

Figure 7.16 Pullout test configuration 


\section{(c) Environmental conditioning and testing plan}

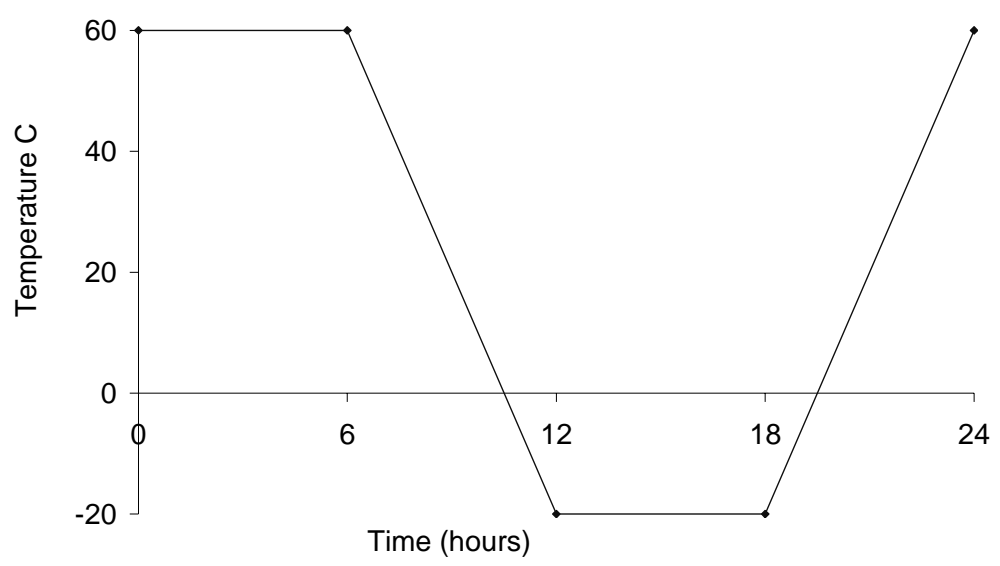

Figure 7.17 One thermal cycle

Table 7.7 Testing plan

\begin{tabular}{|c|c|c|c|c|c|}
\hline Specimen types & Bar type & Control & $\begin{array}{c}\text { Environment } \\
\mathrm{W}\end{array}$ & $\begin{array}{c}\text { Environment } \\
\mathrm{T}\end{array}$ & $\begin{array}{c}\text { Environment } \\
\mathrm{E}\end{array}$ \\
\hline \multirow{4}{*}{ Pullout } & GFRP 3 & 3 & 3 & 3 & 3 \\
\hline & GFRP $1(\# 4)$ & 3 & 3 & 3 & 3 \\
\hline & GFRP 4 & 3 & 3 & 3 & 3 \\
\hline & CFRP & 3 & 3 & 3 & 3 \\
\hline Concrete & & 3 & 3 & 3 & 3 \\
\hline cylinders & & 3 & 3 & 3 & 3 \\
\hline for compressive & & 3 & 3 & 3 & 3 \\
\hline strength & & 3 & 3 & 3 & 3 \\
\hline \multirow{3}{*}{$\begin{array}{l}\text { FRP bars } \\
\text { embedded in } \\
\text { concrete } \\
\text { cylinders } \\
\text { for interface }\end{array}$} & GFRP 3 & & 1 & 1 & 1 \\
\hline & GFRP $1(\# 4)$ & & 1 & 1 & 1 \\
\hline & GFRP 4 & & 1 & 1 & 1 \\
\hline
\end{tabular}

The specimens were conditioned in three environments (W, T and E) after being for 27 days in the curing tank. The first group of specimens was submerged in water within a curing tank for 90 days at room temperature (W). Specimens in environment $\mathrm{T}$ were immersed in tap water at $60{ }^{0} \mathrm{C}$ of temperature controlled tanks for 90 days. The specimens subjected to environment E were held in environmental chambers (model CSZ 
$\mathrm{ZH}-16$ ) for thermal cycles (in air) as shown in Fig. 7.17 for 30 days. One group of specimens was tested for obtaining results of unconditioned specimens before environmental conditioning. The testing plan is summarized in Table 7.7.

\subsubsection{Test Results and Discussions}

All specimens in pullout tests failed through the free-end slip. After the pullout tests, concrete cylinders were split to check the bond failure mode. As shown in Fig. 7.18, GFRP bar surfaces were still attached to concrete while core bars have been pulled out. For GFRP4 bars, the sand coating layer was totally removed from the bar surface. It can be seen that the bond failure for GFRP bar specimens occurred at the bar surface as expected. For CFRP bar specimens, the bond failure occurred both in concrete and bar surface. There was almost no change of bond failure mode for conditioned specimens.

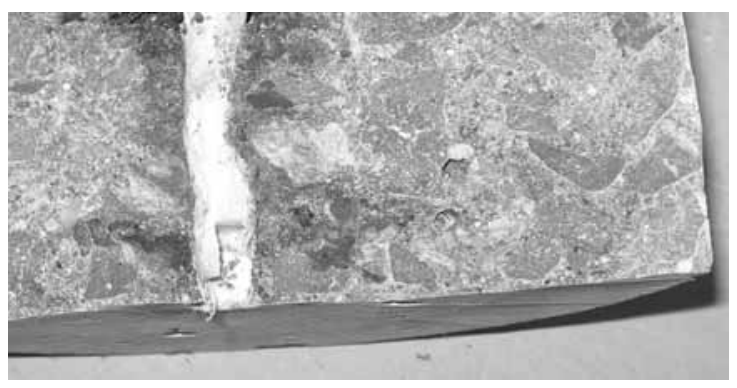

GFRP3

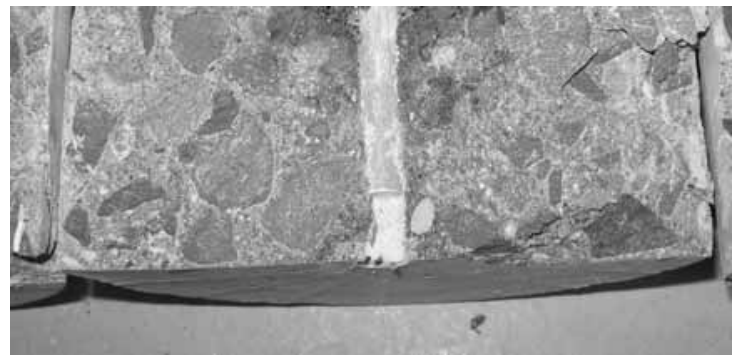

GFRP4

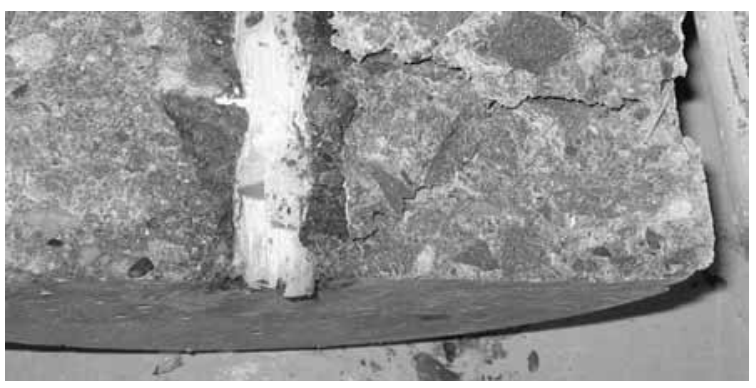

GFRP1 (\#4)

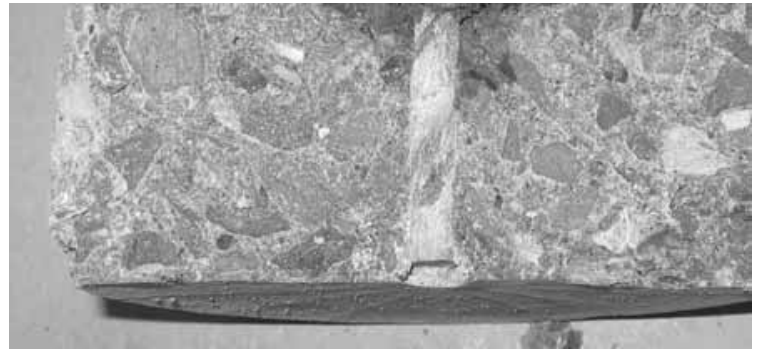

CFRP

Figure 7.18 Typical bond failure modes of pullout tests

In addition to pullout tests, FRP bars embedded in concrete cylinders were split following environment conditioning. The bars were extracted as shown in Fig.7.19. It can 
be observed that the FRP bar surfaces of specimens exposed to environment $\mathrm{E}$ are relatively intact and clean, while attached concrete are found on the surfaces of those exposed to environments $\mathrm{T}$ or $\mathrm{W}$. This phenomenon may be explained by the fact that the interfaces (adhesion) for specimens in environment $\mathrm{E}$ were weakened due to the micro cracking of concrete, which was introduced by bursting stresses within the concrete due to the mismatch of thermal expansions of FRP bars and concrete. It can also be found that there are much more surface degradations for GFRP3 and GFRP1 (\#4) bars subjected to environments $\mathrm{T}$ or $\mathrm{W}$. Moreover, for those in environment $\mathrm{T}$, the color of bar surfaces is also changed a little bit. Concrete cylinders were also tested for compression strengths after exposures.

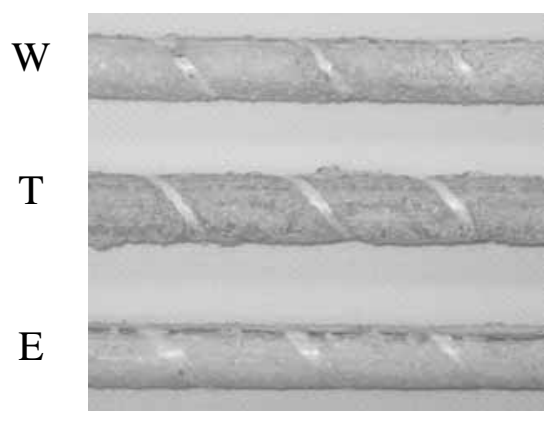

GFRP3

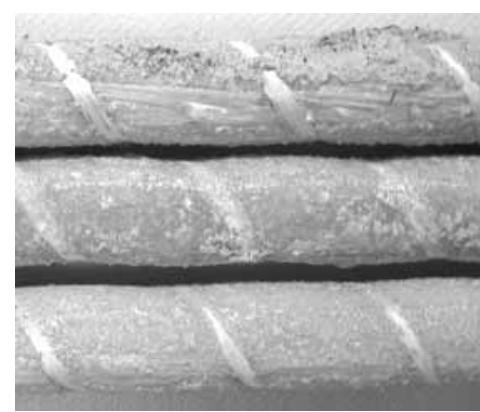

GFRP1 (\#4)

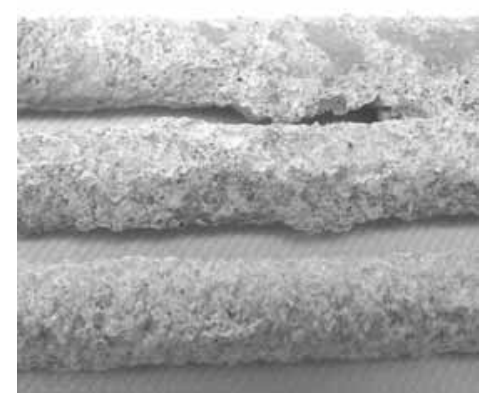

GFRP4

Figure 7.19 FRP bars extracted from concrete cylinders after exposure

Test results in terms of bond strength values and bond slip curves are summarized in Figs. 7.20, and 7.211 and Table 7.8. It can be concluded from Fig. 7.20 that the bond strength of FRP bars does not depend much on the concrete strength in the range of this study, as expected, since bond failure occurred at the bar surface in most cases. But in the preliminary study, the bond strength depended on the concrete strength since the bond failure in that case was different. 


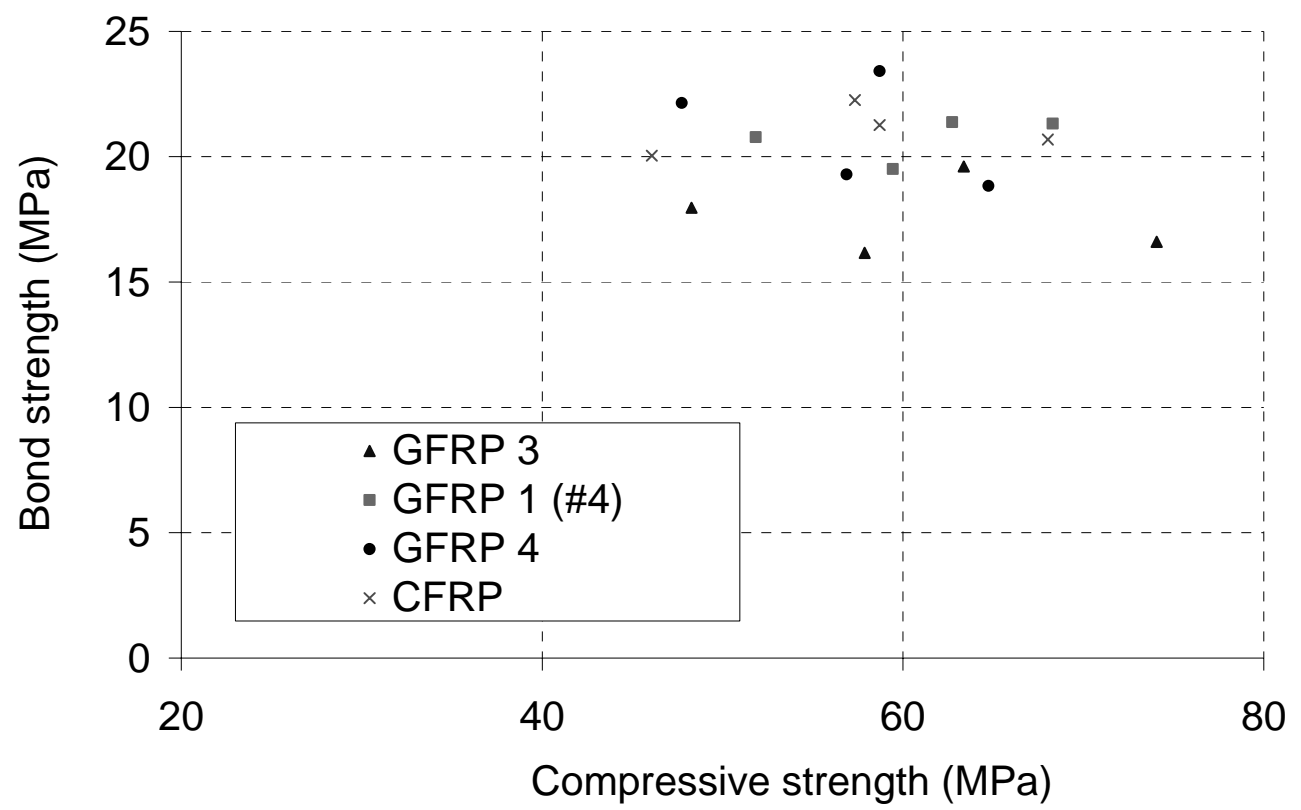

Figure 7.20 Concrete strengths vs. FRP bar bond strengths

The typical bond stress vs. free end slip curves are summarized in Fig. 7.21. It can be observed that the bond slip behaviors of FRP bars with different surfaces are quite different. The bond failure of CFRP bar and GFRP4 bar are relative brittle. The sudden free-end slip was accompanied by considerable energy release. There is no data recorded for that short moment and the pullout resistance seems to be reduced to almost zero. Finally, the friction increased the residual bond strength to a certain level in the following slip. The residual bond strength is about $75 \%$ of its ultimate bond strength for CFRP bars, while only about $15 \%$ for GFRP4 bars. The low residual bond strength of GFRP4 bars is due to the failure of interface between sand coating layer and core bar during the pullout as observed in Fig.7.18, and the smooth core bar could not provide much friction. 


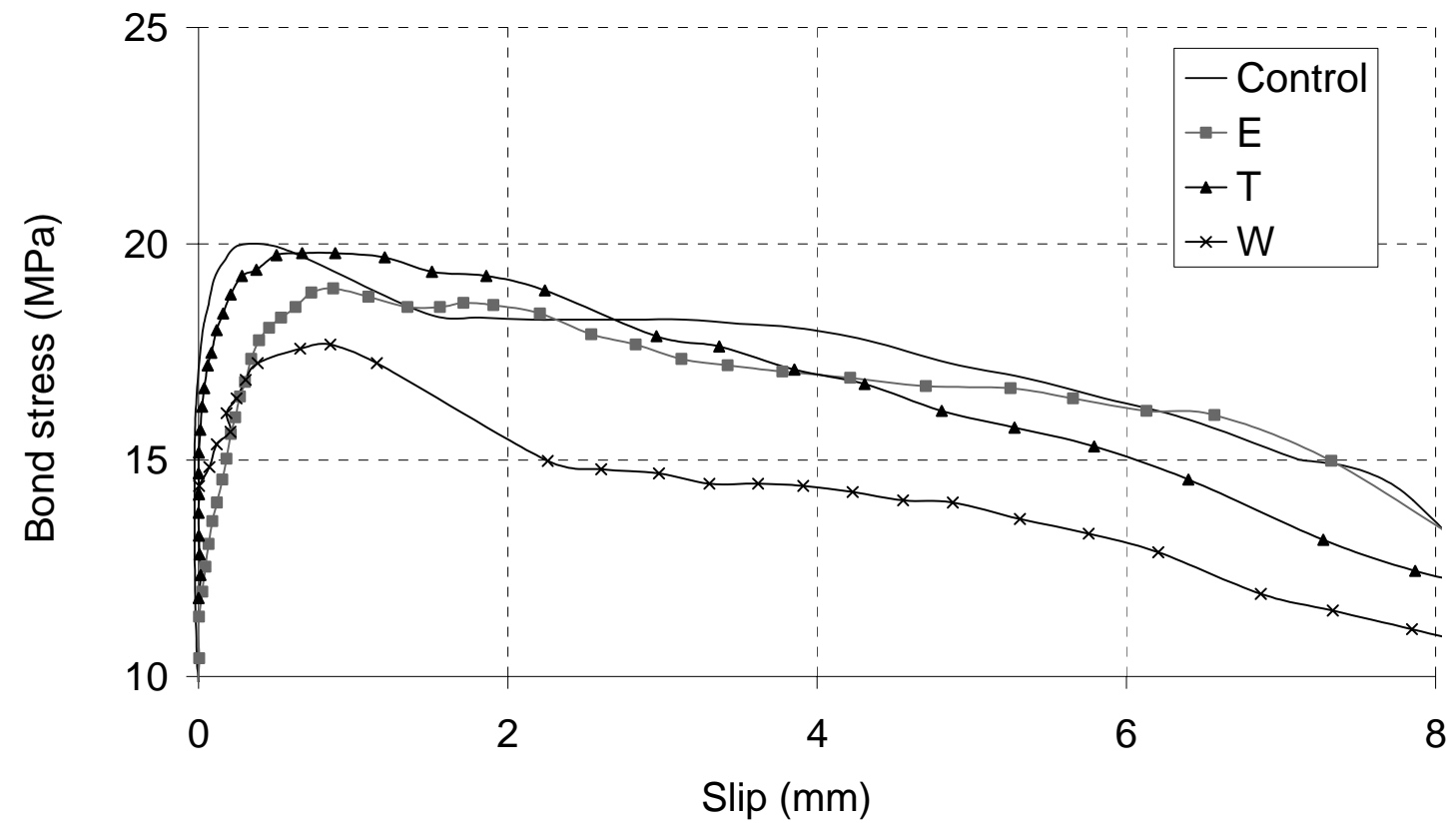

(a) GFRP3

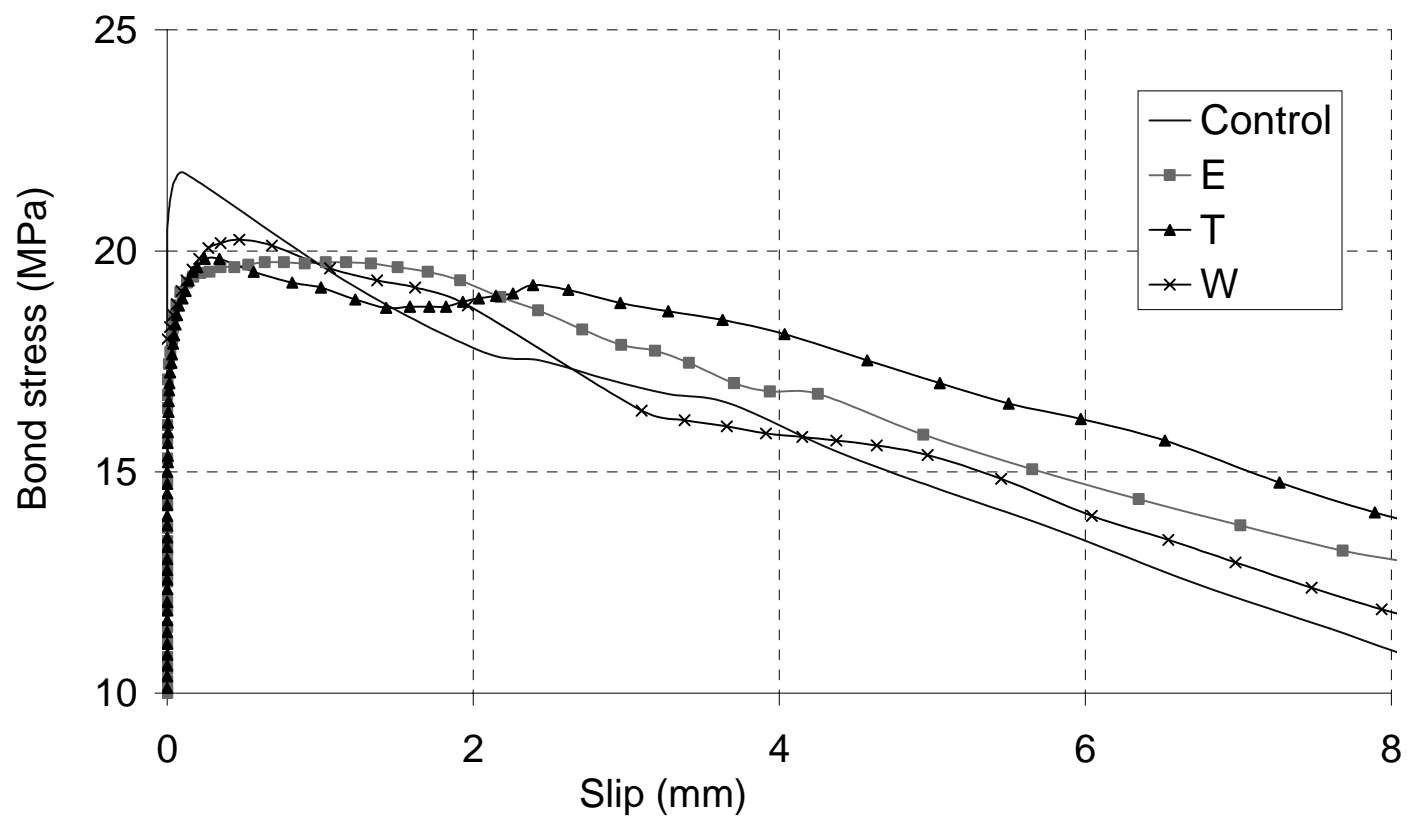

(b) GFRP1 (\#4) 


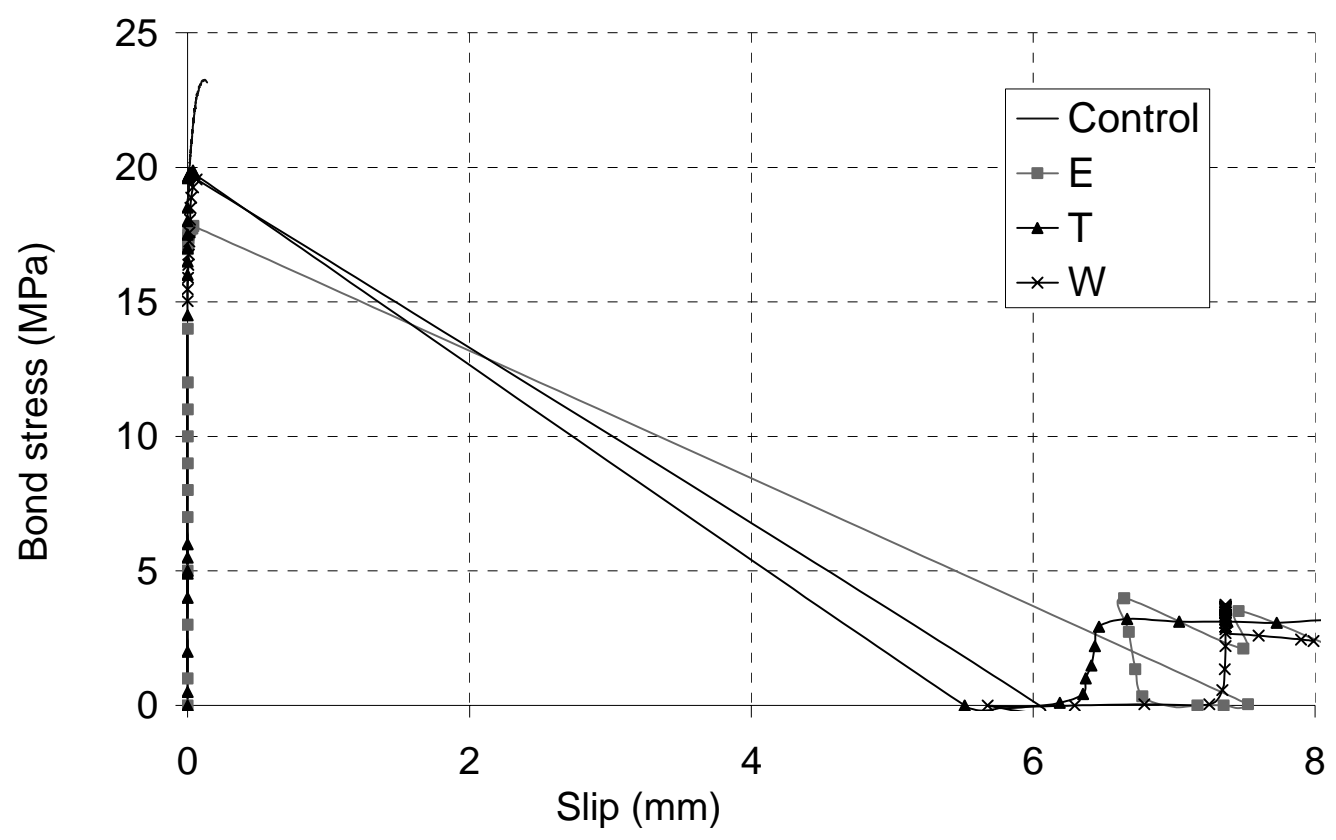

(c) GFRP4

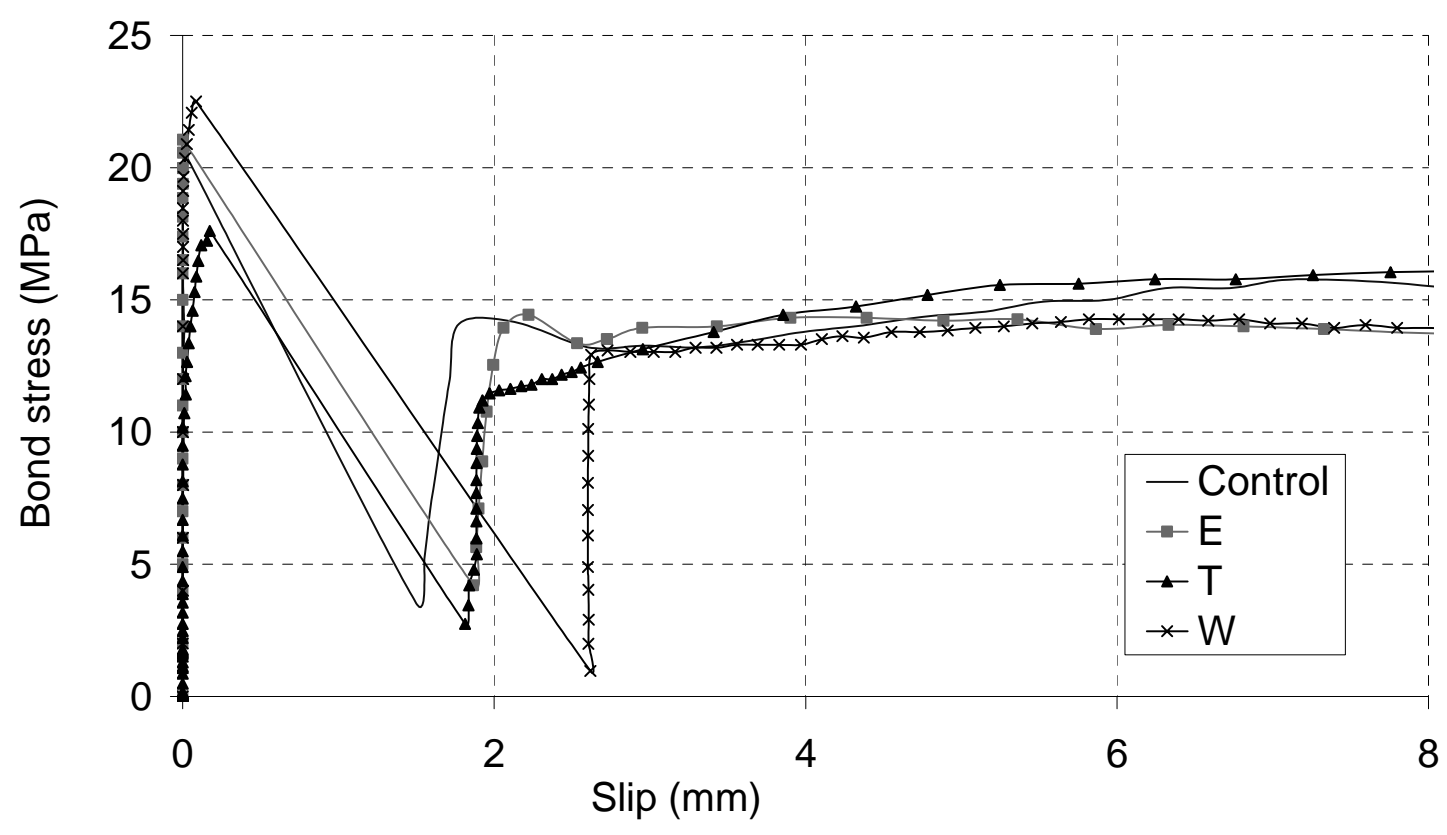

(d) CFRP

Figure 7.21 Comparisons of typical free-end slips 
For GFRP3 and GFRP1 (\#4) bars, the environmental conditionings increased the freeend slip especially for those subjected to environment $\mathrm{E}$ before the ultimate bond strengths were reached. This is caused by the weakened FRP bar surface due to the environmental conditioning. Also, the concrete micro cracking for those in environment E introduced extra increase of free-end slip. It is worth noting that for GFRP3 bars, the residual bond strengths of conditioned specimens are less than those of control specimens, while for GFRP1(\#4) bars the residual bond strengths of conditioned specimens are larger than those of control specimens. The reason for this may be that since the diameter of GFRP1(\#4) bar surface is larger than that of GFRP3 bar, the friction provided by the swelled GFRP1(\#4) bar surface was more than of those of untreated bars, even though the conditioned specimens had same extent of degradation.

Compared to the test results of the preliminary study and other studies (Okelo and Yuan, 2005, Achillides and Pilakoutas, 2004, and Tepfers, 2006), the bond strength values for untreated specimens from this study can be considered as upper limits of FRP bar bond strengths. From Table 7.8, it can be observed that untreated GFRP4 bar has better bond strength than other types of bars due to its sand coating surface. But about $18 \%$ bond strength reduction is observed for GFRP4 bar specimens after exposures to environment $\mathrm{W}$ or environment $\mathrm{E}$. This bond strength reduction is due to the interface degradation under the sand coating layer. For GFRP3 bar specimens, the bond strength degradation is in the range of $8 \sim 18 \%$ following conditioning. The bond strength reduction is mainly due to the degradation of bar surface. Compared to GFRP3 bars, less degradation of bond strength is found for GFRP1 (\#4) bars. The reason for this may also be that since surface deformation is more for GFRP1 (\#4) bars, much more mechanical 
interlocking is provided by swelled GFRP1 (\#4) bars, even though the bar surface has the same extent of degradation as GFRP3 bars (the thicknesses of resin rich layers from both bars are similar). Little bond strength reduction is found for CFRP bar specimens. This may be due to the excellent durability performance of CFRP bars as found in Chapter 3 .

Table 7.8 Bond strengths of FRP bars

\begin{tabular}{|c|c|c|c|c|c|c|c|}
\hline \multirow{2}{*}{ Bar type } & \multirow{2}{*}{$\begin{array}{l}\text { Concrete } \\
\text { strength } \\
(\mathrm{MPa})\end{array}$} & \multicolumn{3}{|c|}{ Specimen No. } & \multirow{2}{*}{$\begin{array}{c}\text { Average } \\
\text { bond strength } \\
(\mathrm{MPa})\end{array}$} & \multirow{2}{*}{$\begin{array}{c}\text { COV } \\
(\%)\end{array}$} & \multirow{2}{*}{$\begin{array}{c}\text { Bond } \\
\text { strength } \\
\text { Retention } \\
(\%)\end{array}$} \\
\hline & & 1 & 2 & 3 & & & \\
\hline & \multicolumn{7}{|c|}{ Control } \\
\hline GFRP3 & 63.4 & 20.08 & 20.02 & 18.74 & 19.61 & 3.9 & 100 \\
\hline GFRP1(\#4) & 62.7 & 21.79 & 19.79 & 22.58 & 21.38 & 6.7 & 100 \\
\hline GFRP4 & 58.7 & 22.95 & 24.07 & 23.23 & 23.42 & 2.5 & 100 \\
\hline \multirow[t]{2}{*}{ CFRP } & 57.3 & 25.35 & 20.45 & 20.98 & 22.26 & 12.1 & 100 \\
\hline & \multicolumn{7}{|c|}{ Environment $\mathrm{W}$} \\
\hline GFRP3 & 74.1(117) & 17.71 & 18.71 & 13.41 & 16.61 & 17.0 & 84.7 \\
\hline GFRP1(\#4) & $68.3(109)$ & 20.26 & 22.30 & 21.42 & 21.33 & 4.8 & 99.7 \\
\hline GFRP4 & $64.7(110)$ & 16.21 & 19.58 & 20.70 & 18.83 & 12.4 & 80.4 \\
\hline \multirow[t]{2}{*}{ CFRP } & $68.0(119)$ & 22.72 & 20.80 & 18.53 & 20.68 & 10.2 & 92.9 \\
\hline & \multicolumn{7}{|c|}{ Environment T } \\
\hline GFRP3 & $48.3(76)$ & 19.89 & 14.40 & 19.61 & 17.97 & 17.2 & 91.6 \\
\hline GFRP1(\#4) & $51.9(83)$ & 19.84 & 21.77 & 20.75 & 20.79 & 4.7 & 97.2 \\
\hline GFRP4 & $47.7(81)$ & 24.16 & 19.89 & 22.39 & 22.15 & 9.7 & 94.6 \\
\hline \multirow[t]{2}{*}{ CFRP } & $46.1(80)$ & 17.83 & 19.58 & 22.72 & 20.04 & 12.4 & 90.1 \\
\hline & \multicolumn{7}{|c|}{ Environment $\mathrm{E}$} \\
\hline GFRP3 & $57.9(91)$ & 14.03 & 19.02 & 15.43 & 16.16 & 15.9 & 82.4 \\
\hline GFRP1(\#4) & $59.4(95)$ & 20.96 & 17.1 & 19.66 & 19.24 & 10.2 & 90.0 \\
\hline GFRP4 & $56.7(97)$ & 16.87 & 17.83 & 23.20 & 19.30 & 17.7 & 82.4 \\
\hline CFRP & $58.7(102)$ & 21.15 & 21.33 & 21.33 & 21.27 & 0.5 & 95.6 \\
\hline
\end{tabular}

Note: the value in "()" is the percentage in relation to original concrete strength

Usually less bond strength reduction was found for specimens exposed to environment $\mathrm{T}$, though concrete strengths decreased due to the conditioning. The reason for this phenomenon is that FRP bars may absorb more water and swelled, which increase the mechanical interlocking and friction, thus countering the effect of degradation of FRP bar surface. In the preliminary study, since the bond strength 
depended on the concrete strength, the degradation of bond for specimens in Solution3 was more obvious. Significant tensile strength degradation was found for GFRP bars exposed to environment $\mathrm{T}$ according to chapters three and four, but material degradation did not necessarily introduce bond strength degradation in such case. A similar situation was also found in other studies (e.g. Sen et al., 1998). The environment E not only induced micro cracking in concrete but also weakened the GFRP surfaces. Though the transverse thermal expansion of FRP bars is much larger than that of concrete, especially for CFRP bars, the mismatch of thermal expansion did not introduce much more degradation of bond. This may be due to the bond failure mode in this study, which was mainly within the FRP bar surface. Moreover, due to the low transverse Young's modulus of FRP bars, the micro cracking of concrete is not so extensive.

\subsection{Numerical Simulation}

In this section, numerical methods are used to simulate the bond slip behavior and determine the development length of FRP bars. Relatively little work has been done on the numerically modeling for the bond of FRP bars (e.g. Focassci et al., 2000 and Achillides and Pilakoutas 2006). The critical issue for numerical analysis is to find a reasonable local bond-slip constitutive law. The proposed local bond-slip constitutive laws for FRP bars from published literature are summarized schematically in Fig.7.22. The model proposed by Achillides and Pilakoutas (2006) was obtained from extrapolation of experimental results and no analytical expression was provided. The CMR model by Cosenza et al. (1997) is for the ascending branch only. 


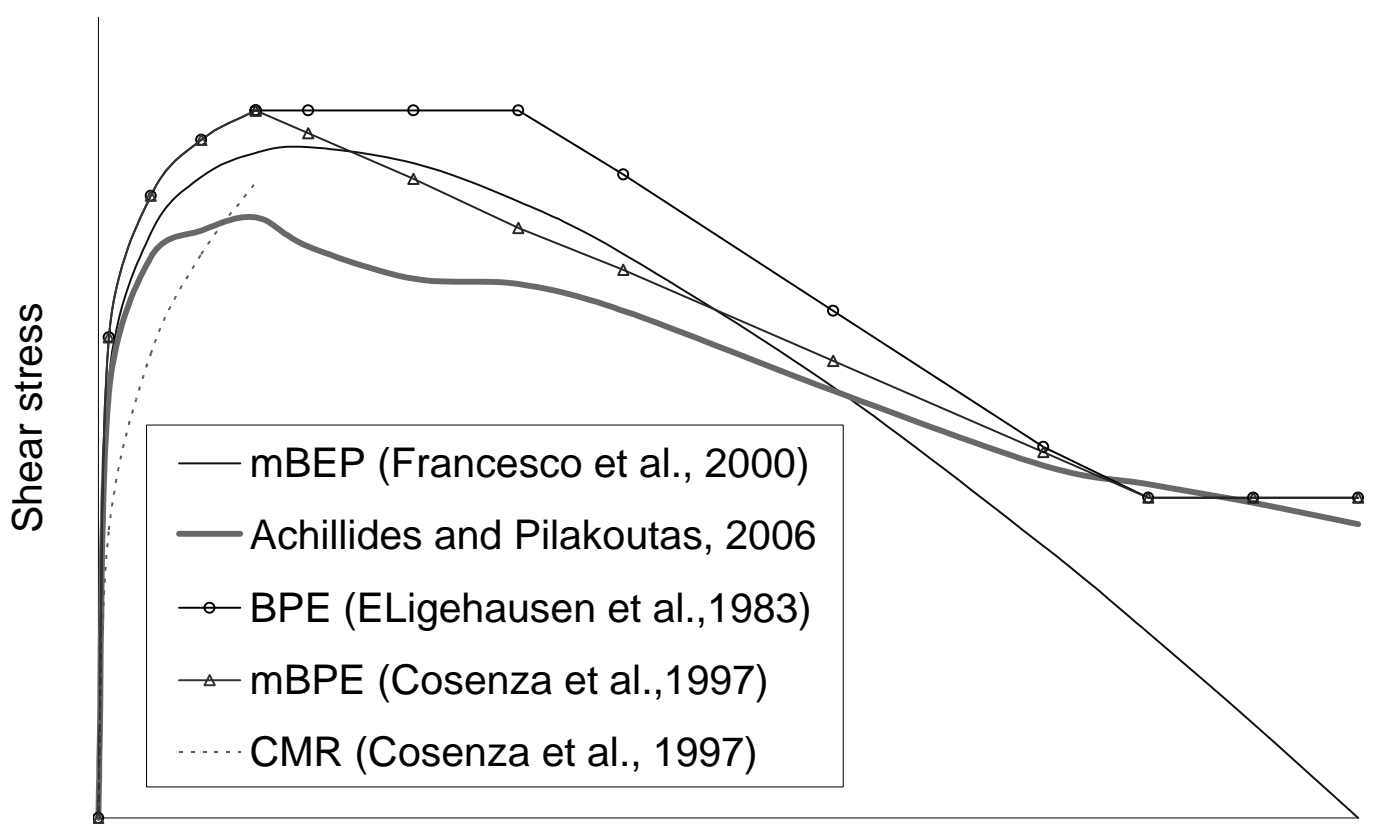

Slip

Figure 7.22 Local bond slip constitutive laws

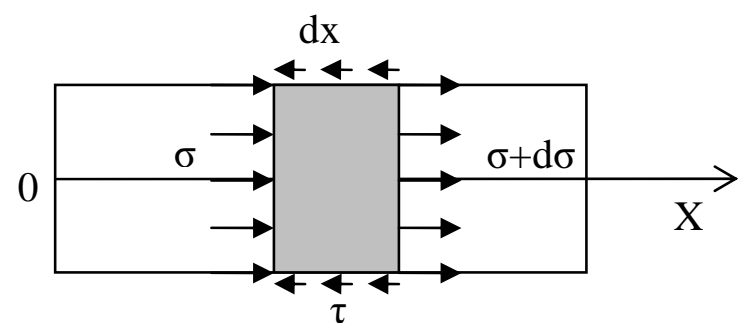

Figure 7.23 Bond stress and normal stress distribution for FRP bars in concrete

The bond stress and normal stress distribution for FRP bars in concrete can be schematically shown in Fig. 7.23. The governing equation for slip can be expressed by the following equation:

$$
\begin{aligned}
& \pi D \tau d x=\frac{\pi D^{2} d \sigma}{4} \\
& \frac{4 \tau}{D}=\frac{d \sigma}{d x}=E \frac{d \varepsilon}{d x}
\end{aligned}
$$




$$
\frac{d^{2} s(x)}{d x^{2}}=4 \frac{\tau(s)}{E D}
$$

where, $\mathrm{D}$ is the bar diameter; $\mathrm{E}$ is the Young's modulus of the bar; $\mathrm{s}=\mathrm{s}(\mathrm{x})$ is the slip, a relative displacement between concrete and bar surface; where $x$ is a reference axis along the bar; and $\tau=\tau(\mathrm{s})$ is the shear stress depending on the slip, s. To solve equation $7.1 \mathrm{c}$, a local bond-slip constitutive law, $\tau=\tau(\mathrm{s})$, and boundary conditions such as free end slips and strains are needed. Once the slip along the bar $(\mathrm{s}(\mathrm{x}))$ is obtained, the normal force in the bar can be determined using slips at the loaded and free ends by an energy method as follows. The work done by the external force along the bar can be calculated as:

$$
W_{e n t}=\int_{0}^{x} \pi D d x \int_{f}^{(x)} \tau(s) d s
$$

where, $\mathrm{W}_{\text {ent }}$ is the external energy done by the bond stress, and $\mathrm{s}_{\mathrm{f}}$ is the free end slip. Then the elastic energy, $\mathrm{W}_{\mathrm{int}}$, in the bar can be expressed as:

$$
W_{\mathrm{int}}=\frac{\pi D^{2}}{4} \int_{0}^{x} \frac{1}{2} E \varepsilon^{2} d x=\frac{\pi D^{2}}{8 E} \int_{0}^{x} \sigma^{2}(x) d x
$$

Then from equations 7.3 and 7.4 , the following equations can be obtained:

$$
\begin{aligned}
& \int_{0}^{x} \pi D \int_{s f}^{s(x)} \tau(s) d s d x=\int_{0}^{x} \frac{\pi D^{2}}{8 E} \sigma^{2}(x) d x \\
& \int_{0}^{x}\left\{\pi D \int_{s f}^{s(x)} \tau(s) d s-\frac{\pi D^{2}}{8 E} \sigma^{2}(x)\right\} d x=0 \\
& \pi D \int_{s f}^{s(x)} \tau(s) d s-\frac{\pi D^{2}}{8 E} \sigma^{2}(x)=0 \\
& \pi D \int_{s f}^{s(x)} \tau(s) d s-\frac{2 N^{2}(x)}{E \pi D^{2}}=0 \\
& N(x)=\sqrt{E \frac{\pi D^{2}}{2} \pi D \int_{s f}^{s(x)} \tau(s) d s}
\end{aligned}
$$


where, $\mathrm{N}(\mathrm{x})$ is the normal force. It is worth noting that the analytical approach does not consider the deformation of concrete and can only give the relative slips between FRP and concrete. Francesco et al. (2000) proposed a back calculation method by minimizing the differences between numerically simulated and experimental results of bond slips to optimize the unknown parameters of an assumed local bond-slip law. For the finite element (FE) analysis proposed by Achillides and Pilakoutas (2006), the pullout specimens were modeled as shown in Fig. 7.24. The interaction between FRP bar and concrete was modeled as a nonlinear spring element. The force deflection relationship for the spring was obtained from experiment results of pullout specimens with different embedment lengths.

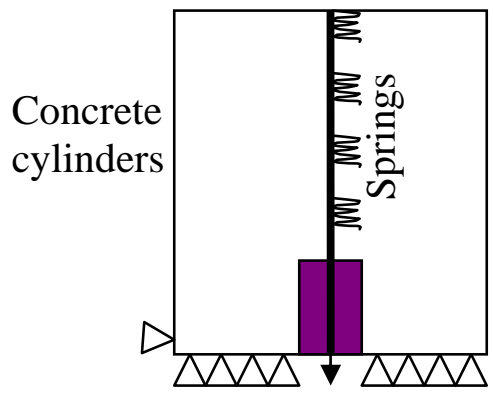

Figure 7.24 FE model for the pullout specimen

For the analytical approach, it is found that the shape of simulated bond-slip curve is the same as that of assumed local bond-slip law by solving equation 7.1 using proposed relationships as shown in Fig.7.22. From the experimental results of this study, it can be inferred that the bond strength first came from the chemical adhesion, then mechanical interlocking, and finally the friction. Moreover, the bond-slip curves for different types of bars are quite different. So it will be a difficult task to use a general $\tau=\tau(\mathrm{s})$ relationship to include all these variables and to obtain numerical results, which will agree well with test 
results. This situation was also encountered by Galati et al. (2006) when only one general $\tau=\tau(\mathrm{s})$ expression was used for their test results.

So in this study, it is proposed that the expression for $\tau=\tau(\mathrm{s})$ relationship should be obtained by curve fitting of the bond-slip curve of each test result. To illustrate this method, one example is presented in the following section according to the test results of one GFRP3 bar specimen. The local bond stress slip relationship for this specimen is assumed as equation 7.7, which has the same shape of bond slip curve as of GFRP3 bars. This expression is modified from the equation proposed for the shear stress slip relationship of interface between concrete and externally bonded FRP sheet (Dai et al., 2005).

$$
\tau=\tau_{f}+A e^{-B s(x)}\left(1-e^{-C s(x)}\right)
$$

Where, $\tau_{\mathrm{f}}, \mathrm{A}, \mathrm{B}$, and $\mathrm{C}$ are the unknown parameters; and $\tau_{\mathrm{f}}$ is assumed as the residual bond strength due to friction. This expression may also be applicable to GFRP1 (\#4) bars, while it may not be good for GFRP4 and CFRP bars. The initial values of these parameters are obtained through curve fitting of the bond slip curve of the test result. Then final values of those parameters are determined by minimizing the differences between numerically simulated and experimental bond slips.

The values for the parameters of equation 7.7 were obtained as listed in Table 7.8. Using equation 7.7 and the values of parameters in Table 7.8, the bond-slip curves from analytical approach and FE analysis can be obtained. For the finite element method, the analysis was carried out in ANSYS 10.0 and the detail model information is summarized in Table 7.9. The force deflection relationship for the nonlinear spring as shown in Fig. 7.25 is derived from the $\tau=\tau(\mathrm{s})$ obtained through the analytical approach. As mentioned 
in section 7.3.1, the residual bond strength will affect the determination of development length as shown in Fig. 7.25.

Table 7.8 Values for the parameters of equation 7.7

\begin{tabular}{lllll}
\hline Specimen & $\tau_{\mathrm{f}}(\mathrm{MPa})$ & $\mathrm{A}(\mathrm{MPa})$ & $\mathrm{B}\left(\mathrm{mm}^{-1}\right)$ & $\mathrm{C}\left(\mathrm{mm}^{-1}\right)$ \\
\hline GFRP1bar-2 & 15.8 & 2.609 & 0.686 & 7.959 \\
\hline
\end{tabular}

Table 7.9 Detail information for FE analysis

\begin{tabular}{cccc}
\hline Components of specimens & Element & Cross section $\left(\mathrm{mm}^{2}\right)$ & Young's Modulus (GPa) \\
\hline FRP bar & Link 1 & 71.33 & 45.8 \\
Concrete & Plane 42 & N/A & 33.5 \\
FRP-Concrete interaction & Combin 39 & N/A & N/A \\
\hline
\end{tabular}

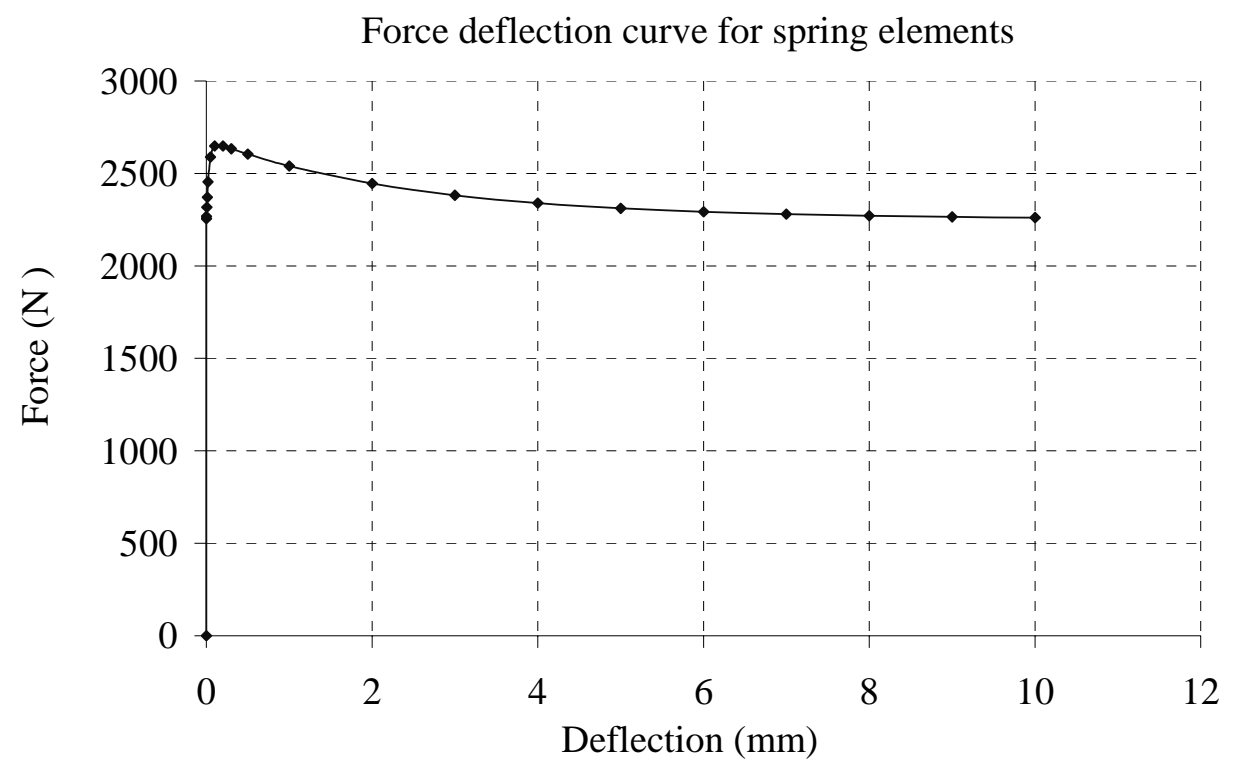

Figure 7.25 Force deflection curve for the spring elements (FRP bar elements with

$$
\text { lengths of } 5 \mathrm{~mm} \text { ) }
$$

The results are compared in Fig. 7.26. It should be pointed out that the free end slip of test results was the relative slip between FRP and concrete, while the loaded end slip 
included the deformation of concrete. So for the free end slip, the results from both analytical approach and FE analysis agree well with test results. But for the loaded end, much less slip is found from the analytical approach than that of test results as shown in Fig. 7.26, while the slip from FE analysis follows closely the experimental results. The difference between results of FE analysis and test is due to the deformations of wooden plate and loading grip. When the concrete deformation at the loaded end is subtracted from loaded end slip, the relative loaded end slip from FE analysis agrees well with the analytical results.

Since the local bond stress slip curve can be obtained by this method, and normal forces in the bar can be calculated using equation 7.6, the development length to develop full tensile strength of this FRP bar can be determined. Using the values of parameters in Table 7.8, the development length for this bar (ultimate tensile strength is $856 \mathrm{MPa}$ as listed in Table 7.5) is about $120 \mathrm{~mm}$. So with an embedment length of $120 \mathrm{~mm}$ in concrete, bond and tensile failures will occur at the same time during pullout test with the free end slip of about zero, and maximum slip (at the loaded end) of $\mathrm{s}(120)=1.1 \mathrm{~mm}$. Similarly, FE analysis can also be performed to determine the development length by increasing the embedment length step by step. The development length calculated according to design guides (ACI 440, 2003 and CSA-S806, 2002) is about 3.5 times of predicted $120 \mathrm{~mm}$. The design guides seem to be very conservative. The same situation was found by other studies when the average bond strength from pullout tests were used (Benmokrane et al., 2002). But when the possibilities of concrete splitting and material degradation due to environment and sustained load are taken into account, it is reasonable to recommend conservative designs. 


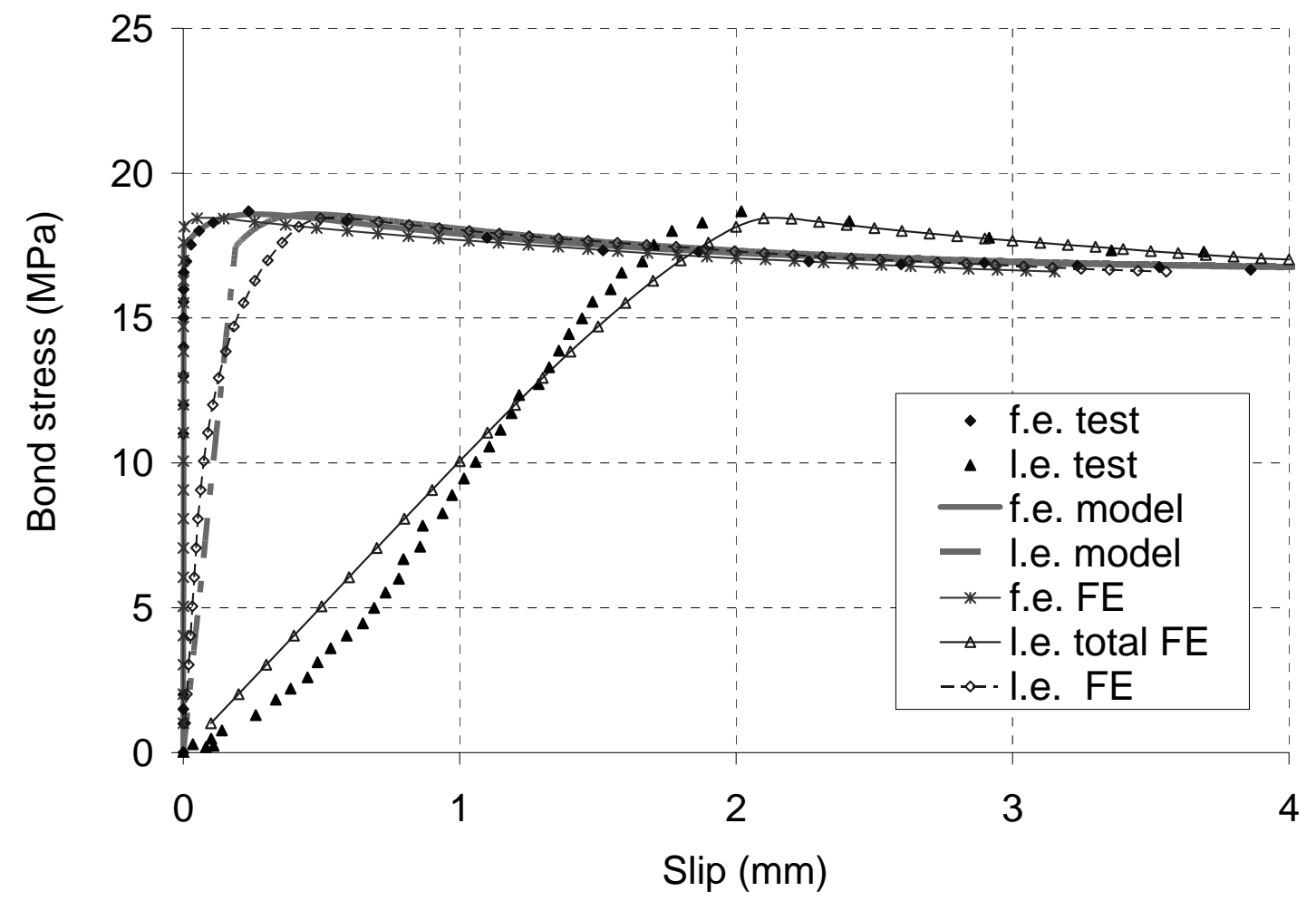

Figure 7.26 Comparisons of bond slip curves from test, analytical approach (model) and

FE analysis. (f.e. $=$ free end, l.e. =loaded end, l.e. total= loaded end including the deformation of concrete)

The advantages of this method are that the local bond-slip law and parameters can be quickly determined, which avoids tedious computations. Once the bond-slip curve from experimental results is available for one type of bar, the development length for this type of bar can be easily obtained by the proposed procedure. But the development length provided by this procedure should be treated as a lower limit. In addition, this method can only give the development length as long as the failure mode of bond remains unchanged (failure occurs in bar surface). But as the FRP surface degrades, the deteriorated FRP surface will be the weakest link of the FRP-concrete bond at certain service time. 


\subsection{Concluding Remarks}

On the basis of the experimental investigation of this study, the following concluding remarks can be made.

From the preliminary study, it can be found that the bond strength and bond slip behavior of GFRP bars also depend on the concrete strength when the concrete compressive strength is relatively low. The elevated temperature and alkalinity accelerated the degradation of bond. But since the bond failure was due to the shear failure of concrete and FRP bar surface, the reduction of bond capacity may be due to the decreased concrete strength after exposure. Less degradation may be found for those embedded in HPC than specimens in NC.

But with the concrete compressive strength in the range of 46 74 $\mathrm{MPa}$ (in section 7.3), the pull-through bond failure for GFRP bars mainly occurred in bar surfaces. Therefore the bond strength of FRP bars was not controlled by the concrete strength. The maximum possible bond capacity of FRP bars (with the bond failure at FRP bar surfaces) can be obtained through the pullout test. CFRP bars and GFRP4 bars have relatively brittle bond behavior, while GFRP4 bars have little residual bond strength due to the failure of sand coating layer after the peak bond stress. The bond behavior of FRP bars depends much on the properties of their surfaces. Environmental conditioning did not change the bond failure mode of FRP bars. Significant bond strength reductions were observed for GFRP bars due to the degradation of bar surfaces after exposures. The thermal cycles (environment E) not only introduce micro cracking of concrete, but also attack the FRP bar. The micro cracking increased the free end slip before ultimate bond strengths were reached for GFRP3 and GFRP1 (\#4) bars, while it did not introduce much 
more degradation for all four types of FRP bars. The environment of saturated concrete at elevated temperature (environment $\mathrm{T}$ ) did not accelerate the bond strength reduction. Numerical methods developed in this study can be easily used to simulate the bond slip curve and determine the development length of FRP bars.

Further research can be done to find efficient accelerated aging method for the bond of FRP bars. The degradation of bond may be related to the degradation of FRP materials through the change of parameters for local bond stress-slip relation, $\tau=\tau(\mathrm{s})$. Before any environmental reduction factor can be suggested for the bond strength of FRP bars, more research is also needed for the bond degradation due to environmental exposures when the bond failure occurs mainly due to the shear failure of surrounding concrete. 


\section{CHAPTER EIGHT CONCLUSIONS AND RECOMMENDATIONS}

This study is focused on the investigation of durability performance for FRP bars and their bond with concrete, and the development of durability prediction models for FRP bars. The durability performance of FRP bars was studied after exposure to different environments including water, ocean water, simulated concrete pore solutions, saturated concrete, and saturated concrete under sustained loading. Tensile strength retentions of FRP bars were tested and considered as the indicator of durability performance. Analytical analysis including SEM and EDAX was also carried out to study the degradation mechanism. Based on the test results, a prediction procedure was developed for the durability performance of GFRP bars. In addition, the durability performance of FRP-concrete bond was investigated after exposure to water, hot water and thermal cycles, respectively. Pullout tests were conducted to obtain the bond capacity and bondslip curves. A numerical analysis procedure was proposed to simulate bond-slip curves and determine development lengths.

\subsection{Conclusions}

\subsubsection{Durability Performance of Bare FRP bars in Simulated Environments}

CFRP bars exhibited superior durability performance in simulated environments. CFRP bars can be considered as durable materials in civil infrastructure applications and further durability study should be focused on GFRP bars. In general, GFRP1 bars had 
better durability performance than GFRP2 bars. But the degradation was significant for both bars in such short exposure times of this study compared to their expected service life. Durability performance of GFRP bars depend on their constituents and manufacturing characteristics. In addition to the constituents of FRP bars, the quality of manufacturing and particularly fiber/matrix interphase influenced the durability of FRP bars, as observed from this study. It was found that the ILSS of GFRP bars deteriorated at a slower rate than tensile strength.

NC pore solution (simulated as Solution 2) was the most aggressive condition for bare FRP bars. HPC environment (simulated as Solution 3) was less aggressive to GFRP bars than simulated NC environments. The addition of chloride ions in alkaline solutions did not accelerate the environmental attack on GFRP bars. It was found that generally the aggressiveness of the solutions decreased in the following order: NC pore solution being the most severe followed by HPC pore solution, tap water, and ocean water. Both WD and FT cycles had negligible effects on degradation process, and therefore, these two exposure conditions are not recommended as critical for performance tests.

Since in this study the bare FRP specimens were directly exposed to the solutions until testing, the reported experimental results should be considered as conservative. It is necessary that FRP-concrete combinations be considered for testing in addition to bare FRP bars to evaluate the durability of FRP reinforcement, since the protocols of bare FRP testing are too harsh for realistic conditions. But the test procedure in this study can be used for comparative testing of composite material, material screening, quality control and specifications. 
Elevated temperature accelerated the degradation of bare FRP bars in simulated environments. Durability prediction models may possibly be developed by studying the acceleration effects of elevated temperatures.

\subsubsection{Durability Performance of GFRP bars in Concrete}

GFRP4 bars had better durability performance than GFRP3 bars. Saturated concrete environment was more aggressive to GFRP than water, while GFRP bars had much better durability performance in dry concrete than in water or saturated concrete. Elevated temperature accelerated the degradation of GFRP bars in concrete. Sustained loading was successfully applied to GFRP bars using the spring-bracket assemblies.

According to the short term test results, different load levels applied in this study had little effect on degradation rate, and sustained tension applied in this study did not result in substantially more degradation in GFRP bars. Compared to alkalinity and load, moisture and elevated temperature play more important roles in the environmental attack to GFRP bars.

The degradation rates for GFRP embedded in concrete decreased very fast as the exposure time increased. The reported short-term results in this study should be considered as conservative since GFRP bars in field conditions are subjected to lower sustained load and humidity, and have thicker concrete cover in most cases.

\subsubsection{Analytical Analysis}

The properties of matrices and the chemical compositions of fibers are different, though all four types of GFRP bars were composed of E-glass fibers and vinyl ester matrices. The diameter of fibers in GFRP1 and GFRP3 bars was more uniform than that 
of GFRP2 and GFRP4 bars. For unconditioned specimens, many more voids were observed in matrices of GFRP1, GFRP2 and GFRP3 than those in GFRP4 and CFRP. The transverse section of the bar showed that these voids are localized. The voids may be due to the manufacturing process used.

The deterioration of matrices and/or fiber/matrix interphase was obvious for conditioned FRP bars. There is a distinct increase in the number and sizes of voids for conditioned GFRP1, GFRP2 and GFRP3 specimens. Moreover, voids were developed progressively toward the core of the bar section.

The EDAX analysis of conditioned FRP bars did not show any difference in chemical elements. GFRP4 bars should have relatively better durability performance than other GFRP bars according to the analytical analysis, which agreed well with the results of mechanical test.

The voids and defects of GFRP bars due to manufacture and/or degradation are highly localized. This fact can be used to explain that the environmental conditioning may degrade significantly the strength but not the stiffness of FRP bars, because the strength is determined by local weakness while the stiffness represents the overall stress-strain characteristics of the bar.

\subsubsection{Durability Prediction Models}

The dominant degradation mechanism for GFRP bars in alkaline media is the fiber/matrix degradation; this degradation mode does not appear to change with temperature or time. Elevated temperature can be used to accelerate the degradation of GFRP bars in alkaline environment. Further, the temperature dependence of degradation rate can be described by Arrhenius equation. 
Prediction procedures have been developed in this study for the durability performance of GFRP bars. The Arrhenius analysis was included in the procedure to determine the validity of accelerated test.

The accelerated test method and prediction procedure used in this study can be good options to assess the long-term durability performance of GFRP bars. This procedure may also be used for FRP materials exposed to other conditions.

From the master curves of bare GFRP bars in simulated solutions, after 1156 day exposure in Solution 3 at $20{ }^{\circ} \mathrm{C}$, the tensile strength retention of GFRP1 bars is expected drop to $50 \%$. For GFRP2 bars exposed to Solution 2 at $20{ }^{0} \mathrm{C}$, the tensile strength retention will be $50 \%$ only after 178 days. For GFRP bars in simulated solutions, the degradations were significant for both GFRP1 and GFRP2 bars in such short exposure times compared to their expected service life. Based on a diffusion model, similar trend was also predicted for GFRP bars directly exposed to alkaline solution by Sen et al. (2002). The predicted service life for a specific E-glass/vinyl ester reinforcement used by the U.S. navy was only between 1.6 to 4.6 years.

Using the obtained master curves for GFRP bars in concrete, the tensile strength retentions are predicted for GFRP3 bars after 50 year exposure in saturated loaded or notloaded concrete at $10{ }^{\circ} \mathrm{C}$. When equation 6.6 is applied, the retentions are about $38 \%$ for loaded condition and $45 \%$ for not-loaded condition, respectively. When equation 6.8 is applied, the retention for not-loaded specimens is $25 \%$, but the loaded specimens fail since the strength retention is not enough to carry sustained load within the 50 year exposure. It is found that equation 6.6 gives more reasonable predictions according to the discussion in the previous paragraphs. It can be seen that sustained load accelerated the 
environmental attack, though this situation is not so obvious according to the short term test results.

It is worth noting that if the master curve for prediction is developed for one type of GFRP bars in a specific exposure condition, it may not be applicable to other types of GFRP bars used in different environments.

\subsubsection{Bond of FRP Bar and Concrete}

From the preliminary study, it can be found that the bond strength and bond-slip behavior of GFRP bars depended on the concrete strength since the concrete compressive strength was relative low. The bond failure was due to the shear failure of concrete and FRP bar surface. The bond capacity degraded after environmental conditioning. Less degradation was found for those embedded in HPC than specimens in NC.

But with the concrete compressive strength in the range of 46 74 $\mathrm{MPa}$ (in section 7.3), the pullout bond failure for GFRP bars mainly occurred in bar surfaces. Therefore the bond strength of FRP bars was not controlled by the concrete strength. The maximum possible bond strengths of FRP bars (with the bond failure at FRP bar surfaces) were obtained. CFRP bars and GFRP4 bars have relatively brittle bond behavior, while GFRP4 bars have little residual bond strength due to the failure of sand coating layer after the peak bond stress. So the bond behavior of FRP bars depended much on the properties of their surfaces. Environmental conditioning did not change the bond failure mode of FRP bars. Significant bond strength reductions were observed for GFRP bars due to the degradation of bar surfaces after exposures. The thermal cycles not only introduced micro cracking of concrete, but also attacked the FRP bar. The micro cracking in concrete increased the free end slip before ultimate bond strengths were reached, while it did not 
introduce much more degradation for all four types of FRP bars. The environment of saturated concrete at elevated temperature did not accelerate the bond degradation.

A simple but effective method has been proposed to determine the local bond-slip law. So numerical methods can be easily used to simulate the bond-slip curve and determine the development length of FRP bars.

\subsection{Recommendations}

Based on test results in this study, the following recommendation can be made. The effects of parameters such as humidity of concrete, load level, and concrete cover thickness on the degradation of embedded GFRP bars should also be investigated. The correlation should be determined between degradations of FRP bars in accelerated testing environment and field conditions. More analytical analysis should be done to investigate the degradation mechanisms of FRP bars both in accelerated ageing and field conditions. Long term data of FRP bars from field conditions should be collected and compared to those from accelerated tests. The durability performances of properties such as ILSS and flexural strength should also be investigated in the future.

Some recommendations can be made for an effective accelerated ageing test method for FRP bars. The tensile strength retention can be used as an indirect measure of the durability performance of FRP bars, due to favorable characteristics, such as ease of implementation, sensitivity to environmental exposure, and constant degradation mechanism. FRP bars can be embedded in saturated concrete for conditioning and elevated temperature can be effectively used as acceleration factor. The highest elevated temperature adopted should be lower than the moisture-saturated glass transition temperature $(\mathrm{Tg})$ of the resin, and if this value is not provided, $60{ }^{\circ} \mathrm{C}$ may be used as the 
highest elevated temperature. The set of elevated temperatures used in this study such as 20, 40, 50 and $60{ }^{\circ} \mathrm{C}$ can be a good choice. For the purpose of durability prediction using models based on Arrhenius relation, test data of at least three different exposure times at three different temperatures (a total of nine) should be collected. The more data at different temperatures and different exposure times are collected, the more accurate the prediction will be. Also, both exposure temperatures and exposure times should be chosen to be distinctly apart within a given range, in order to obtain apparent degradation results. To improve prediction capability, the exposure time should be long enough, so that the slope of strength retention vs. exposure time plot approaches to zero. For example, in this study, according to Figs. 6.15 and 6.16, the exposures times for $60{ }^{0} \mathrm{C}$ should be longer than 200 days for not-loaded and longer than 400 days for loaded specimens. Before the prediction functions are developed, the Arrhenius plots should be shown to be straight lines with high correlation coefficients (e.g. $\left.\mathrm{R}^{2}>0.8\right)$ and nearly parallel to each other, to check the consistent degradation mechanism induced by accelerated tests.

More types of FRP bars should be studied for durability performances in order to recommend general environmental reduction factors for design guides. There is an urgent need to unify the production of FRP bars, which will benefit the development of test methods and design codes.

Further research can be done to find effective accelerated ageing method for the bond of FRP bars. The traditional pullout specimens may not be good for the durability study of bond. New specimens should be proposed for the bond durability to avoid the swelling of FRP bars after exposure. 
More research can be done to relate the FRP material properties to the bond through the parameters of local bond slip law if the bond failure occurs in FRP bar surface. Before any environment reduction factor can be suggested for the bond strength of FRP bars, more research is needed for the bond degradation due to the environment exposures when the bond failure occurs mainly due to the shear failure of surrounding concrete. 


\section{REFERENCES}

Achillides, Z., and Pilakoutas, K., "Bond Behavior of Fiber Reinforced Polymer Bars under Direct Pullout Conditions," Journal of Composites for Construction, 8(2), 2004, pp. 173-181.

Achillides, Z., and Pilakoutas, K., "FE Modeling of Bond Interaction of FRP Bars to Concrete," Structural Concrete, 7(1), 2006, pp. 1464-4177.

ACI 440, "State-of-the-Art Report on Fiber Reinforced Plastic (FRP) Reinforcement for Concrete Structures," American Concrete Institute, Farmington Hills, MI, 1996.

ACI 440, "Guide for the Design and Construction of Concrete Reinforced with FRP Bars,” American Concrete Institute, Farmington Hills, MI, 2003.

ACI 440, "Guide Test Methods for Fiber-reinforced Polymers (FRPs) for Reinforcing or Strengthening Concrete Structures," American Concrete Institute, Farmington Hills, MI, 2004.

Al-Dulaijan, S.U., Al-Zahrani, M.M., Nanni, A., Bakis, C.E., and Boothby, T.E., "Effect of Environmental Pre-conditioning on Bond of FRP Reinforcement to Concrete," Journal of Reinforced Plastic and Composites, 20(10), 2001, pp. 881-900.

Almusallam, T.H., and Al-Salloum, Y., "Durability of GFRP Rebars in Concrete Beams under Sustained Loads at Severe Environments," Journal of Composites Materials, 40 (7), 2006, pp. 623-637.

Alsayed, S.H., Alhoziamy, A.M., Al-Salloum, Y.A., and Almusallam, T.H., "Durability of the Second Generation of GFRP Rebars under Sever Environments," Proceeding of $2^{\text {nd }}$ International Conference on Durability of Fiber Reinforced Polymer (FRP) Composites for Construction, Montreal, Canada, 1998, pp.651-664.

Aindow, A.J., Oakley, D.R., and Proctor, B.A., "Comparison of the Weathering Behavior of GRC with Predictions Made from Accelerated Aging Tests," Cement and Concrete Research, 14(2), 1984, pp. 271-274.

Anderson, K., Allard, B., Bengtsson, M., and Magnusson, B., "Chemical Composition of Cement Pore Solutions," Cement and Concrete Research, 19, 1989, pp. 327-333.

ASTM, "Annual Book of ASTM Standards," American Society for Testing and Materials, West Conshohocken, PA, 2000.

Bakis, C.E., Freimanis, A.J., Gremel, D., Nanni, A., "Effect of Resin Material on Bond and Tensile Properties of Unconditioned and Conditioned FRP Reinforcement Rods," 
Proceeding of the $1^{\text {st }}$ International Conference on Durability of Fiber Reinforced Polymer (FRP) Composites for Construction, Sherbrooke, Canada, 1998, pp. 403-413.

Bakis, C.E., Al-Dulaijan, S.U., Nanni, A., Boothby, T.E., and Al-Zahrani, M.M., "Effect of Cyclic Loading on Bond Behavior of GFRP Rods Embedded in Concrete Beams," Journal of Composites Technology and Research, 20(1), 1998a, pp. 29-37.

Bank, L.C., and Gentry, T.R., "Accelerated Test Methods to Determine the Long-Term Behavior of FRP Composite Structures: Environmental Effects." Journal of Reinforced Plastic and Composites, 14, 1995, pp. 559-587.

Bank, LC, Gentry, T.R., Thompson, B.P., and Russell, S.J., "A Model Specification for FRP Composites for Civil Engineering Structures," Construction and Building Materials, 17, 2003, pp. 405-437.

Bank, L.C., Puterman, M., Katz, A., "Effect of Material Degradation on Bond Properties of Fiber Reinforced Plastic Reinforcing Bars in Concrete," ACI Materials Journal, 95(3), 1998, pp. 232-243.

Balendran, R.V., and Leung, H.Y., "Flexural Behavior of Concrete Beams Internally Reinforced GFRP Rods and Steel Rebars,”Structural Survey, 21(40), 2003, pp.146-157.

Barbero, E.J., "Introduction to Composite Materials Design," Taylor \& Francis, Philadelphia, PA, 1999.

Beddow, J., Purnell, P. and Mottram, J.T., "Application of GRC Accelerated Ageing Rationales to Pultruded Structural GRP," $9^{\text {th }}$ International Conference on Fiber Reinforced Composite, University of Newcastle upon Tyne, 2002, pp. 215-221.

Benmokrane, B., and Chennouf, A., "Pull-out Behavior of FRP Ground Anchors," Proceeding of $42^{\text {nd }}$ SAMPE Symposium and Exhibition, Anaheim, CA, 1997, pp. 311324.

Benmokrane, B., Wang, P., Ton-That T.M., Rahman, H., Robert J.F., "Durability of Glass Fiber-reinforced Polymer Reinforcing Bars in Concrete Environment," Journal of Composites for Construction, 6(3), 2002, pp. 143-153.

Benmokrane, B., Zhang, B., Laoubi, K., Tighiouart, B., and Lord, I., "Mechanical and Bond Properties of New Generation of Carbon Fiber Reinforced Polymer Reinforcing Bars for Concrete Structures," Canada Journal of Civil Engineering, 29, 2002, pp. 338343.

Bradshaw, R.D., Brinson, L.C., "Physical Aging in Polymer Composites: An Analysis and Method for Time Aging Time Superposition," Polymer Engineering and Science, 31(1), 1997, pp. 31-34. 
Burgoyne, C.J., and Guimaraes, G.B., "Stress-Rupture Data for Aramid Fibers", Proceeding of $2^{\text {nd }}$ International Conference on Advanced Composite Materials in Bridges and Structures, Montreal, Canada, pp. 59-66, 1996.

Byars, E.A., Waldron, P., Dejke, V., Demis, S., Heddadin, S., "Durability of FRP in Concrete - Deterioration Mechanisms," International Journal of Materials and Product Technology, 19(1-2), 2003, pp. 28-39.

Caceres, A., Jamond, R.M., Hoffard, T.A., and Malvar, L.J., "Accelerated Testing of Fiber Reinforced Polymer Matrix Composites-Test Plan," SP-2091-SHR, Naval Facilities Engineering Service Center, Port Hueneme, CA, 2000.

CSA-S806, "Design and Construction of Building Components with Fiber-Reinforced Polymers," Canadian Standards Association, 2002.

Chen, Y., Davalos, J.F., Ray, I. and Kim, H.Y., “Accelerated Aging Tests for Evaluations of Durability Performance of FRP Reinforcing Bars for Concrete Structures," Composite Structures, 78(1), 2007, pp. 101-111.

Chen, Y., Davalos, J.F. and Ray, I., "Durability Prediction for GFRP Reinforcing Bars Using Short-term Data of Accelerated Aging Tests," ASCE Journal of Composites for Construction, 10(4), 2006, pp. 279-286.

Chaallal, O., Benmokrane, B., and Masmoudi, R., "An Innovative Glass-fiber Composite Rebar for Concrete Structures," Advanced Composite Materials in Bridge and Structures, Canadian Society for Civil Engineering, 1992, pp. 169-177.

Chin, J. W., Aouadi, K., and Nguyen, T., "Effects of Environmental Exposure on Fiber Reinforced Plastic Materials used in Construction," Journal of Composites Technology and Research, 19(4), 1997, pp.205-213.

Chin, J.W., Hughes, W.L., Signor, A., "Elevated Temperature Aging of Glass Fiber Reinforced Vinyl Ester and Isophthalic Polyester Composites in Water, Salt water and Concrete Pore Solution," American Society of Composites $16^{\text {th }}$ Technical Conference, Blacksburg, VA, 2001, pp. 1-12.

Charles, R.J., "Chapter 12: The Strength of Silicate Glasses and Some Crystalline Oxides," Proceedings of an International Conference on the Atomic Mechanisms of Fracture, Swampscott, MA, 1959, pp. 225-249.

Clear, K.C., Hartt, W.H., McIntyre, J., Lee, S. K., "Performance of Epoxy-coated Reinforcing Steel in Highway Bridges," Transportation Research Board, NCHRP Report $370,1995$.

Coomarasamy, A., and A.K.C. I., "Evaluation of Fiber Reinforced Plastic (FRP) Materials for Long-term Durability in Concrete Structures," Proceeding of the $1^{\text {st }}$ 
International Conference on Durability of Fiber Reinforced Polymer (FRP) Composites for Construction, Sherbrooke, Canada, 1998, pp. 325-336.

Coomarasamy, A., and Goodman, S., "Investigation of the Durability Characteristics of Fiber Reinforced Plastic (FRP) Materials in Concrete Environment," Journal of Thermoplastic Composite Materials, 12(3), 1999, pp. 214-226.

Cosenza, E., Manfredi, G., Pecce, M., and Realfonzo, R., "Bond between Glass Fiber Reinforced Plastic Reinforcing Bars and Concrete- Experimental Analysis," Proceeding of $4^{\text {th }}$ International Symposium on Fiber Reinforced Polymer Reinforcement for Reinforced Concrete Structures, ACI SP-188, Baltimore, MD, 1999, pp. 347-358.

Cowley, T. W., and Robertson, M.A., "Effect of $\mathrm{pH}$ and Temperature on Fiberglassreinforced Composites in Sodium Hypochlorite Solutions," Materials Performance, 30(7), 1991, pp. 46-49.

Cox, J.V., and Cochran, B., "Bond between Carbon Fiber Reinforced Polymer Bars and Concrete II: Computational Modeling," Journal of Composites for Construction, 7(2), 2003, pp.164-171.

Crank, J., "The Mathematics of Diffusion,” Oxford University Press, 1975.

Dai, J., Ueda, T., and Sato, Y., "Development of the Nonlinear Bond Stress-slip Model of Fiber Reinforced Plastics Sheet-concrete Interfaces with A Simple Method," Journal of Composites for Construction, 9 (1), 2005, pp. 52-62.

Davalos, J.F., and Chen, A., "Buckling Behavior of Honeycomb FRP Core with Partially Restrained Loaded Edges under Out-of-plane Compression," Journal of Composite Materials, 39(16), 2005, pp. 1465-1485.

Davalos, J.F., Chen, Y., and Ray, I., "Durability Prediction for GFRP Bars in Concrete." 2007. (Under preparation)

Davalos, J.F., Lin, C., Ray, I., Barth, K.E., and Brayack, D., "Technical and Economic Feasibility Study of External Retrofit with FRP of Concrete T-beam Bridges," Journal of Composites for Construction, 2007. (Under review)

Debaiky, A.S. Nkurunziza, G., Benmokrane B., and Cousin, P., "Residual Tensile Properties of GFRP Reinforcing Bars after Loading in Severe Environments," Journal Composite for Construction, 10 (5), 2006, pp. 370-380.

Dejke, V., "Durability of FRP Reinforcement in Concrete-Literature Review and Experiments," Thesis for the Degree of Licentiate of Engineering, Chalmers University of Technology, Goteborg, Sweden, 2001. 
Devalapura, R.K., Gauchel, J.V., Greenwood, M.E., Hankin, A., and Humphrey, T., "Long-term Durability of Glass-Fiber Reinforced Polymer Composites in Alkaline Environments," Proceeding of the $3^{\text {rd }}$ International Symposium, Non-metallic (FRP) Reinforcement For Concrete Structures, Sapporo, Japan, 1997, pp. 83-90.

Devalapura, R.K., Greenwood, M.E., Gauchel, J.V., and Humphrey, T.J., "Evaluation of GFRP Performance Using Accelerated Test Methods." Proceeding of the $1^{\text {st }}$ International Conference on Durability of Fiber Reinforced Polymer (FRP) Composites for Construction, Sherbrooke, Canada, 1998, pp. 107-116.

Diamond, S. "Effects of Two Danish Flyashes on Alkali Contents of Pore Solutions of Cement-Flyash Pastes", Cement and Concrete Research, 11(3), 1981, pp. 383-394.

Eligehausen R., Popov E.P., Bertero, V.V. (1983). Local bond stress-slip relationships of deformed bars under generalized excitations. Report No. UCB/EERC-83/23, Earthquake Engineering Research Center.

El-Badry, M., and Abdalla, H., "Experimental Studies on Thermal Cracking in Concrete Members Reinforced with FRP Reinforcement," Proceeding of the $1^{\text {st }}$ International Conference on Durability of Fiber Reinforced Polymer (FRP) Composites for Construction, Sherbrooke, Canada, 1998, pp. 107-116.

EI-Salakawy, E., Benmokrane, B., EI-Ragaby, A. and Nadeau, D., “ Field Investigation on the First Bridge Deck Slab Reinforced with Glass FRP Bars Constructed in Canada," Journal of Composites for Construction, 9(6), 2005, pp. 470-479.

Francesco, F., Nanni, A., and Bakis, E.C., "Local Bond-slip Relationship for FRP Reinforcement in Concrete," Journal of Composites for Construction, 4(1), 2000, pp. 2431.

Galati, N., Nanni, A., Dharani, L.R., Focacci, F., and Aiello, M.A., "Thermal Effects on Bond between FRP rebar and Concrete," Composites Part A: Applied Science and Manufacturing, 37(8), 2006, pp. 1223-1230.

Gentry, T.R., Bank, L.C., Thompson, B.P., Russell, J.S., "An Accelerated-test-based Specification for Fiber Reinforced Plastic for Structural Systems," Proceeding of $2^{\text {nd }}$ International Conference on Durability of Fiber Reinforced Polymer (FRP) Composites for Construction, Montreal, Canada, 2002, pp. 13-24.

Gonenc, O., "Durability and Service-life Prediction of Concrete Reinforcing Materials," M.S. Thesis, University of Wisconsin-Madison, 2001.

Gowripalan, N., and Mohamed, H.M., "Chloride-ion Induced Corrosion of Galvanized and Ordinary Steel Reinforcement in High-performance Concrete," Cement and Concrete Research, 28(8), 1998, pp. 1119-1131. 
Haramis, J., Verghese, K.N.E., Lesko, J.J., and Weyers, R.E., "Characterization of FreeThaw Damage Mechanism in Composites for Civil Infrastructure," Proceeding of the 3rd Concrete on Advanced Composite Materials in Bridges and Structures, Ottawa, Canada, 2002, pp. 663-670.

ISIS, "Reinforcing Concrete Structures with Fiber Reinforced Polymers (Design Manual No. 3)," Intelligent Sensing for Innovative Structures, 2001.

Iskander, M., Mohamed, A.,and Hassan, M., "Durability of Recycled Fiber-reinforced Polymer Piling in Aggressive Environments," Transportation Research Record, 1808(022310), 2002, pp. 153-161.

Iyer, S.L., and Sivakumar, R., "Graphite Prestressed Piles and Fiberglass Prestressed Pilecaps for U.S. Navy Pier in California," Proceeding Infrastructure: New Material and Methods for Repair, San Diego, USA, 1994, pp. 392-399.

JSCE, "Recommendation for Design and Construction of Concrete Structures Using Continuous Fiber Reinforcing Materials," Concrete Engineering, Series 23, Japanese Society of Civil Engineering, 1997.

Kanda, M.S., Ohno, K., Hihara, K., Kawamoto, Y., Kondo, S., and Iizumi, A., "Material Properties of FRP Prestress Tendons," Proceeding of FIP Symposium, Kyoto, Japan, 1993, pp. 687-694.

Karbhari, V.M., Chin, J.W., Hunston, D., Benmokrane, B., Juska, T., Morgan, R., Lesko, J.J., Sorathia, U., and Reynaud, D., "Durability Gap Analysis for Fiber-reinforced Polymer Composite in Civil Infrastructure," Journal of Composites for Construction, 7(3), 2003, pp. 238-247.

Kasturiarachchi, K., and Pritchard, G., "Water Absorption of Glass/epoxy Laminates under Bending Stresses," Composites, 14(3), 1983, pp. 244-250.

Kato, Y., Nishimura, T., and Uomoto, T., "The Effect of Ultraviolet Rays to FRP Rods," Proceeding of $1^{\text {st }}$ International Conference on Durability of Fiber Reinforced Polymer (FRP) Composites for Construction, Sherbrooke, Canada, 1998, pp. 487-497.

Katsuki, F., and Uomoto, T., "Prediction of Deterioration of FRP Rods Due to Alkali Attack," Non-metallic (FRP) Reinforcement for Concrete Structures, RILEM, London, UK, 1995, pp. 82-89.

Katz, A., Berman, N., and Bank, L.C., "Effect of Cyclic Loading and Elevated Temperature on the Bond Properties of FRP Rebars," Proceeding of the $1^{\text {st }}$ International Conference on Durability of Fiber Reinforced Polymer (FRP) Composites for Construction, Sherbrooke, Canada, 1998, pp. 403-413. 
Lewis, G., Bedderand, S., and Reid, I., "Stress Corrosion of Glass Fibers in Acidic Environments," Journal of Materials Science Letters, 3, 1984, pp. 728-732.

Litherland, K.L., Oakley, D.R. and Proctor, B.A., "The Use of Accelerated Aging Procedures to Predict the Long Term Strength of GRC Composites," Cement and Concrete Research, 1(11), 1981, pp 455-466.

Losberg, A., "Force Transfer and Stress Distribution at Anchorage and Curtailment of Reinforcement," Report No.608, Chalmers University of Technology, Department of Building Technology, Goteborg, Sweden, 1969.

Malvar, L.J., Jamond, R.M., Hoffard, T.A., and Novinson, T., "GFRP Composites in Simulated Marine Environments," Proceeding of ${ }^{2 n d}$ International Conference on Durability of Fiber Reinforced Polymer (FRP) Composites for Construction, Montreal, Canada, 2002, pp. 153-164.

Malvar, L.J., Cox, J.V., and Cochran, B., "Bond between Carbon Fiber Reinforced Polymer Bars and Concrete I: Experimental Study," Journal of Composites for Construction, 7(2), 2003, pp.154-163.

Mashima, M., and Iwamoto, K., "Bond Characteristics of FRP Rod and Concrete after Freezing and Thawing Deterioration," ACI SP-138, International Symposium on Fiber Reinforced Plastic Reinforcement for Concrete Structures, Vancouver, Canada, 1993, 5169.

Matzeg, R., and Santrach, D., "Effects of the Glass Fiber Type on Corrosion Resistance of FRP Laminates," SAMPE Quarterly (USA), 23(1), 1991, pp. 12-19.

Metcalfe, A.G., and Schmitz, G. K., "Mechanism of Stress Corrosion in E-glass Filaments," Glass Technology, 13(1), 1972, pp. 5-16.

Micelli, F., Nanni, A., and Tegola, A.L., "Effects of Conditioning Environment on GFRP Bars," Proceeding of $22^{\text {nd }}$ SAMPE Europe International Conference, CNIT Paris, 2001.

Micelli, F., and Nanni, A., "Durability of FRP Rods for Concrete Structures," Construction and Building Materials, 18(7), 2004, pp. 491-503.

Mufti, A., Onofrei, M., Benmokrane, B., Banthia, N., Boulfiza, M., Newhook, J., Bakht, B., Tadros, G. and Brett, P., "Durability of GFRP Reinforced Concrete in Field Structures," Proceeding of $7^{\text {th }}$ Internal Symposium on Fiber Reinforced Polymer Reinforcement for Reinforced Concrete Structures , Kansas City, MO, 2005.

Mukherjee, A., and Arwikar, S.J., "Performance of Glass Fiber-reinforced Polymer Reinforcing Bars in Tropical Environments Part I: Structural Scale Tests," ACI Structural Journal, 102(5), 2005, pp. 745-753. 
Nanni, A., Conrad, J.O., Bakis, C.E., and Uchno, J., "Material Properties of C-bar Reinforcing Bar," Civil Engineering Department, Pennsylvania State University, PA, 1997.

Nanni, A., Bakis, C.E., and Mathew, J.A., "Acceleration of FRP Bond Degradation," Proceeding of the $1^{\text {st }}$ International Conference on Durability of Fiber Reinforced Polymer (FRP) Composites for Construction, Sherbrooke, Canada, 1998, pp. 45-56.

Nkurunziza, G., Cousin, P., Masmoudi, R., Benmokrane, B., "Effect of Sustained Tensile Stress and Temperature on GFRP Composite Bars Properties:1 Preliminary Experiment in Deionised Water and Alkaline Solution," International Journal of Materials and Product Technology, 9(1-2), 2003, pp. 15-27.

Nkurunziza, G., Debaiky, A., Cousin, P., Benmokrane, B., "Durability of GFRP Bars: A Critical Review of the Literature", Progress in Structural Engineering and Materials, 7(4), 2005, pp. 194-209.

Okelo, R., and Yuan, L.R., "Bond Strength of Fiber Reinforced Polymer Rebars in Normal Strength Concrete," Journal of Composites for Construction, 9(3), 2005, pp. 203213.

Pantuso, A., Spadea, G., Swamy, R.N., "An Experimental Study on the Durability of GFRP bars," Proceeding of $1^{\text {st }}$ International Conference on Composite in Infrastructure, Tucson, Arizona, 1998, pp. 476-487.

Phani, K.K., and Bose, N.R., "Temperature Dependence of Hydrothermal Ageing of CSM-Laminate during Water Immersion," Composite Science and Technology, 29, 1987, pp. 79-87.

Prian, L., and Barkatt, A., "Degradation Mechanism of Fiber-reinforced Plastic and Its Implications to Prediction of Long-term Behavior," Journal of Material Science, 34, 1999, pp. 3977-3989.

Porter, M.L., "Durability Issues for FRP Reinforcement to Concrete Structures," Proceeding of $44^{\text {th }}$ International SAMPE Symposium, 1999, pp. 2246-2254.

Porter, M.L., Barnes, B.A., "Accelerated Durability of FRP Reinforcement for Concrete Structures," Proceeding of the $1^{\text {st }}$ International Conference on Durability of Fiber Reinforced Polymer (FRP) Composites for Construction, Sherbrooke, Canada, 1998. pp. 191-201.

Pritchard, G., "Reinforced Plastic Durability," CRC Press, Woodhead Publishing Limited, Cambridge, UK, 2000.

Rahman, A.H., Lauzier, C., Kingsley, C., Richard, J., and Crimi, J., "Experimental Investigation of the Mechanism of Deterioration of FRP Reinforcement for Concrete." 
Proceeding of $2^{\text {nd }}$ International Conference on Composite in Infrastructure, Tucson, Arizona, 1998, pp. 501-511.

RILEM, "Bond Test for Reinforcing Steel 2: Pullout test," Recommendation RC6, RILEM/CEB/FIP, Bageux, France, 1978.

Rizkalla, S., Abdelrahman, A., and Mcvey, M., "Material Properties of C-bar Reinforcing Rod," ISIS Canada, Winnipeg, Canada, 1997.

Rostasy, F.S., and Scheilbe, M., "Engineering Model for Forecast of Stress Rupture Strength of Stressed Aramid Fiber Reinforced Polymer Bars Embedded in Concrete." Proceeding of $4^{\text {th }}$ International Symposium on Fiber Reinforced Polymer Reinforcement for Reinforced Concrete Structures, SP-188, 1999, pp. 1049-1062.

Saadatmanesh, H., and Tannous, F.E., "Durability of Fiber Reinforced Plastic (FRP) Rebars and Tendons in Aggressive Environments," Proceedings of the International Seminar on Repair and Rehabilitation of Reinforced Concrete Structures: The State of the Art, Maracaibo, Venezuela, 1998, pp. 120-133.

Saadatmanesh, H., and Tannous, F.E., "Relaxation, Creep and Fatigue Behavior of Carbon Fiber Reinforced Plastic Tendons," ACI material Journal, 96(2), 1999, pp. 143153.

Sekijima, K., Otsuka, Y., and Konno, T., "Durability of Fiber Reinforced Polymer Reinforcement Embedded in Concrete," Proceeding of $4^{\text {th }}$ International Symposium on Fiber Reinforced Polymer Reinforcement for Reinforced Concrete Structures, SP-188, 1999, pp. 501-513.

Sen, R., Mullins, G., and Salem, T., "Durability of E-Glass/Vinyl Ester Reinforcement in Alkaline Solution,” ACI Structural Journal, 99(3), 2002, pp. 369-375.

Sen, R., "Durability of Advanced Composites in a Marine Environment," International Journal of Materials and Product Technology, 19(1-2), 2003, pp. 118-129.

Sen,R., Shahawy, M., Sukumar, S., and Rosas, J., "Effect of Tidal Exposure on Bond of CFRP rods," Proceeding of $2^{\text {nd }}$ International Conference on Composite in Infrastructure, Arizona, Tucson, 1998, pp. 512-523.

Shi, C., Stegemann, J.A., Caldwell, R.J., "Effect of Supplementary Cementing Materials on the Specific Conductivity of Pore Solution and Its Implications on the Rapid Chloride Permeability Test (AASHTO T277 and ASTM C1202) Results," ACI Materials Journal, 95(4), 1998, pp. 389-394.

Shield, C.K., French, C.W., and Hanus, J.P., "Bond of Glass Fiber Reinforced Plastic Reinforcing Bar for Consideration in Bridge Decks," Proceeding of $4^{\text {th }}$ International 
Symposium on Fiber Reinforced Polymer Reinforcement for Reinforced Concrete Structures, ACI SP-188, Baltimore, MD, 1999, pp. 347-358.

Sonobe, Y. et al., "Design Guidelines of FRP Reinforced Concrete Building Structures," Journal of Composites for Construction, 1(3), 1997, pp. 90-115.

Stone, D., Koenigsfeld, D., Myers, J., Nanni, A., "Durability of GFRP Rods, Laminates and Sandwich Panels subjected to Various Environmental Conditionings," Proceeding of $2^{\text {nd }}$ International Conference on Durability of Fiber Reinforced Polymer (FRP) Composites for Construction, Montreal, Canada, 2002, pp. 213-224.

Svecova, D., Rizkalla, S.H., Vogel, H., Jawara, A., "Durability of GFRP Bars in Lowheat High Performance Concrete," Proceeding of $2^{\text {nd }}$ International Conference on Durability of Fiber Reinforced Polymer (FRP) Composites for Construction, Montreal, Canada, 2002, pp. 75-86.

Tannous, F.E., Saadatmanesh, H., "Environmental Effects on the Mechanical Properties of E-Glass FRP Rebars,” ACI Materials Journal, 95(2), 1998, pp. 87-100.

Tannous, F.E., and Saadatmanesh, H., "Durability of AR Glass Fiber Reinforced Plastic Bars," Journal of Composites for Construction, 3(1), 1999, pp. 12-19.

Tepfers, R., and Lorenzies, L. D., "Bond of FRP Reinforcement in Concrete-A Challenge," Mechanics of Composite Materials, 39(4), 2003, pp. 315-328.

Tepfers, R., Molander, I., and Thalenius, K., "Experience from Testing of Concrete Reinforced with Carbon Fiber and Aramid Fiber Strands," XIV Nordic Concrete Congress and Nordic Concrete Industry Meeting, 1992, pp. 337-347.

Tepfers, R., "Bond Clause Proposals for FRP bars/rods in Concrete Based on CEB/FIP Model Code 90 Part 1: Design Bond Stress for FRP Reinforcing Bars," Structural Concrete, 7(2), 2006, pp. 1464-4177.

Tokyo Rope Manufacturing Co. Ltd., “CFCC Technical Data,” Corporate Report, 1989.

Uomoto, T., "Durability of FRP as Reinforcement for Concrete Structures," Proceeding of the $3^{\text {rd }}$ Concrete on Advanced Composite Materials in Bridges and Structures, Ottawa, Canada, 2000, pp. 3-20.

Uomoto, T., "Use of Fiber Reinforced Polymer Composites as Reinforcing Material for Concrete," Journal of Materials in Civil Engineering, 14(3), 2002, pp. 191-209.

Wickert, C.L., Vieira, A.E., Dehne, J.A., Wang, X, Wilder, D.M., and Barkatt, A., "Effects of Salts on Silicate Glass Dissolution in Water: Kinetics and Mechanisms," Physics and Chemistry of Glasses, 40(3), 1999, pp. 157-170. 
Wolff, R., and Miesseler, H.J., "New Materials for Prestressing and Monitoring Heavy Structures," Concrete International, 11(9), 1989, pp. 86-89. 